\title{
A Demonstration of the Applicability of Implementing the Enhanced Remedial Action Priority System (RAPS) for Environmental Releases
}
G. Whelan
M. B. Walter
J. G. Droppo, Jr.
J. W. Buck
D. L. Strenge

December 1989

\section{Prepared for the}

Office of Environment, Safety, and Health

U.S. Department of Energy

under Contract DE-AC06-76RLO 1830

Pacific Northwest Laboratory

Operated for the U.S. Department of Energy

by Battelle Memorial Institute 


\section{DISCLAIMER}

This report was prepared as an account of work sponsored by an agency of the United States Government. Neither the United States Government nor any agency thereof, nor Battelle Memorial Institute, nor any of their employees, makes any warranty, expressed or implied, or assumes any legal liability or responsibility for the accuracy, completeness, or usefulness of any information, apparatus, product, or process disclosed, or represents that its use would not infringe privately owned rights. Reference herein to any specific commercial product, process, or service by trade name, trademark, manufacturer, or otherwise, does not necessarily constitute or imply its endorsement, recommendation, or favoring by the United States Government of any agency thereof, or Battelle Memorial Institute. The views and opinions of authors expressed herein do not necessarily state or reflect those of the United States Government or any agency thereof.

\section{PACIFIC NORTHWEST LABORATORY operated by \\ BATTELLE MEMORIAL INSTITUTE \\ for the \\ UNITED STATES DEPARTMENT OF ENERGY \\ under Contract DE-AC06-76RLO 1830}

Printed in the United States of America

Available to DOE and DOE contractors from the

Office of Scientific and Technical Information, P.O. Box 62, Oak Ridge, TN 37831;

prices available from (615) $576-8401$. FTS 626-8401.

Available to the public from the National Technical Information Service,

U.S. Department of Commerce, 5285 Port Royal Rd., Springfield, VA 22161.

NTIS Price Codes, Microfiche A01

Printed Copy

\begin{tabular}{|c|c|c|c|}
\hline Price Code & Page Range & Price Code & Page Range \\
\hline $\mathrm{A} 02$ & $1-10$ & A15 & $326 \cdot 350$ \\
\hline $\mathrm{A} 03$ & $11-50$ & A16 & $351-375$ \\
\hline A04 & $51-75$ & A17 & $376-400$ \\
\hline A05 & $76 \cdot 100$ & A18 & $401-425$ \\
\hline A06 & $101-125$ & A19 & $426-450$ \\
\hline A07 & $126-150$ & $A_{20}$ & $451-475$ \\
\hline A08 & $151-175$ & A21 & $476-500$ \\
\hline A09 & $176-200$ & $A 22$ & $501-525$ \\
\hline A10 & $201-225$ & $A 23$ & $526-550$ \\
\hline A11 & $226-250$ & A24 & $551-575$ \\
\hline A12 & $251-275$ & A25 & $576-600$ \\
\hline A13 & $276-300$ & A99 & $601-U p$ \\
\hline A14 & $301-325$ & & \\
\hline
\end{tabular}


PNL -7102

UC $-602,630$

\section{A DEMONSTRATION OF THE APPLICABILITY OF IMPLEMENTING THE ENHANCED REMEDIAL ACTION PRIORITY SYSTEM (RAPS) FOR ENVIRONMENTAL RELEASES}
G. Whe lan
J. G. Droppo, Jr.
D. L. Strenge
M. B. Walter
J. W. Buck

December 1989
Prepared for the Office of Environment, Safety, and Health U.S. Department of Energy under Contract DE-ACO6-76RLO 1830

Pacific Northwest Laboratory Richland, Washington 99352 



\section{PREFACE}

This report is one of a series that provide support to the U.S. Department of Energy's use of a human health impact-based methodology for ranking environmental issues. This methodology is referred to as the Multimedia Environmental Pollutant Assessment System (MEPAS) 0 for the Environmental Survey ranking effort, or as the Remedial Actin Priority System (RAPS) for other applications. This testing report documents a demonstration of the applicability of implementing the major components of the MEPAS/RAPS model at waste sites where contaminants have been released and monitored in the environment. Simulated contaminant levels are compared with measured environmental levels documented by monitoring programs.

Other reports under preparation in the series include a sensitivity study for user-definable parameters, a sensitivity study for the Environmental Survey ranking criteria, and a collection of MEPAS/RAPS application papers.

- Copyright 1989 Battelle Memorial Institute. 


\section{ABSTRACT}

The Remedial Action Priority System (RAPS) and the Multimedia Environmental Pollutant Assessment System (MEPAS) were developed to prioritize problems associated with potential releases of hazardous chemical and radioactive materials in a scientific and objective manner based on limited site information. Although RAPS was originally developed for only U.S. Department of Energy (DOE) inactive waste disposal sites, it was enhanced to include sites with active operations for OOE's Environmental Survey ranking effort. For survey applications, the enhanced RAPS is referred to as MEPAS. This report documents the modei testing efforts of the RAPS/MEPAS methodology for the atmospheric, surface water, groundwater, and exposure components. Comparisons are given of model outputs with measured data at three sites: the U.S. Department of Energy's Mound facility in Ohio and Hanford facility in Washington, and a chromium-cadmium plating site in New York. The results show that the simulated magnitudes, spacial and temporal trends, and distributions of contaminants corresponded well with the measured data. 



\section{EXECUTIVE SUMMARY}

In 1985 and 1986, Pacific Northwest Laboratory (PNL) developed the Remedial Action Priority System (RAPS). The RAPS methodology represents an approach that prioritizes hazardous and radioactive mixed waste disposal sites in a scientific and objective manner based on limited site information. The RAPS methodology provides the U.S. Department of Energy's Office of Environment, Safety, and Health (DOE-ESH) with a management tool for assistance in allocating funds and human resources for further investigations and possible remediation at its inactive waste sites.

A version of the RAPS methodology was used by DOE-ESH for application in its environmental survey effort. For this application, the code was referred to as the Muitimedia Environmental Pollutant Assessment System (MEPAS). The distinction is that RAPS refers to the overall methodology, whereby MEPAS refers to RAPS as used in the Environmental Survey application. As a consequence, the RAPS testing results reported in this document apply directly to RAPS as well as the MEPAS survey application.

Under the guidance of DOE-ESH, PNL has developed a program to review, analyze, and test all major aspects of the RAPS methodoiogy. Under the program, the methodology and its mathematical formulation have been independently reviewed by technical authorities in the private and public sectors. An extensive sensitivity analysis is being completed to determine the effects of 1) specific input parameters, 2) initial and boundary conditions, 3) distributions of input parameters, and 4) interrelationships among input parameters affecting model response over short and long time frames. Finally, the various components of the RAPS methodology are being implemented at actual sites where contaminant levels have been monitored in the environment. The monitored contaminant levels are then compared to simulated contaminant levels associated with the application of RAPS to these sites. The purpose of the comparison is to demonstrate the applicability of implementing the RAPS methodology to a variety of hazardous waste sites or releases of contaminants into the environment. 
This document is associated with the third aspect of the program, and reports on the results associated with applying components of the RAPS methodology to a variety of sites with different contaminant release mechanisms. These applications illustrate the type of data typically required to implement the methodology and several of the types of contaminant releases (e.g., direct discharge, French drain, crib, tile field, and stack) that can be considered by the methodology. Thus, they demonstrate the applicability of the methodology at a wide variety of sites.

The RAPS methodology was applied at three facilities to demonstrate the surface water, atmospheric, groundwater, and exposure assessment components of the methodology. These facilities are listed below with a brief summary of the components comprising RAPS that were tested at each.

- DOE's Mound facility in Miamisburg, Ohio -- The surface water, atmospheric, and exposure assessment components of RAPS were applied at the Mound facility. The surface water component addresses a direct discharge of tritium, plutonium-238, and uranium-233,234 from the Mound facility to the nearby Great Miami River. The atmospheric component addresses a stack release of tritium and plutonium-238 into the atmosphere. The exposure assessment component of the methodology computes concentrations of tritium or plutonium-238 in local fish, grass, and tomatoes. In each of these applications, simulated and observed contaminant levels are compared.

- DOE's Hanford facility in Richland, Washington -- The subsurface and atmospheric components of the RAPS methodology were applied at the Hanford facility. Various aspects addressing flow and solute movement associated with the partially saturated zone were tested at the Hanford facility. Simulated and monitored deep-drainage rates were compared at two sites, one with vegetation and one with bare soil. Solute movement of plutonium-238, americium-241, or plutonium-239,240 in the partially saturated zone was also addressed at two sites where the spacial distribution of contamination had been monitored. The atmospheric component was applied at the B-C crib site. In the assessment, the atmospheric component of RAPS simulates the 
resuspension of soil particles contaminated with cesium-137. This analysis compares simulated surface emission rates with those historically used at the $B-C$ crib site at the Hanford facility.

- Chromium-Cadmium plating waste site in Massapequa, New York -- The subsurface component of the RAPS methodology was applied at the Massapequa, New York, site. Solute movement associated with the saturated zone was tested at this site. Simulated and observed concentrations of hexavalent chromium and cadmium, spacially and temporally distributed, are compared.

To assess the applicability of the components of the RAPS methodology to these sites, certain aspects pertaining to the results should be considered in the interpretation of simulated and monitored environmental levels. These aspects include contaminant levels, temporal and spacial trends, the current state of knowledge associated with a component of the methodology, and the intended level of sophistication of the RAPS methodology. These aspects are briefly discussed below.

- contaminant levels -- Contaminant levels refer to the magnitude of the concentrations of contaminants. Ideally, the magnitudes of the simulated contaminant concentrations would match those of the observed concentrations. This comparison would provide insight as to how well a particular model recreates complex, real-world phenomena.

- temporal and spacial trends -- Temporal and spacial trends refer to how well the simulated results match the temporal and spacial distribution of the in situ observations. It is important for the shape of a simulated isopleth to correspond, in time and space, to the shape of the observed isopleth, even though all simulated contaminant levels (i.e., magnitudes) may differ from the observed levels by some factor.

- current state of knowledge -- To place the results presented in this report into the proper perspective, one should consider the current state of knowledge associated with the transporting medium (e.g., subsurface, surface water, or the atmosphere) or exposure assessment 
component. For example, the mechanisms governing flow and solute movement in some transport pathways (e.g., the partially saturated zone) are not as well defined or understood as those in other transport pathways (e.g., a riverine environment where sedimentation is not a governing phenomenon). This discrepancy could, therefore, potentially lead to sreater variability between simulation and observed results for those pathways that are not as well understood mechanistically. The greater variability is more a reflection of the lack of knowledge of a particular phenomenon than it is of the methodology that is trying to simulate it.

- intended level of sophistication -- The intended level of detail (e.g., simple versus complex) and application (e.g., comparative versus predictive analysis) of the methodology should be considered in any decision for determining the applicability of the methodology's components to simulate the migration, fate, exposure, and effects of contaminants released into the environment. All computerbased methodologies, no matter how complex, represent simplifications of real-world conditions. Complex computer codes are usually developed to address detailed mechanistic phenomena (hence, the large number of input parameters). Simple codes handle fewer of the detailed phenomenological aspects of real-world conditions by combining many of these aspects into fewer parameters; it is, therefore, difficult to ensure the accuracy of results at all sites under all conditions with application of simple codes. To alleviate this problem, the RAPS methodology was developed to be used more as a comparative tool than a predictive tool; the application results, therefore, represent an order-of-magnitude analysis.

When considering these four aspects, the simulation results presented in this document reflect the observed conditions monitored in the environment exceedingly wel1; this is especially true given that the results simulated by RAPS are not calibrated to the observed results. 
The simulated results in this report are presented as if monitored information were not available; however, the simulated results are compared with monitored data. The results show that the spacial and temporal trends and distributions of contaminants observed in the environment are reflected in all of the simulated results. In most cases, the simulated levels of contamination tend to reflect, both temporally and spacially, those levels monitored in the environment, even at those sites where monitored contaminant levels varied by as much as 13 orders of magnitude. 



\section{ACKNOWLEDGMENTS}

Developing a multimedia contaminant environmental exposure and risk assessment methodology incorporates a wide spectrum of engineering and scientific technologies and involves the specialized expertise of several researchers. One researcher cannot adequately address the complexities associated with an assessment methodology that covers solute migration through four major transport environments (i.e., overland, groundwater, surface water, and air), human dose through four routes of exposure (i.e., ingestion, inhalation, dermal contact, and external dose), and health effects associated with exposure to carcinogenic and noncarcinogenic constituents. The principal contributors to this report and the chapter to which they contributed are as follows:

- Chapter 1.0 -- G. Whelan

- Chapter 2.0 -- G. Whel an

- Chapter 3.0 -- G. Whelan

- Chapter 4.0 -- G. Whel an and M. B. Walter

- Chapter 5.0 -- G. Whelan and M. B. Waiter

- Chapter 6.0 -- J. G. Droppo, ur. and J. W. Buck

- Chapter 7.0 -- D. L. Strenge

The authors would like to thank the following researchers from Pacific Northwest Laboratory (PNL) for their valuable technical comments during the application of the Remedial Action Priority System (RAPS): G. W. Gee, E. A. Jacobson, T. W. Horst, M. J. Fayer, R. M. Smith, and Y. Unishi. Many of the original concepts associated with this methodology were developed in concert with Y. Onishi, R. L. Skaggs, and B. L. Steelman of PNL. Appreciation is extended to R. Neff and D. G. Carfagno of Mound and T. J. McLaughlin and X. S. Cramer of PNL for supplying information on the sites analyzed in this report.

Special thanks goes to the following PNL support personnel who made this document possible: editing -- L. K. Grove, S, G. Weiss, M. E. Strong, and K. R. Hanson; word processing -- N. C. Waugh, C. C. Morgan, and R. Demonia; graphics -- L. G. Wattenburger, D. W. McCue, K. K. Kachele, C. C. Harbour, and T. M. Willard; and duplicating -- E. C. Debattista and 0. P. Valadez. The 
authors would like to thank 0 . R. Simpson most of all, for having the patience to coordinate the compilation of this document while editing it.

Finally, special thanks goes to the U.S. Department of Energy's (DOE) Uffice of Environment, Safety, and Health for supporting the development, review, and testing of the RAPS methodology. The support and technical guidance provided by $R$. Aiken (Office of Environmental Audit) and $P$. van Haagen (formerly with DOE) are especially appreciated. This work was supported by DOE under Contract DE-ACO6-76RLO 1830. 


\section{CONTENTS}

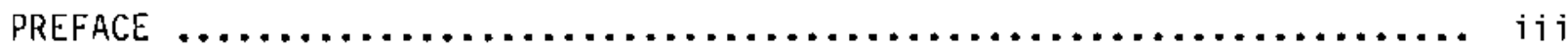

ABSTRACT $\ldots \ldots \ldots \ldots \ldots \ldots \ldots \ldots \ldots \ldots \ldots \ldots \ldots \ldots \ldots \ldots \ldots \ldots \ldots \ldots \ldots \ldots$

EXECUTIVE SUMMARY $\ldots \ldots \ldots \ldots \ldots \ldots \ldots \ldots \ldots \ldots \ldots \ldots \ldots \ldots \ldots \ldots \ldots \ldots \ldots \ldots \ldots \ldots$

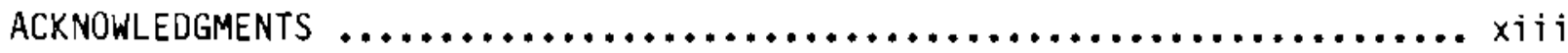

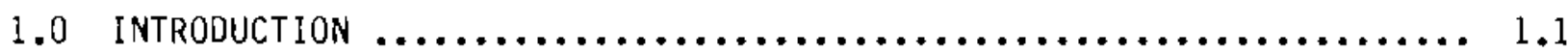

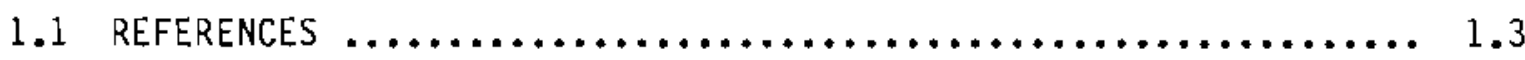

2.0 OVERVIEN OF THE REMEDIAL ACTION PRIORITY SYSTEM $\ldots \ldots \ldots \ldots \ldots \ldots \ldots \ldots . . \ldots$

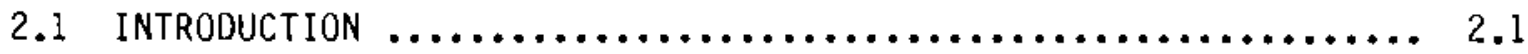

2.2 REMEDIAL ACTION PRIORITY SYSTEM $\ldots \ldots \ldots \ldots \ldots \ldots \ldots \ldots \ldots \ldots \ldots .2 . \ldots \ldots \ldots$

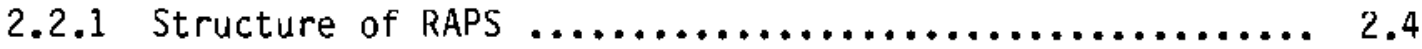

2.2.2 RAPS Solute Transport Pathways and Exposure Assessment Component ................................. 2.7

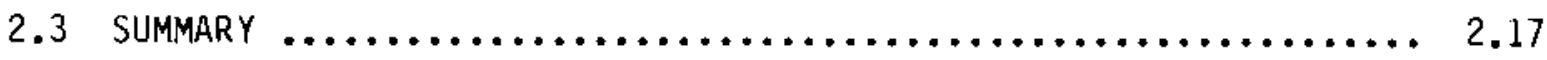

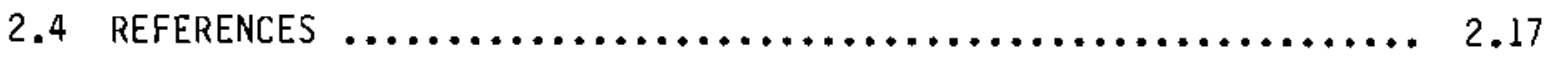

3.0 SOURCE-TERM SCENARIO DEVELOPMENT $\ldots \ldots \ldots \ldots \ldots \ldots \ldots \ldots \ldots \ldots \ldots \ldots \ldots . \ldots \ldots$

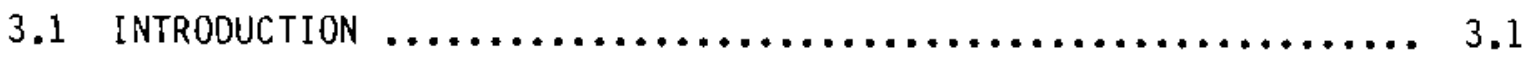

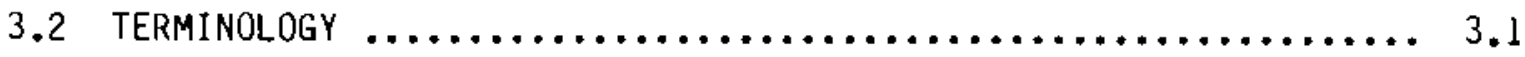

3.3 APPLICATION OF THE RAPS METHODOLOGY TU IDENTIFIEO

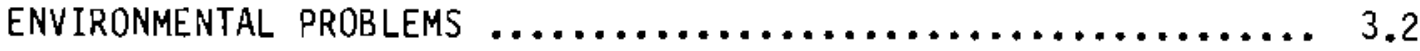

3.3.1 Identifying the Origin of the Potentially Released Contaminants .............................. 3.6

3.3.2 Describing the Potential Release and Determining Its Physical Location ....................... 3.6

3.3.3 Quantifying the Source Term ................... 3.7

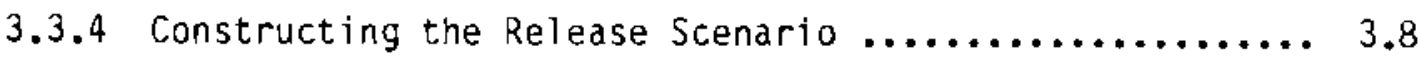

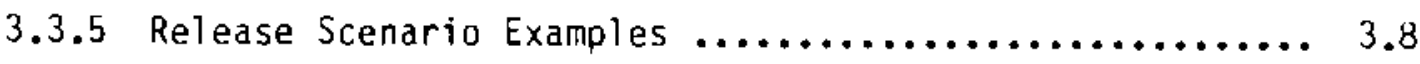




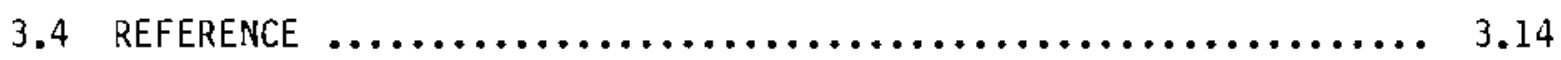

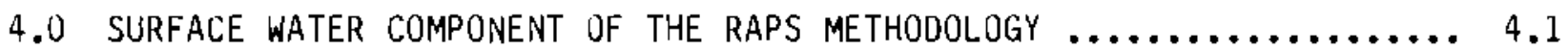

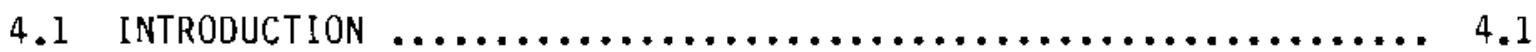

4.2 MATHEMATICAL FORMULATIONS ASSOCIATED WITH THE SURFACE WATER COMPONENT OF THE RAPS METHODOLOGY $\ldots \ldots \ldots \ldots \ldots \ldots \ldots \ldots \ldots, 4.4$

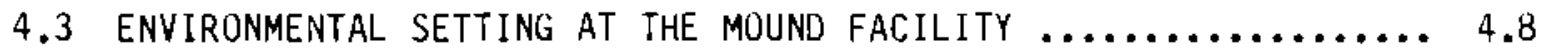

4.3.1 Purpose of the Mound Facility $\ldots \ldots \ldots \ldots \ldots \ldots \ldots \ldots, 4.8$

4.3.2 Location and Site Setting $\ldots \ldots \ldots \ldots \ldots \ldots \ldots \ldots \ldots \ldots, 4.8$

4.3.3 Mound's Environmental Control Monitoring Program ....... 4.11

4.3.4 Quality Assurance of Monitored Data at the Mound

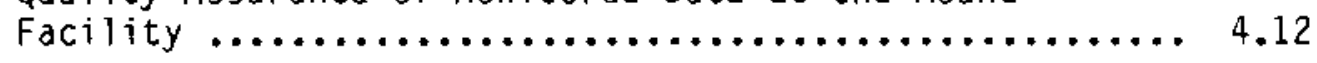

4.3.5 Background Information on the Great Miami River ....... 4.13

4.3.6 History of Effluent Releases from the Mound Facility to the Surface Water Environment ........... 4.15

4.3.7 Procedures and Results of the Mound Facility Sampling Analyses in the Great Miami River .................. 4.23

4.4 APPLICATION OF THE SURFACE WATER COMPONENT OF THE RAPS METHODOLOGY

4.4.1 Scenario Development for the Great Miami River ........ 4.26

4.4.2 Quantification of Parameters for the Great

Miami River $. . . \ldots \ldots \ldots \ldots \ldots \ldots \ldots \ldots \ldots \ldots \ldots \ldots, 4.29$

4.4.3 Results Associated with the Application of RAPS to the

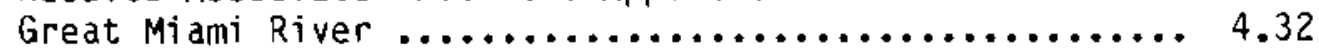

4.5 CONCLUSIONS ASSOCIATED WITH THE APPLICATION OF RAPS TO THE GREAT MIAMI RIVER $\ldots \ldots \ldots \ldots \ldots \ldots \ldots \ldots \ldots \ldots \ldots \ldots \ldots \ldots \ldots \ldots \ldots \ldots, 4.35$

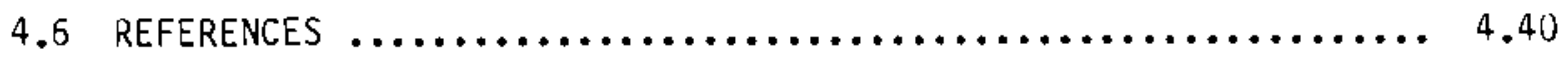

5.0 SUBSURFACE COMPONENT OF THE RAPS METHODOLOGY $\ldots \ldots \ldots \ldots \ldots \ldots \ldots, 5.1$

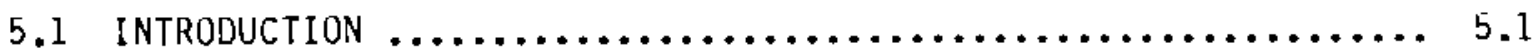

5.2 MATHEMATICAL FORMULATIONS $\ldots \ldots \ldots \ldots \ldots \ldots \ldots \ldots \ldots \ldots \ldots \ldots \ldots \ldots \ldots, 5.6$

5.2.1 Precipitation-Generated Percolation Rate ............ 5.6 
5.2.2 Partially Saturated and Saturated Zones .............. 5.18

5.3 DeEp-dRainage Rates at the hanford facility $\ldots \ldots \ldots \ldots \ldots \ldots, 5.24$

5.3.1 Environmental Setting at the Hanford Facility ......... 5.25

5.3.2 Application of RAPS for Estimating Deep Drainage at the Hanford Facility ............................... 5.30

5.3.3 Results Associated with Estimating Evapotranspiration Rates and Deep-Drainage Volumes Using RAPS at the

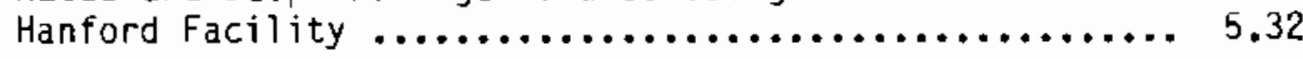

5.4 APPLICATION OF THE RAPS METHODOLOGY TO THE PARTIALLY SATURATED

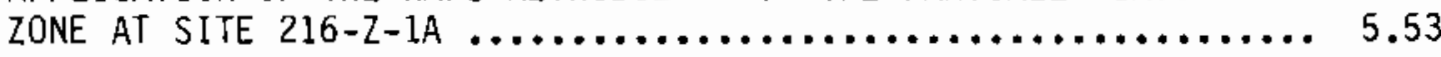

5.4.1 Description of Site $216-Z-1 A$..................... 5.53

5.4.2 Application of RAPS to Site $216-Z-1 A \ldots \ldots \ldots \ldots \ldots . . .5 .58$

5.4.3 Results Associated with the Application of RAPS to Site $216-Z-1 A$................................. 5.69

5.5 APPLICATION OF THE RAPS METHODOLOGY TO THE PARTIALLY SATURATED

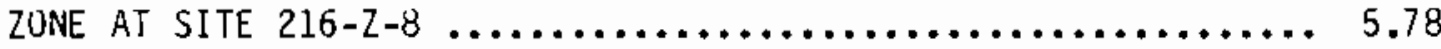

5.5.1 Description of Site $216-Z-8 \ldots \ldots \ldots \ldots \ldots \ldots \ldots \ldots \ldots . . .79$

5.5.2 Application of RAPS to Site $216-2-8 \ldots \ldots \ldots \ldots \ldots \ldots . .6 .85$

5.5.3 Results Associated with the Application of RAPS to

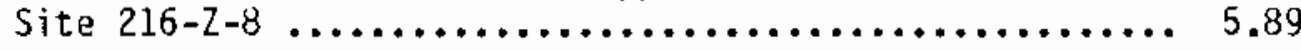

5.6 APPLICATION OF THE RAPS METHODOLOGY TO THE SATURATED ZONE AT THE SOUTH FARMINGDALE-MASSAPEQUA DUMP SITE $\ldots \ldots \ldots \ldots \ldots \ldots \ldots . . \ldots .92$

5.6.1 Description of the South Farmingdale-Massapequa Dump Site ................................. 5.92

5.6.2 Application of RAPS to the South Farmingdale-Massapequa Dump Site ................................ 5.94

5.6.3 Results Associated with the Application of RAPS to the South Farmingda\}e-Massapequa Dump Site ............. 5.100

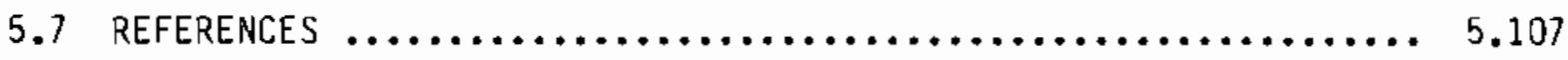

6.0 ATMOSPHERIC COMPONENT OF THE RAPS METHODOLOGY $\ldots \ldots \ldots \ldots \ldots \ldots \ldots .6 .1$

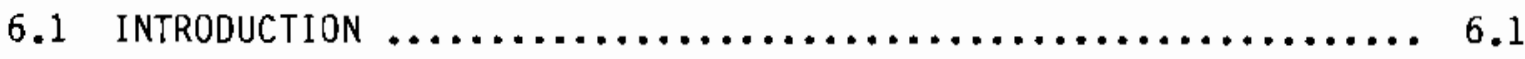




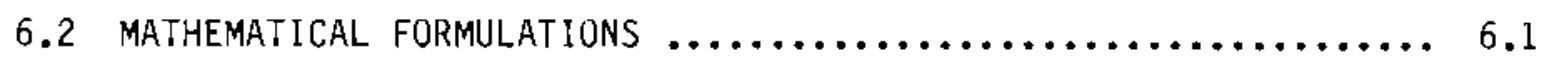

6.2.1 Particle Suspension Component $\ldots \ldots \ldots \ldots \ldots \ldots \ldots \ldots \ldots .6 .2$

6.2 .2 Dispersion, Transport, and Deposition $\ldots \ldots \ldots \ldots \ldots .6 .9$

6.3 SUSPENSION COMPUTATION TEST APPLICATION $\ldots \ldots \ldots \ldots \ldots \ldots \ldots .6 .18$

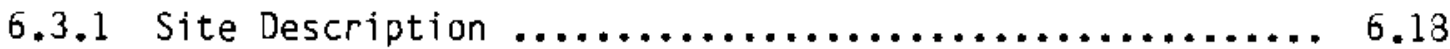

6.3.2 Application of RAPS Suspension Component to Hanford .... 6.26

6.3.3 0iscussion of Suspension Testing Results ............ 6.28

6.4 TRANSPORT, DISPERSION, AND DEPOSITION AT THE MOUND FACILITY $\ldots . .6 .29$

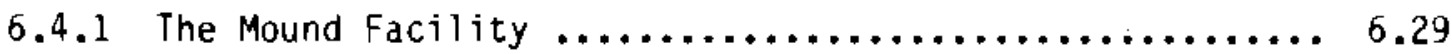

6.4.2 Atmospheric Transport and Dispersion Climatology ....... 6.31

6.4 .3 Radioactive Atmospheric Releases $\ldots \ldots \ldots \ldots \ldots \ldots \ldots \ldots .6 .31$

6.4.4 Application of RAPS To Mound's Stack Releases ........ 6.35

6.4 .5 Discussion $\ldots \ldots \ldots \ldots \ldots \ldots \ldots \ldots \ldots \ldots \ldots \ldots \ldots \ldots \ldots, 6.47$

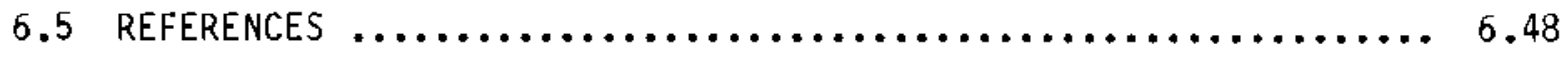

7.0 EXPOSURE AND HEALTH EFFECTS COMPONENT OF THE RAPS METHODOLOGY $\ldots \ldots \ldots 7.1$

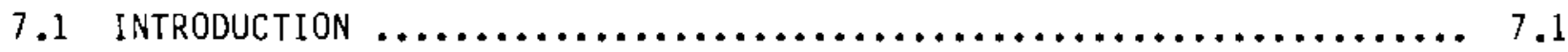

7.2 MATHEMATICAL FORMULATIONS ASSOCIATED WITH THE EXPOSURE

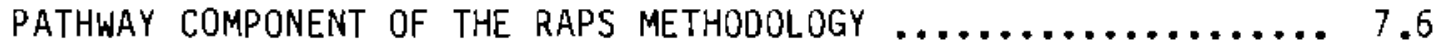

7.2 .1 Innalation $\ldots \ldots \ldots \ldots \ldots \ldots \ldots \ldots \ldots \ldots \ldots \ldots, 7.6$

7.2 .2 Drinking-Water Ingestion $\ldots \ldots \ldots \ldots \ldots \ldots \ldots \ldots \ldots \ldots \ldots, 7.6$

7.2 .3 Aquatic-food Ingestion $\ldots \ldots \ldots \ldots \ldots \ldots \ldots \ldots \ldots \ldots, 7.7$

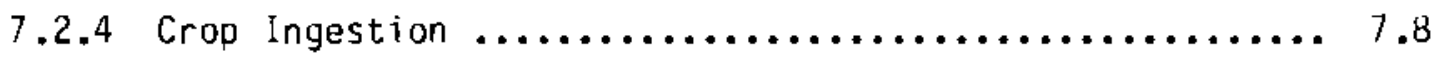

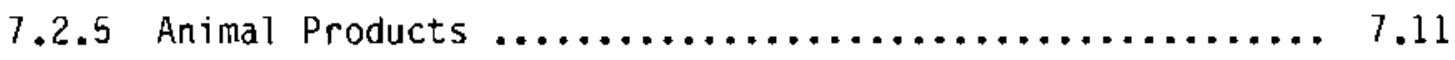

7.2.6 External Exposure to Radionuclides $\ldots \ldots \ldots \ldots \ldots \ldots \ldots .7 .12$

7.2.7 Dermal Contact/Inadvertent Ingestion $\ldots \ldots \ldots \ldots \ldots \ldots \ldots, 7.12$

7.2.8 Dose Conversion Factors $\ldots \ldots \ldots \ldots \ldots \ldots \ldots \ldots \ldots \ldots \ldots \ldots . . .13$ 
7.3 COMPARISON OF MONITORED AND SIMULATED PATHWAY CONCENTRATIONS

FOR THE MOUND FACILITY ............................. 7.14

7.3.1 Aquatic-Food Pathway Simulation ................. 7.14

7.3.2 Vegetation Contamination Pathways ............... 7.20

7.4 SUMMARY OF EXPOSURE PATHWAY MODEL COMPARISONS $\ldots \ldots \ldots \ldots \ldots \ldots \ldots 7.25$

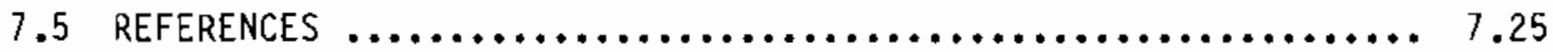




\section{FIGURES}

2.1 Schematic Diagram Illustrating the Interactions Between the Various Contaminant Transporting Media and How the Contaminants Affect Man Through His Environment ........................... 2.3

2.2 Simplified Diagram Outlining the Interactions Between the Transport Pathways and Exposure Assessment Components of the RAPS Methodology

4.1 Diagram of the Surface Water Environment $\ldots \ldots \ldots \ldots \ldots \ldots \ldots \ldots \ldots . \ldots . \ldots$

4.2 Southwestern Ohio and Location of Mound Facility ............. 4.9

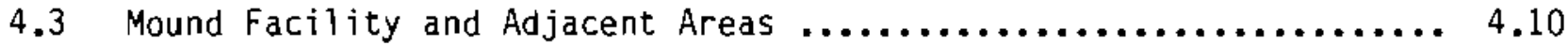

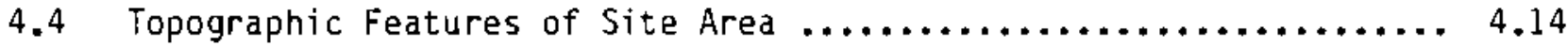

4.5 Flow Duration at Miamisburg, Ohio $\ldots \ldots \ldots \ldots \ldots \ldots \ldots \ldots \ldots \ldots \ldots \ldots . \ldots \ldots$

4.6 Mound Facility Drainage Ditch and Underground Pipe ........... 4.18

4.7 Mound Facility Drainage Ditch in Relation to Miami-Erie Canal and Great Miami River ................................. 4.19

4.8 Waterways Adjacent to Mound Facility before July $1976 \ldots \ldots \ldots \ldots \ldots .22$

4.9 Offsite Water Sampling Locations ........................ 4.24

4.10 Simulated Versus Observed ${ }^{238} \mathrm{Pu}$ Concentrations in the Great Miami River at Sampling Location 1 for the Years 1973 Through 1978 .... 4.25

4.11 Simulated Versus Observed ${ }^{3} H$ Concentrations in the Great Miami River at Sampling Location 1 for the Years 1973 Through 1978 ..... 4.26

4.12 Simulated Versus Observed 233,234 U Concentrations in the Great Miami River at Sampling Location 1 for the Years 1973 Through 1978

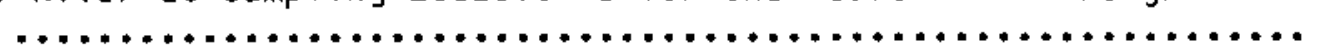

4.13 Simulated Versus observed ${ }^{238} \mathrm{Pu}$ Concentrations in the Great Miami River at Sampling Location 2 for the Years 1979 Through 1985 ..... 4.28

4.14 Simulated Versus Observed ${ }^{3} \mathrm{H}$ Concentrations in the Great Miami River at Sampling Location 2 for the Years 1979 Through 1985 ..... 4.29

4.15 Simulated Versus Observed 233,234 U Concentrations in the Great Miami River at Sampling Location 2 for the Years 1979 Through 1985 
4.16 Simulated Versus Observed ${ }^{238} \mathrm{Pu}$ Concentrations in the Great Miami River at Sampling Location 3 for the Years 1979 through 1985 ...... 4.31

4.17 Simulated Versus Observed ${ }^{3} \mathrm{H}$ Concentrations in the Great Miami River at Sampling Location 3 for the Years 1979 Through 1985 ..... 4.32

4.18 Simulated Versus Observed $233,234 \mathrm{U}$ Concentrations in the Great Miami River at Sampling Location 3 for the Years 1979 Through 1985

4.19 Simulated Versus observed ${ }^{238} \mathrm{Pu}$ Concentrations in the Great Miami River at Sampling Location 4 for the Years 1973 Through 1978 ..... 4.34

4.20 Simulated Versus Observed ${ }^{3} H$ Concentrations in the Great Miami River at Sampling Location 4 for the Years 1973 Through 1978 ..... 4.35

4.21 Simulated Versus Observed $233,234 \mathrm{~V}$ Concentrations in the Great Miami River at Sampling Location 4 for the Years 1973 Through 1978

4.22 Simulated Versus observed ${ }^{238} \mathrm{Pu}$ Concentrations in the Great Miami River at Sampling Location 5 for the Years 1979 Through 1985

4.23 Simulated Versus Observed ${ }^{3} \mathrm{H}$ Concentrations in the Great Miami River at Sampling Location 5 for the Years 1979 Through 1985

4.24 Simulated Versus 0bserved $233,234 \mathrm{U}$ Concentrations in the Great Miami River at Sampling Location 5 for the Years 1979 Through 1985

5.1 Diagram of the Movement of Water in and Around an Inactive Waste Site ................................ 5.2

5.2 Diagram of the Groundwater Environment:

a) Contaminant Levels or Fluxes at a Surface Water Boundary and

b) Contaminant Levels at a Withdrawal Well $\ldots \ldots \ldots \ldots \ldots \ldots \ldots \ldots \ldots .4$

5.3 Location of the Hanford Meteorology Station on the Hanford

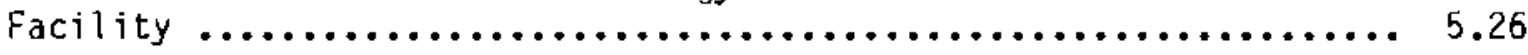

5.4 Cumulative Potential Evaporation by Four Methods for $1947 \ldots \ldots \ldots .37$

5.5 Cumulative Potential Evaporation by Four Methods for $1948 \ldots \ldots . . .58$

5.6 Comparison of Various Techniques for Estimating Potential

Evapotranspiration .................................... 5.39

5.7 Comparison of Actual Evapotranspiration as Computed by Various

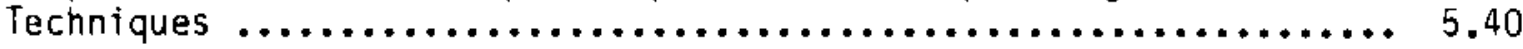


5.8 Soil Moisture Capacity Versus Deep-Drainage Volume at the Hanford Facility Using Historical (1912 to 1980) Hanford Meteorology

Station $\mathrm{Cl}$ imatic Data ................................. 5.43

5.9 Precipitation at Grass Site and Hanford Meteorology Station During 1983

5.10 Soil Moisture Capacity Versus Deep-Drainage Volume at the Grass and Bare-Soil Sites on the Hanford Facility Using 1983 Hanford Meteorology Station Climatic Data ....................... 5.50

5.11 Comparison of Observed and Simulated Actual Evapotranspiration for the First 4 Months of 1984 at the Burial Waste Test Facility Site on the Hanford Facility ......................... 5.52

5.12 Location of the 216-Z-1A waste Site at the Hanford Facility ..... 5.54

$5.13216-Z-1 A$ Crib Construction Details $\ldots \ldots \ldots \ldots \ldots \ldots \ldots \ldots \ldots \ldots \ldots$

5.14 Plan View of Cribs, Tile Field, and Well Locations at the 216-2-1A waste Site ....................................... 5.57

5.15 Stratigraphy of the Subsurface Region Beneath the 216-Z-1A Waste Site for Cross Section A-A' .............................. 5.59

5.16 Stratigraphy of the Subsurface Region Beneath the 216-Z-1A Waste Site for Cross Section B-B'

5.17 Isopleths for Total Activity for Cross Section A-A' at Site 216-Z-1A

5.18 Isopleths for Total Activity for Cross Section B-B' at Site

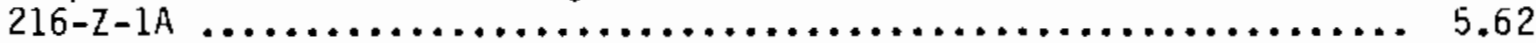

5.19 Moisture Release Curve ............................... 5.68

5.20 Plutonium-239,240 Isopleths for Cross Section A-A' at Site $216-Z-1 A$

5.21 Plutonium-239,240 Isopleths for Cross Section B-B' at Site $216-2-1 A$

5.22 Americium-24l Isopleths with a $K_{d}$ Equaling $0.1 \mathrm{ml} / \mathrm{g}$ for Cross Section $A-A^{\prime}$ at Site $216-Z-1 A$

5.23 Americium-241 Isopleths with a $\mathrm{K}_{\mathrm{d}}$ Equaling $0.1 \mathrm{mi} / \mathrm{g}$ for Cross Section $B-B^{\prime}$ at Site $216-Z-1 A$

5.24 Americium-24l Isopleths with a $\mathrm{K}_{\mathrm{d}}$ Equaling $0.5 \mathrm{ml} / \mathrm{g}$ for Cross Section $A-A^{\prime}$ at Site 216-Z-1A 
5.25 Americium-24l Isopleths with a $K_{d}$ Equaling $0.5 \mathrm{ml} / \mathrm{g}$ for Cross Section $B-B^{\prime}$ at Site $216-Z-1 A$............................. 5.76

5.26 Simulated and Observed Spacially Varying Plutonium-239 Concentrations Beneath the $216-Z-1$ A Waste Site $\ldots \ldots \ldots \ldots \ldots \ldots \ldots .6 .77$

5.27 Simulated and Observed Spacially Varying Plutonium-240

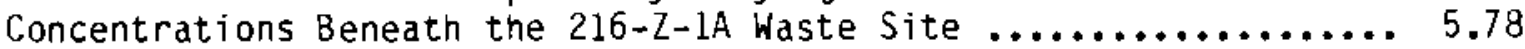

5.28 Simulated and Observed Spacially Varying Americium-241

Concentrations, with a $K_{d}$ Equaling $0.1 \mathrm{ml} / \mathrm{g}$, Beneath the

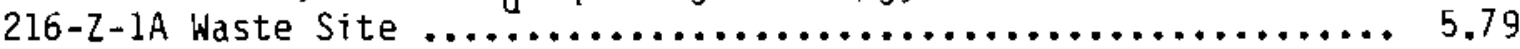

5.29 Simulated and Observed Spacially Varying Americium-241 Concentrations, with a $K_{d}$ Equaling $0.5 \mathrm{ml} / \mathrm{g}$, Beneath the

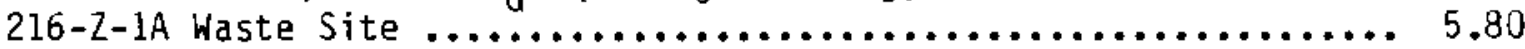

5.30 Location of the 216-Z-1A Waste Site at the Hanford Facility ...... 5.81

5.31 The 216-Z-8 French Drain Site ............................ 5.82

5.32 Schematic Diagram of the $216-Z-8$ French Drain System $\ldots \ldots \ldots \ldots \ldots . . .63$

5.33 Simulated and Observed Spacially Varying Plutonium-239

Concentrations Beneath the $216-Z-8$ waste Site ................ 5.91

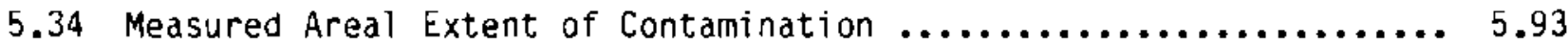

5.35 Source Function for Cadmium and Chromium $\ldots \ldots \ldots \ldots \ldots \ldots \ldots \ldots \ldots . .9 . \ldots$

5.36 Temporal Variation in the Chromium Concentration at Different Locations Downgradient of the Area Source ..................... 5.102

5.37 Spatial Variations in the Chromium Concentration for the Years $1949,1953,1958$, and 1962

5.103

5.38 Temporal Variation in the Cadmium Concentration at Different Locations Downgradient of the Area Source ................... 5.104

5.39 Spatial Variation in the Cadmium Concentration for the Years

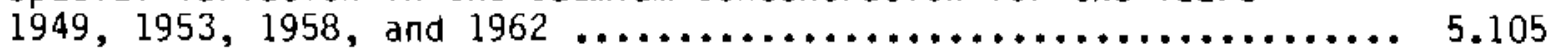

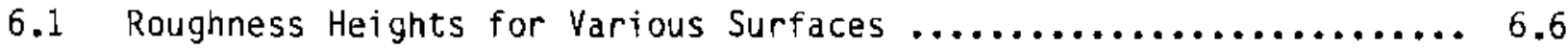

6.2 B-C Cribs Controlled Area ............................... 6.19

6.3 Contours of ${ }^{137}$ Cs Surface Contamination in the $B-C$ Cribs

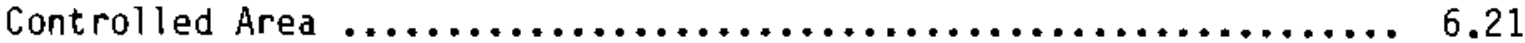

6.4 Contours of Normalized Suspended Air Concentration $\bar{u} c / K$ in the B-C Cribs Controlled Area 
6.5 Normalized Suspended Air Concentration for a Uniform Area

Source as a Function of Downwind Distance .................... 6.24

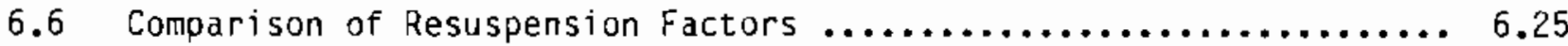

6.7 Locations of Mound Air-Monitoring Stations ................... 6.30

6.8 Wind Roses for Mound and Wright-Patterson Air Force Base ....... 6.33

6.9 Comparison of Computed and Monitored ${ }^{238}$ Pu Air Concentrations for 1985 Operations at Mound, Based on a Typical Stack Release ....... 6.39

6.10 Comparison of Computed and Monitored $238 \mathrm{Pu}$ Air Concentrations

for 1985 Operations at Mound, Based on a Ground-Level Release .... 6.40

6.11 Computed and Monitored ${ }^{238} \mathrm{Pu}$ Air Concentrations as a Function of Downwind Oistance for 1985 Operations at Mound, Based on a Typical Stack Release ........................................ 6.41

6.12 Computed and Monitored ${ }^{238}$ Pu Air Concentrations as a Function of Downwind Distance for 1985 Operations at Mound, Based on a GroundLevel Release ...................................... 6.42

6.13 Comparison of Computed and Monitored Tritium Air Concentrations for 1985 Operations at Mound, Based on a Typical Stack Release ... 6.43

6.14 Distribution of Surface Contamination at Mound $\ldots . . . \ldots \ldots \ldots \ldots . . . . .44$

7.1 Exposure Pathways to Humans $\ldots \ldots \ldots \ldots \ldots \ldots \ldots \ldots \ldots \ldots \ldots \ldots \ldots \ldots . . \ldots \ldots$

7.2 Exposure Pathways Considered by RAPS $\ldots \ldots \ldots \ldots \ldots \ldots \ldots \ldots \ldots \ldots \ldots$

7.3 0ffsite Water-Sampling Locations for the Mound Facility ......... 7.16

7.4 Comparison of Simulated and Observed Tritium Concentrations in Fish ......................................... 7.17

7.5 Comparison of Simulated and ubserved ${ }^{238} \mathrm{Pu}_{\mathrm{u}}$ Concentrations in Fish

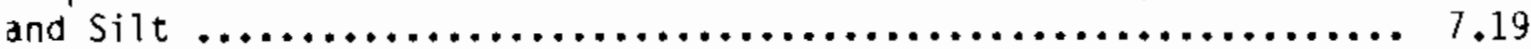

7.6 Comparison of Simulated and Observed Tritium Concentrations in Grass ........................................... 7.22

7.7 Comparison of Simulated and Observed Tritium Concentrations in Tomatoes 


\section{TABLES}

4.1 Depth-Discharge Relationship for the Great Miami River at Miamisburg, onio .................................. 4.17

4.2 Contaminant Inventory Released Per Year .................... 4.20

4.3 Constituent and Hydraulic Information $\ldots \ldots \ldots \ldots \ldots \ldots \ldots \ldots \ldots . . . . . . . . . .40$

5.1 Climatologic Summary for the Hanford Area ................... 5.29

5.2 Parameters Associated with the Hanford Facility as Required for RAPS ........................................ 5.31

5.3 Reported Estimates of Recharge at Selected Arid Sites ......... 5.42

5.4 Average Annual Infiltration Volume Calculations Using the RAPS Methodology at the Hanford Facility ................... 5.44

$5.51983 \mathrm{Climatologic}$ Summary for the Hanford Area $\ldots \ldots \ldots \ldots \ldots \ldots \ldots . . . .47$

5.6 Climatologic Sumary for the First 5 Months of 1984 for the Hanford Area ............................................... $5 . \ldots$

5.7 Summary of Contaminant Inventories Released from the 216-Z-1A

Site ............................................. 5.58

5.8 Data for the $216-Z-1$ A Site Assessment $\ldots \ldots \ldots \ldots \ldots \ldots \ldots \ldots \ldots \ldots . \ldots \ldots$

5.9 Data for the $216-Z-8$ Site Assessinent $\ldots \ldots \ldots \ldots \ldots \ldots \ldots \ldots \ldots \ldots \ldots . \ldots . \ldots$

5.10 Data for the South Farmingdale-Massapequa Chromium-Cadmium Site

Modeling ........................................... 5.101

6.1 Typical Surface Roughness Lengths $\ldots \ldots \ldots \ldots \ldots \ldots \ldots \ldots \ldots \ldots \ldots \ldots . \ldots \ldots$

6.2 Surface Contamination Labels For Figure $6.3 \ldots \ldots \ldots \ldots \ldots \ldots \ldots . . \ldots .61$

6.3 Hanford Wind Speed, Wind Direction, and Stability Summary ....... 6.26

6.4 Average Winds at the Mound Facility, by Sector $\ldots . \ldots \ldots \ldots \ldots . . .6 .32$

6.5 Dayton Wind Speed, Wind Direction, and Stability Summary ........ 6.34

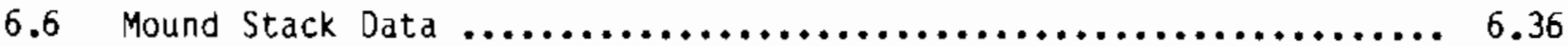

6.7 Concentrations of ${ }^{238} \mathrm{Pu}$, Including Environmental Levels in Air at Offsite Sampling Locations in 1985 


\subsection{INTRODUCTION}

The U.S. Department of Energy's (DOE) inactive hazardous waste disposal sites are currentiy being evaluated under its CERCLA (Comprehensive Environmental Response, Compensation, and Liability Act of 1980) program to determine whether migration of hazardous substances has occurred and whether remediation will be required. Consequently, DOE is in the process of locating, identifying, and evaluating potential problems associated with its inactive hazardous and radioactive mixed waste disposal facilities, and controlling the migration of hazardous substances from such facilities to minimize potential hazards to health, safety, and the environnent. Limited resources are available to conduct detailed site investigations and characterizations of all potentially hazardous and radioactive mixed waste sites identified. Therefore, an assessment methodology is required to prioritize waste sites according to risk, based on limited available information, so that detailed site characterizations are performed first on those sites that exhibit the highest potential risks. Consequently, Pacific Northwest Laboratory (PNL) was requested to develop a risk assessment methodology. The methodology developed is called the Remedial Action Priority System (RAPS). The RAPS methodology will provide DOE with a management tool to assist it in determining priorities for further site investigations.

The RAPS methodology uses empirically, analytically, and semianalytically (i.e., temporally convoluted analytical solution) based mathematical algorithms to predict the potential for contaminant migration from a site to receptors of concern using pathways analyses. Four major pathways of contaminant migration are considered in the RAPS methodology: surface water, groundwater, atmospheric, and overland. Using the predictions of contaminant transport, simplified exposure assessments are performed for important receptors. The risks associated with the site can then be calculated relative to the risks of other sites for each pathway and for all pathways together.

Under the guidance of DOE, PNL has developed a program to review, analyze, and test all aspects of the RAPS methodology. Under the program, the methodology and its mathematical formulations have been independently reviewed by 
technical authorities in the private and public sectors (see whelan et al. 1987). An extensive sensitivity analysis is currentiy under way to determine the effects of 1) specific input parameters, 2) initial and boundary conditions, 3) distributions of input parameters, and 4) interrelationships among input parameters affecting model response over short and long time frames. Finally, the various components of the RAPS methodology are being implemented at actual sites where contaminant levels have been monitored in the environment. The monitored contaminant levels are then compared to simulated contaminant leveis associated with the application of RAPS to these sites. The purpose of the comparison is to demonstrate the applicability of the RAPS methodology to perform order-of-magnitute analysis to a variety of hazardous waste sites or releases of contaminants into the environment.

The comparison of predicted and measured contaminant concentrations in the environment is documented in this report. The RAPS methodology has been applied to several sites that have released and monitored the release of contaminants in the environment to demonstrate the application of the surface water, atmospheric, groundwater, and exposure assessment components of the methodology. These applications illustrate the type of data typically required to implement the methodology and several of the types of contaminant releases (e.g., direct discharge, French drain, cribs, tile field, and stacks) that can be considered by the methodology. Thus, they demonstrate the applicability of implementing the methodology at a wide variety of sites. The results contained in this report are summarized in whelan et al. (1988).

The remainder of this report is divided into six chapters. Chapter 2.0 presents an overview of the RAPS methodology. Chapter 3.0 describes how complex, real-world situations are converted into equivalent simplified scenarios, on which the RAPS methodology bases its analysis. Chapters 4.0, 5.0, and 6.0 describe the application of the surface water, groundwater, and atmospheric components of RAPS, respectively, to a variety of sites that release contaminants into the environment. Finally, Chapter 7.0 tests several food-chain algorithms by presenting a comparison between monitored and simulated contaminant levels in fish, grass, and tomatoes. 


\subsection{REFERENCES}

Whelan, G., D. L. Strenge, J. G. Droppo, Jr., and B. L. Steelman. 1987. The Remedial Action Priority System (RAPS): Mathematical Formulations. PNL-6200, prepared for the Office of Environment, Safety, and Health, U.S. Department of Energy, Washington, D.C. by Pacific Northwest Laboratory, Richland, Washington.

Whelan, G., S. M. Brown, D. L. Strenge, A. P. Schwab, and P. J. Mitchell. 1988. Contaminant Assessment Modeling Under the Resource Conservation and Recovery Act. EA-5342, Electric Power Research Institute, Palo Alto, California. 
6.8 Incremental Concentrations of Tritium Oxide in Air at Offsite

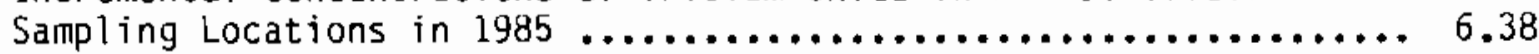

6.9 Total Annual ${ }^{238} \mathrm{Pu}$ Deposition, Computed for the Year 1985 for

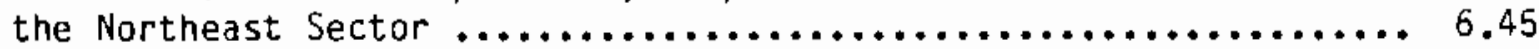

6.10 Comparison of Computed Total $238 \mathrm{Pu}$ Deposition with Measured Soil Concentrations in the Northeast Sector, Assuming a Stack Release ......................................... 6.46

6.11 Comparison of Computed Total ${ }^{238} \mathrm{Pu}$ Deposition with Measured Soil Concentrations in the Northeast Sector, Assuming a Ground-Level Release. ........................................... 6.46

7.1 Mound Facility Annual Environmental Monitoring Report References ......................................... 7.15

7.2 Parameter Values for Vegetation Calculation................. 7.24 



\subsection{OVERVIEW OF THE REMEDIAL ACTION PRIORITY SYSTEM(a)}

\subsection{INTRODUCTION}

For several decades, the U.S. Department of Energy (DOE) and its predecessor agencies have been involved in a wide range of activities that generate hazardous substances, both chemical and radioactive. In some cases, these substances have migrated from the disposal sites, and further site investigations and possible site remediation are needed. These circumstances, coupled with the enactment of environmental regulations such as the Comprehensive Environmental Response, Compensation, and Liability Act of 1980 (CERCLA) require that action be taken to identify and reduce or el iminate, in an environmentally responsible manner, the potential hazards related to the past disposal activities.

The DOE policy for CERCLA, as stated by DOE (1985), is to identify and evaluate potential problems associated with hazardous waste disposal sites and to provide steps to help control the migration of hazardous substances from such facilities to minimize potential hazards to health, safety, and the environment. A typical approach in accomplishing the goals of this policy is to 1) locate and identify those hazardous waste disposal sites that may pose an unacceptable risk; 2) quantify the presence (or absence) of hazardous substances for these sites by conducting preliminary surveys and comprehensive investigations, if necessary; 3 ) develop a site remediation plan for sites that pose an unacceptable risk by evaluating alternative technologies for either controlling the migration of hazardous substances or decontaminating the disposal site; 4) implement the recommended remedial measures; and 5) prepare documentation of remedial actions and establish any site monitoring requirements necessary to verify the effectiveness of the actions.

Assessment methodologies or frameworks have been and are being developed that address the concerns related to risks as well as the migration, fate, and exposure of contaminants released into the environment. (b) These

(a) This chapter is based on Whelan et a?. (1985, 1986, 1987, 1988).

(b) For a discussion of assessment methodologies, refer to whelan et al. (1987). 
contaminants can undergo complex processes of transport, degradation and decay, transformation, biological uptake, and intermedia transfer among atmospheric, overland, groundwater, and surface water pathways. The interactions of these various media pathways and linkages to humans are illustrated in Figure 2.1. The assessment frameworks integrate many of these complex components in an attempt to address a complicated environmental setting in a logical, consistent, cogent, objective manner. Each assessment framework is developed to meet a particular objective and, therefore, cannot arbitrarily be applied to all assessment situations. For example, the Remedial Action Priority System (RAPS) methodology is being developed for DOE to rank, according to potential risk, hazardous and radioactive-mixed waste sites so the most hazardous sites can be further investigated first (Whelan and Steelman 1984). The RAPS methodology addresses contaminant migration, fate, exposure, and risk through four major environmental transport pathways (i.e., groundwater, overland, surface water, and atmospheric). The RAPS methodology was developed with a level of sophistication appropriate for use in ranking sites according to their relative hazard potential; the methodology was not necessarily developed to be used in a predictive mode to simulate the actual risks posed by a particular site resulting from the release of contaminants into the environment (Whelan et al. 1986). The RAPS methodology, therefore, meets the needs of DOE but may not meet the needs of other government agencies or private groups for conducting different types of as sessments.

To fully comprehend the approach being considered for identifying and evaluating those hazardous waste sites, this section presents the rationale behind the development of the RAPS methodology and a description of the structure of RAPS, the various components that comprise the system, and the key features and characteristics of the system.

\subsection{REMEDIAL ACTION PRIORITY SYSTEM}

The RAPS methodology uses empirically, analytically, and semianalytically based mathematical algorithms and a compositely coupled pathways analysis to predict the potential for contaminant migration from a waste site to important environmental receptors. Subsurface (groundwater), overland, 


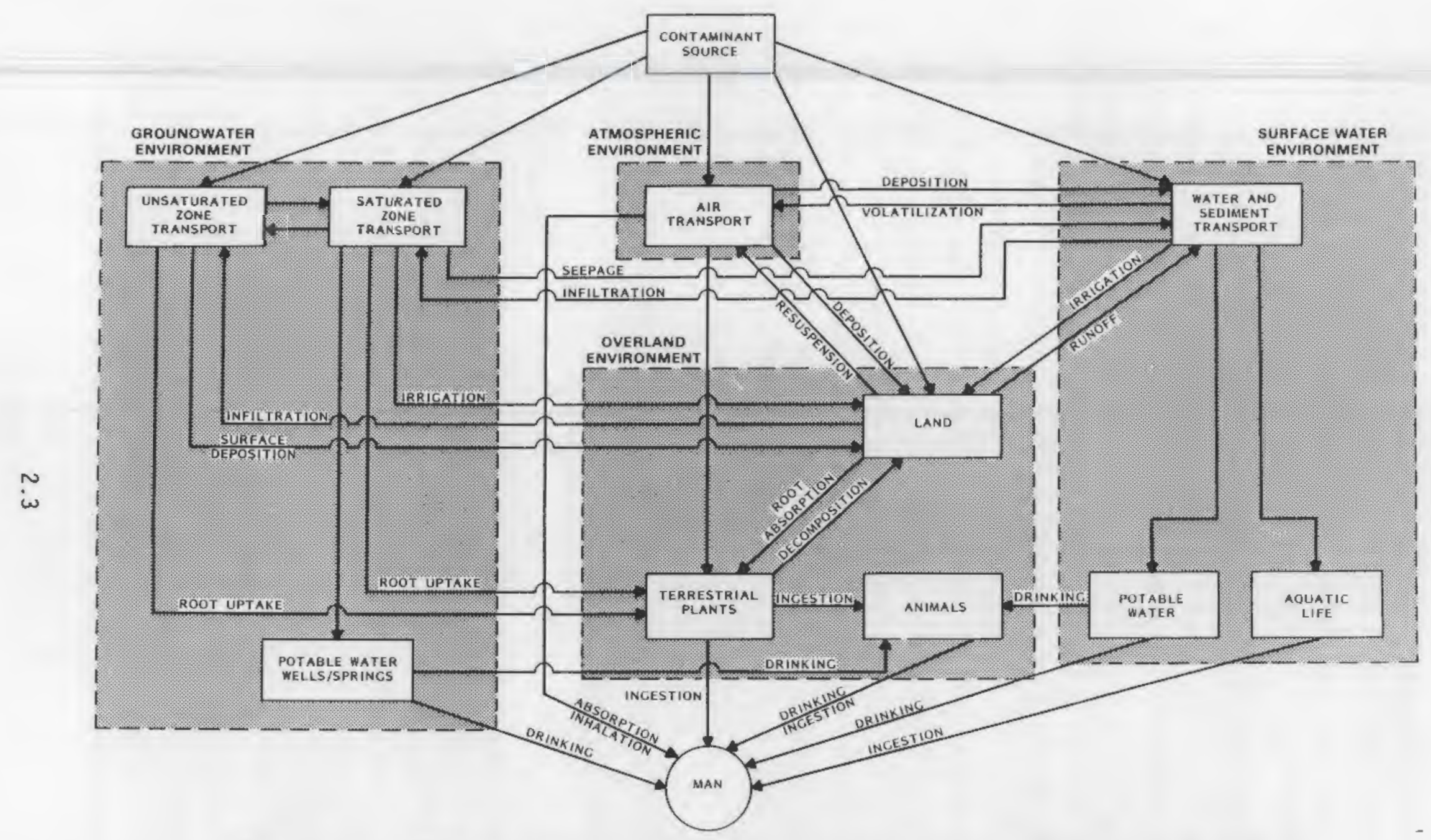

FIGURE 2.1. Schematic Diagram Illustrating the Interactions Between the Various Contaminant Transporting Media and How the Contaminants Affect Man Through His Environment (after Whelan et al. 1983) 
surface water, and atmospheric pathways are considered. Using the predictions of contaminant transport, simplified exposure assessments are performed for important receptors. The risks associated with the sites are then calculated relative to other sites for all pathways of concern.

Based on input data that are readily available at DOE facilities, the RAPS methodology considers 1) specific site information and constituent characteristics associated with the pathways; 2) chemical and radioactive wastes; 3) the potential direction of contaminant movement; 4) contaminant retention (e.g., environmental mobility, dispersion, and decay/degradation), where applicable; 5) contaminant toxicities; 6) population distributions; 7) various routes or types of exposure (e.g., inhalation, ingestion, derma 7 contact, and external dose); 8) time until a population is exposed or exposure begins (i.e., time of contaminant arrival); and 9) duration of exposure (i.e., the length of time a population is continually exposed to a contaminant). Time of contaminant arrival and duration of exposure are critical considerations in a site prioritization; the sooner a population is exposed, the greater the urgency for site characterization and possible remediation. Likewise, the longer a population is exposed to a contaminant, the greater the potential severity of that exposure. Consideration of both of these factors is absent from more simplified ranking methodologies.

\subsubsection{Structure of RAPS}

Structuraliy, the RAPS methodology is based on the compositely coupled multimedia model ing approach (see Whelan et al. 1987). Each transport pathway addressed by RAPS has a set of codes that describe the migration and fate of contaminants. These transport pathway codes are systematically integrated with an exposure assessment component that considers the type, time, and duration of exposure and the location and size of the population exposed. Figure 2.2 presents a simplified diagram outlining the various pathways and their interactions, as considered by the RAPS methodology.

To implement the methodology at a site, the user designates the appropriate transport pathways by identifying the path [i.e., route(s)] the contaminants may take from the waste site through the various media. The user is then prompted to supply site and constituent (i.e., contaminant) 
Perform Exposure

Pathway Analysis

Identify Source Develop Data Base

Perform Transport Pathway Analysis
Compute

Risk

in

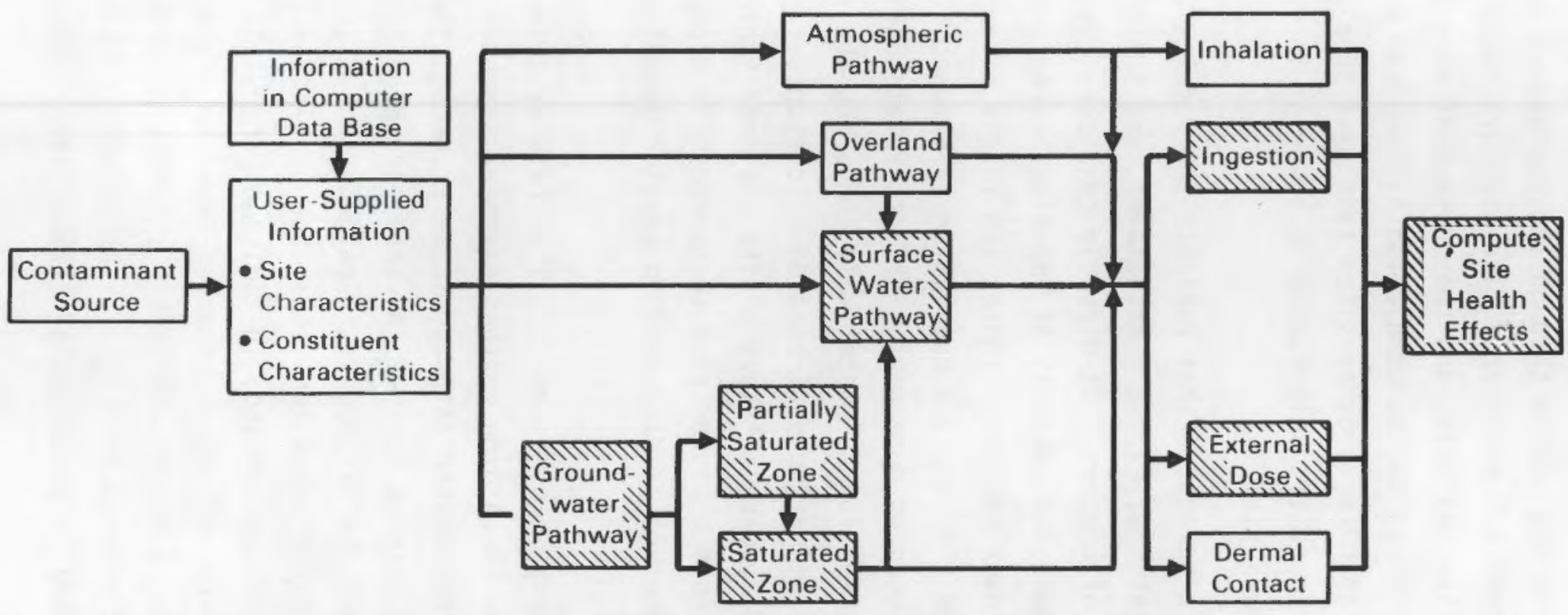

FIGURE 2.2. Simplified Diagram Outlining the Interactions Between the Transport Pathways and Exposure Assessment Components of the RAPS Methodology. (Shaded boxes indicate a potential contaminant transport and exposure route using the RAPS methodology.) (after Whelan et al. 1986, 1987) 
information. Based on these data, the migration and fate of the contaminants are simulated from the source through the designated transport pathways to important environmental receptors. The exposure route to the population is integrated into the analysis, and the subsequent risk [i.e., the Hazard Potential Index (HPI)] to the population is computed for the site. The site HPI is compared to HPIs at other sites that have been previously analyzed. The sites are then objectively ranked in order of increasing risk, according to the HPI for each site.

The HPI is a parameter that reflects the results of the multimedia transport calculations, exposure assessment, and the effects of an exposure to a population of concern. It directly considers contaminant levels that reflect persistence and mobility at important receptors, population distributions, contaminant toxicity, routes and levels of exposure, duration of exposure, and the time until a population is exposed. It is also based on scientifically accepted dose-health effects relationships. The HPI is used as a relative marker for quantitatively comparing the potential for the migration, fate, and effects of hazardous substances. By itself, an HPI does not indicate the absolute risk at a site but does indicate whether one site potentially presents a higher risk to surrounding receptors of concern than another site. The HPI is discussed in greater detail in whelan et al. (1987).

The shaded boxes in Figure 2.2 illustrate an example application of the RAPS methodology. According to this example, leachate leaves the waste site and enters the groundwater pathway, travels through the partially saturated zone, enters and travels through the saturated zone, leaves the groundwater pathway and enters the surface water pathway, and migrates through a nearby river. At designated usage locations, the population is externally exposed to contaminants of concern and, in addition, ingests a portion of the contaminated river water. An HPI is computed based on the exposure to the population and is compared to HPIs for other sites to prioritize the site, relative to others, based on relative risk. Example applications of the RAPS methodology are presented in whelan et al. $(1985,1987,1988)$. 


\subsubsection{RAPS Soiute Transport Pathways and Exposure Assessment Component}

As illustrated in Figure 2.2, four transport pathways and an exposure component are addressed by the RAPS framework. For each pathway, contaminant retardation is described, where applicable, by an equilibrium (i.e., partition or distribution) coefficient. First-order degradation/decay is assumed for all contaminants that do not result in decay products (e.g., radionuclides).

For contaminants that decay, the parent contaminants are initially treated as conservative substances (i.e., no decay products or degradation). Upon reaching the environmental receptor, radiological decay is corrected in a separate calculation, and the code subsequently computes the temporal distribution of each decay product. The Bateman equation is then used to calculate the concentrations of all important decay products in the chain (Bateman 1910 , as reported by code11 et al. 1982). The approach for analyzing each of the pathways considered in RAPS is briefly discussed below.

\subsubsection{Groundwater Pathway}

The quantity of leachate likely to be generated during the operational lifetime of a hazardous waste facility is a major factor controlijng the degree to which a site will require analysis. The site leachate quantity is controlied by local meteorologic, geologic, and hydrologic conditions and the design and operation of the facility. Given the limited availability of literature data on leachate quantities generated by landfills, available estimation techniques are used to quantify the leachate.

A modified method of the one proposed by Thornthwajte and Mather (1955, 1957), Fenn et a1. (1975), and Dass et a1. (1977) is used to compute leachate quantities from landfills. The quantity of leachate produced at a given landfill site is estimated with a water-balance calculation, using monthly estimates of precipitation, potential evapotranspiration, temperature, and runoff. The principal source of moisture is precipitation (rainfait and snowfall) over the landfill site. Of the precipitation that falls on a landfill site, a portion runs off, some is Tost to evapotranspiration, and the remainder percolates through the 1 andfili. Water that percolates through the $f-1]$ eventually exits as leachate. Simpier methods have been proposed 
(e.g., Knight et al. 1980); however, these methods are not nearly as precise. More complex methods also have been proposed and developed (e.g., ICF 1984; Schroeder et al. 1984), but their complexity precludes their use in a preliminary ranking system scheme. A review of the mathematical algorithms that describe the technique for computing leachate quantities from 1 andfills is provided by whelan et al. (1987).

The RAPS methodology addresses long-term average environmental conditions resulting from the release of contaminants from a hazardous waste site. Because the anaiyses are performed assuming no changes to current land use, groundwater, or surface water practices (such as remedial actions to the waste or population changes), the potential health exposure associated with the migration and fate of contaminants from a waste site may continue for hundreds to thousands of years, particulariy for the groundwater transport pathway. The exposure analysis component of RAPS is currently based on 70-year increments (i.e., approximately one human life), with average concentrations being defined for each increment.

Contaminants exiting the bottom of the landfill migrate through a partially saturated or saturated groundwater zone. In the partially saturated zone, flow is usualiy assumed to be in a vertical direction. Because this flow is generally unidirectional (i.e., vertically downward), one-dimensional modeling is performed. The RAPS methodology uses a one-dimensional, unsteady, semianalytical code to simulate contaminant leaching and movement through the partially saturated zone. The solution algorithm to the advective-dispersive equation for the partially saturated zone is based on homogeneous and isotropic soil parameters (see Van Genuchten and Alves 1982 ; Donigian et a1. 1983). The partially saturated soil beneath the waste site is assumed to be at a unit potentiai hydraulic gradient. The moisture content is assumed to fluctuate between field capacity and saturation. If the infiltration rate (leach rate) from the waste site is less than the soil transmission rate (i.e., hydraulic conductivity at field capacity), as described by the general equation for liquid flow in the partially saturated zone (see Hanks and Ashcroft 1980; Hillel 1980), the leachate moves through 
the soil at the infiltration rate. For an infiltration rate equal to or greater than the transmission rate, the leaching water is assumed to move at the transmission rate.

The predominant movenent of the leachate in the saturated zone is assumed to be in the direction of the groundwater flow. A three-dimensional advective-dispersive equation describes the migrating plume as it disperses and attenuates through the saturated aquifer. Advection represents the transport of solute caused by the mass motion of water, while dispersion represents solute transport by unaccounted variations in the fluid velocity and molecular motion. Dispersion is considered in the longitudinal, lateral, and vertical directions. Adsorption/desorption interactions between the contaminant and the flowing water and soil are addressed with an equilibrium (i.e., distribution) coefficient $\left(K_{d}\right)$. The distribution coefficient partitions the contaminant between the soil surface and water. Soil properties are assumed to be homogeneous, and the flow is assumed steady and only in the longitudinal direction.

Solutions for the advective-dispersive equations for the partially saturated and saturated zones have been formulated in terms of an instantaneous contaminant reiease (i.e., a putse release over zero time). The RAPS methodology generalizes these solutions for arbitrary time-varying releases by convoluting response functions (i.e., temporaliy varying contaminant leach or flow rates) with instantaneous contaminant release solutions.

The RAPS groundwater component computes contaminant levels at wells and at the edge of streams and calculates solute fluxes from the groundwater environment to the surface water environment. The solution algorithms are based on Green's functions and have been reported by several researchers (e.g., Yeh 1981; Codell et a1. 1982; Van Genuchten and Alves 1982). Figure 2.2 illustrates the potentiai interactions between the groundwater pathway and the other environmental transport pathways addressed by the RAPS methodology. A review of the mathematical algorithms describing the groundwater pathway was presented by whelan et al. (1987). 


\subsubsection{Surface Water Pathway}

Nontidal rivers, estuaries, open fresh and saltwater bodies, open coasts, wetlands, etc. represent many of the surface water components that could be included in the RAPS methodology. Of these many surface water components, RAPS is currently capable of addressing nontidal rivers and wetlands. Open freshwater bodies (e.g., lakes, reservoirs, and impoundments) are planned for integration into the main body of the methology at a later date. Nontidal rivers refer to fresh water bodies with unidirectional flow in definable channels. Because the RAPS methodology is compositely coupled, other surface water pathways can be added when necessary.

By assuming a continuous release over the lifetime of the waste disposal facility, contaminant releases to the surface water environment in the RAPS methodology are relatively long term. Because transient solutions for contaminant migration and fate calculations are most applicable for batch and infrequent releases over relatively short periods of time (Codell et al. 1982), steady-state solutions to the advective-dispersive equation are most applicable. The three-dimensional, steady-state, vertically integrated mass balance equation for contaminant transport in a riverine environment (where longitudinal advection dominates longitudinal dispersion) forms the basis for all surface water solution algorithms (Codell et al. 1982). Contaminants released into a river are transported through the system by the processes of advection and dispersion. Dispersion is considered in the longitudinal and lateral directions. A description of contaminant movement is based on steady, unidirectional flow in a straight, rectangular channel.

Wetlands are transitional areas between uplands and aquatic habitats. They are characterized by plant communities adapted to life in saturated soi? conditions. Wetlands have been classified by the U.S. Fish and Wildlife Service (Cowardin et aT. 1979) based on life form, water regime, substrate type, and water chemistry. Wet] ands are defined by system, subsystem, class, subclass, dominance type, and special modifiers. Mathematically, the wetland component consists of 1) a steady-state or time-varying chemical mass flux from upstream pathways (e.g., air, surface water, and/or groundwater), 2) a water column of constant depth and surface area, 3) a constant plant biomass, 
and 4) a constant detritus/sediment mass. The mass of the chemical of interest partitions among the water column, detritus sediments, and plant biomass. The chemical is also allowed to 1) volatilize at a rate determined by the reaeration rate, 2) decay following first-order kinetics, or 3) Teave the wetland with out-flowing water. Animal uptake of chemicals is handled by the exposure component of RAPS. Chemical movement in and out of the wetland, chemical degradation, and chemical partitioning between dissolved, adsorbed, and $p$ Tant biomass phases are described by an overall time-varying mass balance algorithm. A review of the wetland component of the RAPS methodologies is provided by Knight and Brown (1987).

The open freshwater body component addresses a wide variety of aquatic environments ranging from small ponds to natura? lakes and man-made impoundments. No single simple model can adequately address the range of mixing processes and various contaminant sources and risks found in open water body environments. In RAPS, environmental complexity is handled using a suite of relatively simple algorithms that involve different boundary conditions and idealized solutions optimized for specific process assumptions. The selection process provides criteria to objectively evaluate avajlabie data and potential transport pathways. The general advection-diffusion equation with steady, unidirectional flow is used to describe contaminant transport in the open water body environment. The spacial effects of mixing processes for determining contaminant concentrations are simulated by several different open water body types, including 1) a we11-mixed case, 2) a two-layer, horizontally well-mixed case, and 3) a vertically well-mixed case with horizontal gradients in one dimension (i.e., well-suited to long, narrow lakes and runof-the-river impoundments). The source/sink term is considered constant, which produces an equilibrium concentration, and temporally varying contaminant concentrations result from convoluted time-dependent source terms that are instantaneously released into the environment. A review of the mathematical algorithms describing nontidal rivers is provided by whe lan et al. (1987) and Knight and Brown (1987). 


\subsubsection{Overland Pathway}

The driving mechanism transporting contaminants through the overland pathway is overland flow. Overland flow is that portion of precipitation that ultimately appears as flowing water on the ground surface; it occurs primarily because of rainfall or snowmelt in excess of abstraction demands (e.g., interception, evapotranspiration, infiltration) and/or the emergence of soil water into drainage pathways. Because overiand flow controls the distribution of contaminants on land surfaces, its spacial and temporal distribution is simulated for describing solute migration and fate through this environment. Many of the characteristics describing the watershed and hazardous waste sites are used in computing overland water movement and subsequent contaminant transport. If an unlimited supply of contamination was available for transport, then the overland flow rate would control the mass flux of contaminant moving downgradient. As the flow rate increases, the potential for increasing the contaminant mass flux would also rise.

The algorithms describing the overland pathway are based on easily attainable data. Estimation techniques are based on the curve number technique of the U.S. Department of Agricuiture's Soil Conservation Service (SCS), as presented by SCS (1972, 1982), Kent (1973), USBR (1977), and Haun and Barfield (1978). The techniques are also based on the method of characteristics as illustrated by Eagleson (1970), Hjelmfelt (1976), Witinok (1979), Whelan (1980), and Witinok and Whelan (1980).

The SCS curve number technique incorporates into its computations soil classifications, soil cover, land-use treatment or practice, hydrologic condition for infiltration, locale (i.e., location within the United States), initial moisture abstraction, antecedent moisture conditions, and potential maximum moisture retention. The algorithms are empirically based and represent a method of estimating direct runoff volumes from storms. The direct runoff inventory computed using the SCS technique is temporally distributed using the method of characteristics with the kinematic wave approximation. The method of characteristics defines the path of wave propagation along 
which partial differential equations become ordinary differential equations with analytical solutions. Overland contaminant levels are then computed based on the overland flow hydrographs.

As Figure 2.2 indicates, the overland transport pathway can interact with the surface water pathway or directly supply the exposure assessment component with contaminant levels for computing the site HPI. A review of the mathematical algorithms describing the overland pathway is provided by Whelan et ai. (1987).

\subsubsection{Atmospheric Pathway}

Complex phenomena are associated with the migration and fate of contaminants released to the atmosphere (Cupitt 1980). The atmospheric component of the RAPS methodology considers release mechanisms and characteristics, dilution and transport, washout by cloud droplets and precipitation, and deposition on the underlying surface cover. The atmospheric pathway model provides a realistic computation of these processes within the constraints of using limited, readily available site information.

The prediction of contaminant movement through the atmospheric pathway involves using codes that address atmospheric suspension/emission, transport, diffusion, and deposition. Input to the codes includes site-specific ciimatologic information such as wind direction, wind speed, and precipitation. Output from the models consists of average air and surface contaminant levels that are then used as input to the exposure assessment component. Currently, contaminant transport is assumed to occur sufficiently fast that chemical transformations can be neglected.

The atmospheric pathway is modeled in a manner to maximize the validity of comparisons between sites. The suspension/emission rates are based mainly on empirical relationships using site characteristics. The atmospheric transport and dispersion are computed in terms of sector-averaged values using Gaussian dispersion principles similar to that proposed by Busse and Zimmerman (1973) and examined by Culkowski (1984). Deposition is computed as the sum of outputs from empirical wet and dry deposition algorithms described in whelan et al. (1987). 
The relative importance of the atmospheric pathway between different sites is controlled by a combination of geographic and climatic influences. Distances, directions, winds, and atmospheric stability are controlling parameters. The dispersion relationships used in the atmospheric component depend on local site characteristics. Because the dispersion is a strong function of downwind distance from the source, the physical distances between the contaminant sites and population centers are of prime importance. The relative proximity of sites and population centers are important in terms of the local frequencies of wind directions, particularly in areas with topographic channeling of winds. The relative rates of atmospheric dilution between the sites are mainly a function of local wind speeds and atmospheric stability parameters.

In the operationa 1 mode, the atmospheric pathway component computes contaminant levels as a function of the direction and distance that coincides with population centers surrounding the site. Inhalation represents the major route of exposure to contaminants via the atmospheric pathway. RAPS a] so considers the ingestion route of exposure through the food chain and from wet and dry deposition on vegetation, and subsequent ingestion of contaminated food materials derived from the soils. In addition, external dose can be addressed, although its effects are usually insignificant compared to the inhalation exposure route. The interaction and coupling between the atmospheric pathway and exposure assessment components of the RAPS methodology is illustrated in Figure 2.2. A preliminary review of the mathematicai algorithms describing the atmospheric pathway is provided by whelan et al. (1987).

\subsubsection{Exposure Assessment Component}

Results from each of the four transport pathways are used in the exposure assessment component to calculate the HPI for each important waste-site contaminant. The exposure assessment component considers potential exposure of the surrounding population through the following exposure routes:

1) external dermal contact to chemicals; 2) external dose from radiation;

3) inhatation of airborne contaminants; and 4) ingestion of contaminated drinking water, soil, crops, animal products, and aquatic foods. In 
evaluating the HPI values, the important exposure routes and populations at risk are first defined. Then, based on the air, water, and soil contaminant levels provided by the transport pathway analyses, an estimate is made of the average daily human exposure to each contaminant. Estimation of the daily exposure is based on simple multiplicative models describing the transfer of pollutants from air, water, or $0 i 1$ to humans. The daily exposure rate is next converted to an average individual health impact factor using mathematical codes for radionuclides, carcinogenic chemicals, and noncarcinogenic chemicals. The health impact factor is intended to indicate the level of potential for health impact to an average member of the exposed population. For radionuclides, the health impact factor is based on cancer risk estimates of the National Academy of Sciences Committee on the Biological Effects of Ionizing Radiation (NAS 1980). The health impact factor for chemical carcinogens are currently based on cancer potency factors defined by the EPA (1982). Health impact factors for non-carcinogenic chenicals are based on the ratio of daily exposure rates to allowable exposure rates as defined by reference doses (EPA 1982).

One key feature of the exposure assessment component is the estimation of the average exposure. The exposure modes inciuded in RAPS are as follows:

- drinking water ingestion -- For groundwater, overland, and surface water transport pathways. Factors may be applied to the water concentration to account for purification of the water in a treatment plant.

- aquatic food ingestion (fish and invertebrates) -- For overland, surface water, and groundwater transport pathways. Average daily intake is estimated using bioconcentration factors and average daily ingestion rates for aquatic foods.

- crops -- For all transport pathways. Crops may be contaminated from irrigation with contaminated water or by direct deposition onto plants and soil. Two crop types are considered: leafy vegetables with the edible portion subject to direct deposition, and other crops such as root and pod vegetables and fruit. Crop concentrations are estimated using soil-to-plant transfer factors 
and air-to-edible plant transfer factors. Average daily intake is estimated using average daily ingestion rates for vegetables and leafy vegetables.

- animal product -. For all transport pathways. Contaminated animal products result from animal ingestion of contaminated water and contaminated feed. Feed contamination may occur from direct deposition onto feed crops or pasture from air or through using contaminated irrigation water. Using contaminated animal drinking water is only considered for the three water transport pathways (i.e., overland, groundwater, and surface water). The concentration of contaminant in animal meat and milk is estimated using animal ingestion-to-animal product transfer factors. Average daily intake of exposed individuals is estimated using average daily ingestion rates for meat and milk.

- water immersion (domestic bathing and swimming) -- For groundwater and surface water transport pathways. Dermal contact (for chemicals) and radiation exposure are included for domestic bathing for both water transport pathways. Exposure from swimming in contaminated water is also considered for the surface water pathway. For chemicals, an equivalent daily intake amount is estimated based on dermal contact time and absorption characteristics of the chemical pollutant. For irradiation exposures, the dose from immersion in water is estimated using dose conversion factors. A contribution to the radiation dose may also be included for recreational boating and shoreline fishing.

- soil ingestion -- For the atmospheric transport pathway. Contaminated soil is assumed to be ingested each day with the ingestion rate based on a lifetime average.

- inhalation -- For the atmospheric transport pathway. The daily average intake is estimated using an average inhalation rate for the exposed population.

The interaction and coupling between the exposure assessment component and the transport pathways of the RAPS methodology is illustrated in 
Figure 2.2. A review of the mathematical algorithms describing the exposure and health effects assessments are provided by whelan et al. (1987).

\subsection{SUMMARY}

The RAPS methodology prioritizes hazardous waste sites in a scientific and objective manner based on limited site information. The RAPS methodology is more sophisticated than other ranking methodologies and bases its approach on site and constituent (i.e., chemical and radionuclide) characteristics (see Whelan et a1. 1987). The RAPS methodology requires minimum user know] edge of risk assessment and the least possible amount of required input data. It considers four major transport pathways for contaminant migration: groundwater, overland, surface water, and atmospheric. Each pathway is described by empirically, analytically, and/or semianalytically based mathematical algorithms, with the results being expressed as the dimensionless parameter (modified according to constituent toxicity and human exposure) called the Hazard Potential Index (HPI). The potential health impacts of a site, based on HPIs, are calculated relative to the health impacts of other sites for each pathway and for all pathways together; sites are then ranked and identified for additional site investigation and possible remediation.

\subsection{REFERENCES}

Bateman, H. 1910. "The Solution of a System of Differential Equations 0ccurring in the Theory of Radioactive Transformations." Proc. Cambridge Phil. Soc. 16:423-427.

Busse, A. D., and J. Zimmerman. 1973. User's Guide for the CT imatological Dispersion Mode I. EPA-RA-73-024, U.S. Environmental Protection Agency, Research Triangle Park, North Carotina.

Codel1, R. B., K. T. Key, and G. Whelan. 1982. A Collection of Mathematical Models for Dispersion in Surface Water and Groundwater. NUREG-0868, Office of Nuclear Reactor Regulation, U.S. Nuclear Regulatory Commission, Washington, D.C.

Cowardin, L. M., V. Carter, F. L. Golet, and E. T. LaRoe. 1979. Classification of Wetlands and Deepwater Habitats of the United States.

FWS/0BS-79/31, U.S. Fish and Wildlife Service, Washington, D.C. 
Culkowski, W. M. 1984. An Initial Review of Several Meteorological Models Suitable for Low-Level Waste Disposal Facilities. NUREG/CR-3838, U.S. Nuclear Regulatory Commission, Washington, D.C.

Cupitt, L. T. 1980. Fate of Toxic and Hazardous Materials in the Air Environment. EPA-600/3-80-084, U.S. Environmental Protection Agency, Research Triangle Park, North Carolina.

Dass, P., G. R. Tamke, and C. M. Stoffel. 1977. "Leachate Production at Sanitary Landfills." J. Environ. Eng. Division. Proc. Am. Soc. Civil.Eng. 103: EE6.

DOE. 1985. Comprehensive Environmenta] Response, Compensation, and Liability Act Program. DOE Order 5480.14, U.S. Department of Energy, Washington, D.C.

Donigian, A. S., Jr., T. Y. R. Lo, and E. W. Shanahan. 1983. Rapid Assessment of Potential Groundwater Contamination under Emergency Response Conditions. Prepared by Anderson-Nichols and $\mathrm{Co.}$, Inc., for the U.S. Environmental Protection Agency, Athens, Georgia.

Eagieson, P. S. 1970. Dynamic Hydrology. McGraw-Hi11, Inc., New York.

EPA. 1982. Health Effects Assessment Summary for 300 Hazardous Organic Constituents. Environmental Criteria and Assessment Office, U.S. Environmental Protection Agency, Cincinnati, Ohio.

Fenn, D. G., K. J. Han zey, and T. V. DeGeare. 1975. Use of the Water Balance Method for Predicting Leachate Generation from Solid Waste Disposal Sites. SW-168, U.S. Environmental Protection Agency, Washington, D.C.

Hanks, R. J., and L. Ashcroft. 1980. Applied SoiT Physics. Springer Verlag, New York.

Haun, C. F., and B. J. Barfield. 1978. Hydrology and Sedimentology of Surface Mined Lands. University of Kentucky, Lexington, Kentucky.

Hillel, D. 1980. Fundamentals of Soil Physics. Academic Press, Inc., New York.

Hjelmfelt, A. T. Jr. 1976. Modeling of Soil Movement Across a Watershed. Completion Report for Project A-076-M0, Missouri Water Resources Center, University of Missouri, Columbia, Missouri.

ICF. 1984. The Risk-Cost Analysis Model: Phase III Report. Prepared by ICF, Incorporated, for the Office of Solid Waste, Economic Analysis Branch, U.S. Environmental Protection Agency, Washington, D.C.

Kent, K. M. 1973. A Method for Estimating Volume and Rate of Runoff in Smal1 Watersheds. SCS-TP-149, U.S. Department of Agriculture, Soil Conservation Service, Washington, 0.C. 
Knight, R., and S. M. Brown. 1987. Wetland Pathway Model: Documentation Report and User's Manual. Prepared by CH2M Hill for Pacific Northwest Laboratory, Richland, Washington.

Knight, G., E. H. Rothfuss, and K. D. Yard. 1980. FGD Sludge Disposal Manual. Second ed. EPRI CS-1515, Electric Power Research Institute, Palo Alto, California.

NAS. 1980. "The Effects on Populations of Exposure to Low Levels of Ionizing Radiation." National Academy of Sciences Committee on the Biological Effects of Ionizing Radiations, National Research Council, Washington, D.C.

Schroeder, P. R., A. C. Gibson and M. D. Smolen. 1984. The Hydrologic Evaluation of Landfill Performance (HELP) Mode]. U.S. Environmenta] Protection Agency, Cincinnati, Ohio.

SCS. 1972. "Hydrology Guide for Use in watershed Planning." In SCS National Engineering Handbook, Section 4, Hydrology, Supplement A, U.S. Department of Agriculture, Soil Conservation Service, Washington, D.C.

SCS. 1982. SCS National Engineering Handbook, Section 4, Hydrology, 1982 Update. U.S. Department of Agriculture, Soil Conservation Service, Washington, D.C.

Thornthwaite, C. W., and J. R. Mather. 1955. "The Water Balance." In Publications in Climatology, Vol. VIII, No. l, Drexel Institute of Technology, Laboratory of Climatology, Centerton, New Jersey.

Thornthwaite, C.W., and J. R. Mather. 1957. "Instructions and Tables for Computing Potential Evapotranspiration and the Water Balance." In Publications in Climatology, $V_{0}$ l. $x$, No. 3, Drexel Institute of Technology, Laboratory of CTimatology, Centerton, New Jersey.

USBR. 1977. Design of Sma 11 Dams. U.S. Department of the Interior, Bureau of Reclamation, U.S. Government Printing Office, Washington, D.C.

Van Genuchten, M. T., and W. J. Alves. 1982. Analytical Solutions of the One-Dimensional Convective-Dispersive Solute Transport Equation. Technical Bulletin No. 166l, U.S. Department of Agriculture, Washington, D.C.

Whelan, G. 1980. Distributed Model for Sediment Yield. Master's Thesis, Iowa Institute of Hydraulic Research, University of Iowa, Iowa City, Iowa.

Whelan, G., and B. L. Steelman. 1984. "Development of Improved Risk Assessment Tools for Prioritizing Hazardous and Radioactive-Mixed Waste Disposa? Sites." In Proceedings of the Fifth DOE Environmenta] Protection Information Meeting, CONF-841187, U.S. Department of Energy, washington, D.C. 
Whelan, G., F. L. Thompson, and S. B. Yabusaki. 19B3. Multimedia Contaminant Environment Exposure Assessment Methodology as Applied to Los Alamos, New Mexico. PNL-4546, Pacific Northwest Laboratory, Richland, Washington.

Whelan, G., B. L. Steelman, D. L. Strenge, and K. A. Hawley. 1985. "Development of the Remedial Action Priority System: An Improved Risk Assessment Tool for Prioritizing Hazardous and Radioactive-Mixed Waste Disposal Sites." In Proceedings of Management of Uncontrolled Hazardous Waste Sites, November 4-6, 1985. Hazardous Materials Control Research Institute, Silver Spring, Maryland.

Wheian, G., B. L. Steelman, D. L. Strenge, and J. G. Droppo. 1986. "Overview of the Remedial Action Priority System (RAPS)." In Pollutants in a Multimedia Environment, ed. Y. Cohen, pp. 191-227, Plennum Press, New York.

Whelan, G., D. L. Strenge, J. G. Droppo, Jr., B. L. Steelman, and J. W. Buck. 1987. The Remedial Action Priority System (RAPS): Mathematical Formulations. PNL-6200, prepared for the Office of Environment, Safety, and Health, U.S. Department of Energy, Washington, D.C. by Pacific Northwest Laboratory, Richland, Washington.

Whelan, G., S. M. Brown, D. L. Strenge, A. P. Schwab, and P. J. Mitche11. 1988. Contaminant Assessment Modeling Under the Resource Conservation and Recovery Act. EA-5342, Electric Power Research Institute, Palo Alto, California.

Witinok, P. M. 1979. Distributed Watershed and Sedimentation Model. Master's Thesis, University of Iowa, Iowa City, Iowa.

Witinok, P. M., and G. Whelan. 1980. "Distributed Parameter Sedimentation Mode1." Proc. Iowa Acad. Sci. 87(3)103-111.

Yeh, G. T. 1981. AT1230: Analytical Transient One-, Two-, and ThreeDimensional Simulation of Waste. Transport in the Aquifer System. ORNL-5602, Oak Ridge National Laboratory, Oak Ridge, Tennessee. 


\subsection{SOURCE-TERM SCENARIO DEVELOPMENT(a)}

\subsection{INTRODUCTION}

Modeling, no matter how complex, represents a simplification of real-world conditions (Whelan et al. 1988). For a modeling exercise to succeed, the complexities associated with the real-world situation must be simplified such that the scenario that is eventually addressed incorporates the most important phenomena in the modeling exercise. The purpose of this chapter is to provide insight into how real-world situations can be converted to simpilfied scenarios on which the RAPS methodorogy can base its analysis.

This chapter is divided into three more sections. So the terminology will not be misunderstood, Section 3.2 defines several terms used in this chapter and throughout the report. Section 3.3 reviews the initial questions that should be answered to construct an appropriate assessment scenario for the RAPS methodology. The final section 1 ists the reference cited in this chapter.

\subsection{TERMINOLOGY}

This section defines five terms used in this chapter and throughout this report. These definitions are presented to prevent any misunderstanding of the meaning of the terms:

- facility -- The term facility refers to any location under one management that contains one or more designated hazardous waste sites. For example, the Hanford facility, although large in areal extent, is a single facility.

(a) This chapter is based on two position papers: whelan, G. 1986. "The Multimedia Environmental Pollutant Assessment System (MEPAS): Review of Data Requirements." Submitted to Mr. J. Barker of the Office of Environmental Audit, Office of Environment, Safety, and Health, U.S. Department of Energy, Washington, D.C., November 11, 1986; and Hawley, K. A. 1986. "MEPAS and the Environmental Survey." Submitted to Mr. R. Aiken of the Office of Environmental Audit, Office of Environment, Safety, and Health, U.S. Department of Energy, Washington, D.C., November 19, 1986. 
- hazardous waste site -- The term site refers to a unit in a specified facility that releases contaminants into the environment. Examples are stacks, vents, landfills, holding ponds, lagoons, caissons, cribs, French drains, tile fields reverse wells, and trenches.

- physical environment -- The physical environment is represented by four specific environments or transport pathways: subsurface (or groundwater), surface water, overland, and atmospheric.

- source term -- The source term is the waste site and the quantity or concentration, form, and rate of potential release of the material of concern.

- potential release scenario -- The potential release scenario is the simplified system, modeled after the real-world situation, that describes how the contaminants are potentially released into the environment.

\subsection{APPLICATION OF THE RAPS METHODOLOGY TO IDENTIFIED ENVIRONMENTAL PROBLEMS}

Unlike most assessment methodologies that are developed before data sources are identified, the RAPS methodology was developed to use, for the most part, readily available information; (a) that is, RAPS is structured around known data sources. Although significantly more sophisticated than a questionnaire-type methodology (e.g., HARM), RAPS uses site-specific data (when available), local or regional data (where appropriate), and computer-suggested values (when necessary).

Much of the data used by RAPS is available in local or regional reports, including site-specific, state, and federal documents. For example, all of the climatic information is available either from local weather stations or from data bases maintained by the National Weather Service and the National Uceanic and Atmospheric Administration. Much of the regional soil information is available in U.S. Geological Survey (USGS) reports and maps, SCS County Soil Surveys, and Agricultural Research Service reports. Chemical information is

(a) Noting all of the shortcomings associated with such an assumption. 
available in chemical data bases, of which there are many. Much information is also available from local agencies, such as public health departments, water districts, and waste water treatment plants. The Bureau of Reclamation, U.S. Army Corps of Engineers, and USGS have tremendous amounts of information on streams, lakes, and rivers, as well as other environments.

While a wealth of information is potentially available on each site, the order in which that information is collected and analyzed is very important. By setting priorities for data collection and analysis, the user of the methodology can concentrate on the important aspects of the site. By focusing on one initial set of data, the user of the methodology can more easily convert the complex, real-world situation to an appropriate simplified scenario. The assessment exercise should initially address the following questions:

- Where is the potential release? The location needs to be identified on a map or in some other manner (e.g., latitude and longitude).

- where does the potential release originate? Does the potential release originate from a stack or holding tank?

- What are the constituents of interest? To address the potential hazard that may exist from a potential release of contaminants into the environment, the constituents of interest inust be known. Therefore, specify the chemical compounds or radionuclides, $\mathrm{pH}$, organic solvents.

- What is the physical form of the material? Is it a liquid, solid, or gas?

- How much material is concerned? This question can be answered in several ways. For example, an estimate of the waste inventory, contaminant concentrations, or the rate of potential release could be used.

- What are the driving forces behind the potential release? For potential nonatmospheric releases, identify the source of the liquid transporting the constituents. Because water represents the driving mechanism in transporting constituents, identify the source of the liquid; a liquid such as rainfall, solvents, or paint will typically 
provide the basis for transporting constituents. For example, if precipitation is the source of the liquid (e.g., in the form of snowmelt runoff or rainfail), then the problem requires meteorologic information, which will be used to compute infiltration rates, overland runoff rates, and so on. If the constituent itself is in a liquid form and so is the source of the liquid transporting the constituents, then the leakage (e.g., from a drum) represents the source to the environment.

- What is the physical geometry of the source? Is it a point, a line, or an area source?

- How is the constituent being potentially released and where is it going? The release mechanism helps define the medium to which the contaminant is being potentially released. For example, is the contaminant leaching into the groundwater system, being entrained into the atmosphere, or being discharged directly into a river? Note that this question does not concern the number of media through which a contaminant may eventually migrate, but concerns only the medium that the contaminant first enters. Understanding the release mechanism will also provide insight into the nature of the mode of potential release. For example, a storage tank receives liquid wastes; when the tank becones full, the excess waste enters an overflow system that transports the waste from the tank and releases the waste directly into the subsurface environment. Knowing how the potential release occurs makes it evident that the overflow system represents the source of contamination; in addition, insight may be gained on when the overflow system is in operation.

- How long does the potential release last? Is it a single, short-term event, an intermittent release, or a continuous long-term discharge? Does it last for minutes, days, or years?

While the questions may seem straightforward, they can be difficult to answer for a complex release mechanism. However, these questions must be 
addressed if a proper assessment is to be inade using RAPS. In certain circumstances, it may be necessary to substitute estimates for hard data. This is acceptable, but it should be noted that the accuracy of the assessment ninges on the quality of the data used.

To address these questions, data from five broad categories are needed:

1) constituents of interest

2) level of contamination

3) inechanisin of potential contaminant release

4) source of the water (or liquid) transporting the constituents for potential nonatmospheric releases

5) time frame associated with the potential release of the contaminants into the environment.

In addition to the five major categories listed above that qualitatively and quantitatively describe the source term, the exposure analysis requires the analyst to identify the point in the environment where contamination may enter exposure pathways, such as water supplies and food chains. For example, groundwater contamination may result in exposure when a domestic well becomes contaminated. Surface waters used for irrigation may be contaninated from groundwater seepage. For these examples, the critical points of contamination are the well and the irrigation intake plant, respectively. The location of these environmental contamination points must be identified for the site under investigation.

In addressing these five broad cateyories, a four-step procedure can be used for converting the complex, real-world situation into an appropriate simplified scenario on which the RAPS analysis is based. The four steps are to

- identify the origin of the potentially released contaminants

- describe the potential release and determine its physical location

- quantify the source term

- construct the release scenario. 
Each step is described in more detail below. After the last step has been described, several examples are presented to illustrate how one might construct a release scenario.

\subsubsection{Identifying the Origin of the Potentially Released Contaminants}

Establishing the origin of the potentially released contaminants means, in effect, finding out where the contaminants were generated, stored, treated, or disposed of. For example, in a situation where waste tanks are leaking, the origin of the potential release of contaminants to the ground is the reservoir of material that was stored in the tanks. Another example is the discharge of radioactive material from a stack. The origin of the potentially released contaminants could be a process occurring in a laboratory or waste that is disposed of in an incinerator with the off gas being discharged to the stack. A more complex case is a waste pond draining to a canal that, in turn, empties into a river. The origin of the potential release of contaminant to the river is the material passing through the canal, and the origin of the potential release to the canal is the wastes released from the pond. The reason for establishing the origin of the potential release of the contaminants is that it is a means of directing the investigator to information on the original source, composition, and quantity of the contaminants being potentially released.

\subsubsection{Describing the Potential Release and Determining Its Physical Location}

The RAPS methodology requires specific information on the physical geometry of the point of potential release to the environment. For potential nonatmospheric releases, three geometric categories are possible: point sources (such as wells, drainage pipes, or small tanks); line sources (such as cracked pipes, manifolds, or cracks); or area sources (such as landfills, ponds, tile fields, or storage yards). For potential atmospheric releases, sources fall into only two categories: point sources (such as a stack or vent) and area sources (such as a contaminated surface). The exact dimensions of the source can be obtained from a map or can be estimated for input to RAPS. This estimation can be obtained from a map or can be done visually, by walking the site, or by use of measuring devices. However, exact dimensions (for example, to within a foot) are not required. 
The methodology also requires data on the location of the potential release to the environment. This location may be completely different from the place where the contamination has originated. Examples of such cases are as follows:

- A landfill from which constituents are leaching because of snowneit -. The landfill is both the origin of the potential release of contaminants and the location of the release to the physical environment.

- A holding pond from which contaminants overflow into a canal that transports contaminated water to a nearby river -- The point of discharge from the canal into the river is the location of the potential release to the river. The canal itself may represent a narrow area source for the groundwater environment if water leaches from the canal; consequently, its location must also be specified.

- A stack releasing contaminants -- The location of the stack is the point of potential release to the atmospheric environment.

- A landfill that generates and potentially releases gaseous effiuents -- The landfill is both the origin and the location of potential release to the atmospheric environment.

The location of the source may be specified through the use of latitude and longitude, site maps, topographical maps, or road maps. The locations should be as accurate as reasonably achievable. The site's position relative to significant physical features should also be specified. This information would include, for instance, which side of the river the facility is on and whether it is situated on a short, steep slope.

\subsubsection{Quantifying the Source Term}

The potential impacts associated with a potential release of material to the environinent depend directiy on the quantity, concentration, form, and rate of release. This information is called the "source term." The nature of the source term will vary with the process or facility being considered. 
The kinds of information used to quantify source terms include the following:

- radionuclide inventories (e.g., Ci) and/or chemical inventories (e.g., kg) and the physical form of the contaminant

- radionuclide concentrations (e.g., $\mathrm{Ci} / \mathrm{m}^{3}$ and $\mathrm{Ci} / \mathrm{g}$ ) and/or chemical concentrations (e.g., $\mathrm{g} / \mathrm{ml}$ and $\mathrm{kg} / \mathrm{g}$ )

- radionuclide release rates (e.g., Ci/s) and/or chemical release rates $(\mathrm{e} . \mathrm{g} ., \mathrm{kg} / \mathrm{s})$.

For liquid systems, data on $\mathrm{pH}$ and the type of liquid (aqueous or organic) are also part of the source term.

\subsubsection{Constructing the Release Scenario}

Choosing the appropriate release scenario is critical to the success of the assessment. The release scenario dictates what information must be collected for the environimental problem to be evaluated. The release scenario guides both the choice of the source term and the identification of the release point. Consequently, development of an accurate release scenario is extremely important to the success of the assessment. Without development of the release scenario and identification and quantification of the source term, no meaningful assessment can be made by any method; in effect, the analysis becomes merely subjective.

Understanding how the contaminants are likely to move into the environment is the key to developing the release scenario. The inajor question to be answered to develop the release scenario is whether the situation can result in a potential release to the physical environment. If it cannot, then it is inappropriate to use RAPS. If it can, how can it? Will the potential release be to the atmosphere, surface water, groundwater, or soil? The question of how the material can be potentially released to the environment is difficult and must be answered precisely for the release scenario to be correctly developed.

\subsubsection{Release Scenario Examples}

It is difficult to give precise instructions on how to construct release scenarios. For that reason, a series of example situations are described. 
The following examples are intended to illustrate specific situations that may be encountered and to give guidance on how one inight proceed in constructing a release scenario for the purpose of identifying information necessary to implement the RAPS methodology.

\subsubsection{Example 1 -- Leaking Barrels in a Storage Area}

During a site assessment, it was noticed that a storage area held a large number of 55-gallon drums that were suspected of leaking. The drums were used to store corrosive material and had corroded enough that some of the stored material had been discharged to the surface of the storage yard.

One of the first questions that must be answered is "where is the potential release to the environment actually occurring?" Is material being discharged from the drums directly to the air and/or soil, or are the drums stored on a concrete pad where the material must volatilize for it to enter the environment, be resuspended by air currents, or be transported over the concrete pad to the surrounding soils? The key to answering the question is defining exactly where the potential release to the environment occurs. The concrete pad is effectively an impermeable barrier to the ground surface, and the contaminants can only impact the environment if they are rnoved off the surface of the pad. Even if the material is not likely to volatilize or be resuspended, it could be released through dissolution and subsequent runoff from the edge of the concrete pad. In this case, the edge of the concrete pad constitutes a line source, and the release scenario is runoff or leaching from the edge of the pad. The source terin is the rate of potential release and the quantity of the material that is available for movement on the surface of the pad.

The following other issues should al so be addressed:

- Is the entire inventory of the drums likely to leak from the drums (or only some fraction)?

- What is the time period over which the potential release is likely to occur or has occurred?

- What other factors may contribute to the movement of the material into the environment? 
For this situation, the following information would also be needed:

- location of the release point

- identity of the contaminants in the drums (This information might be obtained from a shipping manifest, if one is available.)

- quantities and concentrations of material, by constituent, that could potentially be released to the storage pad

- rate at which material may be potentially released from the drums and the anticipated duration of the potential release (Is the potential release unique and short-term, continuous, or intermittent?)

- dimensions of the storage pad

- actual contamination levels on the storage pad or the surrounding soils (This information would be useful, but it is not essential.)

- presence of other factors that may affect the movement of contaminants (e.g., if the concrete pad is periodically hosed down, the volume of water and how frequently this occurs are pertinent factors).

\subsubsection{Example? -- Nonfunctional Stack Sampling Systems}

During a site assessment, it was determined that the sampling system at a particular stack was not functioning appropriately (i.e., sampling was not isokinetic, or the calibration was off, or the system was broken). Because of this malfunction, contaminants may have been released into the environment.

In this situation, the release scenario is the undetected discharge of material through the stack. The release point is the stack. The source term is the quantity of material that might have been potentially released through the stack while the monitoring systern was not functioning. The following information would be required.

- location of the potential release point

- height of the stack

- flow rate through the stack 
- identity and form of the material that might have been released from the stack

- total inventory of material, by constituent, that might have been released froin the stack (This might be estimated from a maximum facility or laboratory inventory.)

- time interval over which the potential release could have occurred (Is the release one-time, continuous, or intermittent?).

\subsubsection{Example 3 -- Leaking Storage Tanks with a Sump System}

During a site assessment, it was determined that a series of storage tanks were leaking and that the material was being collected in a sump. Because of this leak, the potential impact to the surrounding environment must be assessed.

Unless the sump is suspected of discharging its contents directly to the environment, no potential release will have occurred, and the situation does not represent an appropriate analysis for the RAPS methodology. However, if the sump does leak, then the sump, not the storage tanks, is the point source, and the following information should be collected.

- location of the potential release point (both in terms of map coordinates and relative to the ground surface and the water table)

- identify the constituents

- total volume of solution and material that could be potentially released through the sump [The total volume might be represented by the combined volumes of the storage tanks, the total quantity of material (by constituent) placed in the tanks, or some fraction of either. Inventories of the material, concentrations of the material in the tanks, and additional data (if available) on pH and the type of solution (aqueous, organic, etc.) are all needed.]

- time period over which the potential release occurred (This will necessarily be only a best estimate.)

- leak rate of the sump and other information as available. 


\subsubsection{Example 4 -- Holding Ponds that Discharge to a River}

A series of holding ponds that were used to temporarily store heated process water before it was discharged to a river through canals were evaluated. The process water was high in corrosion inhibitors and contained short-lived radionuclides. The ponds were designed with impermeable liners, and their contents were discharged by pumping the material to unlined transfer canals that emptied into a nearby river. The impact on the environment of the stored heated process water must be evaluated.

Each pond and canal system has multiple release scenarios, release points, and source terms. If the material volatilizes, the pond surfaces and, to a lesser extent, the canal surface are area sources for the potential release of contaminants to the atmosphere. Material is also potentially released from the bottom of the ponds and the canal and from the canal where it discharges to the river.

For each of the release scenarios, the following information would be needed:

Scenario A -- The pond as an area source potentially releasing contaminants to the ground.

- identity of the constituents

- dimensions of the pond

- concentrations of the constituents in the liquid and the sediments (if available)

- leak rate of the pond to the ground

- the time of year and length of tirne water remains in the pond

- information on the construction of the pond [e.g., the liner material and other construction materials (such as clay) should be identified].

Scenario $B$-- The pond as an area source potentially releasing contaminants to the atmosphere. 
- identity of the constituents and their form

- dimensions of the pond

- concentrations of the constituents in the liquid and the sediments (if available)

- the time of year and length of time water remains in the pond

- potential release rate from the surface (in $\mathrm{g} / \mathrm{m}^{2} / \mathrm{s}$ or $\mathrm{Ci} / \mathrm{m}^{2} / \mathrm{s}$ ).

Scenario $C_{--}$- The canal as a line source potentially discharging contaminants to the groundwater.

- identity of constituents

- dimensions of the canal

- concentration of constituents in the discharged solution, including particulate or dissolved fractions

- schedule of when effluent is in the canal (this might be determined from documents monitoring the flow-through rate)

- concentrations of contaminants in the soil in the vicinity of the canal.

Scenario $D \rightarrow$ The canal as a line source potentially discharging contaminants to the atmosphere.

- identity and form of the constituents

- dimensions of the canal

- concentrations of the constituents in the liquid and on the sediments (if availabie)

- the time of year and length of time water remains in the cana1

- potential release rate from the surface (in $\mathrm{g} / \mathrm{m}^{2} / \mathrm{s}$ or $\mathrm{Ci} / \mathrm{m}^{2} / \mathrm{s}$ ).

Scenario E - - The canal as a point source potentially discharging contaminants to the river.

- width of the discharge point

- concentration of constituents as they are discharged 
- duration of the discharge and its frequency

- discharge rate of solution to the river.

Any or all of the scenarios could occur concurrently at the site. The purpose of this example is to illustrate that a muititude of exposure scenarios can exist, each of which must be addressed, together or separately, as appropriate.

\subsection{REFERENCE}

Whelan, G., S. M. Brown, D. L. Strenge, A. P. Schwab and P. J. Mitchell. 1988. Contaminant Assessment Modeling Under the Resource Conservation and Recovery Act. EA-5342, Electric Power Research Institute, Palo AT to, California. 


\subsection{SURFACE WATER COMPONENT OF THE RAPS METHODOLOGY}

\subsection{INTRODUCTION}

The surface water component of RAPS is addressed in this section. The term surface water refers to nontidal rivers. The surface water component estimates surface water contaminant concentrations downstream from the release point. The computed contaminant concentrations are used by the exposure assessment component of RAPS to calculate the dose to the surrounding population and subsequent health effects associated with the dose. Potential exposure of humans to contaminants via the surface water pathway can be associated with ingestion (e.g., drinking contaminated water), dermal contact (e.g., swimming), or external dose (e.g., swimming). Figure 4.1 is a diagram of the surface water environment.

Because contaminant releases to a surface water body in the RAPS methodology are relatively long term, the migration and fate of contaminants through the surface water environment are described by the steady-state, twodimensional advective-dispersive equation for solute transport. The results are based on analytical solutions that are well established in the literature (see Whelan et al. 1987). The surface water solutions account for the major mechanisms of constituent persistence (i.e., degradation/decay), advection, and hydrodynamic dispersion. Persistence is described by a first-order degradation/decay coefficient; for radionuclides, the surface water component also accounts for decay products. Advection is described by constant unidirectional flow in the longitudinal direction. Hydrodynamic dispersion is accounted for in the longitudinal (for travel time estimations) and lateral (for contaminant concentration calculations) directions. The processes associated with adsorption/desorption between the water column and suspended and bed sediments are not addressed. The complexities and subsequent data requirements associated with instream sediment transport and sedimentation processes preclude their use in this simplified assessment methodology. Neglecting these processes should, in most cases, represent a conservative assumption. 


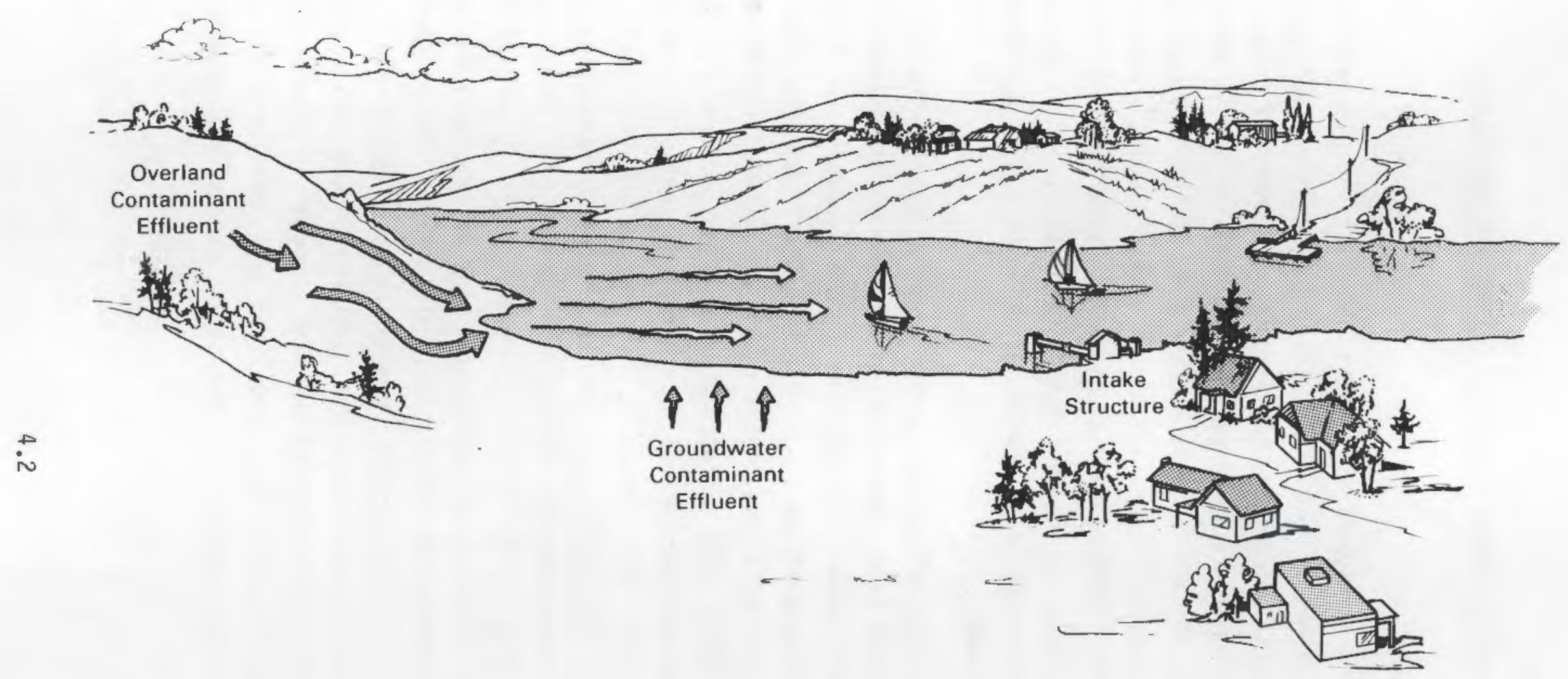

FIGURE 4.1. Diagram of the Surface Water Environment (After Whelan et al. 1987) 
In the RAPS methodology, contamination can enter the surface water environment in one of three ways: 1) the groundwater environment can supply transient contaminant fluxes along the stream bank adjacent to the subsurface - aquifer; 2) the overland runoff can supply nonpoint-source steady-state contaminant fluxes from the land adjacent to the stream; 3) contaminants can be directly discharged to the stream (Whelan et al. 1986, 1987). Although the RAPS methodology currently allows contamination to enter the stream in any one of these three ways, the same type of boundary condition (i.e., temporally varying flux boundary condition) is used for each mode of entering the surface water environment.

This chapter presents a comparison that was done between monitored and simulated instream contaminant levels in an actual riverine environment. As noted in Chapter 1.0, the purpose of this comparison was to test the applicability of the surface water component of the RAPS methodology at an established DOE facility. The Mound Laboratory, operated by the Monsanto Research Corporation, in Miamisburg, Ohio, was chosen as the location for the comparison for several reasons:

- Several DOE(a) personnel felt that the Mound Laboratory represented a "typical" DOE facility (i.e., typical in terms of the quality and quantity of available data).

- A moderate-sized river (i.e., Great Miami River) is located nearby into which the facility regularly discharges effluent.

- Because the facility is relatively small, the number of waste streams are more manageable.

- Personnel at the Mound facility established an environmental monitoring program to ensure the quality of monitored instream contaminant levels.

- Instream levels of potential contaminants have been continuously monitored for over 10 years.

(a) Personnel associated with the Office of Environment, Safety, and Health, Washington, D.C. 
- The effluent discharges from the Mound facility to the nearby Great Miami River were continuously monitored for over 10 years. The inventory of constituents released from the facility and the mass flux of constituents from the facility were regularly recorded.

- Access to the Mound's facilities, records, and personnel was granted by DOE.

This chapter is further divided into four sections. First, the mathematical formulations associated with the surface water component of the RAPS methodology is described. Second, the environmental setting at the Mound facility is presented; this reviews the purpose of the facility, location and site setting, environmental control monitoring program, its quality assurance program, and the results of facility sampling analyses in the Great Miami River. Next, a description of the application of the surface water component to the Great Miami River is presented. Finally, the results that compare simulated and observed contaminant levels in the river are summarized.

\subsection{MATHEMATICAL FORMULATIONS ASSOCIATED WITH THE SURFACE WATER CDMPONENT DF} THE RAPS METHODOLOGY (a)

The surface water component of the RAPS methodology provides estimates of surface water contaminant concentrations at downstream locations from the release point.

The advective-dispersive equation represents the mathematical description for solute movement through a riverine surface water body. The surface water flow is assumed to be steady and uniform; the solution algorithm is developed for the limiting case of unidirectional advective transport with threedimensional (longitudinal, lateral, and vertical) dispersion. The advectivedispersion equation for rivers can be described by the following expression:

(a) This section is based on Chapter 6 of Whelan et al. (1987). 


$$
\frac{\partial C}{\partial t}+u \frac{\partial C}{\partial x}=E_{x} \frac{\partial^{2} C}{\partial x^{2}}+E_{y} \frac{\partial^{2} C}{\partial y^{2}}+E_{z} \frac{\partial^{2} C}{\partial z^{2}}-\lambda C
$$

where $C=$ dissolved instreain contaminant concentration $(\mathrm{g} / \mathrm{ml} \text { or } \mathrm{Ci} / \mathrm{ml})^{(\mathrm{a})}$

$u=$ average instream flow velocity $(\mathrm{cm} / \mathrm{s})$

Ex, Ey, Ez $=$ dispersion coefficients in the $x, y$, and $z$ directions, respectively $\left(\mathrm{cm}^{2} / \mathrm{s}\right)$

$\lambda=$ degradation/decay constant $[=(\ln 2) /($ hal $f-1$ ife $)]\left(s^{-1}\right)$.

$t=\operatorname{time}(s)$

Equation (4.1) does not account for the effects of contaminant adsorption to or desorption from sediment particles suspended in the water column or in the river bed. This assumption is conservative in most cases.

Contaminant releases to the surface water environment in the RAPS methodology are relatively long term. Because transient solutions for contaminant migration and fate calculations are most applicable for batch and infrequent releases over relatively short periods of time (Codell et al. 1982), steadystate solutions to the advective-dispersive equation are most applicable. The steady-state, vertically integrated mass balance equation for contaminant transport in a riverine environment (where longitudinal advection dominates longitudinal dispersion) can be written as follows:

$$
u \frac{\partial C}{\partial x}=E_{y} \frac{\partial^{2} C}{\partial y^{2}}-\lambda C
$$

in which

$$
\frac{\partial C}{\partial y}=0 \text { at } y=0
$$

and

$$
\frac{\partial C}{\partial y}=0 \text { at } y=B
$$

(a) When two sets of units are provided, the first refers to chemicals, and the second refers to radionuclides. 
where $B=$ width of stream channel $(\mathrm{cm})$.

When Equation (4.2) is solved with the appropriate boundary conditions [i.e., Equation (4.3) or (4.4)], the surface water pathway is described by an analytical expression that characterizes the transport of contaminants through a river environment. For a point source(a) contaminant release from the bank of a stream, the solution to Equation (4.2) employing the boundary conditions defined by Equation (4.3) is very similar to those outlined by Codell et al. (1982), Strenge et al. (1986), and Whelan et al. (1987):

$$
C=\left(\frac{Q C}{u B h}\right) \exp \left(-\frac{\lambda x}{u}\right)\left[1+2 \sum_{n=1}^{\infty}\left[\exp \left(-\frac{n^{2} \pi^{2} E_{y} x}{u B^{2}}\right)\left(\cos \frac{n \pi y}{B}\right)\right]\right]
$$

where $Q c=$ contaminant flux at the source $(\mathrm{g} / \mathrm{s}$ or $\mathrm{Ci} / \mathrm{s})$

$$
\begin{aligned}
& h= \\
x= & \text { depth of stream }(\mathrm{cm}) \\
n= & \text { index on series expansion } \\
y= & \text { lateral distance from bank where source release is located } \\
& \text { (where } y \text { is equivalent to } B \text { ) }(\mathrm{cm}) .
\end{aligned}
$$

All other terms retain their previous definitions.

When a contaminant is released from a source along the stream bank, it is spacially redistributed -- longitudinally, vertically, and laterally -- by the transporting medium. Because contaminant levels are spacially distributed at any designated receptor (e.g., intake structure), one contaminant concentration does not describe the spacial distribution unless the contaminant is uniformly mixed in the stream. Because the exposure component of the RAPS methodology

(a) The term 'point source' refers to the source-term configuration, which reflects simplifying assumptions and does not refer to the exact technical definition associated with the concentration equation. Note, for example, that a vertically averaged point source represents a line source in the $z$ direction. 
required oniy one temporally distributed contaminant concentration per receptor location per time interval, the contaminant concentration of the fully mixed region is used.

Under a fully mixed condition in the river, the concentration is assumed to be vertically integrated. Lateral contaminant migration is bounded by the banks of the water body, and complete lateral mixing occurs at some distance downstrean from the contaminant source. However, if the fully mixed condition across the entire width of the stream is not reached, an effective concentration must be developed for use by the exposure pathway model. The RAPS methodology computes an effective concentration, based on the fully mixed condition and the longitudinal distance the contaminant has migrated. The lateral distance in the surface water body over which contamination is considered to be fully mixed begins on the side of the river where the contaminant was released and extends some distance $\left(\ell_{1}\right)$ across the river. Within this region (i.e., $0<y<\ell_{m}$ ), the contaminant level is assumed to be spacially constant; therefore, the concentration at $y=0$ is used in computing the exposure levels for the exposure component of the RAPS methodology. By assuming that $y$ equals 0 , Equation (4.5) reduces to

$$
C=\left(\frac{Q c}{u l_{m} h}\right) \exp \left(-\frac{\lambda x}{u}\right)\left\{1+\left[2 \sum_{n=1}^{\infty} \exp \left(-\frac{n^{2} \pi^{2} E_{y} x}{u\left(e_{m}\right)^{2}}\right)\right]\right\}
$$

A line source along the edge of the stream can be represented by distributing a series of point sources equivalent in length to the line source. As the downstream receptor location is moved farther away, the line source resembles a point source located at the center of the line source. As the receptor location is moved closer to the center of the line source, oniy that portion of the source term upstream of the receptor has an opportunity to influence contaminant levels at the receptor; in effect, the strength of the source term is reduced. Under these circumstances, the line source can be approximated as a point source that is located at one-half the distance between the receptor location and the upstream end of the line source. 


\subsection{ENVIRONMENTAL SETTING AT THE MOUND FACILITY}

This section briefly reviews historical data concerning the release of liquid effluents from the Mound facility into the nearby Great Miami River. This information provides a more thorough understanding of the mechanisms by which liquid effluents are released into the river as well as insight into the quality and quantity of data being used to test the applicability of the surface water component of the RAPS methodology.

\subsubsection{Purpose of the Mound Facility}

The Mound facility is government owned and is operated by Monsanto Research Corporation for DOE. The facility began operations in 1949 to manufacture nonnuclear weapons components and tritium-containing components or nuclear weapons that are assembled at other DOE facilities. Production activities are conducted in 105 buildings. Currently, the facility's mission includes (Carfagno and Farmer 1986)

- research, development, engineering, production, and surveillance of components for DOE weapons programs

- the recovery and purification of tritium from scrap materials received from other DOE facilities

- separation, purification, and sale of stable isotopes

- DOE programs in nuclear safeguards and waste management, heat source testing, and fusion fuel systems.

\subsubsection{Location and Site Setting}

The Mound facility is located on a 306-acre site in southern Montgomery County in southwestern Ohio at the southern boundary of the city of Miamisburg; it is $0.93 \mathrm{~km}(0.58 \mathrm{mi})$ due east of the Great Miami River. The site is $16 \mathrm{~km}$ (10 mi) south-southwest of Dayton, Ohio, and $50 \mathrm{~km}$ (31 mi) north-northeast of Cincinnati, Ohio (DOE 1979). The location of the Mound facility with respect to Dayton and Cincinnati is depicted in Figure 4.2. Figure 4.3 is a more detailed illustration of the area surrounding the facility.

The Mound facility is situated on a high area overlooking Miamisburg, the Great Miami River, and the river plain area to the west (DOE 1979). The 


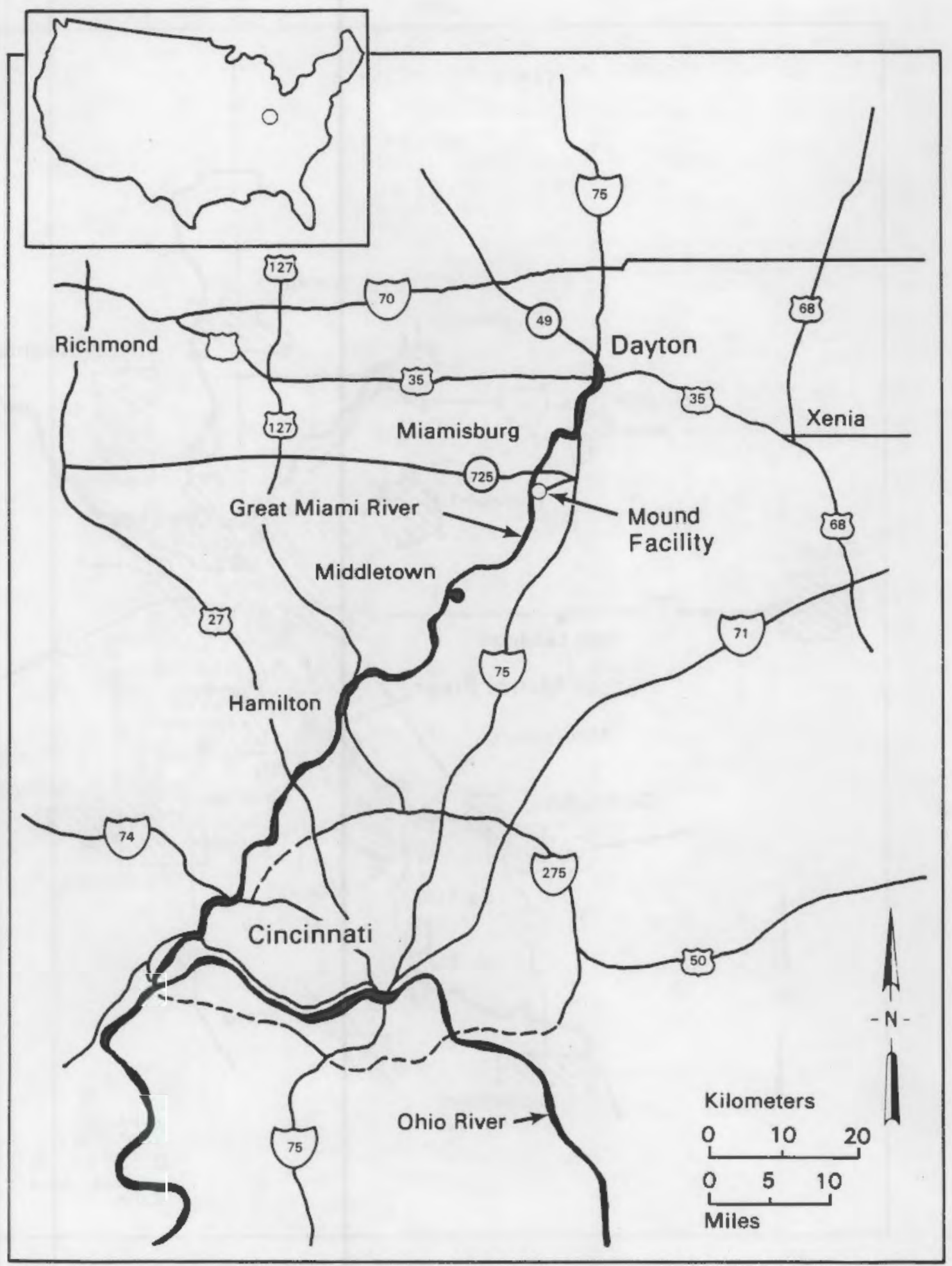

FIGURE 4.2. Southwestern Ohio and Location of Mound Facility 


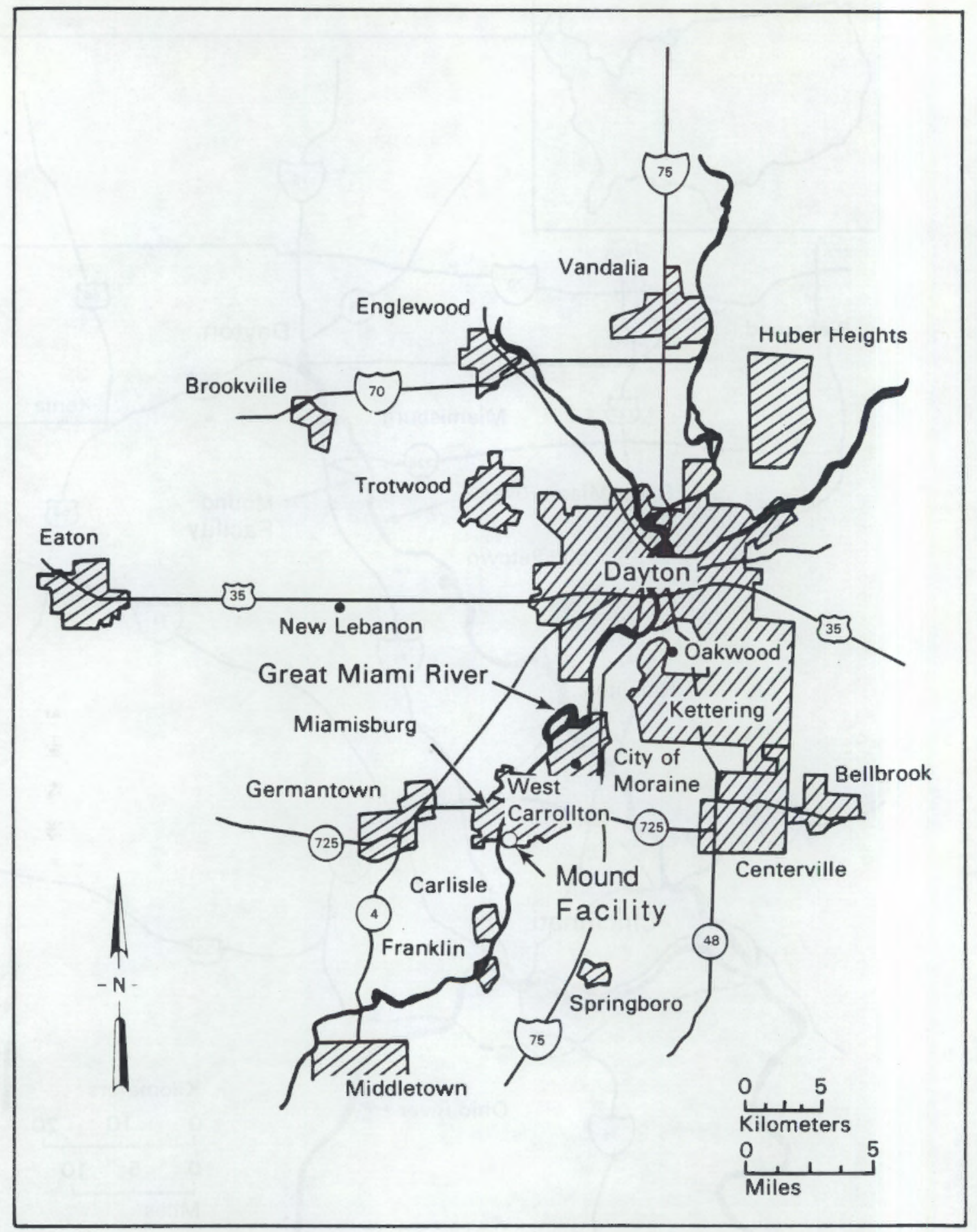

FIGURE 4.3. Mound Facility and Adjacent Areas 
predominant geographical feature in the region surrounding the Mound facility is the Great Miami River, which flows from northeast to southwest through Miamisburg. The river valley is highly industrialized. The remainder of the region is predominantly farmland, dotted with light industry and small communities (DOE 1979).

The Mound facility discharges liquid effluents to the Great Miami River. Tritium, plutonium-238, and uranium-233,234 were the constituents of interest for testing the applicability of the surface water component of the RAPS methodology. In many instances, the measured contaminant levels in the river are at or near monitored background levels. When elevated levels (although small) of these constituents occur in the river, they can be attributed to only the waste stream being discharged from the Mound facility; therefore, the source of the constituents monitored in the Great Miami River is the Mound facility.

\subsubsection{Mound's Environmental Control Monitoring Program}

The Mound facility has an environmental control program whose fundamental objective is "the containment of radioactive discharges to levels well within the existing standards" (Carfagno and Farmer 1986). As part of this program, waste streams are monitored and controlled at each operating step, resulting in no more than low-level releases of liquid wastes to the environment that are within permitted limits (Carfagno and Farmer 1986).

As part of the Mound Environmental Control Program monitoring functions, air, water, vegetation, foodstuffs, and sediment samples are collected from the environment at distances up to $48 \mathrm{~km}(30 \mathrm{mi})$. These samples are then analyzed for specific radionuclides that are handled at the Mound facility. The results of the environmental analyzes associated with the Mound Environmental Control Program have been documented in a suite of environmental monitoring reports that reviewed contaminant releases into the environment and the subsequent levels of the contaminants in the environment (see Carfagno and Farmer 1983, 1984, 1985, 1986; Farmer and Carfagno 1978, 1979, 1980, 1981, 1982; Farmer et a1. 1976, 1977; Carfagno and Robinson 1975; Carfagno and Westendorf 1973, 1974; MRC 1971, 1972). The primary purpose of these reports was to detail the impact, if any, that the Mound facility's operations have had in the environment. Mound personnel have used several calculational techniques to present 
this monitored environmental information; these calculational techniques, as reported by Carfagno and Farmer (1986), are noted as follows:

The concentrations (that are reported in these documents) of various radionuclides ... that result from the operation of the Mound facility are termed "incremental". The term 'incremental' denotes a concentration value that exceeds normal environmental levels of the same radionuclide. The 'environmental level' is that level found in the environment where Mound operations would have no impact. These environmental levels are subtracted from all onsite and offsite data except where noted. Some values may be negative, which are included in averages. These values, if negative, are reported as the environmental level (e.1.).

\subsubsection{Quality Assurance of Monitored Data at the Mound Facility}

A quality assurance (QA) program has been part of the Mound Environmental Control Program for several years. This QA program was first mentioned in annual environmental monitoring reports by Farmer and Carfagno (1980) and has been mentioned in every subsequent annual environmental monitoring report (i.e., Carfagno and Farmer 1983, 1984, 1985, 1986; Farmer and Carfagno 1981, 1982). The prograin has an internal and an external part (Farmer and Carfagno 1980).

The internal portion consists of blank value analyses for each group of samples. A blank value, as noted by Carfagno and Farmer (1986), is a "measurement result for a contaminant determined by following through the chemical analysis procedure without a true sample, but rather using deionized water, a clean filter paper, or only the reagents used in the analysis. They continue to note that

"analysis of 'blanks' is essential because many of the samples analyzed show contaminant concentrations at or below the lower detection limit of the analytical method being used. Analyzing 'blanks' is essential in verifying the absence of excessive laboratory contamination or detector background. Also, the standard deviation of the 'blank values' is used to calculate lower detection limits ...." 
Farmer and Carfagno (1980) note that if the blank values are consistently small in comparison with sample values, no contamination problems occurred during analytical procedures, indicating good control.

The external portion of the QA program involves the Mound facility's participation in DOE's Quality Assessment Program. This program is conducted by DOE's Environmental Measurements Laboratory (EML), which prepares reference samples for analysis by DOE laboratories throughout the country. Results of significance to the environmental monitoring program at the Mound facility are summarized in Farmer and Carfagno (1980, 1981, 1982) and Carfagno and Farmer (1983, 1984, 1985). Note that for calendar year 1982, samples were not provided by EML; consequently, the Mound facility obtained outside reference samples (i.e., water samples containing tritium, plutonium-239, and uranium-234,238) from the U.S. Environmental Protection Agency (EPA) through their Environmental Radioactivity Laboratory Intercomparison Studies Program. Results from the EPA program that are of significance to the environmental program at the Mound facility are summarized in Carfagno and Farmer (1983). For more information on QA, refer to MRC (1981) and Carfagno and Farmer (1986).

\subsubsection{Background Information on the Great Miami River}

The Mound facility lies within the Great Miami River drainage basin, which covers a significant portion of southern Ohio and small segments of southeastern Indiana. The drainage area at Miamisburg, 1 mile upstream from the Mound facility, is $7022 \mathrm{~km}^{2}\left(2711 \mathrm{mi}^{2}\right)$. The major water body in the vicinity of the ground facility is the Great Miami River (DOE 1979).

The nearest USGS gaging station to the Mound facility on the Great Miami River is at Miamisburg, Ohio (i.e., station number 03271500; see Figure 4.4, USGS gaging station). Its exact location is latitude $39^{\circ} 38^{\prime} 40^{\prime \prime}$; longitude $84^{\circ} 17^{\prime} 23^{\prime \prime}$; in Section 31, R.6, T.1, Montgomery County, Hydrologic Unit 05080002; on the east bank of the river, 183 (600 ft) downstream of the bridge on State Highway 725 at Miamisburg, $0.5 \mathrm{~km}$ (0.3 mi) downstream from Bear Creek, $5.2 \mathrm{~km}$ (3.2 $\mathrm{mi}$ ) upstream of Crains Run, and at River Mile 66.4 (Shindel et al. 1985). 


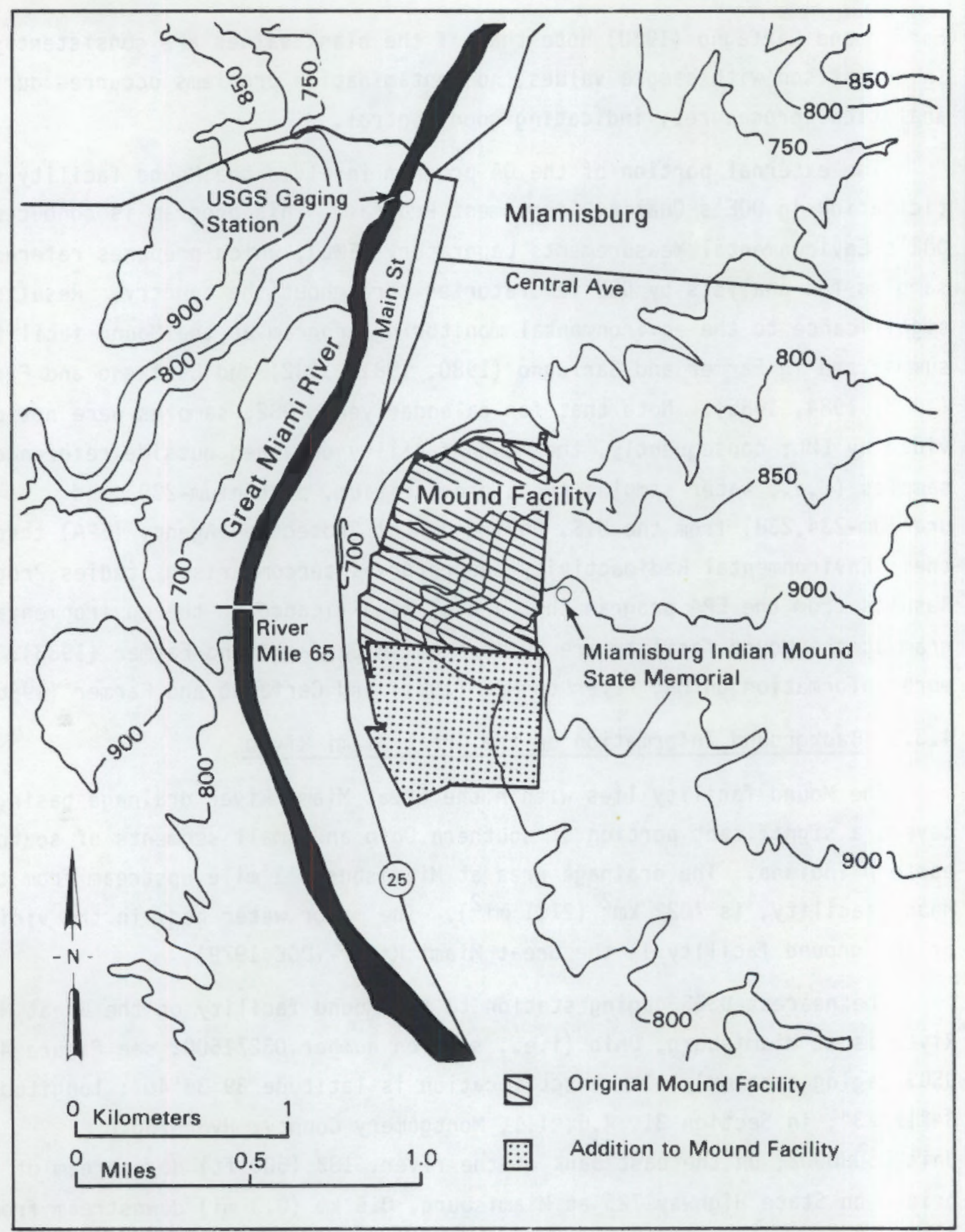

FIGURE 4.4. Topographic Features of Site Area (After DOE 1979) 
Based on 47 years of record, the average discharge in the Great Miami River at Miamisburg is $68.90 \mathrm{~m}^{3} / \mathrm{s}\left(2433 \mathrm{ft}^{3} / \mathrm{s}\right)$. The maximum measured discharge, occurring on January $21-22,1959$, is $1750 \mathrm{~m}^{3} / \mathrm{s}\left(61,800 \mathrm{ft}^{3} / \mathrm{s}\right)$, and the minimum measured discharge, occurring on September 7 , 1925 , is $4.19 \mathrm{~m}^{3} / \mathrm{s}$ (148 $\left.\mathrm{ft}^{3} / \mathrm{s}\right)$. A flow-duration curve based on discharge records at Miamisburg between 1931 to 1960 is presented in Figure 4.5 (DOE 1979). Although this flow-duration curve does not exactly match the current 47 years of record, it provides an excellent estimate of the relationship between the flow and the percent of time the discharge has been equaled or exceeded.

Shindel et al. (1985) recorded gage heights at the Mianisburg gaging station to $6.294 \mathrm{~m}(20.65 \mathrm{ft})$. Gage heights, corresponding to various discharges, are presented in Table 4.1. The width of the river varies between $46 \mathrm{~m}$ (150 ft) and $60.0 \mathrm{~m}(200 \mathrm{ft})$ (DOE 1979).

\subsubsection{History of Effluent Releases from the Mound Facility to the} Surface Water Environment

Tritium, plutonium-238, and uranium-233,234 were chosen to help test the applicability of the surface water component of the RAPS methodology for the follwing reasons:

- The annual inventory of each constituent discharged to the Great Miami River is known.

- Contaminant levels in the river have been continuously monitored over the years at severai locations.

- Elevated levels (although small) of these constituents can only be attributed to the waste stream being discharged from the Mound facility; therefore, the source of the constituents monitored in the river is the Mound facility. This claim cannot necessarily be made for other constituents (i.e., inorganic wastes) that are discharged with the effluent waste stream from the facility.

- Decay characteristics of these constituents are well understood. The history surrounding the release of tritium, plutonium-238, and uranium-233,234 is briefly reviewed below. These data are from DOE (1979). 


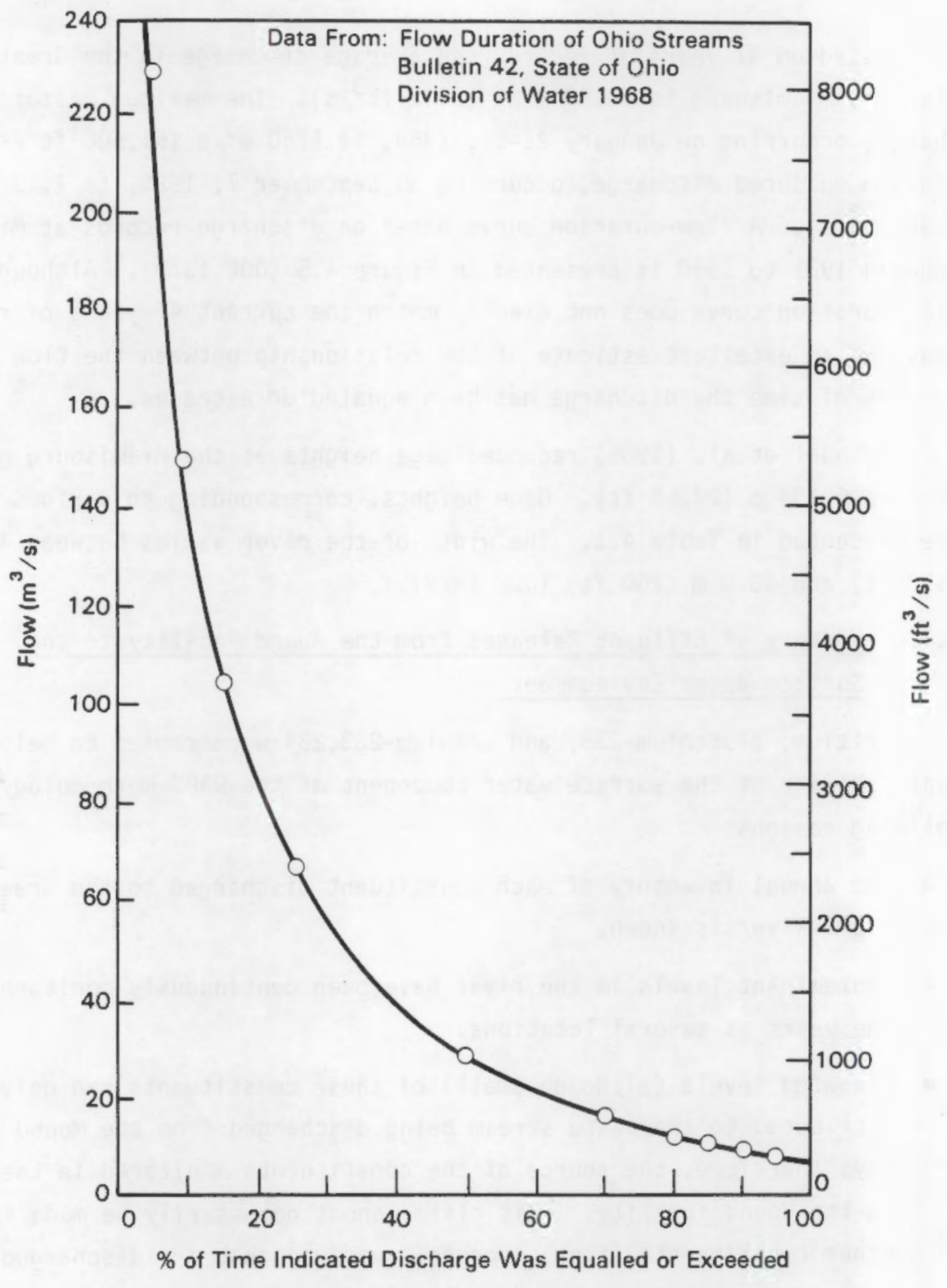

FIGURE 4.5. Flow Duration at Miamisburg, Ohio (After DOE 1979) 
TABLE 4.1. Depth-Discharge Relationship for the Great Miami River at Miami sburg, Ohio

\begin{tabular}{|c|c|c|c|c|}
\hline \multicolumn{2}{|c|}{ DISCHARGE, } & \multicolumn{2}{|c|}{ GAGE HEIGHT } & DATE OF OCCURRENCE \\
\hline$\left(\mathrm{m}^{3} / \mathrm{s}\right)$ & $\left(\mathrm{ft}^{3} / \mathrm{s}\right)$ & (m) & $(f t)$ & \\
\hline 521 & 18400 & 3.261 & 10.70 & $3 / 22 / 84^{(a)}$ \\
\hline 864 & 30500 & 3.536 & 11.60 & $3 / 14 / 70^{(b)}$ \\
\hline 1440 & 50800 & 4.926 & 16.16 & $1 / 10 / 30^{(b)}$ \\
\hline 1470 & 51800 & 5.121 & 16.80 & $4 / 21 / 20^{(b)}$ \\
\hline 1470 & 51800 & 4.916 & 16.13 & $5 / 15 / 33^{(b)}$ \\
\hline 1560 & 55000 & 5.029 & 16.50 & $2 / 27 / 29$ (b) \\
\hline 1750 & 61800 & 6.294 & 20.65 & $1 / 21 / 59(a, b)$ \\
\hline
\end{tabular}

(a) Shindel et al. (1985).

(b) Data supplied by Miami Conservatory District (DOE 1979).

- Iritium Liquid Effluent -- Before 1970, process water with tritium was discharged to an onsite radioactive waste treatment facility; the water was collected in large holding tanks, and the tritium concentration was determined. Because tritium could not be economically recovered from large volumes of water, the water was diluted with raw well water to reduce concentrations below the DOE Radioactivity Concentration Guide (RCG) for tritium and subsequently discharged to the Great Miami River via the open site drainage ditch and the old Miami-Erie Canal (Figures 4.6 and 4.7 , respectively).

Since 1970, all process liquid wastes containing tritium have been collected and disposed of by packaging, solidification, and off-site approved burial at DOE and commercial burial sites. Only water with very low concentrations of tritium from the laundry, shower baths, and lavatories in the process area were discharged directly to the Great Miami River via the underground pipe effluent line (i.e., effluent discharge station 001) after processing through the sanitary waste disposal facility (see underground pipe in Figure 4.6). 


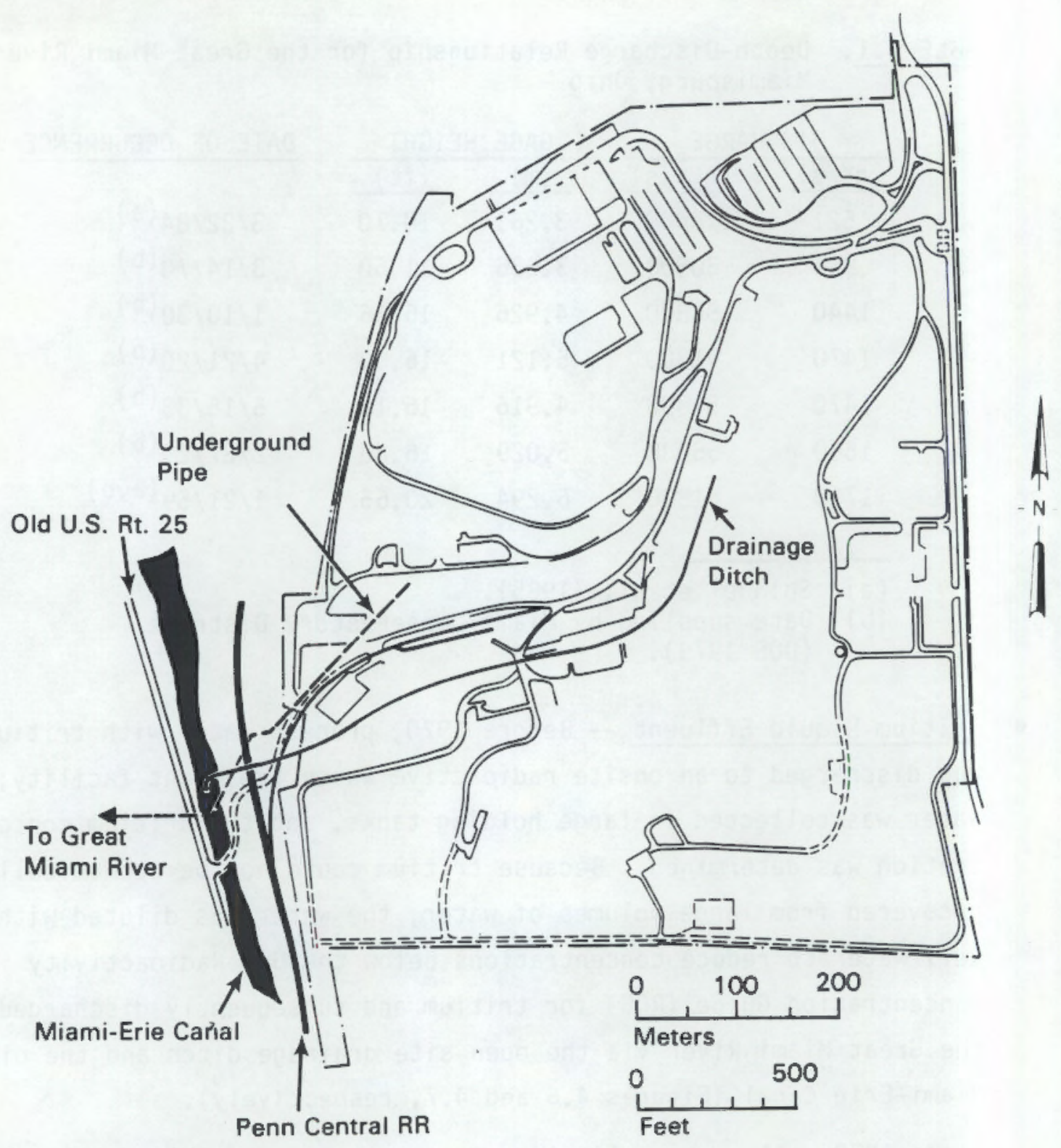

FIGURE 4.6. Mound Facility Drainage Ditch and Underground Pipe (After DOE 1979)

Before 1969, several thousand curies of tritium were discharged in liquid effluents. The exact quantities are unknown because liquid waste disposal regulations in 1969 required that only the tritium concentration in the effluent be in compliance with the prevailing $R C G$, which is a concentration standard. Recording the total quantity of tritium released, expressed in curies, was not an operating requi rement. 


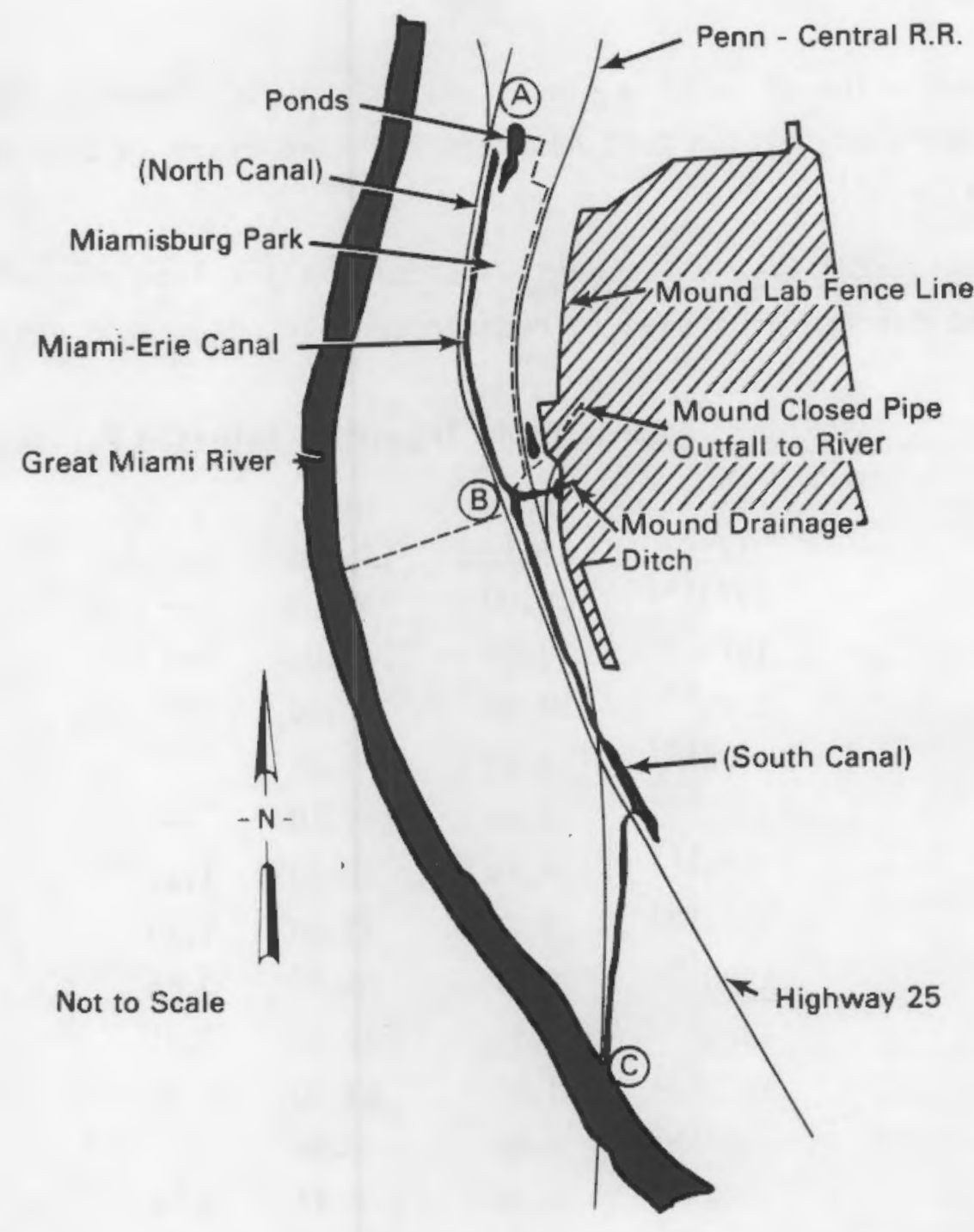

FIGURE 4.7. Mound Facility Drainage Ditch in Relation to Miami-Erie Canal and Great Miami River (After DOE 1979)

In 1970, a continuous monitoring system that accumulated data on the total inventory of tritiated water leaving the site was installed in the site drainage ditch. By 1971, a similar system was installed in the underground pipe effluent stream. Since then, the effluent discharged through the drainage ditch and underground pipe have been continuously sampled for the total curies of tritium discharged and 
concentration of tritium since 1971. Table 4.2 presents the annual inventory of tritium that has been released since 1973 from the Mound facility.(a)

- Plutonium-238 Liquid Effluent -- Liquid wastes from plutonium operations are processed to recover the plutonium when economically

TABLE 4.2. Contaminant Inventory Released Per Year

\begin{tabular}{|c|c|c|c|}
\hline Year & $\begin{array}{l}\text { Pu-238 } \\
\text { (mCi) }\end{array}$ & $\begin{array}{l}H-3 \\
(\mathrm{C} i)\end{array}$ & $\begin{array}{r}U-233 \\
(\mathrm{mC} i) \\
\end{array}$ \\
\hline $1973(a)$ & $\overline{16.00}$ & 50.00 & -. \\
\hline $1974(b)$ & 20.00 & 105.00 & -- \\
\hline $1975^{(c)}$ & 18.00 & 58.00 & -- \\
\hline 1976 (d) & 3.00 & 46.00 & -- \\
\hline $1977(\mathrm{e})$ & 2.80 & 56.70 & -- \\
\hline $1978^{(f)}$ & 4.90 & 32.40 & 1.20 \\
\hline $1979(g)$ & 3.20 & 33.90 & 1.20 \\
\hline $1980^{(h)}$ & 0.77 & 26.10 & 0.65 \\
\hline $1981^{(i)}$ & 1.11 & 22.00 & 0.61 \\
\hline $1982^{(j)}$ & 1.21 & 13.70 & 0.56 \\
\hline $1983(k)$ & 1.00 & 7.94 & 0.50 \\
\hline $1984(1)$ & 1.34 & 8.47 & 0.47 \\
\hline $1985^{(m)}$ & 0.99 & 5.82 & 0.40 \\
\hline
\end{tabular}

(a) Carfagno and Westendorf (1974).

(b) Carfagno and Robinson (1975)

(c) Farmer et al. (1976).

(d) Farmer et al. (1977).

(e) Farmer and Carfagno (1978).

(f) Farmer and Carfagno (1979).

(g) Farmer and Carfagno (1980).

(h) Farmer and Carfagno (1981).

(i) Farmer and Carfagno (1982).

(j) Carfagno and Farmer (1983).

(k) Carfagno and Farmer (1984).

(1) Carfagno and Farmer (1985).

(m) Carfagno and Farmer (1986).

(a) Inventories of tritium were unavailable at the time of this report for the years 1970 through 1972. 
feasible. Liquid wastes that do not contain sufficient plutonium to be recovered are solidified and shipped offsite for storage at a disposal site. The low-level liquid wastes, (a) however, are transferred to the waste disposal building at the Mound facility where they are chemically processed for plutonium removal and assayed before batch discharge to the Great Miami River.

In the 1970s, two liquid effluent streams left the Mound facility: 1) a drainage ditch that provided natural drainage for the site and that carried storm, sewer, and some cooling water discharges (i.e., effluent discharge station 002) and 2) an underground pipeline (i.e., effluent discharge station 001) that carried sanitary and industrial waste effluents after processing directly to the Great Miami River (see Figure 4.8).

For effluent discharges that left the site via the drainage ditch, the water flowed south through the remnants of the abandoned MiamiErie Canal system, then to a second open ditch that passed under a highway (i.e., South Canal), continuing to the river. In the early to mid-1970s, the City of Miamisburg built a small diversion that caused some of the liquid effluent to flow north into another section of the abandoned canal (i.e., North Canal) to two small ponds in the immediate area. Any overflow from the ponds entered directly into the Miamisburg storm drain system and then to the river. In 1976, the flow in the drainage ditch was redirected away from the North Canal. Table 4.2 lists the annual inventory of plutonium-238 that has been released since 1973 from the Mound facility.

- Uranium-233,234 Liquid Effluent -- The Mound facility conducts only small-scale operations involving uranium. Liquid wastes containing uranium are processed in the waste disposal facility. The wastes are eventually discharged through effluent discharge station 001. Table 4.2 presents the annual inventory of uranium-233 that has been released since 1978 from the Mound facility.

(a) Those wastes containing less than $10^{6}$ disintegrations per minute per milliliter. 


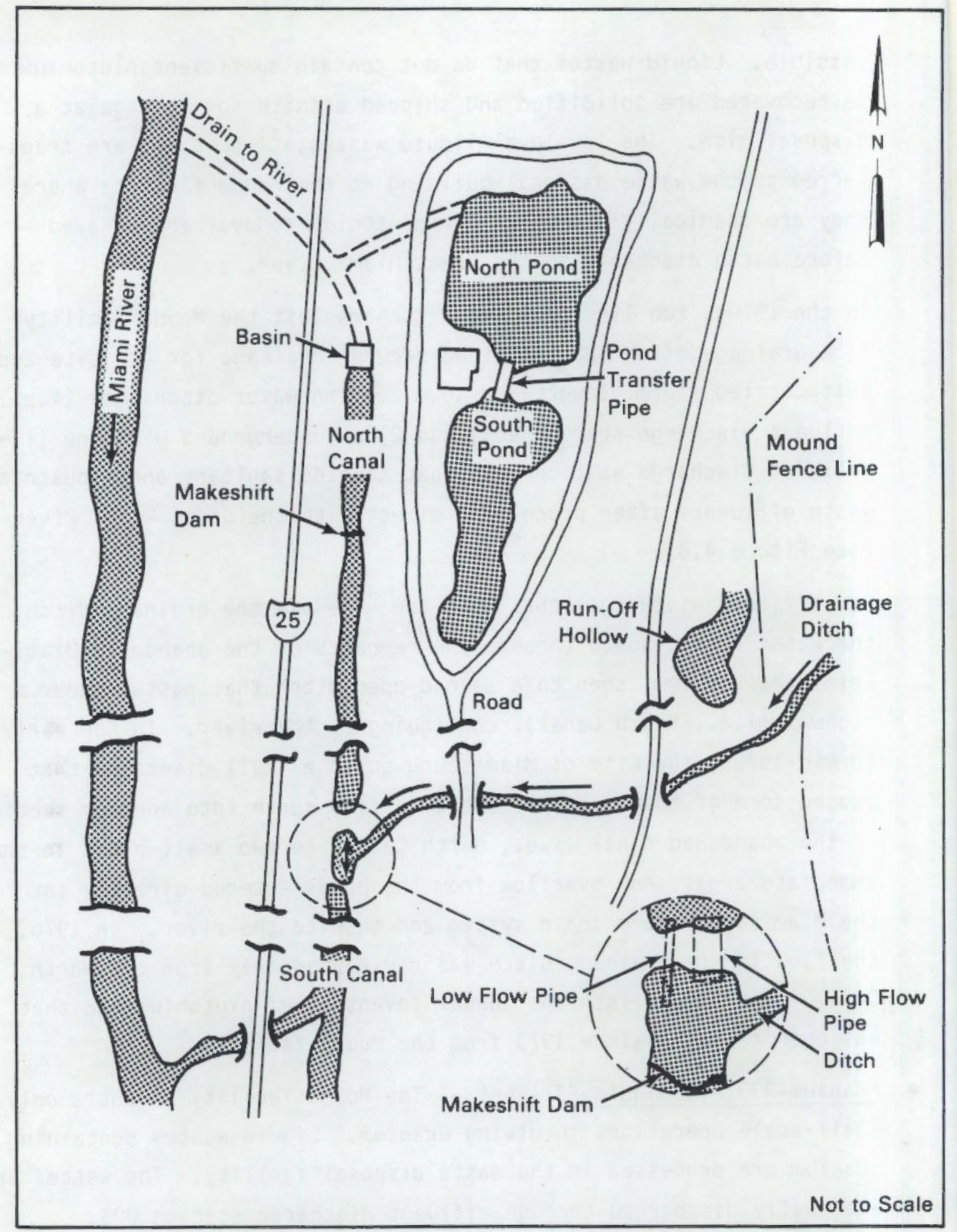

FIGURE 4.8. Waterways Adjacent to Mound Facility before July 1976 (After DOE 1979) 
Currently, two major monitored waste streams leave the Mound facility and discharge into the Great Miami River. Effluent discharge station 001 contains 1) effluent from the sanitary sewage treatment plant; 2) storm water runoff, single-pass cooling water, zeolite softener backwash, boiler-plate blowdown, and discharge from the radioactive waste disposal facility (i.e., all radioactive wastes); and 3 ) wastes from the electroplating facility. Effluent discharge station 002 contains single-pass cooling water, cooling-tower blowdown, zeolite softener backwash, and most of the plant storm water runoff (Carfagno and Farmer 1986).

4.3.7 Procedures and Results of the Mound Facility Sampling Analyses in the Great Miami River

Water samples along the Great Miami River have been collected since at least 1970. Since 1973, the locations were selected according to guidelines recommended by EPA (1972) (see Carfagno and Westendorf 1974). Figure 4.9 shows the locations of the various offsite surface water sampling stations that have been used since 1973. These sampling locations were chosen to provide representative samples of river water after considerable mixing of the effluent from the Mound facility. From 1973 through 1978, downstream sampling locations 1 and 4 were used. Because Mound facility personnel felt that these locations did not necessarily represent the contaminant levels in the river, (a) the sampling locations were moved. Downstream sampling locations 2, 3 , and 5 have been used from 1979 to the present. Filtering each sample al so apparently coincided with the shift in the sampling locations.

Water samples have been taken from these locations 5 days per week. Each of the samples has been subjected to specific analyses for tritium and plutonium-238. Currently, the monitoring frequency for uranium-233,234 is unknown. Tritium analyses have been based on a weekly composite of daily samples, and plutonium-238 analyses have been based on a monthly (1973 to 1974), semiannual (1975 to 1978), or quarterly (1979 to the present) composite of daily samples. The change from a monthly to a semiannual composite of daily samples appears to

(a) Personal communication by telephone from Mr. D. G. Carfagno, Monsanto Corporation, Miamisburg, Ohio, to G. Whelan, Pacific Northwest Laboratory, Richland, Washington, November 26, 1986. 


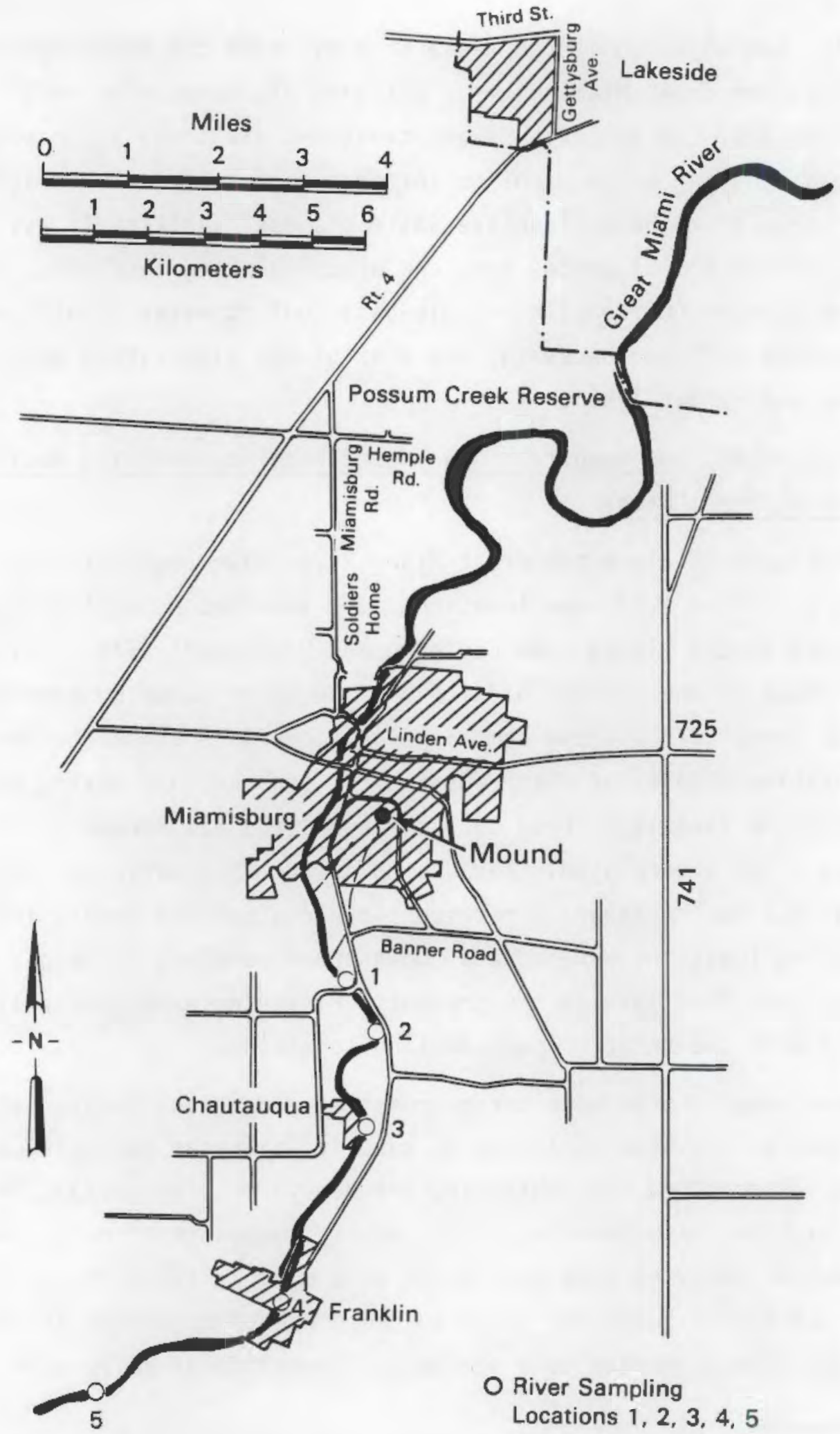

FIGURE 4.9. Offsite Water Sampling Locations (After Carfagno and Farmer 1986) 
have coincided with the introduction of large volume water samples in 1975. Plutonium-238 can be detected in water at a much lower level when large volume water samples are used (Farmer et al. 1977). The change from a semiannual to a quarterly composite of daily samples appears to have coincided with the change in the sampling station locations.

The results of the tritium, plutonium-238, and uranium-233,234 analyses for the offsite sampling locations (shown in Figure 4.9 ) along the banks of the Great Miami River are presented in Figures 4.10 through 4.24. Carfagno and Farmer (1986) note that the error estimates shown with each set of data are estimates of the standard error of the estimated mean at the $95 \%$ confidence level. These values include all sources of variability, such as sampling, analyses, counting statistics, and the propagated error involved when the environmental levels are subtracted from the actual data.

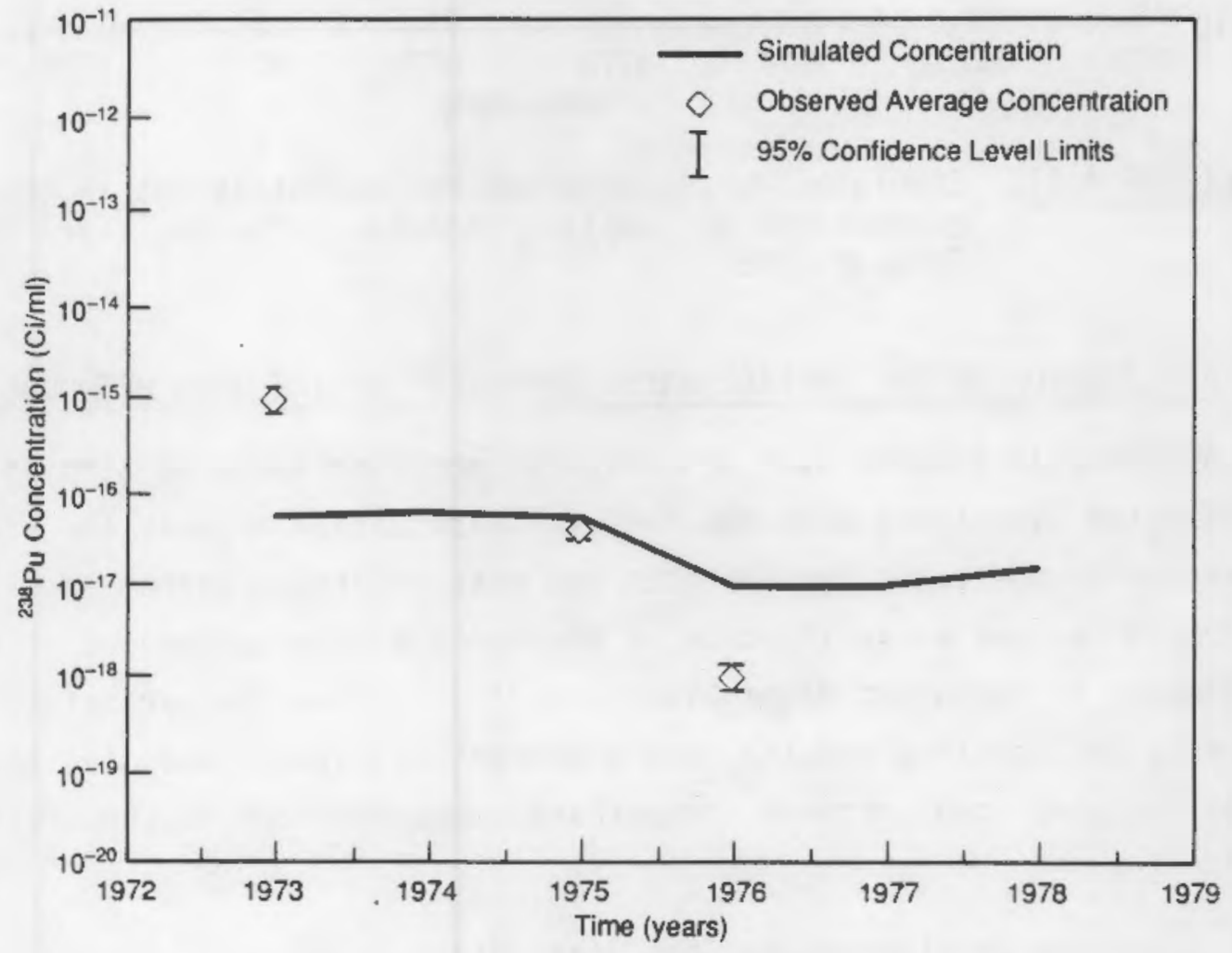

FIGURE 4.10. Simulated Versus Observed ${ }^{238} \mathrm{pu}$ Concentrations in the Great Miami River at Sampling Location 1 for the Years 1973 Through 1978 


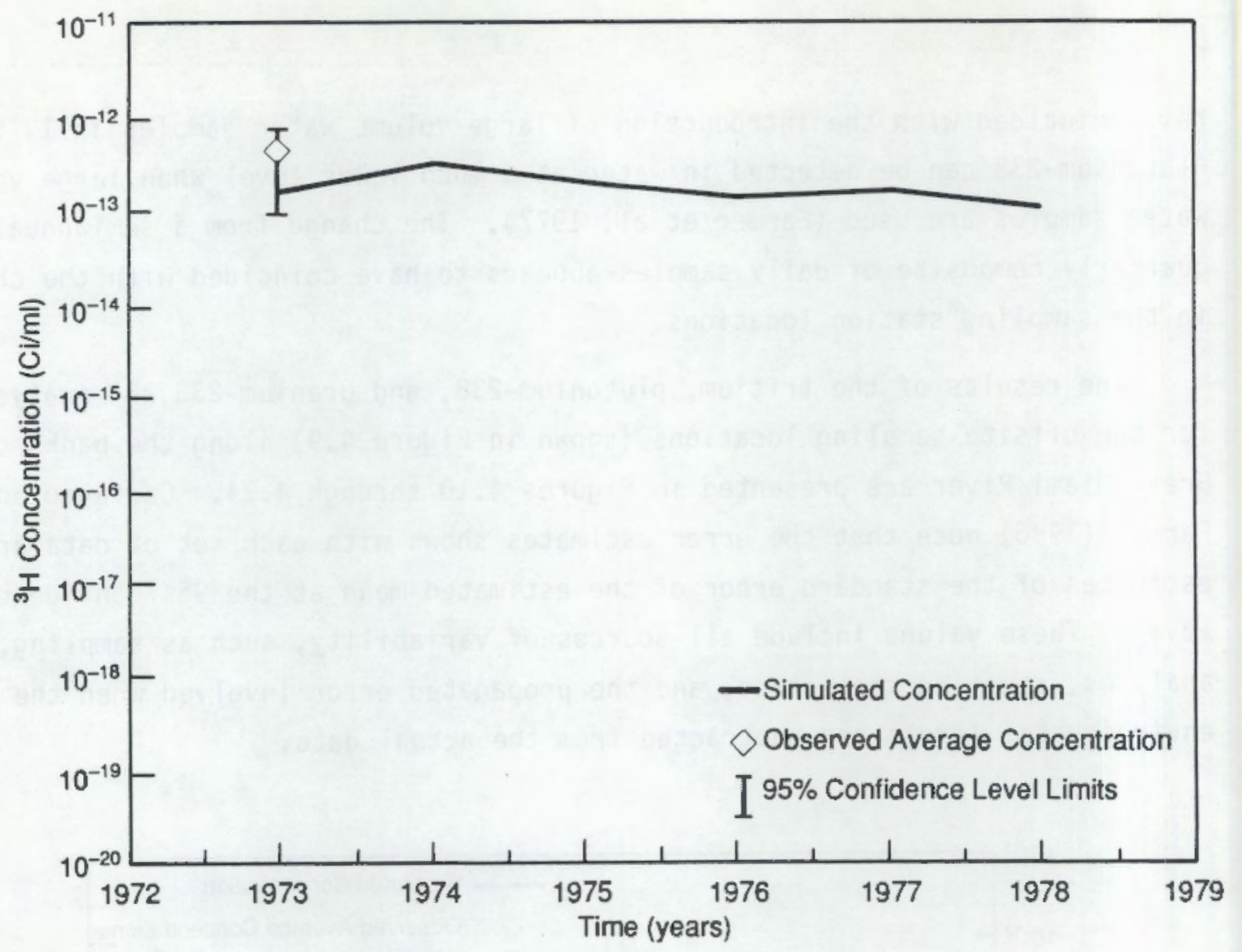

FIGURE 4.11. Simulated Versus Observed ${ }^{3} \mathrm{H}$ Concentrations in the Great Miami River at Sampling Location 1 for the Years 1973 Through 1978

\subsection{APPLICATION OF THE SURFACE WATER COMPONENT OF THE RAPS METHODOLOGY}

As noted in Chapter 3.0 , a successful modeling exercise simplifies the complexities associated with the real-world situation so that the scenario that is eventually addressed incorporates the most important phenomena. This section 1) reviews an application of the surface water component of the RAPS methodology to the Great Miami River and 2) describes the parameters of interest, the modeling results, and a comparison between measured (i.e., monitored) and simulated instream contaminant concentrations in the Great Miami River.

\subsubsection{Scenario Development for the Great Miami River}

Section 4.3 describes the environmental setting at the Mound facility and the history associated with its effluent discharges, each as they pertain to 


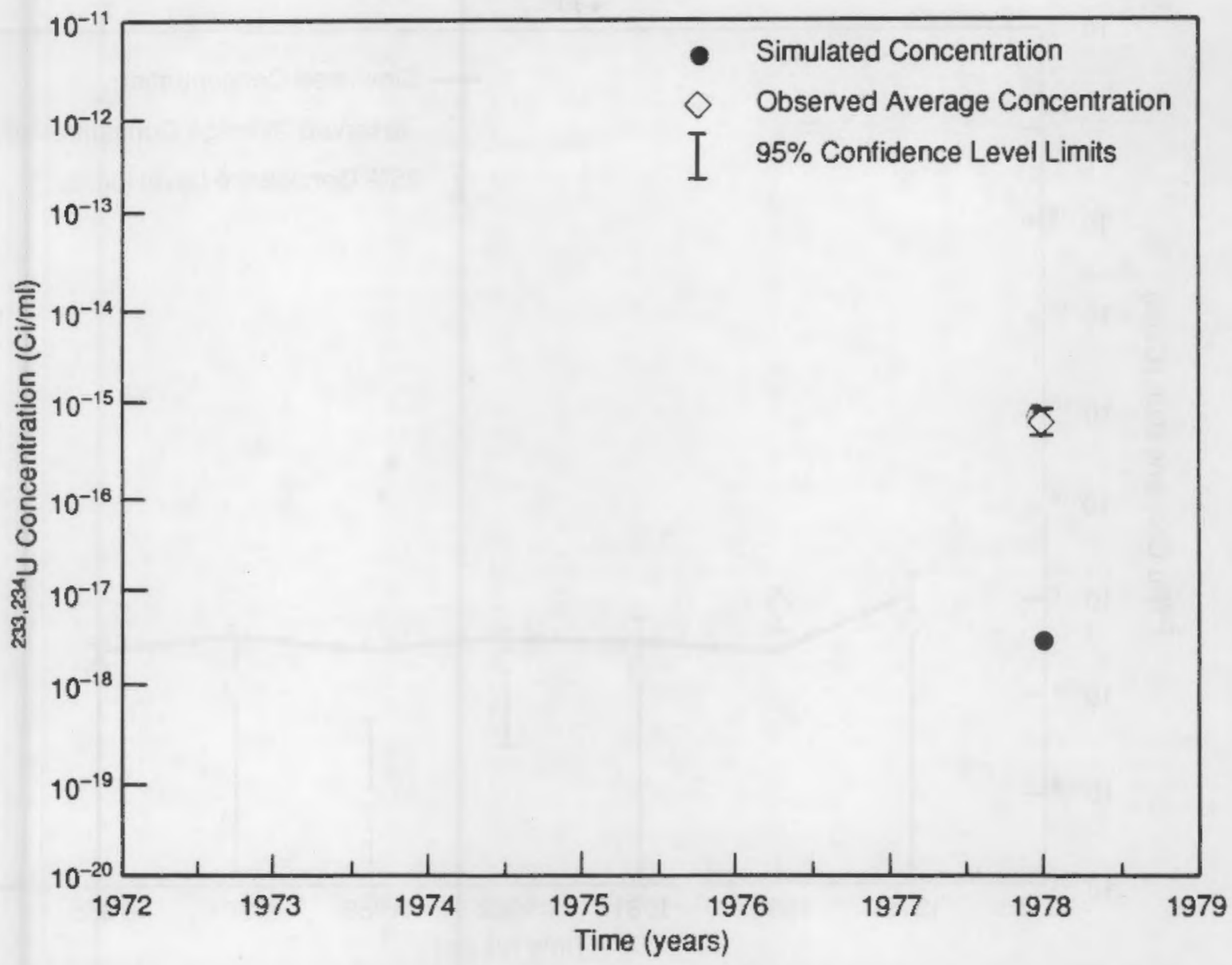

FIGURE 4.12. Simulated Versus Observed $233,234 U$ Concentrations in the Great Miami River at Sampling Location 1 for the Years 1973 Through 1978

the Great Miami River. Although the events surrounding contaminant release into the river are complicated, they can be simplified by addressing only the inost important aspects.

By addressing the five critical areas of concern outlined in Chapter 3.0, the most important aspects associated with the modeling scenario will be defined.

1) constituents of interest and form of constituents -- The constituents of interest, tritium, plutonium-238, and uranium-233,234, are in a liquid effluent that is being discharged to the Great Miami River from the Mound facility. 


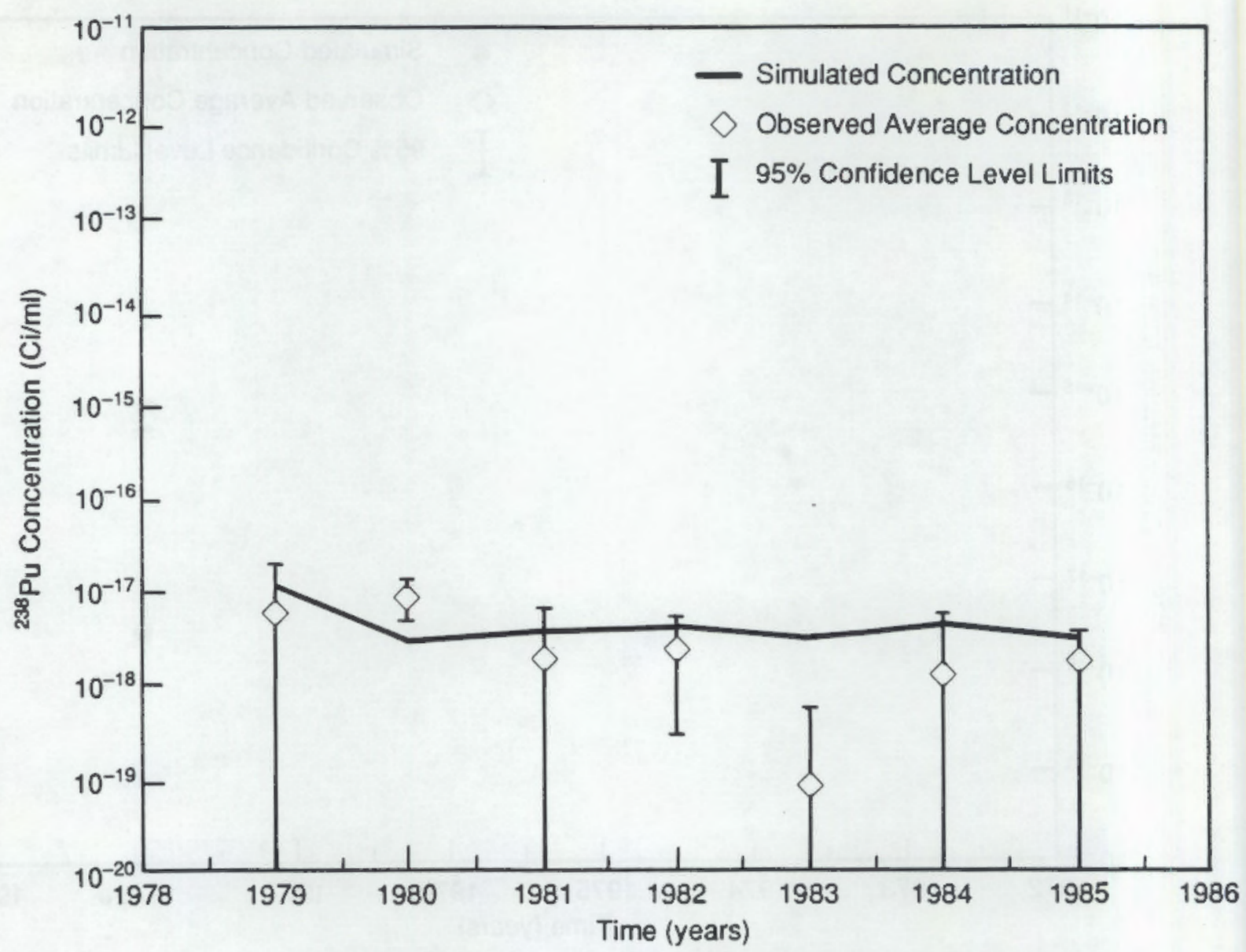

FIGURE 4.13. Simulated Versus Observed ${ }^{238}$ Pu Concentrations in the Great Miami River at Sampling Location 2 for the Years 1979 Through 1985

2) level of contamination -- The level of the contamination is described by the annual inventory of constituents that are being released from the facility to the Great Miami River. These inventories are presented in Table 4.2.

3) mechanism of release -- The contaminants are periodically discharged to the Great Miani River via the South Canal (i.e., effluent discharge 002) or via the underground pipeline (i.e., effluent discharge 001).

4) source of water -- The Great Miami River represents the source of the water that is transporting the constituents through the surface water environment. Note that although the contaminants are being transported to the river in a liquid effluent, the average annual effluent 


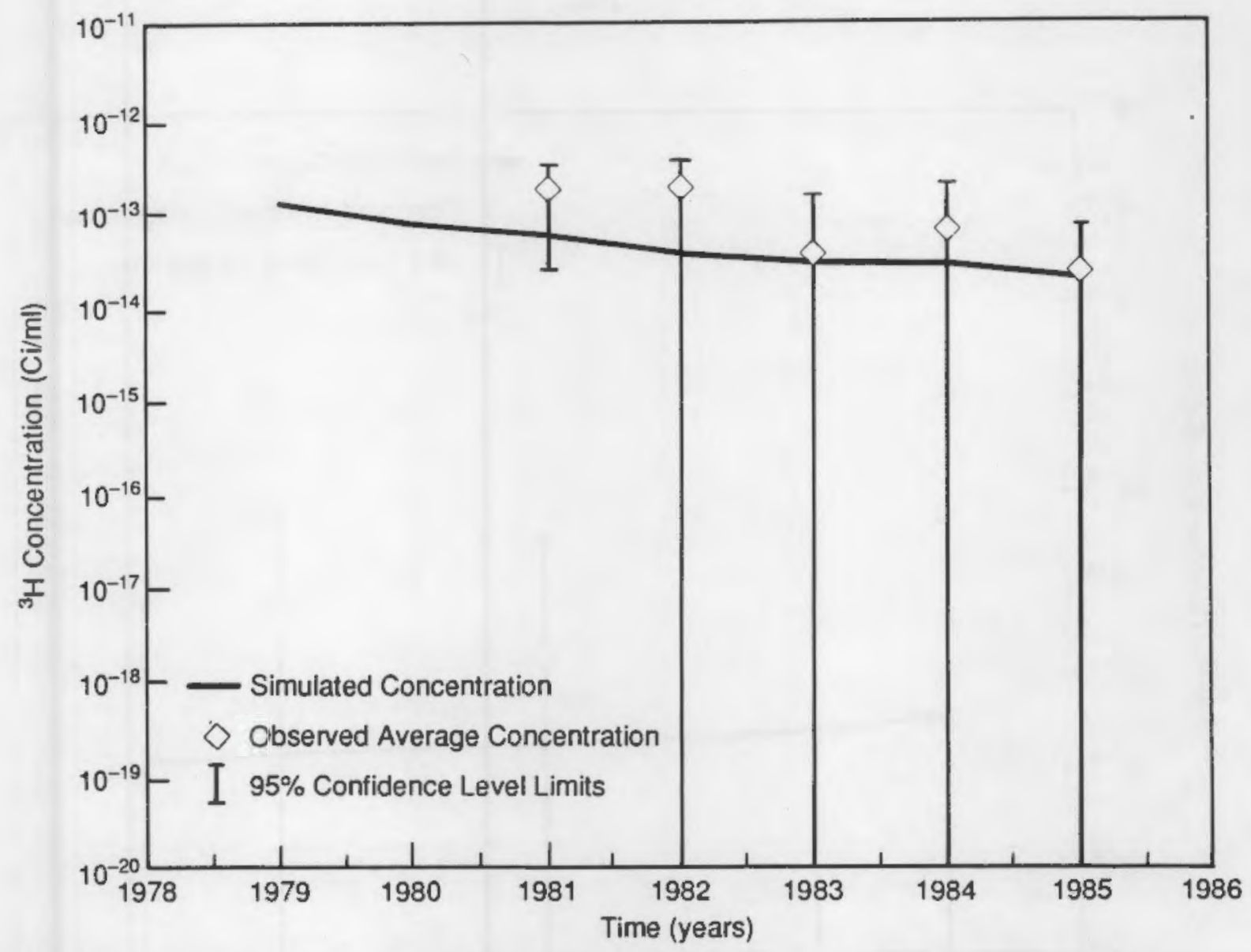

FIGURE 4.14. Simulated Versus Observed ${ }^{3} \mathrm{H}$ Concentrations in the Great Miami River at Sampling Location 2 for the Years 1979 Through 1985

discharge to the river [i.e., $\left.0.0327 \mathrm{~m}^{3} / \mathrm{s}\left(1.15 \mathrm{ft}^{3} / \mathrm{s}\right)\right]$ represents only $0.05 \%$ of the average annual flow rate of the river [i.e., $68.90 \mathrm{~m}^{3} / \mathrm{s}$ $\left.\left(2433 \mathrm{ft}^{3} / \mathrm{s}\right)\right]$.

5) time frame -- The release of the constituents is on an annual-average basis (see Table 4.2).

\subsubsection{Quantification of Parameters for the Great Miami River}

The specific parameters required by RAPS for simulating contaminant migration and fate in a riverine environment can be divided into two categories: constituent and hydraulic information. Each is briefly discussed below.

- Constituent Information -- The RAPS methodology only requires the user to define the constituent of interest, the half-life of the constituent, and the mass flux of the constituent. Table 4.3 


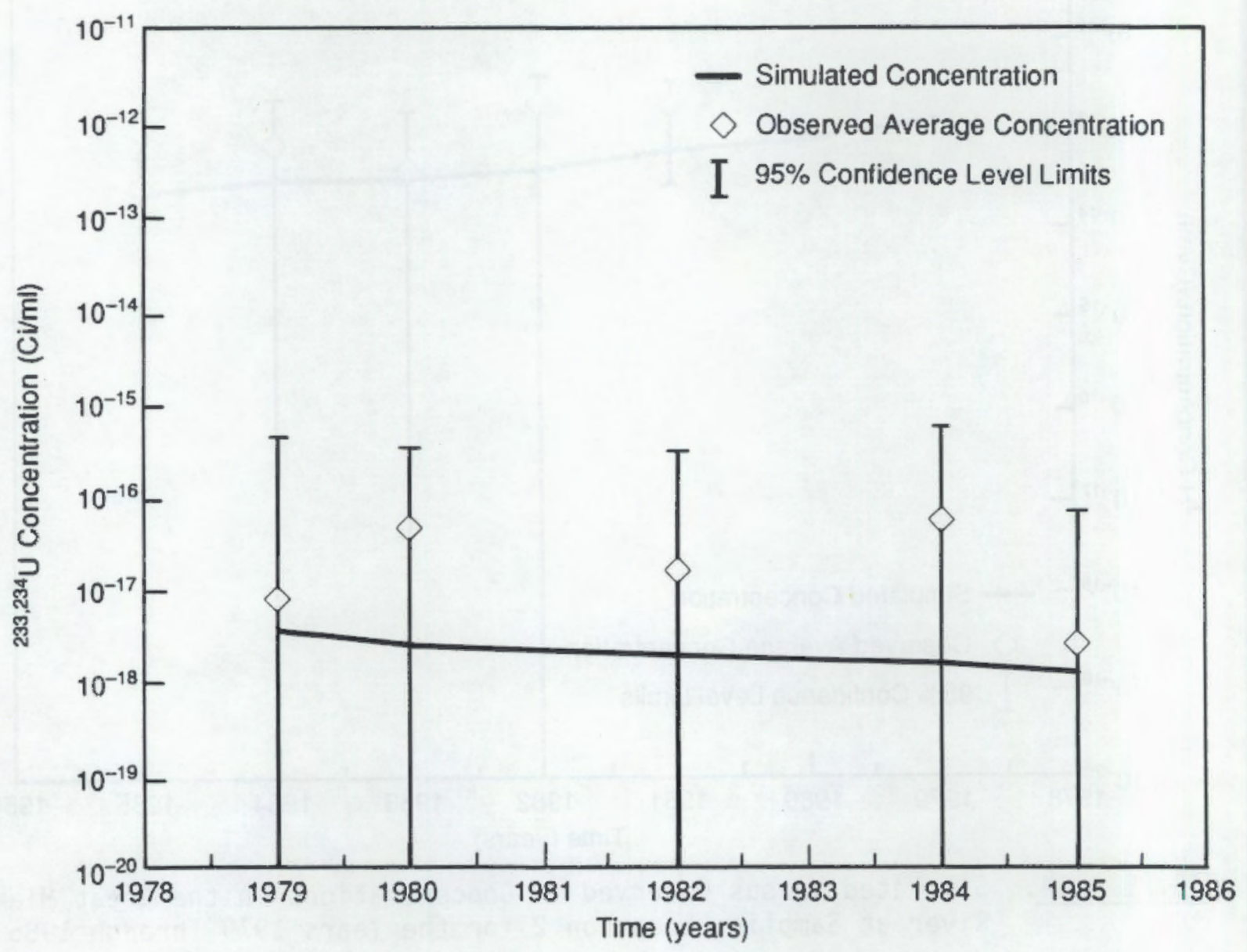

FIGURE 4.15. Simulated Versus Observed $233,234 \mathrm{U}$ Concentrations in the Great Miami River at Sampling Location 2 for the Years 1979 Through 1985

presents the constituents of interest in this testing exercise and their associated half-lives; the annual mass of constituent released to the Great Miami River is presented in Table 4.2 .

- Hydraulic Information -- The RAPS methodology only requires the user to define the geometry of the channel and the average flow velocity of the water in the channel. The geometric information includes the average depth and width of flow. The average flow velocity, on the other hand, can be computed from the average discharge in the channel and the shape (i.e., depth and width of channel) of the channel. 


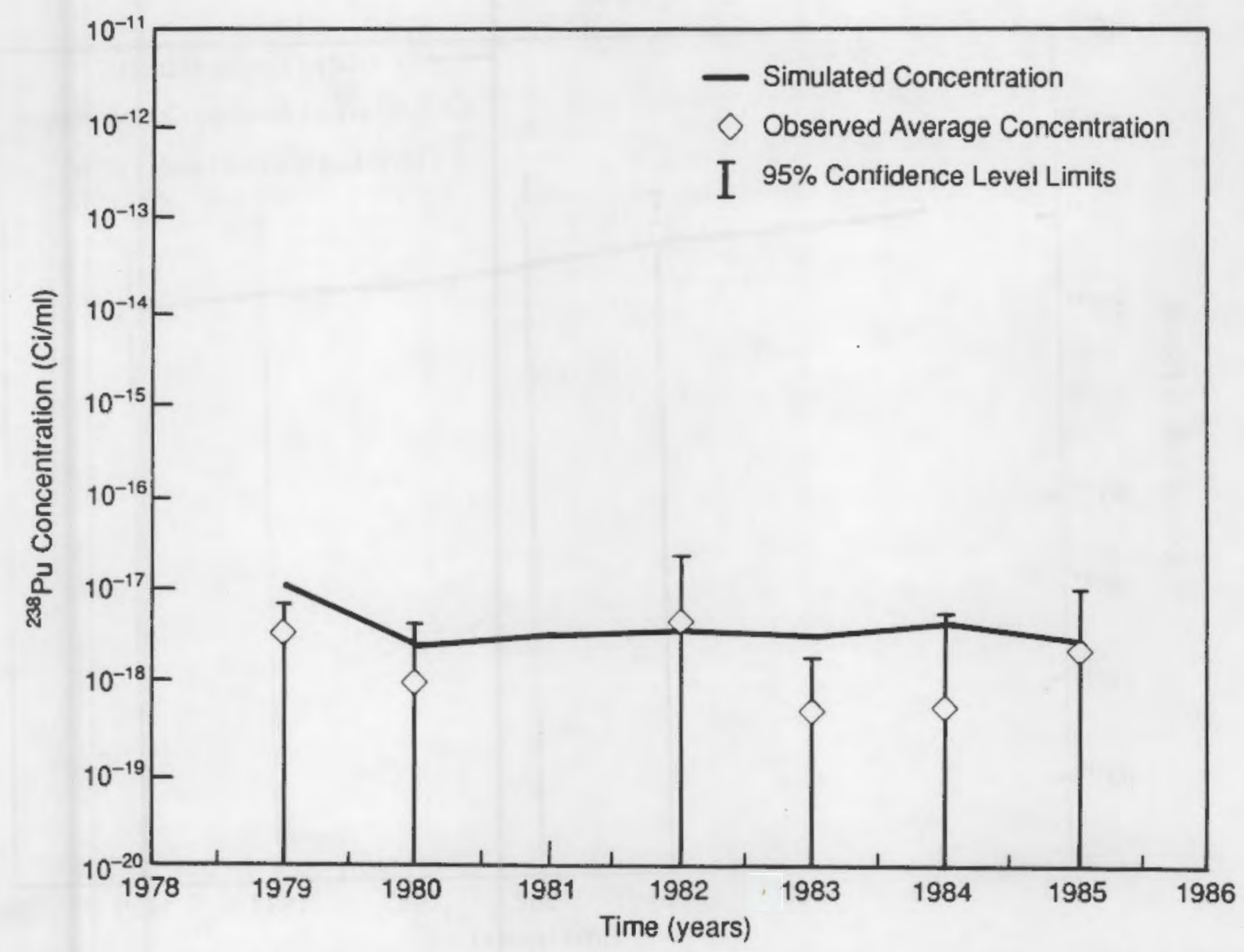

FIGURE 4.16. Simulated Versus Observed ${ }^{238} P_{u}$ Concentrations in the Great Miami River at Sampling Location 3 for the Years 1979 through 1985

The average discharge in any river in the United States can usually be obtained from standard USGS Water-Data Reports. For the Great Miami River at Miamisburg, Ohio, the 47 -year average discharge is $68.90 \mathrm{~m}^{3} / \mathrm{s}\left(2433 \mathrm{ft}^{3} / \mathrm{s}\right)$ (Shindel et al. 1985). The average depth of flow is estimated as $1.11 \mathrm{~m}$ (3.64 ft). According to DOE (1979), the width of the river near the Mound facility varies between $46 \mathrm{~m}(150 \mathrm{ft})$ and $61 \mathrm{~m}(200 \mathrm{ft})$. Assuming an average width of $53 \mathrm{~m}(175 \mathrm{ft})$, the average flow velocity is estimated as $1.16 \mathrm{~m} / \mathrm{s}$ $(3.82 \mathrm{ft} / \mathrm{s})$. A summary of the hydraulic information is presented in Table 4.3. 


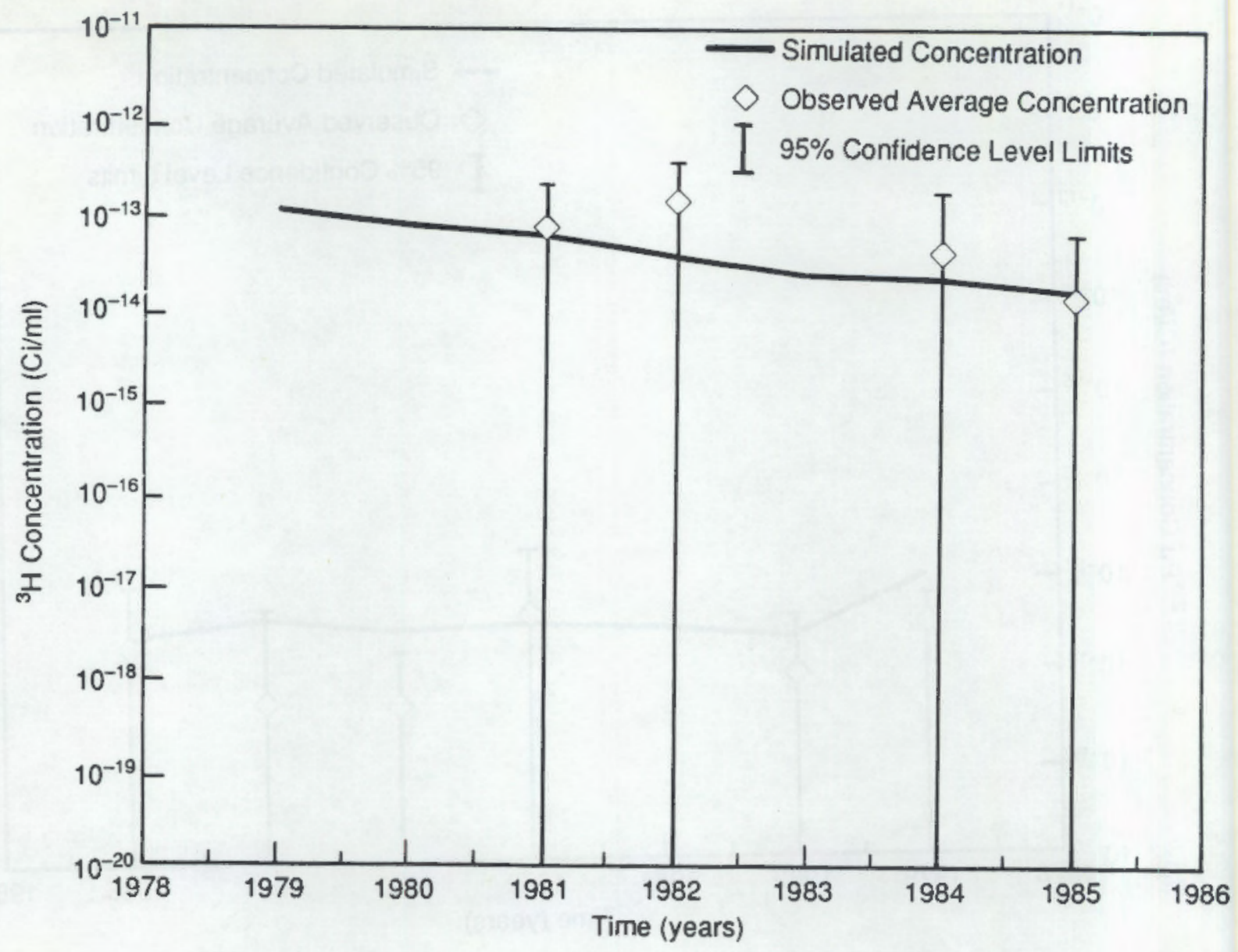

FIGURE 4.17. Simulated Versus Observed ${ }^{3} \mathrm{H}$ Concentrations in the Great Miami River at Sampling Location 3 for the Years 1979 Through 1985

\subsubsection{Results Associated with the Application of RAPS to the Great Miami River}

This section presents the simulated spacial and temporal distribution of tritium, plutonium-238, and uranium-233,234 using the surface water component of the RAPS methodology. This component assumes steady-state, uniform flow conditions in a fixed, rectangular channel. Fully mixed conditions over the full depth and width of the river are not initially assumed but only occur at distances sufficiently downstream of the release point. Note that the sampling locations identified in Figure 4.9 are far enough downstream that the fully mixed condition applies. 


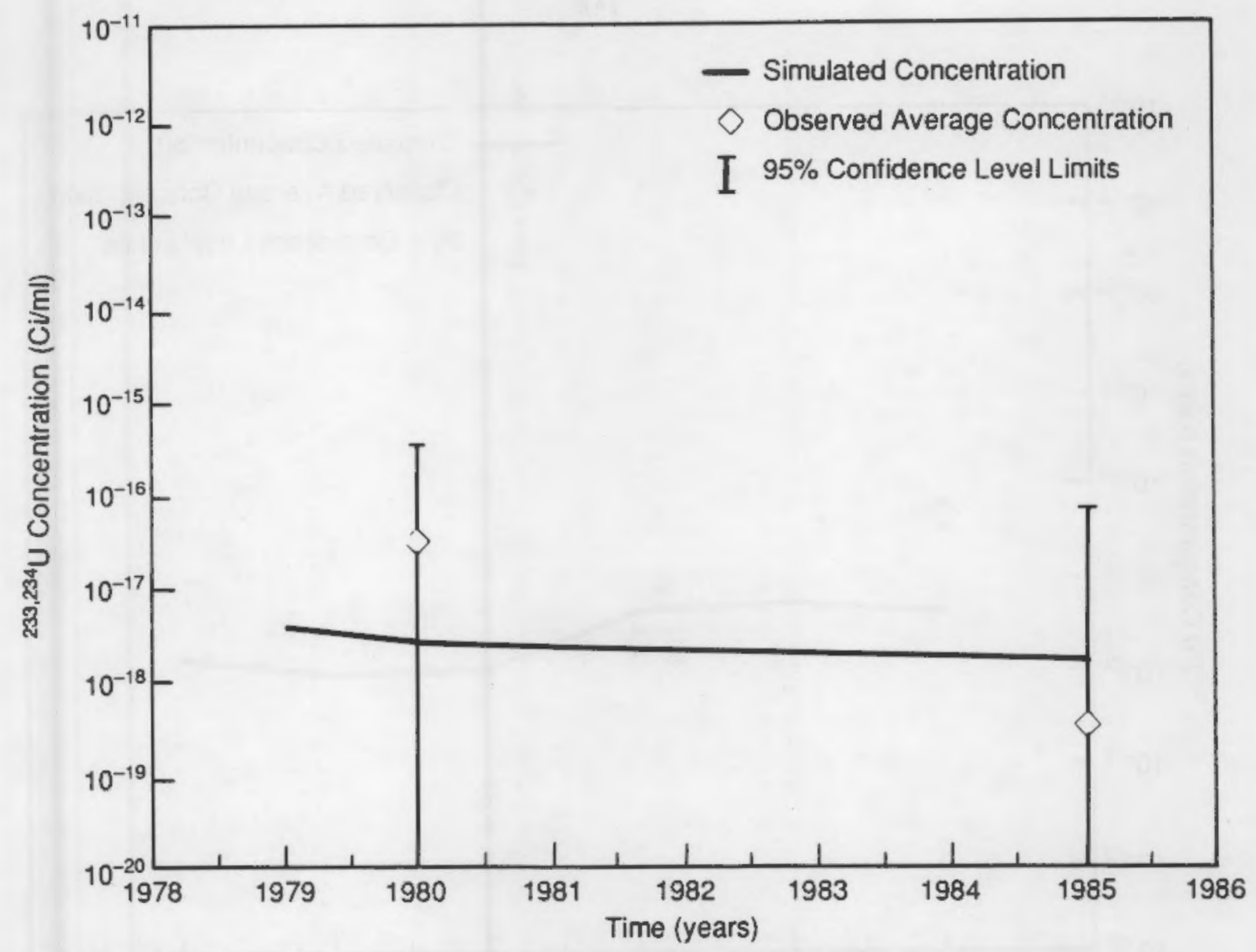

FIGURE 4.18. Simulated Versus Observed $233,234 \mathrm{U}$ Concentrations in the Great Miami River at Sampling Location 3 for the Years 1979 Through 1985

Observed and simulated results are presented in each figure. Observed results are represented by the average incremental concentration (i.e., the open symbol in each plot) bounded by estimates of the standard error of the estimated means at the $95 \%$ confidence interval. The simulated results are represented by the solid line in each figure or by the solid symbol in Figures 4.12 and 4.21 . The results that are presented for the years 1973 through 1978 (i.e., Figures 4.10 through 4.12 and 4.19 through 4.21 ) reflect observed 


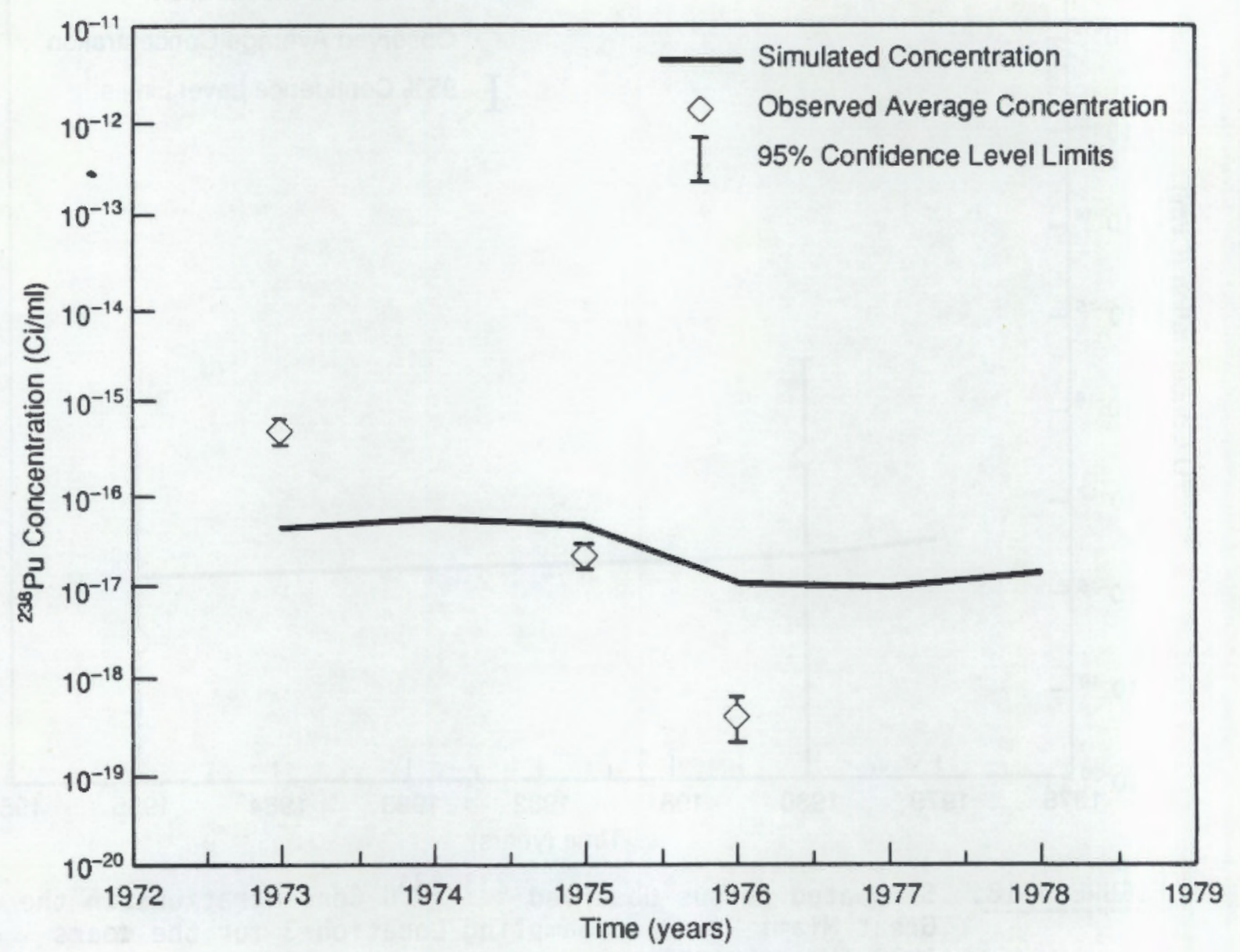

FIGURE 4.19. Simulated Versus Observed ${ }^{238} \mathrm{Pu}$ Concentrations in the Great Miami River at Sampling Location 4 for the Years 1973 Through 1978

concentrations in samples that were not filtered before analysis and reflect sampling locations that Mound personnel do not feel necessarily represented the actual conditions in the Great Miami River.(a)

(a) Personal communication from Mr. D. G. Carfagno, Monsanto Corporation, Miamisburg, Ohio, to G. Whelan, Pacific Northwest Laboratory, Richland, Washington, November 26, 1986. 


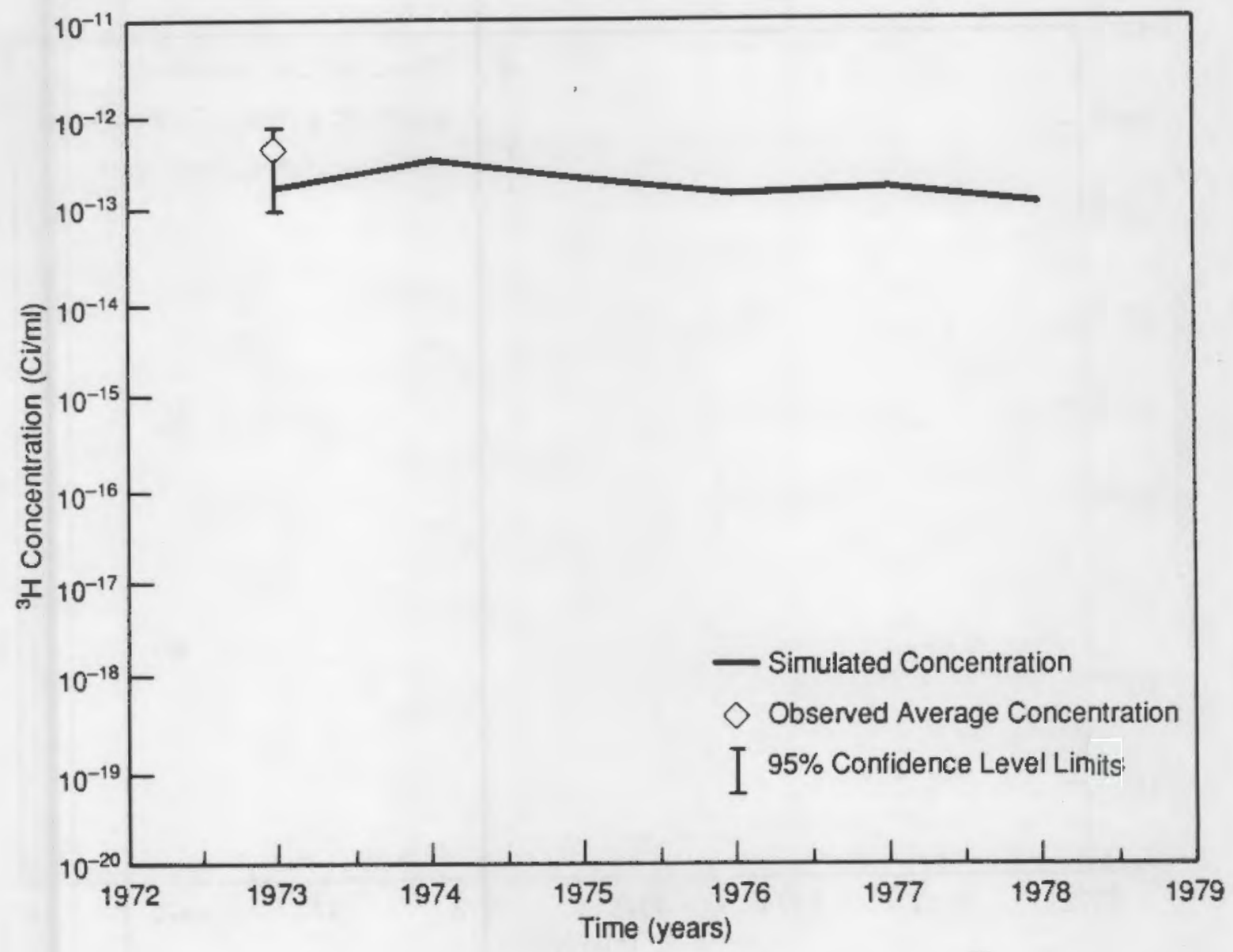

FIGURE 4.20. Simulated Versus Observed ${ }^{3} \mathrm{H}$ Concentrations in the Great Miami River at Sampling Location 4 for the Years 1973 Through 1978

4.5 CONCLUSIONS ASSOCIATED WITH THE APPLICATION OF RAPS TO THE GREAT MIAMI RIVER

The surface water component of the RAPS methodology was used on the Great Miami River, simulating the migration and fate in this riverine environment of tritium, plutonium-238, and uranium-233,234 released from the Mound facility. The constituents were released with effluent discharged from laboratory facilities. Results of the simulation were presented in Section 4.4 and Figures 4.10 through 4.24. Only a qualitative discussion compares the simulated and observed results because

- over the years, different composite sampling time periods were used when analyzing the samples (e.g., monthly versus quarterly versus semiannually composite of daily samples), and large volume samples were not taken over the entire period of record. 


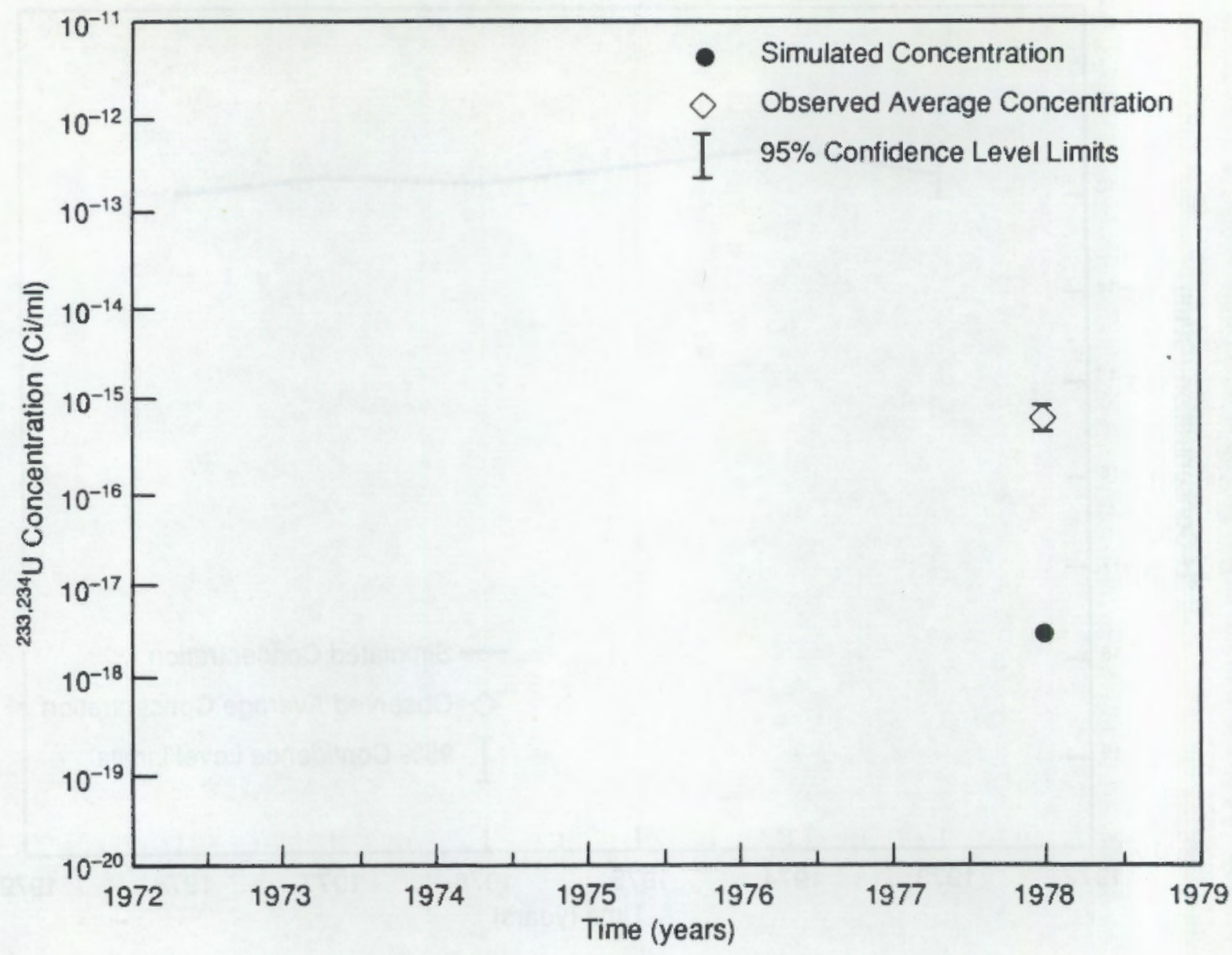

FIGURE 4.21. Simulated Versus Observed $233,234 \mathrm{U}$ Concentrations in the Great Miami River at Sampling Location 4 for the Years 1973 Through 1978

- sampling stations were relocated partway through the period of record.

- a small sample population existed for each constituent at each location for each sampling methodology.

The results presented in Figures 4.10 through 4.24 indicate that, when all samples(a) are analyzed, $51 \%$ of the observed concentrations are higher than

(a) Fifty-three observed instream concentrations are plotted in Figures 4.10 through 4.24. Of this total, 10 occur during the years 1973 through 1978 and 43 occur during the years 1979 through 1985. 


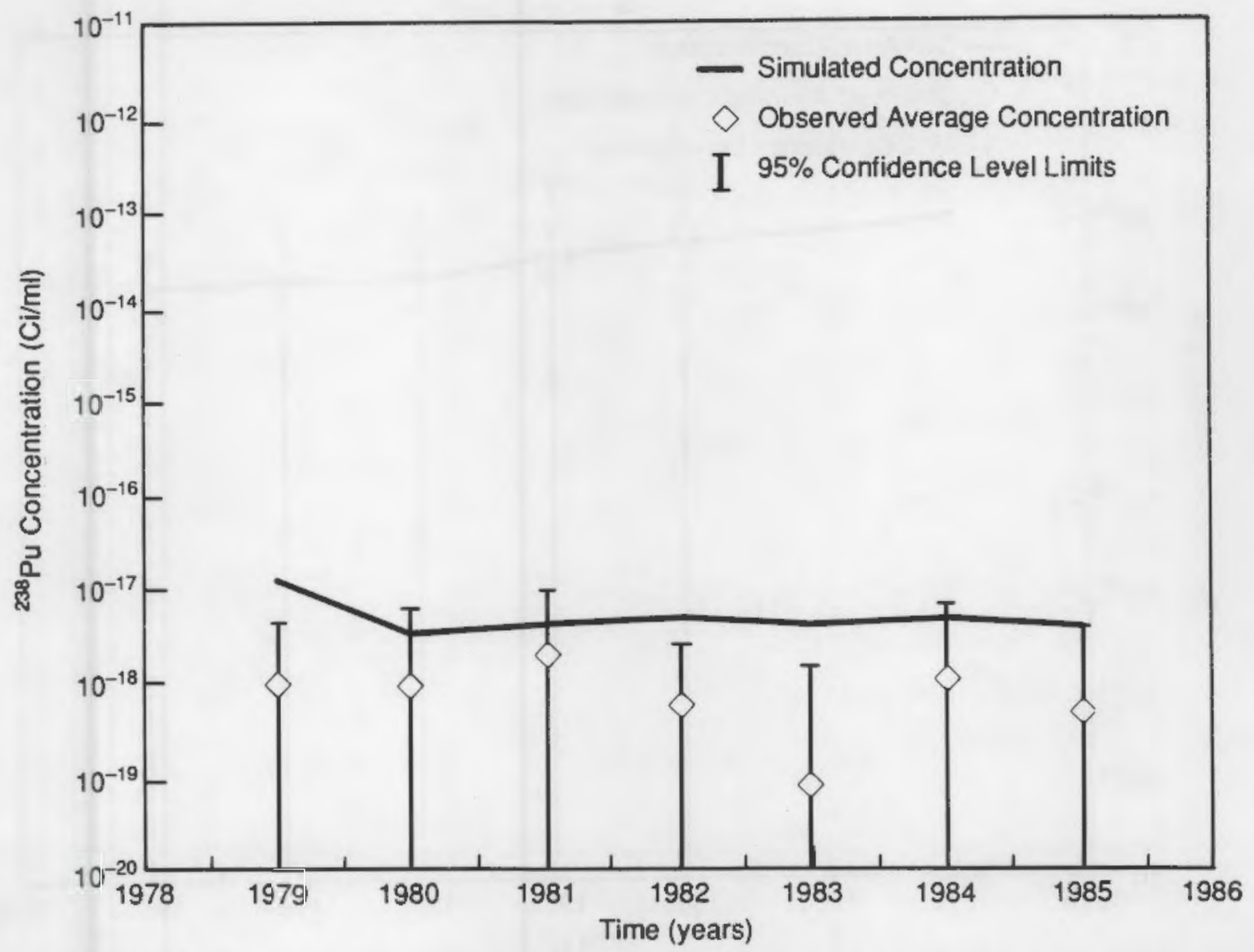

FIGURE 4.22. Simulated Versus Observed ${ }^{238} \mathrm{Pu}$ Concentrations in the Great Miami River at Sampling Location 5 for the Years 1979 Through 1985

their corresponding simulated concentrations; and $49 \%$ of the observed concentrations are lower than their corresponding simulated concentrations.

- $74 \%$ of the simulated concentrations are within the estimates of the standard error of the estimated means at the $95 \%$ confidence level for the observed concentrations. When analyzed by time period, $84 \%$ of the simulated concentrations for the years 1979 through 1985 are within these estimated error ranges; only $30 \%$ of the simulated concentrations for the years 1973 through 1978 are within these estimated error ranges.

- $93 \%$ of the simulated concentrations are either within the estimated error range or within one order of magnitude of the upper or lower 


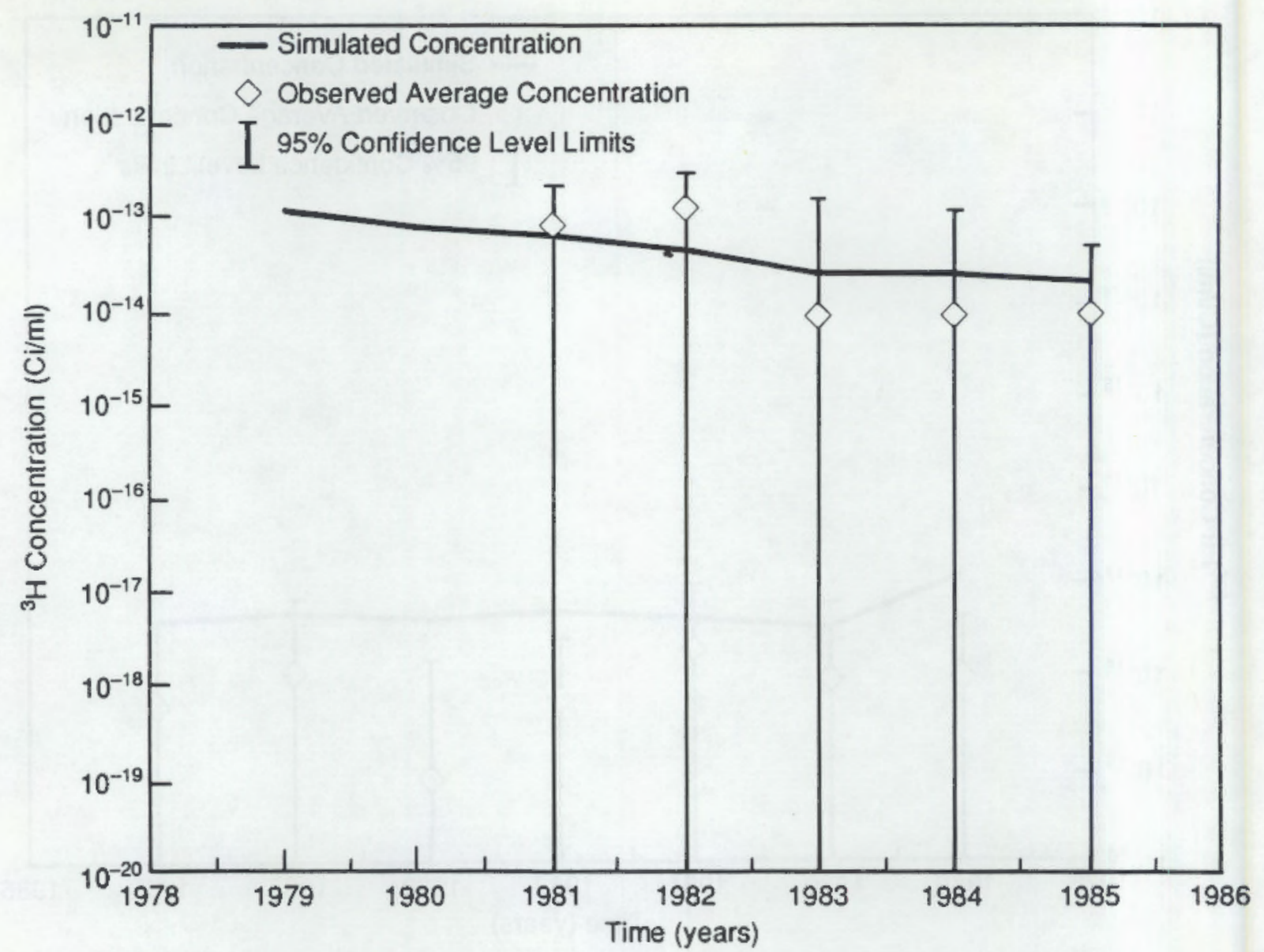

FIGURE 4.23. Simulated Versus Observed ${ }^{3} H$ Concentrations in the Great Miami River at Sampling Location 5 for the Years 1979 Through 1985

$1 \mathrm{imit}$ of the estimate of the standard error of the estimated means at the $95 \%$ confidence level for the observed concentrations. When analyzed by time period, $100 \%$ of the simulated concentrations for the years 1979 through 1985 are either within the estimated error range or within one order of magnitude of the upper or lower 1imit; $60 \%$ of the simulated concentrations for the years 1973 through 1978 are within either the estimated range or within one order of magnitude of the upper or lower limit.

The results of the analysis appear to indicate that the simulated instream concentration levels more closely coincide with the observed instream concentrations during the later years (i.e., 1979 through 1985) than during the earlier years (i.e., 1973 through 1978). This may be due to a number of factors 


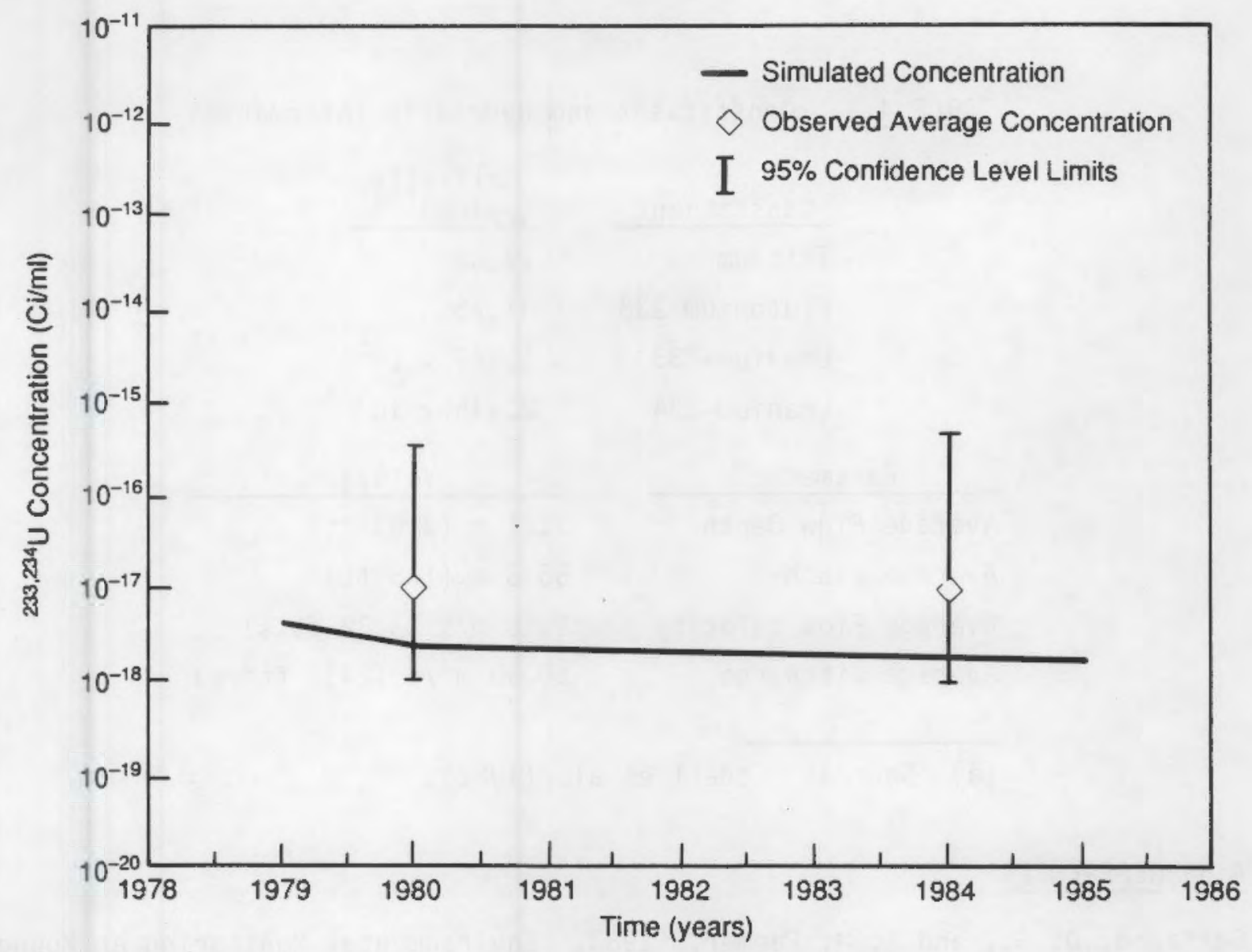

FIGURE 4.24. Simulated Versus Observed 233,234 U Concentrations in the Great Miami River at Sampling Location 5 for the Years 1979 Through 1985

associated with the later years, such as better instrumentation, more large volume samples, different sampling locations, and more samples (i.e., observed concentrations) that were above the average environmental level (i.e., larger sample size).(a)

(a) Over $81 \%$ of the observed concentrations plotted in Figures 4.10 through 4.24 are associated with the years 1979 through 1985. 
TABLE 4.3. Constituent and Hydraulic Information

\begin{tabular}{|c|c|}
\hline Constituent & $\begin{array}{c}\text { Half-Liffe } \\
\text { (years) }\end{array}$ \\
\hline Tritium & 12.36 \\
\hline Plutonium-238 & 87.75 \\
\hline Uranium-233 & $1.855 \times 10^{5}$ \\
\hline Uranium-234 & $2.445 \times 10^{5}$ \\
\hline ameter & Values \\
\hline low Depth & $1.11 \mathrm{~m}(3.63 \mathrm{ft})$ \\
\hline idth & $53.3 \mathrm{~m}(175 \mathrm{ft})$ \\
\hline low Velocity & $1.16 \mathrm{~m} / \mathrm{s}(3.82 \mathrm{ft} / \mathrm{s})$ \\
\hline ischarge & $68.90 \mathrm{~m}^{3} / \mathrm{s}\left(2433 \mathrm{ft}^{3} / \mathrm{s}\right)$ \\
\hline
\end{tabular}

(a) Source: Codell et al. (1982).

\subsection{REFERENCES}

Carfagno, D. G., and B. M. Farmer. 1983. Environmental Monitoring at Mound: 1982 Report. MLM-3055, Environmental Section of the Administration Department at Monsanto Research Corporation, Miamisburg, Ohio.

Carfagno, D. G., and B. M. Farmer. 1984. Environmental Monitoring at Mound: 1983 Report. MLM-3143, Environmental Section of the Administration Department at Monsanto Research Corporation, Miamisburg, Ohio.

Carfagno, D. G., and B. M. Farmer. 1985. Environmental Monitoring at Mound: 1984 Report. MLM-3246, Environmental Section of the Administration Department at Monsanto Research Corporation, Miamisburg, Ohio.

Carfagno, D. G., and B. M. Farmer. 1986. Environmental Monitoring at Mound: 1985 Report. MLM-3349, Environmental Section of the Administration Department at Monsanto Research Corporation, Miamisburg, Ohio.

Carfagno, D. G., and B. Robinson. 1975. Annual Environmental Monitoring Report: Calendar Year 1974. MLM-2232, Environmental Section of the Administration Department at Monsanto Research Corporation, Miamisburg, Ohio. 
Carfagno, D. G., and W. H. Westendorf. 1973. Interim Environmental Monitoring Report: January - June 1973. MLM-2085, Environmental Section of the Administration Department at Monsanto Research Corporation, Miamisburg, Ohio.

Carfagno, D. G., and W. H. Westendorf. 1974. Annual Environmental Monitoring Report: Calendar Year 1973. MLM-2142, Environmental Section of the Administration Department at Monsanto Research Corporation, Miamisburg, Ohio.

Codell, R. B., K. T. Key and G. Whelan. 1982. A Collection of Mathematical Models for Dispersion in Surface Water and Groundwater. NUREG-0868, U.S. Nuclear ReguTatory Commission, Washington, D.C.

DOE. 1979. Environmental Impact Statement -- Mound Facility, Miamisburg, Ohio. DOE/EIS-00140-0, U.S. Department of Energy, Washington, O.C.

Eagleson, P. S. 1970. Dynamic Hydrology. McGraw-Hi11, Inc., New York.

EPA. 1972. Environmental Radioactivity Surveillance Guide. ORP/SID, 72-2. Office of Radiation Programs. U.S. Environmental Protection Agency, Washington, D.C.

Farmer, B. M., and D. G. Carfagno. 1978. Annual Environmental Monitoring Report: Calendar Year 1977. MLM-2515, Environmental Section of the Administration Department at Monsanto Research Corporation, Miamisburg, Ohio.

Farmer, B. M., and D. G. Carfagno. 1979. Annual Environmental Monitoring Report: Calendar Year 1978. MLM-2608, Environmental Section of the Administration Department at Monsanto Research Corporation, Miamisburg, Dhio.

Farmer, B. M., and D. G. Carfagno. 1980. Annual Environmental Monitoring Report: Calendar Year 1979. MLM-2700, Environmental Section of the Administration Department at Monsanto Research Corporation, Miamisburg, Ohio.

Farmer, B. M., and D. G. Carfagno. 1981. Annual Environmental Monitoring Report: Calendar Year 1980. MLM-2822, Environmental Section of the Administration Department at Monsanto Research Corporation, Mianisburg, Ohio.

Farmer, B. M., and 0. G. Carfagno. 1982. Annual Environmental Monitoring Report: Calendar Year 1981. MLM-2930, Environmental Section of the Administration Department at Monsanto Research Corporation, Miamisburg, Ohio.

Farmer, B. M., B. Robinson, and D. G. Carfagno. 1976. Annual Environmental Monitoring Report: Calendar Year 1975. MLM-2317, Environmental Section of the Administration Department at Monsanto Research Corporation, Miamisburg, Ohio. 
Farmer, B. M., B. Robinson and D. G. Carfagno. 1977. Annual Environmental Monitoring Report: Calendar Year 1976. MLM-2416, Environmental Section of the Administration Department at Monsanto Research Corporation, Miamisburg, Ohio.

MRC. 1971. Environmental Monitoring Report: July - December 1970 and 1970 Summary. MLM-1795, Environmental Section of the Administration Department at Monsanto Research Corporation, Miamisburg, Ohio.

MRC. 1972. Environmental Monitoring Report: January - June 1971. MLM-1880, Environmental Section of the Administration Department at Monsanto Research Corporation, Miamisburg, Ohio.

MRC. 1981. Environmental Assessment and Planning Section - Quality Control Manual. Mo-10176, Issue 1. Monsanto Research Corporation, Miamisburg, Ohio.

Shindel, H. L., L. L. Stewart and J. R. Kolva. 1985. Water Resources Data: Ohio - Water Year 1984 - Volume 1. Ohio River Basin. U.S. Geological Survey Water-Data Report OH-84-1. U.S. Geological Survey, Columbus, Ohio.

Strenge, D. L., R. A. Peloquin and G. Whelan. 1986. LADTAP II--Technical Reference and User Guide. NUREG/CR-4013, U.S. Nuclear Regulatory Commission, Office of Nuclear Reactor Regulation, Washington, D.C.

Whelan, G., B. L. Steelman, D. L. Strenge, and J. G. Droppo. 1986. "Overview of the Remedial Action Priority System (RAPS)." In Pollutants in a Multimedia Environment, ed. Y. Cohen, Plenum Press, New York.

Whel an, G., D. L. Strenge, J. G. Droppo, and B. L. Steelman. 1987. The Remedial Action Priority System (RAPS): Mathematical Formulations. PNL6200 , Prepared for the Office of Environment, Safety, and Health, U.S. Department of Energy, Washington, D.C., by Pacific Northwest Laboratory, Richland, Washington. 


\subsection{SUBSURFACE COMPONENT OF THE RAPS METHODOLOGY}

\subsection{INTRODUCTION $(a)$}

Water from a precipitation event moves downward through the soil under the influence of gravity as long as there is a sufficient quantity to overcome the restraining forces of capillary hydraulic potential (i.e., matrix potential). Water is extracted from the partially saturated zone by surface evaporation and as transpiration by growing plant roots; together, these processes are called evapotranspiration. The rates of both extraction processes depend directly on available solar energy (i.e., heat radiation) and surface winds (Simmons and Gee 1981).

Infiltrating water that exceeds the soil water holding capacity will contribute to percolation (i.e., "deep" drainage). The process of water movement through a soil matrix is mechanistically complex (Simmons and Gee 1981). This passage of water is very dynamic and depends on detailed variations in the hydraulic properties of the water in the soil. Water storage by a soil profile is characterized by a water content distribution, which ultimately depends on the detailed spacial variability of hydraulic properties. A single set of measured hydraulic properties cannot accurately represent an areal region (Simmons and Gee 1981).

Quantifying the leachate volume is important for the RAPS methodology because the volume of water that percolates into a waste site is assumed in RAPS to eventually percolate from the site, thereby distributing contaminants in the groundwater environment. Figure 5.1 illustrates the movement of water in and around a waste site.

Contaminants exiting the bottom of a waste site migrate through a partially saturated zone or into a saturated zone. The groundwater component of the RAPS methodology estimates contaminant concentrations in groundwater and/or fluxes at various transporting medium interfaces (i.e., water table surface and edge of stream) and at withdrawal wells. Contaminant concentrations at the interfaces between transporting media and at withdrawal wells provide values of

(a) This section is based on Whelan et al. $(1986,1987)$. 


\section{Movement of Water in and Around an Inactive Waste Site}

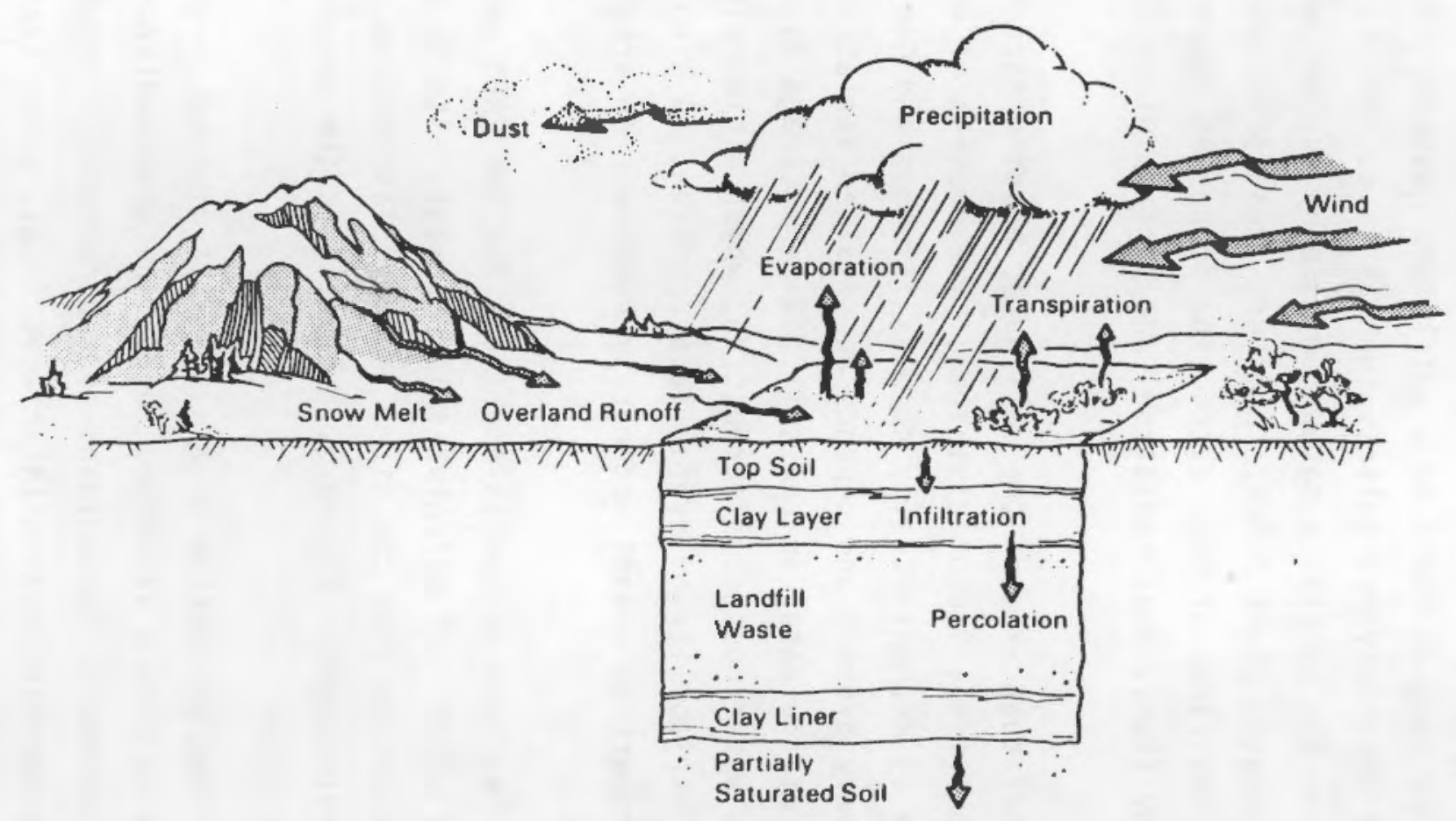

Saturated Soil

FIGURE 5.1. Diagram of the Movement of Water in and Around an Inactive Waste Site (After Whelan et al. 1987) 
contaminant levels for the exposure assessment component of RAPS. Contaminant fluxes at the interface between transporting media represent boundary conditions for the next medium (e.g., groundwater contamination entering a surface water environment). Figure 5.2 illustrates the groundwater environment.

Each of the three aspects of the subsurface component of the RAPS methodology discussed above (i.e., infiltration of water at the soil surface from precipitation events, (a) movement of water and transport of contaminants in the partially saturated zone, and transport of contaminants in the saturated zone) is addressed in this chapter. This chapter compares events monitored in the environment with those simulated by the RAPS methodology. As noted in Chapter 1.0 , the purpose of this comparison is to test the applicability of the subsurface component of the RAPS methodology.

The RAPS methodology is implemented at two different facilities to test each of the three aspects of the subsurface component. First, the well-known dump site in South Farmingdale-Massapequa, on Long Island, New York, was chosen to demonstrate the applicability of the algorithms for the saturated zone component of the RAPS methodology. This site was chosen because data pertaining to this site have been used extensively by various researchers (e.g., see Anderson 1979, Pinder 1973, Codell et al. 1982) for testing other models, both simple and complex. Therefore, the RAPS methodology was implemented using these same data for comparative purposes. Second, the Hanford facility, operated by DOE's Richland Operations Office in Richland, Washington, was chosen for the initial demonstration of 1) the quantification by RAPS of annual percolation (i.e., deep drainage) volume from precipitation events and 2) water and contaminant movement in the partially saturated zone beneath several waste sites. The Hanford facility was chosen for the following reasons:

- Hanford is in an arid region. Implementation of RAPS in an arid region is important for demonstrating the applicability of the infiltration algorithms. Most, if not all, simplified monthly mass balance techniques break down in arid environments because the techniques are based on assumptions for a humid environment.

(a) Quantification of leachate volume. 

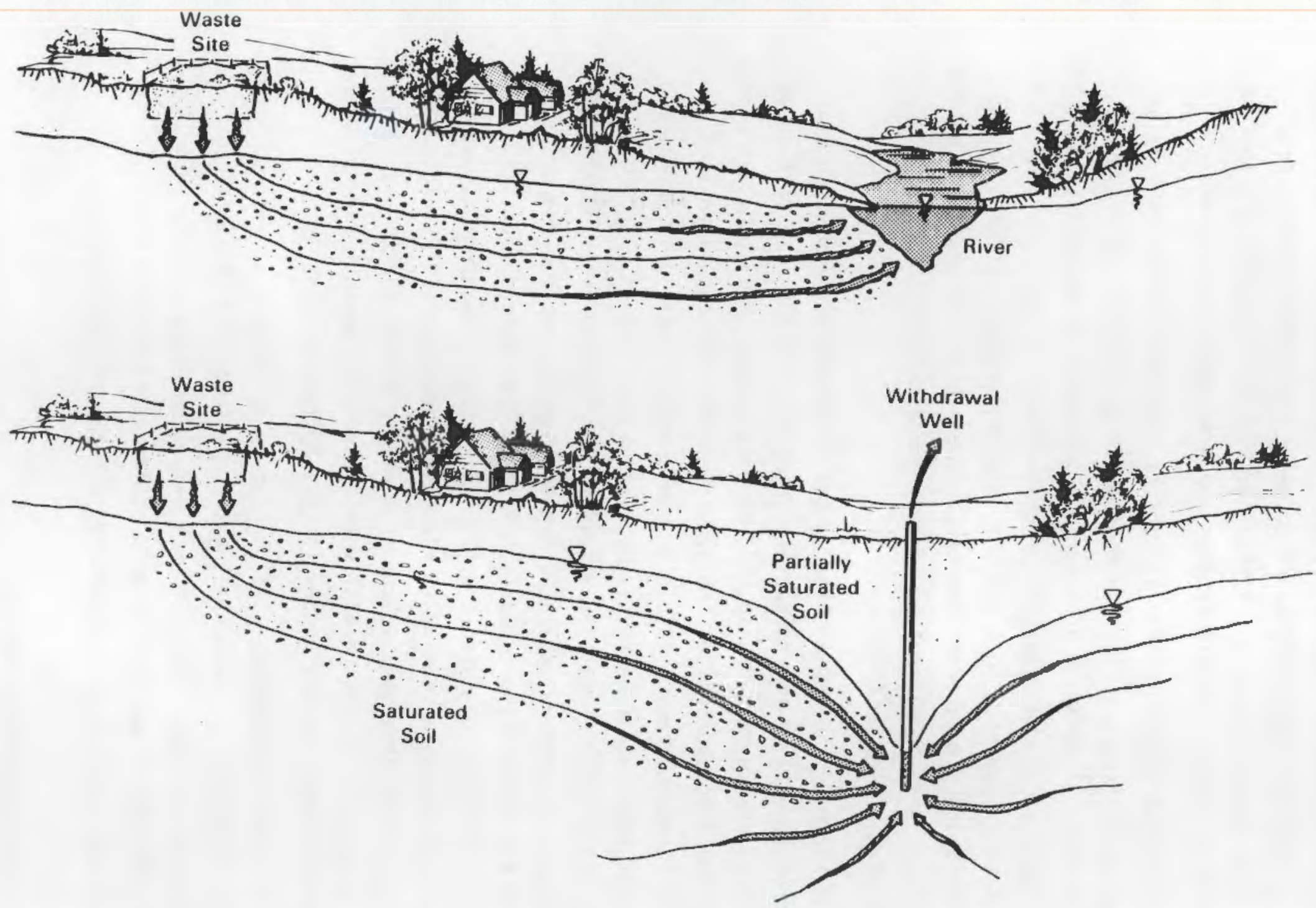

FIGURE 5.2. Diagram of the Groundwater Environment: a) Contaminant Levels or Fluxes at a Surface Water Boundary and b) Contaminant Levels at a Withdrawal Well (After Whelan et al. 1987) 
- The quality and quantity of the climatic and meteorologic data at Hanford are typical of any region in the United States.

- Although the Hanford facility is in an arid region, it also receives snowfall, and average monthly temperatures can fall •below freezing. Implementation of RAPS at Hanford can help demonstrate the applicability of the methodology in regions where snow accumulates.

- The sites chosen to demonstrate the applicability of the partially saturated zone component of the methodology were selected to represent a diversity in disposal techniques (i.e., a crib discharging contaminants to a tile field and a storage tank discharging contaminants to a French drain).

- The partially saturated zone at the Hanford facility is sufficiently deep that fluctuations in the water table do not affect contaminant distributions in the partially saturated zone beneath the waste sites.

- Lysimeter measurements and data concerning contaminant distributions in the partially saturated zone are available for several sites for comparison with simulated results from the RAPS methodology.

- Data are readily available at the Hanford facility, making the implementation of the RAPS methodology at the various sites easier.

- Hanford is a large DOE facility with all of the potential logistic problems associated with its size.

- The U.S. Department of Energy granted access to facility records and personnel.

The remainder of this chapter is divided into seven main sections. Section 5.2 reviews the mathematical algorithms associated with 1 ) quantifying the annual inventory of water infiltrating into and percolating through the soil from precipitation events and 2) describing solute movement in the partially saturated and saturated zones. Sections 5.3 through 5.5 describe the application of the RAPS methodology to various sites at the Hanford facility. Section 5.6 describes the application of RAPS at the South Farmingdale-Massapequa 
dump site. Section 5.7 provides concluding remarks associated with the applications of the subsurface component of the RAPS methodology. Finally, Section 5.8 lists the references cited in the chapter.

\subsection{MATHEMATICAL FORMULATIONS (a)}

This section presents the mathematical formulations in the RAPS methodology associated with quantifying the annual inventory of water percolating through a soil as a result of precipitation events. This section also presents the mathematical formulations associated with simulating solute movement in the partially saturated and saturated zones of the subsurface environment.

\subsubsection{Precipitation-Generated Percolation Rate}

This section presents a relatively simple methodology for estimating the fraction of precipitation (i.e., rainfall and snowmelt) that is lost to infiltration, evapotranspiration, and overland runoff (see figure 5.1). The infiltration estimation techniques are based on those described by Viessman et al. (1977) and Thornthwaite and Mather (1955, 1957), and used by Fenn et al. (1975), Dass et al. (1977), and Whelan et al. (1988). The overland runoff volume is estimated using techniques described by SCS (1972, 1982), Kent (1973), and USBR (1977).

The method outlined herein involves calculating a monthly water-balance using a variety of meteorologic and site information, including monthly estimates of precipitation, potential evapotranspiration, snowmelt, temperature, and runoff. The method assumes that water infiltrates into a well-constructed and well-managed landfill only during periods of precipitation and snowmelt. Some of the precipitation that falls on a landfill site runs off, some is lost to evapotranspiration, and the remainder percolates through the landfill. Whelan et al. (1988) note that water that percolates through the fill eventually leaves the fill as leachate once the moisture content of the fill is between field capacity and saturated conditions. Although the simulation of the dominant mechanisms governing the movement of soil moisture through the

(a) This section is based on whelan et al. $(1986,1987)$. 
soil waste matrix is not completely accurate, it can indicate how a site might respond to different meteorologic and hydrologic conditions.

Long-term meteorological data can be obtained from the Local

Climatological Data: Annual Summary with Comparative Data, publ ished for various years by the Environmental Data Service, National Oceanic and Atmospheric Administration National Climatic Data Center, U.S. Department of Comnerce (USDC) (see for example NOAA 1984). (a) In addition, to estimate overland runoff volumes, data similar to that required by the SCS Curve Number (CN) technique are needed.

To quantify potentiai leachate and net overland runoff volumes (i.e., source-term quantification), 14 intermediate values must be determined. Each of the fourteen steps is briefly discussed below.

1) unadjusted average monthly temperature -- The unadjusted average monthly temperature represents the average monthly temperature at the LCD station, and it has not been adjusted for the elevation difference that may exist between the site proper and the LCD station. The elevation of the LCD station is reported in the LCDs.

2) adjusted average monthiy temperature -- The unadjusted average monthly temperature is adjusted to account for the elevation difference that may exist between the LCD station and the actual site. The user need supply only the site elevation to make the adjustment. Based on information on lapse rates (i.e., rate of temperature change with height in the free atmosphere) by Mockus (1971), Eagleson (1970), and Linsley et al. (1975), an adjusted average monthly temperature can be computed as follows (see whelan et al. 1987):

$$
T_{i}=T u_{i}-0.007\left(h_{1}-h_{0}\right)
$$

(a) The Local Climatic Data Annual Summaries and the associated datacollection stations are designated by LCD. 
where $T_{j}=$ adjusted average monthly temperature at the actual site for the $i$-th month $\left({ }^{\circ} \mathrm{C}\right)$

$\mathrm{Tu}_{j}=$ unadjusted average monthly temperature at the LCD station for the i th month $\left({ }^{\circ} \mathrm{C}\right)$

$h_{1}=$ elevation of actual site $(m)$

$h_{0}=$ elevation of LCO station (m)

$i=$ index for month $(1 \leqslant i \leqslant 12$ with $i=1$ for January, $i=2$, for February,...., and $i=12$ for December).

3) potential evapotranspiration -- Potential evapotranspiration (PET) is the most critical parameter in estimating leaching volumes. If the PET estimate is too high, then the methodology will underpredict the volume of leachate from the waste disposal site. If the PET estimate is too low, then conservative estimates may result.

If an accurate or conservative estimate is desired, such conservatism may fail in arid regions because most of the techniques used for estimating PET were not developed for arid regions.

The modified Blaney-Criddle (MBC) method and the Penman method with correction factor (PMCF) (see Doorenbos and Pruitt 1977) are used to estimate the potential evapotranspiration at the site. Both methods are based on average air temperature, minimum relative humidity, ratio of actual to maximum possible sunshine hours, and average wind speed. The PMCF is also based on the maximum relative humidity and latitude. Each of these parameters can be defined by using the LCOs. Each method for estimating PET is briefly described below. Modified Blaney-Criddle Method. To better define the effect of $\mathrm{Cli-}$ mate on vegetation requirements, Doorenbos and Pruitt (1977) present a modified version of the Blaney-Criddle technique (Blaney and Criddle 1950) that includes such parameters as relative humidity, daytime wind speed, ratio of actual to maximum possible sunshine hours, temperature, latitude, and mean daily percentage of total annual daytime hours. The governing equations, as presented by Doorenbos and Pruitt (1977), are as follows: 


$$
\begin{array}{ccc}
\mathrm{PET}_{i}=\mathrm{a} b \mathrm{c}_{i} \mathrm{P}_{i}\left(0.46 \mathrm{~T}_{i}+8\right) & \text { for } \mathrm{T}_{i}>0^{\circ} \mathrm{C} \\
\mathrm{PET}_{i}=0 & \text { for } \mathrm{T}_{i} \leq 0^{\circ} \mathrm{C}
\end{array}
$$

where $P E T_{j}=$ potential evapotranspiration rate for month $i$ (min/day)

$a=$ coefficient that is a function of elevation

$b=$ coefficient that is a function of latitude

$c_{j}=$ adjustment factor that depends on minimum relative humidity, sunshine hours, and daytime wind speed estimates for month $i$

$P_{i}=$ mean daily percentage of total annual daytime hours as a function of latitude and month $i$

$T_{i}=$ adjusted average monthly temperature for month $i$ $\left({ }^{\circ} \mathrm{C}\right)$.

Techniques for defining the various coefficients and adjustment factors in Equation (5.2) are outlined by whelan et al. (1987). The adjusted average monthly temperature is defined by Equation (5.1). Penman Method with Correction Factor. Doorenbos and Pruitt (1977) developed the modified version of the Penman method (PMCF); it differs from the Penman method (Penman 1948) by using a revised windfunction term in its formulation. The PMCF is based on climatic parameters such as maximum, minimum, and mean relative humidity; ratio of actual to maximum possible sunshine hours; average wind speed; average air temperature; saturation and actual vapor pressures; and net shortwave and longwave solar radiation parameters. The governing PET equations in the PMCF are as follows:

$$
\begin{array}{rr}
\operatorname{PET}_{i}=c_{i}\left(W_{i} R n_{i}+\left(1-W_{j}\right) f(0)_{i}\left(e s_{i}-e a_{i}\right)\right) \text { for } T_{i}>0^{0} \mathrm{C} \\
\operatorname{PET}_{i}=0 & \text { for } T_{i} \leq 0^{\circ} \mathrm{C}
\end{array}
$$


where $c_{j}=$ adjustment factor to compensate for the effect of day and night weather conditions for month $i$

$$
\begin{aligned}
W_{i}= & \text { temperature-related weighting factor for the } i-t h \text { month } \\
R n_{i}= & \text { net radiation } i n \text { equivalent evaporation for month } i \\
& \text { (mm/day) } \\
f(\bar{U})_{i}= & \text { wind-related function for month } i \\
e s_{i}= & \text { saturation vapor pressure at the mean air temperature } \\
& \text { for month } i \text { (mb) } \\
\text { ea } a_{i}= & \text { mean actual vapor pressure of the air for month } i \text { (mb) }
\end{aligned}
$$

Techniques for estimating each of the terms in Equation (5.4) are outlined by whelan et al. (1987).

4) monthly precipitation as rainfall -- This step identifies the total monthly precipitation when adjusted monthly temperatures are above freezing. The average monthly precipitation is supplied by LCDs. The precipitation can fall as rain (i.e., nonfrozen) or snow (i.e., frozen). It is assumed that the monthly precipitation is represented by rainfall if the adjusted average monthly temperature is above freezing. This assumption is not completely accurate, because rainfall and snowfall frequently occur during the same month, especially during springtime. However, if the average temperature for the month is above freezing, much of the snowfall will melt and be a source of water for infiltration and overland runoff.

5) monthly precipitation as snowfall - Precipitation occurring during a month when the adjusted monthly temperature is below freezing is assumed to be in the form of snowfall. The snow is assumed to accumulate on the land surface and to be stored until the first month with an adjusted average monthly temperature greater than zero. Precipitation as snowfall is obtained in the same location on the LCDS as the monthly precipitation as rainfall.

6) precipitation adjusted for snowmelt -- Snowfall is assumed to occur before the ground freezes to any considerable extent. This assumption is important because when the snow melts infiltration will occur. Parameters required for computing snowmelt include average 
temperature, average wind speed, site elevation, mean sky cover (i.e., degree of cloudiness), and monthly precipitation as rainfall. All of this information is supplied by LCDs. In many areas, snowmelt may be the dominant source of runoff or infiltration. The assumption on this methodology is that snow is stored on the ground when the adjusted average monthly air temperature is less than or equal to $0^{\circ} \mathrm{C}\left(32^{\circ} \mathrm{F}\right)$; when the average monthly air temperature rises above $0^{\circ} \mathrm{C}\left(32^{\circ} \mathrm{F}\right)$, the snow melts and is available for infiltration and runoff.

Because the calculations for estimating the source term are crude, simple empirical relationships are used to estimate snowmelt. The heat necessary to induce snowmelt is derived from radiation, condensation of vapor, convection, air and ground conduction, and rainfall. The four most important sources include vapor condensation, convection, radiation, and rainfall (Linsley and Franzini 1972; Linsley et al. 1975; Viessman et al. 1977). The algorithms for describing these four sources of snowmelt are presented in whelan et al. (1987). The total inventory of snowmelt on a monthly basis can be estimated by summing the snowmelt effects of vapor condensation, convection, radiation, and rainfall as follows:

$$
\begin{array}{ll}
M M_{i}=M v c_{i}+M c_{i}+M r_{i}+M p_{i} & \text { for } T_{i}>0^{\circ} \mathrm{C} \\
M_{i}=0 & \text { for } T_{i} \leq 0^{\circ} \mathrm{C}
\end{array}
$$

where $M_{j}=$ total monthly snowmelt for the $i-$ th month $(\mathrm{cm})$

$M v c_{i}=$ average monthly snowmelt from vapor condensation for the $\mathrm{i}$-th month $(\mathrm{cm})$

$M c_{i}=$ average monthly snowmelt from convection for the $i-t h$ month $(\mathrm{cm})$

$M r_{i}=$ average monthly snowmelt from radiation for the $i-t h$ month $(\mathrm{cm})$ 


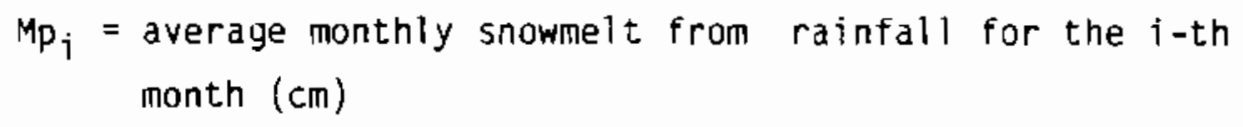

The volume of snowmelt is limited by the amount of snow stored on the land surface. When a month with an adjusted monthly temperature greater than freezing follows a month with a subfreezing temperature, the monthiy precipitation volume is adjusted to account for snowmelt as follows:

$$
P m s_{i}=P \pi_{i}+M_{i}
$$

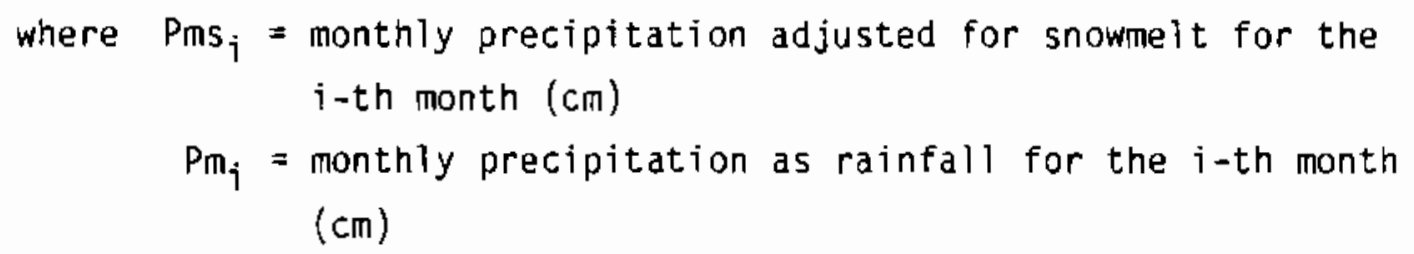

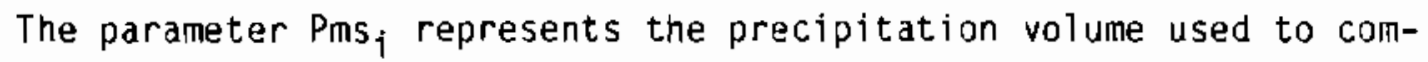
pute the net overland runoff volume and infiltration volume. The specific techniques for defining the parameters in Equations (5.6) and (5.8) are outlined by whelan et al. (1987).

7) monthly overland runoff -- The SCS Curve Number (CN) technique (SCS 1972, 1982; Kent 1973; USBR 1977) is used to compute the overland runoff portion of the monthly water balance at the hazardous waste site. Computations or computing percolation using the CN technique are based on surface characteristics. The soil cover represents the soil type and the vegetation cover represents the vegetation type. To distribute the monthly volume of precipitation into daily precipitation amounts, we assume the following:

1. The monthly volume of precipitation can be equally distributed among the total number of recorded precipitation events with $3.9 \times 10-3 \mathrm{~cm}(0.01 \mathrm{in.})$ or more of volume.

2. The number of precipitation events can be defined by the LCD. 
3. Precipitation is stored on the land surface in the form of snow when the adjusted average monthly temperatures are equal to or below freezing; precipitation is in the form of rainfall when temperatures are above freezing.

Using this technique, the total monthly runoff from the waste site can be estimated as follows:

$$
\begin{aligned}
& V m_{i}=\frac{\left[\mathrm{Pms}_{i}(\mathrm{CN})-0.2 \mathrm{a} \mathrm{m}_{i}[1000-10(\mathrm{CN})]\right]^{2}}{(\mathrm{CN})\left[\mathrm{Pms}_{i}(\mathrm{CN})+0.8 \mathrm{a} \mathrm{m}_{i}[1000-10(\mathrm{CN})]\right]} \\
& \text { for }\left\{\begin{array}{c}
{\left[\mathrm{Pms}_{i}(\mathrm{CN})\right]>\left[0.2 \text { a } \mathrm{m}_{i}[1000-10(\mathrm{CN})]\right]} \\
T_{i}>0^{\circ} \mathrm{C}
\end{array}\right. \\
& V m_{j}=0 \\
& \text { for }\left\{\begin{array}{c}
{\left[\mathrm{Pms}_{i}(\mathrm{CN})\right]<\left[0.2 \text { a m } \mathrm{m}_{i}[1000-10 \text { (CN) }]\right]} \\
\mathrm{T}_{i} \leqslant 0^{\circ} \mathrm{C}
\end{array}\right.
\end{aligned}
$$

where $V_{m_{j}}=$ monthly runoff volume for the $i-t h$ month (cm)

$a=$ conversion parameter between centineters and inches $(a=2.54)$

$m_{j}=$ number of precipitation events during the $i-t h$ month

$\mathrm{CN}=$ curve number.

It is assumed that the runoff calculations using the $C N$ technique are applicable, although snow may be covering the land surface. This condition rarely occurs, because snow usually melts in the first month that the average temperature rises above freezing. A complete review of the development of Equations (5.9) and (5.10) are presented in whelan et al. (1987). 
8) maximum potential percolation -- The maximum potential amount of moisture available for percolation (i.e., maximum percolation) is represented by the precipitation, adjusted for snowmelt during months where the adjusted average monthly temperature is greater than freezing, minus the average monthiy runoff. The maximum potential percolation is expressed by the following expressions:

$$
\begin{array}{ll}
f \max x_{i}=P m s_{i}-V m_{i} & \text { for } T_{i}>0^{\circ} \mathrm{C} \\
\operatorname{fmax}_{i}=0 & \text { for } T_{i} \leq 0^{\circ} \mathrm{C}
\end{array}
$$

where fmax $_{j}=$ maximum amount of moisture available for percolation for the i-th month $(\mathrm{cm})$.

9) potential percolation -- The potential percolation defined as the difference between the maximum potential percolation ( $f_{m a x}$ ) and the monthly PET. Mathematicaliy, the potential percolation is expressed as follows:

$$
\begin{array}{ll}
f p_{i}=f \operatorname{fmax} x_{i}-P E T_{i} & \text { for } T_{i}>0^{\circ} \mathrm{C} \\
f p_{i}=0 & \text { for } T_{i} \leq 0^{\circ} \mathrm{C}
\end{array}
$$

where $f p_{i}=$ potential percolation for the $i$-th month (cm).

10) accumulated potential water loss -- This step represents the potential soil moisture loss during a year. It is computed using the potential percolation and the soil-moisture retention tables published by Thornthwaite and Mather (1957).

Accumulated potential water loss $\left(W L_{j}\right)$ refers to the potential deficiency of moisture in the soil water storage when the PET is significantly larger than the maximum potential percolation. During these periods, the moisture can be depleted from the soil reservoir, creating a moisture 
deficit below saturated conditions. This condition usually occurs during the sumner months in arid regions (e.g., the southwestern United States or arid Pacific Northwest).

A site has the potential for a yearly average moisture deficit in the soil column if the sum of the monthly $f p_{i}$ values is negative. This condition usually occurs in arid and semiarid regions. In arid or dry areas, soil moisture at the end of the wet season is below field capacity; therefore, it is necessary to find an initial value for the accumulated potential water loss with which to start accumulating the negative values of $f p_{j}$. In the RAPS methodology, this initial value is estimated using the method of successive approximations, as outlined by Thornthwaite and Mather (1957). The basis for this method is that the rate of water loss from the soil is proportional to the soil moisture content; that is, as the soil moisture decreases toward the wilting point, extracting water from the soil becomes increasingly more difficult.

In humid areas, the sum of the monthly $f p_{j}$ values will be positive. Because "excess" water exists in humid areas, the value of accumulated potential water loss with which to start accumulating depletion of water moisture from the soil is zero.

The method outlined by Thornthwaite and Mather (1955, 1957) is used to compute the accumulated potential water loss. More information on computing the accumulated potential water loss is given by whelan et al. (1987).

11) soil moisture storage - - This step identifies the moisture contained in the soil column at the end of each month. Soil moisture storage is computed using the PET and the soil moisture retention tables published by Thornthwaite and Mather (1957). Because the soil moisture storage calculations are based on the PET, the soil moisture storage calculations significantly influence the amount of water that percolates into the waste site. The soil moisture storage value for month $i\left(S T_{j}\right)$ represents the soil moisture that is retained in the soil after a given amount of accumulated potential water loss or gain has occurred. 
For both humid and arid areas, $S T_{i}$ for the dry season (i.e., when $f p_{i}<0$ ) is estimated using the accumulated potential water loss values ( $W L_{i}$ ) computed in step 10 and the Thornthwaite and Mather (1957) soil moisture retention tables. The soil moisture retention tables correlate the relationship between $W L_{\mathfrak{i}}$ and $S T_{\mathfrak{j}}$. Using the proper retention table, $S T_{\mathfrak{j}}$ can be identified for each $W L_{i}$ for each dry-season month.

For the first month of the wet season (i.e., first month with a positive $f p_{j}$ following the dry season) and succeeding months, the soil moisture storage is computed as follows:

$$
S T_{i}=\sum_{i=k}^{K}\left\langle S T_{i-l}+f p_{i}\right)
$$

where $S T_{i}=$ soil moisture storage for the $i-t h$ month (cm)

$k=$ index for the first month with a positive $f p_{i}$

$K=$ index for the last month with a positive $f p_{j}$ value

(Note that $k$ can be less than $k$; for example, October (with $k=10$ ) is the first wet month following the dry season and May (with $K=5$ ) is the last wet month prior to the dry season).

For more information, refer to whelan et al. (1987).

12) change in soil moisture storage -- The change in soil moisture storage for the current month is defined as the difference between the current and previous months' soil moistures. Mathematically, the change in this storage is computed as follows:

$$
\Delta S T_{i}=S T_{i}-S T_{i-1}
$$

where $\mathrm{ST}_{i}=$ change in soil moisture storage for the $i$-th month $(\mathrm{cm})$.

13) actual evapotranspiration -- when the PET is less than or equal to the difference between the maximum potential percolation and the change in soil moisture storage (note the potential negative sign), the actual 
evapotranspiration (AET) is equal to the PET. When the PET is greater, the AET is equal to the difference between the maximum potential percolation and change in soil moisture storage (note the potential negative sign). Mathematically, the AET is computed as follows:

$$
\begin{array}{ll}
A E T_{i}=P E T_{i} & \text { for } P E T_{i} \leq\left(f \max x_{i}-\Delta S T_{i}\right) \\
A E T_{i}=\operatorname{fmax}_{i}-\Delta S T_{i} & \text { for } P E T_{i}>\left(f \max x_{i}-\Delta S T_{i}\right)
\end{array}
$$

where $\mathrm{AET}_{j}=$ actual evapotranspiration for the $i-$ th month $(\mathrm{cm})$.

14) leachate generation -- The moisture generated as leachate during any month is also a function of the adjusted average monthly temperature. When $T_{j}$ is below freezing, zero leachate is assumed to be generated.

$$
L G_{i}=0 \quad \text { for } T_{i} \leq 0^{\circ} \mathrm{C}
$$

where $L G_{i}=$ leachate generation for the $i$-th month (cm). When $T_{i}$ is greater than freezing, the leachate generated from the landfill is computed as follows:

$$
L G_{i}=f_{m a x}-A E T_{i}-\Delta S T_{i} \quad \text { for } T_{i}>0^{\circ} \mathrm{C}
$$

Like the cover material over the waste site, the underlying waste exhibits a certain water-holding capacity. Fenn et al. (1975) note that the amount of water that can be added and stored in the waste material depends on the composition of the waste and its initial moisture content (which can vary widely) when delivered to the site.

Theoretically, water will move through a waste layer in much the same way as through a soil layer; the field capacity must be exceeded before the leachate will move. Practicaliy speaking, some channeling of water will occur, because of the heterogeneities associated with the waste, before field capacity is attained. 
In an effort to avoid the complexity associated with various waste forms, the RAPS methodology assumes that the moisture content of the waste equals field capacity. The moisture that infiltrates through the soil layer covering the waste is assumed to eventually exit at the bottom of the waste.

A complete description of the algorithms on which the source-term quantification is based for each of the steps highlighted above is provided by whelan et a1. (1987).

\section{2:2 Partially Saturated and Saturated Zones}

The groundwater component of the RAPS methodology accounts for the major mechanisms of constituent mobility (i.e., adsorption/desorption), persistence (i.e., degradation or decay), advection, and hydrodynamic dispersion. Mobility is described by an equilibrium coefficient that assumes instantaneous adsorption/desorption between the soil matrix and pore water. Persistence is described by a first-order degradation/decay coefficient; for radionuclides, the groundwater component of RAPS also accounts for decay products. Advection is described by constant, unidirectional flow in the vertical direction in the partially saturated zone and in the longitudinal direction in the saturated zone. Hydrodynamic dispersion is described in three dimensions.

Other assumptions associated with the groundwater component of RAPS include the following:

- All aquifer properties are homogeneous and isotropic.

- Flow in both the partially saturated and saturated zones is uniform.

- The groundwater environment is initially free of contamination.

- The effects of withdrawal well drawdown and other transient stresses on the saturated aquifer are not considered in the semianalytical solutions. Hydraulic gradients and flow velocities are assumed to be provided by the user.

The advective-dispersive equation for solute movement through a porous medium with constant, steady-state flow velocity forms the basis of all groundwater solution algorithms. As noted by Codell et al. (1982), the algorithms 
are developed for the limiting case of unidirectional advective transport with three-dimensional dispersion in a homogeneous saturated aquifer. Let $n$ and $n_{e}$ represent total and effective porosities, respectively; then $n-n_{e}$ is the remaining void fraction devoted to nonflowing waters. A mass balance on a differential volume $d V=d x d y d z$ gives the expression:

$$
\begin{aligned}
& n_{e} \frac{\partial C}{\partial t}+\left(n-n_{e}\right) \frac{\partial G}{\partial t}+(1-n) \frac{\partial P}{\partial t}+n_{e} u \frac{\partial C}{\partial x}= \\
& n_{e}\left(E_{x} \frac{\partial^{2} C}{\partial x^{2}}+E_{y} \frac{\partial^{2} C}{\partial y^{2}}+E_{z} \frac{\partial^{2} C}{\partial z^{2}}\right)+\left(n-n_{e}\right)\left[E_{x}^{\prime} \frac{\partial^{2} G}{\partial x^{2}}+E_{y}^{\prime} \frac{\partial^{2} G}{\partial y^{2}}+E_{z}^{\prime} \frac{\partial^{2} G}{\partial z^{2}}\right] \\
& -n_{e} \lambda C-(1-n) \lambda P-\left(n-n_{e}\right) \lambda G
\end{aligned}
$$

where $n_{e}=$ effective porosity (dimensionless)

$C=$ dissolved contaminant concentration in the liquid phase in the flowing voids $(\mathrm{g} / \mathrm{ml}$ or $\mathrm{Ci} / \mathrm{ml})(\mathrm{a})$

$n=$ total porosity (dimensionless)

$G=$ dissoived contaminant concentration in the liquid phase in the nonflowing voids $(\mathrm{g} / \mathrm{ml}$ or $\mathrm{Ci} / \mathrm{ml})$

$\mathrm{P}=$ particulate contaminant concentration in the solid phase $(\mathrm{g} / \mathrm{g}$ or $\mathrm{Ci} / \mathrm{g})$

$u=x$-component groundwater (pore water) velocity $(\mathrm{cm} / \mathrm{s}$ )

$E_{x}, E_{y}, E_{z}=$ dispersion coefficients in the $x, y$, and $z$ directions, respectively $\left(\mathrm{cm}^{2} / \mathrm{s}\right)$

$E_{x}^{\prime}, \bar{E}_{y}^{\prime}, E_{z}^{\prime}=$ diffusion coefficients in the nonflowing voids in the $x, y$, and $z$ directions, respectively $\left(\mathrm{cm}^{2} / \mathrm{s}\right)$

$\lambda=$ degradation/decay constant $[=(1 \cap 2) /($ hal $f-1$ ife $)]$.

$t=$ time

Equation (5.21) can be streamlined with some simplifying assumptions. One assumption is that the dissolved concentration in the nonflowing voids (G)

(a) When two sets of units are provided, the first refers to chemicals and the second refers to radionuclides. 
equals the dissolved concentration in the flowing voids (C). A second assumption is that the contaminant sorption process can be described by a constant (i.e., $K_{d}$ ) representing the ratio between the contaminant adsorbed to the soil matrix (i.e., P) and the contaminant dissolved in solution (C). A final assumption is that the diffusion in the nonflowing voids is comparable with the dispersion in the flowing voids. Using these assumptions, Equation (5.21) can be rewritten as

$$
\frac{\partial C}{\partial t}+u^{\star} \frac{\partial C}{\partial x}=D_{x}^{\star} \frac{\partial^{2} C}{\partial x^{2}}+D_{y}^{\star} \frac{\partial^{2} C}{\partial y^{2}}+D_{z}^{\star} \frac{\partial^{2} C}{\partial z^{2}}-\lambda C
$$

in which

$$
\begin{aligned}
D^{*} & =\frac{n}{n_{e}} \frac{E}{R_{f}} \\
R_{f_{l}} & =\frac{n}{n_{e}}+\frac{\beta}{n_{e}} K d \\
u^{*} & =u / R_{f}
\end{aligned}
$$

where $D_{x}^{*}, D_{y}^{*}, D_{z}^{*}=$ pseudodispersion coefficients in the $x, y$, and $z$ directions, respectively $\left(\mathrm{cm}^{2} / \mathrm{s}\right)$

$R_{f}=$ retardation factor (dimensionless)

$\beta=$ buik density $(\mathrm{g} / \mathrm{ml})$

$K_{d}=$ equilibrium (partition or distribution) coefficient $\left(\mathrm{cm}^{3} / \mathrm{g}\right)$.

Leachate in the saturated zone is assumed to move predominantly in the direction of the groundwater flow. Advection represents the transport of solute caused by the mass motion of water, while dispersion represents solute transport caused by unaccounted variations in the fluid velocity and molecular motion. Dispersion is considered in the longitudinal ( $x)$, lateral ( $y$ ), and vertical ( $z$ ) directions. Soil properties are assumed to be homogeneous, and the flow is assumed to be steady and only in the longitudinal direction. 
As written, Equation (5.22) specifically addresses the general conditions for flow and solute movement in the saturated zone. However, Equation (5.22) can also be applied to the partially saturated zone if minor modifications are made. To apply the equation to the partially saturated zone, the porosities (n and $n_{e}$ ) are assumed to be equal to the soil matrix moisture content. Onedimensional, unidirectional flow and dispersion are assumed to occur in only the vertical ( $z$ ) direction. The partially saturated soil beneath the waste site is assumed to be at a unit potential hydraulic gradient. The moisture content is assumed to fluctuate between field capacity and saturation. The hydraulic conductivity is based on an empirical equation published by Gardner (1960), Gardner et al. (1970), Campbell (1974), and Clapp and Hornberger (1978) and is expressed by Hillel (1980) as

$$
K(\theta)=K_{S}(\theta / n)^{1 / m}
$$

where $K(\theta)=$ hydraulic conductivity $(\mathrm{cm} / \mathrm{s})$

$$
\begin{aligned}
\mathrm{K}_{\mathrm{S}}= & \text { saturated hydraulic conductivity (i.e., permeability) }(\mathrm{cm} / \mathrm{s}) \\
\theta= & \text { moisture content (dimensionless) } \\
\mathrm{m}= & \text { empirically based parameter that is a function of soil } \\
& \text { properties. }
\end{aligned}
$$

Hillel (1980) notes that although attempts have been made to develop theoretically based equations relating hydraulic conductivity to moisture content, the state of the art is such that consistently accurate a priori predictions of $K(\theta)$ from basic soil properties have so far been difficult to attain. If the infiltration rate (leach rate) of water from the waste site is less than the soil transmission rate (i.e., hydraulic conductivity between field capacity and saturation), as described by the general equation for liquid flow in the partially saturated zone (see Hillel 1980; Hanks and Ashcroft 1980), the water moves through the soil at the infiltration rate, accounting for adjustments in the soil moisture content. When the infiltration rate is equal to or greater than the transmission rate of the soil, the leachate is assumed to move at the transinission rate. 
By solving Equation (5.22) with the appropriate boundary and initial conditions, a set of semianaiytical expressions representing concentrations for instantaneous contaminant releases at the source is obtained. The expressions characterize the transport of contaminants through the partially saturated and saturated groundwater zones. These expressions are based on Green's functions and have been reported by several researchers (Codell et al. 1982; Selim and Mansell 1976; Yeh 1981; Yeh and Tsai 1976). Various analytical expressions describing solute concentrations at selected locations and times can be described by one basic equation:

$$
C i_{\ell}=\alpha_{m} X_{i} Y_{j} Z_{k}
$$

in which

$$
a_{m}=1 /\left(R_{f} n_{e}\right)
$$

where $\mathrm{Ci}_{\ell}=i$-th instantaneous solute concentration at location $x, y, z$ and time $t$ for an instantaneous source release $\left(\mathrm{cm}^{-3}\right)(\mathrm{a})(\mathrm{b})$

$a_{m}=$ parameter that ensures mass balance and that is based on initial and boundary conditions

$x_{i}=$ Green's function in the $x$ direction for the $i$-th solution $\left(\mathrm{cm}^{-1}\right)$

$Y_{j}=$ Green's function in the $y$ direction for the $j$-th solution $\left(\mathrm{cm}^{-1}\right)$

$Z_{k}=$ Green's function in the $z$ direction for the $k$-th solution $\left(\mathrm{cm}^{-1}\right)$

Solutions for the advective-dispersive equations for the partially saturated and saturated zones have been formulated in terms of an instantaneous contaminant release (i.e., a pulse release over zero time). The RAPS methodology generalizes these solutions for arbitrary time-varying releases by convoluting response functions (i.e., temporally varying contaminant leach or flow rates) with instantaneous contaminant release solutions.

\footnotetext{
(a) Based on unit mass in grams.

(b) When used in an equation, " $\mathrm{C} i$ " refers to instantaneous solute concentration; otherwise, it refers to the units "curies."
} 


$$
C(\tau)=\int_{0}^{\tau} f(t) C i_{\ell}(\tau-t) d t
$$

where $\tau=$ the time over which contaminant concentration is computed (s)

$f(t)=$ source term expressed as a temporally varying contaminant flux $(\mathrm{g} / \mathrm{s}$ or $\mathrm{C} \mathrm{i} / \mathrm{s})$

Contaminant fluxes are computed to indicate the transfer of contaminants between successive media (e.g., between partially saturated layers or between partially saturated and saturated zones). The fluxes are computed when contaminants leave one medium (e.g., the groundwater environment) and act as boundary conditions to the next medium to be modeled (e.g., the surface water environment). The RAPS methodology can calculate the discharge rate of a contaminant entering a partially saturated layer, the saturated zone, and a surface water body. It is assumed that if the surface water body is the final transporting medium, then all contaminants entering the subsurface environment will eventually enter it, except for that portion of the contaminants lost through degradation/decay.

The RAPS methodology assumes a unidirectional flow field and bases its flux computations on contaminated material crossing an area perpendicular to the flow axis. Using the flow direction $(x)$ in the saturated zone as an example, the instantaneous flux perpendicular to the $x$ direction can be described by the following equation:

$$
\frac{d F i_{\ell}}{d A}=n_{e}\left(u C i_{\ell}-D_{x} \frac{\partial i_{\ell}}{\partial x}\right)
$$

in which

$$
D_{x}=\frac{n E_{x}}{n_{e}}
$$


where $F i_{\ell}=$ instantaneous contaminant flux resulting from an instantaneous contaminant release at the source $(\mathrm{g} / \mathrm{s}$ or $\mathrm{Ci} / \mathrm{s}$ )

$A=$ cross-sectional area perpendicular to the flow direction $\left(\mathrm{cm}^{2}\right)$

$D_{x}=$ psuedolongitudinal dispersion coefficient $\left(\mathrm{cm}^{2} / \mathrm{s}\right)$.

The total flux $\left(\mathrm{Fi}_{\ell}\right)$ across the plane is therefore described by laterally and vertically integrating Equation (5.30):

$$
F i_{\ell}=n_{e} \int_{0}^{n} \pi \int_{-\infty}^{+\infty}\left(u C i_{\ell}-D_{x} \frac{\partial i_{\ell}}{\partial x}\right) d y d z
$$

where $h_{m}=$ depth of the contaminant plume under fully mixed conditions (cm).

As in the case of instantaneous concentrations, these equations can be generalized for arbitrary time-varying releases by the use of the convolution integral, $F(\tau)$,

$$
F(\tau)=\int_{0}^{\tau} f(t) F \dot{i}_{\ell}(\tau-t) d t
$$

A more complete review of the mathematical algorithms describing the groundwater pathway is presented by Whelan et al. (1987).

\subsection{DEEP-DRAINAGE RATES AT THE HANFORD FACILITY}

The process of moisture movement into and through the partially saturated zone is one of the most difficult processes to describe with simplified approaches. As noted in Section 5.1, the process of water movement through a soil matrix is mechanistically complex and cannot be accurately described by a single set of regional hydrologic and hydrautic properties. While recognizing the difficulties associated with describing complex processes with simple approaches, whelan et al. (1987) have developed a methodology for estimating the fraction of precipitation that is lost to evapotranspiration, percolation (i.e., deep drainage), and overland runoff. (Section 5.2 describes this methodology in more detail.) 
Section 5.3 presents the results associated with the application of the methodology to the Hanford facility for estimating evapotranspiration, deep drainage, and runoff.(a) The results of the RAPS simulations are compared with other methods and with monitored data. Three additional sections follow this introduction to Section 5.3. First, the environmental setting at the Hanford facility is described. Next, a brief review of the input requirements is presented. Finally, results associated with estimating evapotranspiration rates and deep-drainage volumes at the Hanford facility are presented.

\subsubsection{Environmental Setting at the Hanford Facility}

This section presents a brief description of the environmental setting at the Hanford facility. Climatic conditions pertaining to the facility are described first, followed by a brief description of the hydrogeology of the region.

\subsubsection{Climatologic Summary of the Hanford Area (b)}

The Hanford area represents a mild and dry climate (Price et al. 1985). Vegetation at the Hanford facility (including the mountainous areas) consists mainly of sagebrush, rabbitbrush, bunchgrass, cheatgrass, and other semiarid plants. Few trees occur, except in isolated cultivated locations (Stone et al. 1983). The meteorologic information on which the annual percolation (i.e., deep drainage) rate calculations are based was collected at the Hanford Meteorology Station (HMS).

Stone et al. (1983) summarize meteorologic information from the HMS (c) from 1912 through 1980. Their information is based on records kept at the HMS from 1946 through 1980, supplemented with precipitation and temperature data taken by the U.S. Weather Bureau cooperative observers at a site about $16 \mathrm{~km}$ (10 mi) east-northeast of the HMS from 1912 to 1943. Monthly, annual, and historical summaries of the HMS data in the following categories are presented:

(a) No appreciable runoff occurs at the sites investigated.

(b) This section is based on Stone et al. (1983).

(c) The Hanford Meteorology Station is maintained for the U.S. Department of Energy by Pacific Northwest Laboratory, which is operated by Battelle Memorial Institute. 
- atmospheric surface temperatures

- subsoir temperatures

- precipitation

- tower wind speeds and direction

- sky cover, visibility, and solar radiation

- psychrometric data

- atmospheric pressure

- miscellaneous meteorologic phenomena (e.g., thunderstorm frequency)

- diffusion climatology

- persistence and extreme values of temperatures, wind speed, and precipitation

- meteorologic instrumentation.

The HMS is situated on a plateau on the Hanford facility (Figure 5.3). The plateau slopes downward toward the Columbia River about $16 \mathrm{~km}$ (10 $\mathrm{mi}$ ) north of the station and upward to the foothills of the Rattlesnake Mountains about $16 \mathrm{~km}$ (10 mi) south. Elevation of the station is $233 \mathrm{~m}$ (733 ft), which is roughly $90 \mathrm{~m}$ (300 ft) above the Columbia River to the north, and the latitude
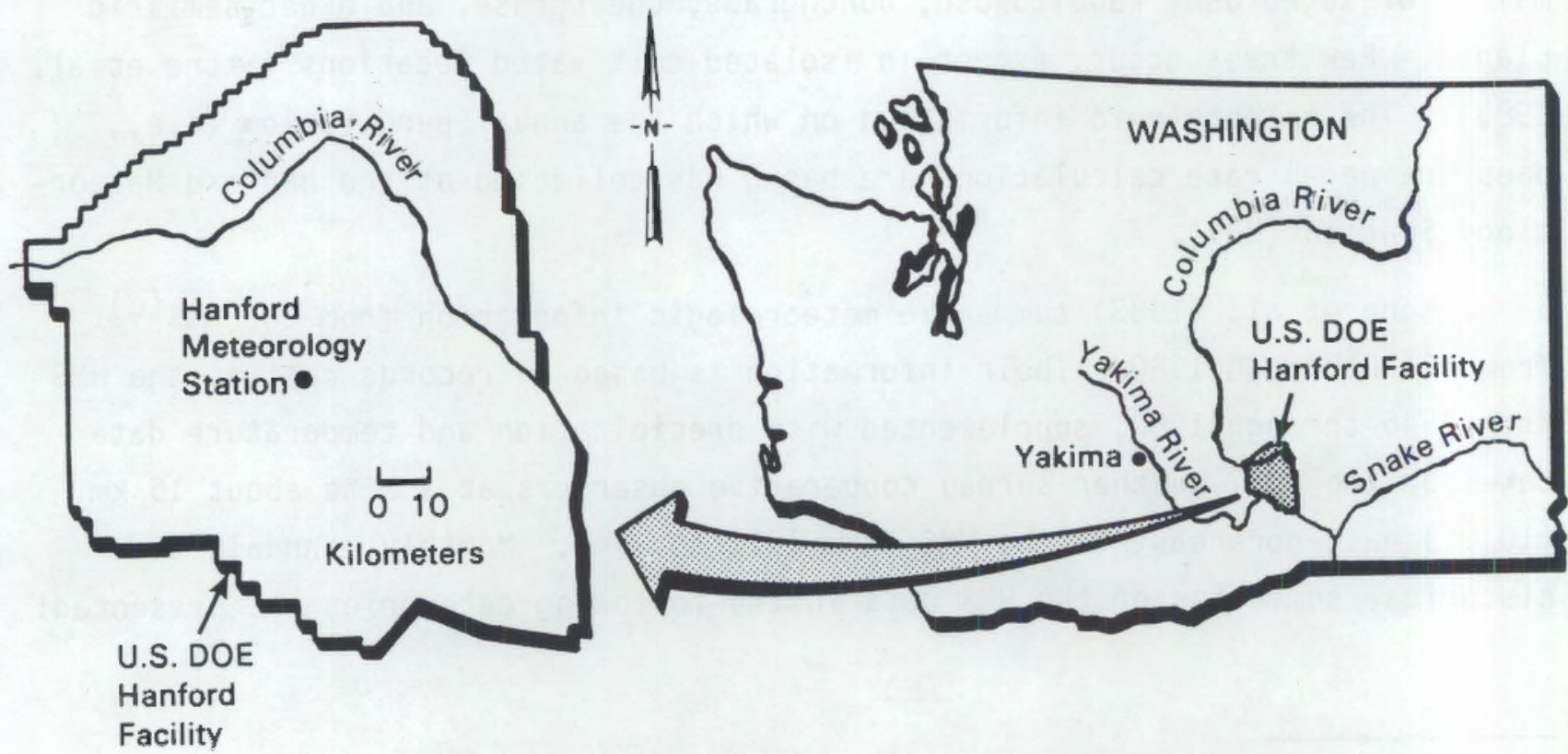

Hanford

FIGURE 5.3. Location of the Hanford Meteorology Station on the Hanford Facility 
and longitude of the station is $46^{\circ} 34^{\prime} N$ and $119^{\circ} 36^{\prime} W$, respectively. Both the Rattlesnake Mountains south and southwest of the station and the Yakima Ridge to the west rise to more than $1070 \mathrm{~m}$ (3500 ft), while the Saddle Mountains beyond the Columbia River to the north rise to more than $760 \mathrm{~m}(2500 \mathrm{ft})$.

Although not visible from the meteorology station, the Cascade Mountains greatly affect the climate of the Hanford Area. This mountain range is located beyond Yakima, Washington, to the west. Because the Hanford facility is in the rain shadow of these mountains, precipitation averages only $16 \mathrm{~cm}(6.3 \mathrm{in.})$ annually. Forty-four percent of the total precipitation occurs from November through January; only $12 \%$ of the total precipitation occurs from July through September. The number of precipitation events with volumes greater than $0.25 \mathrm{~mm}(0.01 \mathrm{in.})$ totals 68 , with $40 \%$ of these events occurring from November through January and only $12 \%$ occurring from July through September. Finally, approximately $38 \%$ of ali precipitation from December through February is snow.

The average annual temperature in the Hanford Area is $12^{\circ} \mathrm{C}\left(53^{\circ} \mathrm{F}\right)$; the average summer temperature is $22^{\circ} \mathrm{C}\left(72^{\circ} \mathrm{F}\right)$, and the average winter temperature is $1.1^{\circ} \mathrm{C}\left(34^{\circ} \mathrm{F}\right)$. Mountain ranges to the north and east shield the area from many of the arctic surges, and half of all winters are free of temperatures lower than $-18^{\circ} \mathrm{C}\left(0^{\circ} \mathrm{F}\right)$. Although temperatures reach $32^{\circ} \mathrm{C}\left(90^{\circ} \mathrm{F}\right)$ or above an average of 55 days per year, minimum temperatures of $21^{\circ} \mathrm{C}\left(70^{\circ} \mathrm{F}\right)$ or above occur only an average of 8 days a year. The lisual cool nights are a result of drainage (or gravity) winds.

Besides serving as a source for cool and cold air drainage (e.g., drainage winds), the Cascade Mountains also have a considerable effect on the wind regime at the Hanford facility. This drainage wind, along with topographic channeling, causes a considerable diurnal range in wind speed during the summer montins. In July, the average hourly wind speed ranges from a low of $2.3 \mathrm{~m} / \mathrm{s}$ $(5.2 \mathrm{mph})$ to a high of $5.81 \mathrm{~m} / \mathrm{s}(13.0 \mathrm{mph})$; in contrast, the corresponding speeds for January are 2.5 and $2.8 \mathrm{~m} / \mathrm{s}$ (5.5 and $6.3 \mathrm{mph}$ ), respectively. Average monthly wind speeds are lowest during the winter months and highest during the summer months with an average annual wind speed of $3.4 \mathrm{~m} / \mathrm{s}(7.7 \mathrm{mph})$. These wind speeds were recorded at a distance of $15 \mathrm{~m}$ (50 ft) from the ground surface. 
Although a complete summary of the meteorologic conditions are reported by Stone et al. (1983), only that portion of the data required to $i m p$ lement the RAPS methodology is summarized. Table 5.1 presents a summary of monthly average values for parameters required by RAPS.

\subsubsection{Surface Hydroyeologic Setting at the Hanford Facility}

The first geologic investigations of the Pasco Basin area (i.e., the region immediately surrounding the Hanford area) were made around the turn of the century by Russell (1903), Smith (1903), Calkins (1905), and Waring (1913). These efforts attempted to evaluate groundwater resources of the semiarid area of eastern Washington. Tallman et al. (1979) note that additional early studies of the soils (Kocker and Strahorn 1919), surface geology (Merriam and Budalda 1917; Bretz 1923), and hydrology (Parker and Piper 1949) were conducted in the hanford area.

The Hanford area is drained by the Yakima and Columbia Rivers (see Figure 5.3). Short-lived ephemeral streams that exist along the western margins of the site (e.g., Cold Creek and Ory Creek) may flow for a short period of time after a heavy rainfall or snownelt. The precipitation that falls on the flat landscape and infiltrates into the permeable sediments replenishes the soil moisture in the upper portion of the partially saturated zone. In this upper zone of the soil profile, the moisture is lost to evapotranspiration and deep drainage into the permeable surface fluvial and eolian sediments (Stone et al. 1972).

The surface fluvial and eolian sediments are represented by loess and sand dunes. These deposits are primarily reworked sediments of the "Hanford" Formation. The thickness of the wind-blown sediments varies considerably, ranging in thickness from zero to more than $9 \mathrm{~m}$ (30 ft) (Tallman et al. 1979). Underlying the surface sediments are glaciofluvial sediments of the Ringold Formation, informally called the Hanford Formation. The glaciofluvial sediments are divided into courser sand and gravel fractions (called Pasco Gravels) that were deposited throughout the Hanford area, and finer sand and silt units called Touchet Beds) that were deposited along the edge of the Pasco Basin. The thickness of the Hanford Formation varies but can be as much as $100 \mathrm{~m}$ (i.e., $300 \mathrm{ft}$ ) (Tallman et al. 1979). 
TABLE 5.1. Climatologic Summary for the Hanford Area (After Stone et al. 1983)

\begin{tabular}{|c|c|c|c|c|c|c|c|c|c|c|c|c|}
\hline \multirow[b]{2}{*}{ Parameter } & \multicolumn{12}{|c|}{ Month } \\
\hline & Jan. & Feb, & March & April & May & Jung & July & August & Sep. & oct. & Nor, & Dec, \\
\hline Temperature $\left({ }^{\circ} \mathrm{C}\right)$ & -1.5 & 2.4 & 7.3 & 11.7 & 16.4 & 20.7 & 24.7 & 23.5 & 18.4 & 11.7 & 4.3 & 0.4 \\
\hline Preclpitation (mm) & 23 & 15 & 9 & 10 & 12 & 14 & 4 & 6 & 8 & 14 & 22 & 23 \\
\hline wind speed $(\mathrm{m} / \mathrm{s})$ & 2.9 & 3.2 & 3.8 & 4.0 & 4.0 & 4.1 & 3.9 & 3.6 & 3.4 & 3.0 & 2.7 & 2.7 \\
\hline Cloudlness (tenths) & 7.9 & 7.6 & 6.8 & 6.4 & 5.9 & 5.3 & 2.9 & 3.4 & 4.1 & 5.8 & 7.7 & 8.1 \\
\hline Number of preclpitation events & 9 & 7 & 6 & 5 & 5 & 5 & 2 & 3 & 3 & 5 & 8 & 10 \\
\hline Maximum relative humldity (x) & 89 & 87 & 66 & 64 & 62 & 54 & 40 & 48 & 56 & 74 & 89 & 90 \\
\hline Minimum relative humldity (x) & 60 & 54 & 44 & 37 & 31 & 30 & 22 & 24 & 33 & 42 & 63 & 69 \\
\hline
\end{tabular}




\subsubsection{Application of RAPS for Estimating Deep Drainage at the Hanford}

Facility

To estimate the volume of water that may enter a waste site and exit as leachate, input parameters must be quantified. Before describing these input requirements, several terms should be defined:

- deep-drainage volume -- Deep drainage or percolation refers to the volume of water that percolates through the partialiy saturated zone that is not susceptible to evapotranspiration. Deep-drainage water eventually moves to the water table surface.

- infiltration volume -- Infiltration refers to the volume of water that passes through the soil surface and is susceptible to evapotranspiration and deep drainage.

- soil moisture capacity -- Soil moisture capacity is also comonly referred to as water-holding capacity or soil-holding capacity. It is defined as a multiple of the available water and the root-zone depth.

- availabie water -- The available water of a soil type is defined as the difference between the field capacity and wilting point.

The parameters required to estimate deep-drainage rates and volumes can be divided into two categories: monthly climatic information and nonclimatic information.

Climatic Information. The RAPS methodology requires the user to supply monthly information pertaining to temperature, precipitation, wind speed, cloudiness, number of precipitation events, and minimum and maximum relative humidity. These data were obtained from standard meteorologic summaries compiled at the HMS. This information is presented in Table 5.1. 
Nonclimatic Information. Nonclimatic information includes latitude, elevations of the weather station and the waste site, soil moisture capacity, overland runoff curve number, and height of the tower measuring wind speeds; this information is presented in Table 5.2. Each parameter is discussed below in more detail.

- latitude -- The latitude for a site on the Hanford facility can be estimated from a topographic map (e.g., USGS 7.5' topographic maps). Because of the central location of the HMS, the latitude associated with its location (i.e., 6.5 ) could be used (Stone et al. 1983).

- elevation of the HMS and the waste site -- The elevation of any site on the Hanford facility can be approximated from a topographic map (e.g., USGS 7.5' topographic maps). The elevation of the HMS is $223 \mathrm{~m}(733 \mathrm{ft}$ ) above sea level (Stone et al. 1983).

- soil moisture capacity -- The soil moisture capacity represents a parameter that can only be defined on a site specific basis. The parameter generally ranges in value from 25 to 400 mom (1 to $160 \mathrm{in.}$.). For more information on the soil moisture capacity, refer to Thornthwaite and Mather (1955, 1957).

- runoff curve number -- The runoff curve number was estimated as equal to 21. The curve number was deterinined from SCS $(1972,1982)$ and USBR (1977); its value was based on the following assumptions:

-- Type I antecedent moisture condition (i.e., warm and dry soils)

TABLE 5.2. Parameters Associated with the Hanford Facility as Required for RAPS

\begin{tabular}{ll}
\multicolumn{1}{c}{ Parameter } & $\frac{\text { Value }}{46.5^{\circ}}$ \\
Eatitude & $223 \mathrm{~m}(733 \mathrm{ft})$ \\
Elevation of weather station & Site specific \\
Soil moisture capacity & Site specific \\
Overland runoff curve number & 21 \\
Height of wind tower & $15 \mathrm{~m}(50 \mathrm{ft})$
\end{tabular}


-- hydrologic soil group A (i.e., high infiltration and low overiand runoff potentials)

-- good hydrologic conditions for potential overland runoff (e.g., not well forested and bare soil exposed to wind and water erosion)

-- pasture with no mechanical treatment

For more information on defining the curve number, see whelan et al. (1987).

- height of the wind tower -- This parameter refers to the height above the surface at which the wind speed measurements were collected. At the HMS, wind speeds were collected at $15 \mathrm{~m}(50 \mathrm{ft})$ (Stone et al. 1983).

\subsubsection{Results Associated with Estimating Evapotranspiration Rates and Deep-Drainage Volumes Using RAPS at the Hanford Facility}

This section presents the results from estimating evapotranspiration rates and deep-drainage volumes at the Hanford facility using the RAPS methodology. These results are then compared to other methods and monitored information, where available. This section is further divided into the following sections.

- comparison of techniques for computing potential and actual evapotranspiration in the Hanford area -- The evapotranspiration algorithms in RAPS are compared to other well-established, traditional techniques to test the applicability of the algorithms included in the RAPS methodology for computing evapotranspiration.

- comparison of long-term deep-drainage volumes estimated by RAPS with measured volumes at the Hanford facility -- This section presents a comparison of long-term deep-drainage volumes that have been measured in the Hanford area with those estinated by the RAPS methodology.

- comparison of 1983 deep-drainage volumes estimated by RAPS with measured volumes at a site on the Hanford facility -- This section presents a comparison of deep-drainage volumes that were measured at a site in the Hanford area during 1983 with those estimated by the RAPS 
methodology. In addition, observed evapotranspiration rates during 1983 and 1984 at a nearby site are compared to those predicted by RAPS.

\subsubsection{Comparison of Techniques for Computing Potential and Actual Evapotranspiration in the Hanford Area}

A hydrologic water balance (i.e., hydrologic budget) is employed in the RAPS methodology to estimate the annual volume of water, originating from precipitation and snowmeit, that percolates at a particular site. A hydrologic budget is a quantitative statement of the balance between total water losses and gains of an area, considering both surface and subsurface water. The most common components of a hydrologic budget include the following factors: precipitation, overland runoff, streamflow, evapotranspiration, and groundwater storage (Wallace 1978). Of these factors, Walton (1970), as reported by Wallace (1978), notes that evapotranspiration and soil moisture requirements have first priority on use of precipitation. Of these two factors, Wallace (1978) notes that soil moisture requirements are generally small compared to evapotranspiration.

As noted in Section 5.2, evapotranspiration is the most important parameter in the RAPS methodology when computing annual percolation volumes. Therefore, the algorithms in RAPS must reflect site conditions by simulating representative evapotranspirations. To test the applicability of the algorithms in the RAPS methodology for computing evapotranspiration, the algorithms are compared to other well-estabijshed, traditional techniques.

The purpose of this section is to use the long-term meteorologic observations that have been collected at the Hanford facility from 1912 to 1980 to compute and compare estimates of evapotranspiration using seven (a) approaches. Each approach is briefly described below.

- Thornthwaite-Mather -- This approach was developed to establish a relatively simple expression for evapotranspiration that would use readily available climatic data (Israelsen and Hansen 1962). The

(a) Note that the RAPS methodology is based on several of the approaches listed and does not constitute a new or independent technique. 
formula was developed on the postulate that temperature was a good index to energy. The Thornthwaite-Mather approach uses a heat index of monthly values based on the average temperatures for each month. In computing evapotranspiration, their approach addresses soil water deficits and water surpluses using soil moisture retention tables. For more information on this approach, refer to Thornthwaite and Mather $(1955,1957)$.

- Penman -- The Penman equation represents an energy balance approach that correlates evapotranspiration to the amount of radiative energy gained by a surface (Wallace 1978). The method is composed of an derodynamic term and an energy term; the relative importance of each term varies with climatic conditions. For more information on this approach, refer to Penman (1948) and Israelsen and Hansen (1962).

- Morton -- The Morton approach represents a modification of the original Penman formulation by revising the form of the psychrometric constant (Wallace 1978). This approach is based on the interactions between the evaporating surfaces and the temperature and humidity of the air passing just above the surface. This method assumes that evaporation is governed by the supply of radiation and water to the surface of the surrounding area (Wallace 1978). For more information, refer to Morton $(1971,1975,1976)$ and Wallace (1978).

- Modified Blaney-Criddle -- The original Blaney-Criddle equation (B1aney and Criddle 1950) involves calculating evapotranspiration from mean monthly temperature, percentage of total annual daylight hours occurring during the period under consideration, and an empirically derived crop coefficient. For a better definition of the effect of climate on vegetative requirements, Doorenbos and Pruitt (1977) present a modified version that includes more climatic data in the analysis. For more information, refer to Doorenbos and Pruitt (1977), Gee and Simmons (1979), and whelan et al. (1987).

- Radiation - The Radiation method is essentially an adaptation of the Makkink formula (Makkink 1957). As the name suggests, this method is based on the amount of incoming solar radiation (Doorenbos and Pruitt 
1977). For more information, refer to Makkink (1957), Gee and Simmons (1979), and Doorenbos and Pruitt (1977).

- Modified Penman with Correction Factor $\rightarrow$ This approach is identical to the Penman method except the equation is multiplied by a correction factor. This correction factor is an adjustment factor to compensate for the effects of day and night weather conditions. For more information refer to Doorenbos and Pruitt (1977), Gee and Simuons (1979), and whelan et a1. (1987).

- RAPS Methodology(a) -- The RAPS methodology uses the Penman, Modified Blaney-Criddle, and Modified Penman with Correction Factor in determining the evapotranspiration at a site. The RAPS methodology adjusts the input parameters to each of these approaches by considering differences that exist between the station where data are collected and the site where the analysis is being applied. Following an adjustment of the input parameters (e.g., temperature and wind speed differences caused by differences in elevations), RAPS then applies these three methods to the site and chooses the method that provides the most conservative results. For more information, see Whelan et al. (1987).

As indicated above, numerous methods have been developed to estimate evaporation from wet plant and soil surfaces. During periods when surfaces are sufficiently wet, evaporation proceeds to a maximum or potential rate (Gee and Simrions 1979). When plants are included in the surface, the concept of potential evapotranspiration (PET) is used. Gee and Simmons (1979) note that according to Rosenburg (1974)

"Potential evapotranspiration (PET) is the evaporation from an extended surface of short green crop which fully shades the ground, exerts little or negligible resistance to the fiow of water, and is always well supplied with water. Potential evapotranspiration cannot exceed free water evaporation under the same weather conditions."

(a) Note that the RAPS methodology is based on several of the approaches 1 isted and does not constitute a new or independent technique. 
Gee and Simmons (1979) continue to note that under arid conditions, PET rates are seldom achieved, because surfaces are most often dry or drying, and vegetation is sparse. Virtually all evapotranspiration models, including the ones mentioned in this section, are based on the PET concept.

Gee and Simmons (1979) and Wallace (1978) compare various combinations of the above six approaches (excluding RAPS) with Hanford area climatologic data. Gee and Simmons (1979) compare four of the approaches to Hanford climatic data for the years 1947 and 1948. These years (i.e., 1947 and 1948) were chosen because 1) their annual precipitation volumes were nearly equal; 2) their total annual precipitations were above average $[23.5$ and $24.1 \mathrm{~cm}$ (9.25 and 9.49 in.), respectively]; and 3) their rainfall distribution patterns were completely different. Figures 5.4 and 5.5 show the cumulative PET at the Hanford site based on data from the HMS for the years 1947 and 1948, respectively.

These figures demonstrate the applicability of the techniques upon which the RAPS methodology is based (i.e., Modified Blaney-Criddle, Modified Penman, and Penman); as such, results from the RAPS methodology are not presented in these figures. The results of this analysis indicate that, except for the Penman method, all other approaches yield the same cumulative PET (Gee and Simmons 1979).

Wallace (1978) compared three of the techniques listed above (i.e., Penman, Morton, and Thornthwaite-ilather) on long-term, historical data collected at the HMS. The data used in the analysis corresponded to long-term average climatic values from 1912 to 1970. Figure 5.6 presents the monthly estimated PET for each of the three techniques. For comparison, the results from a simulation using the RAPS methodology is also included. The RAPS results are based on historical data collected at the HMS for the time period corresponding to 1912 to 1980; these data differ little from those associated with 1912 to 1970 .

Potential evapotranspiration does not provide one with the amount of water that has evaporated and transpired; its calculation is important, though, because it estimates the actual evapotranspiration, which is used in calculating the deep-drainage volume at a site. Figure 5.7 presents a comparison of estimated actual evapotranspiration values for the Thornthwaite-Mather, Morton, 


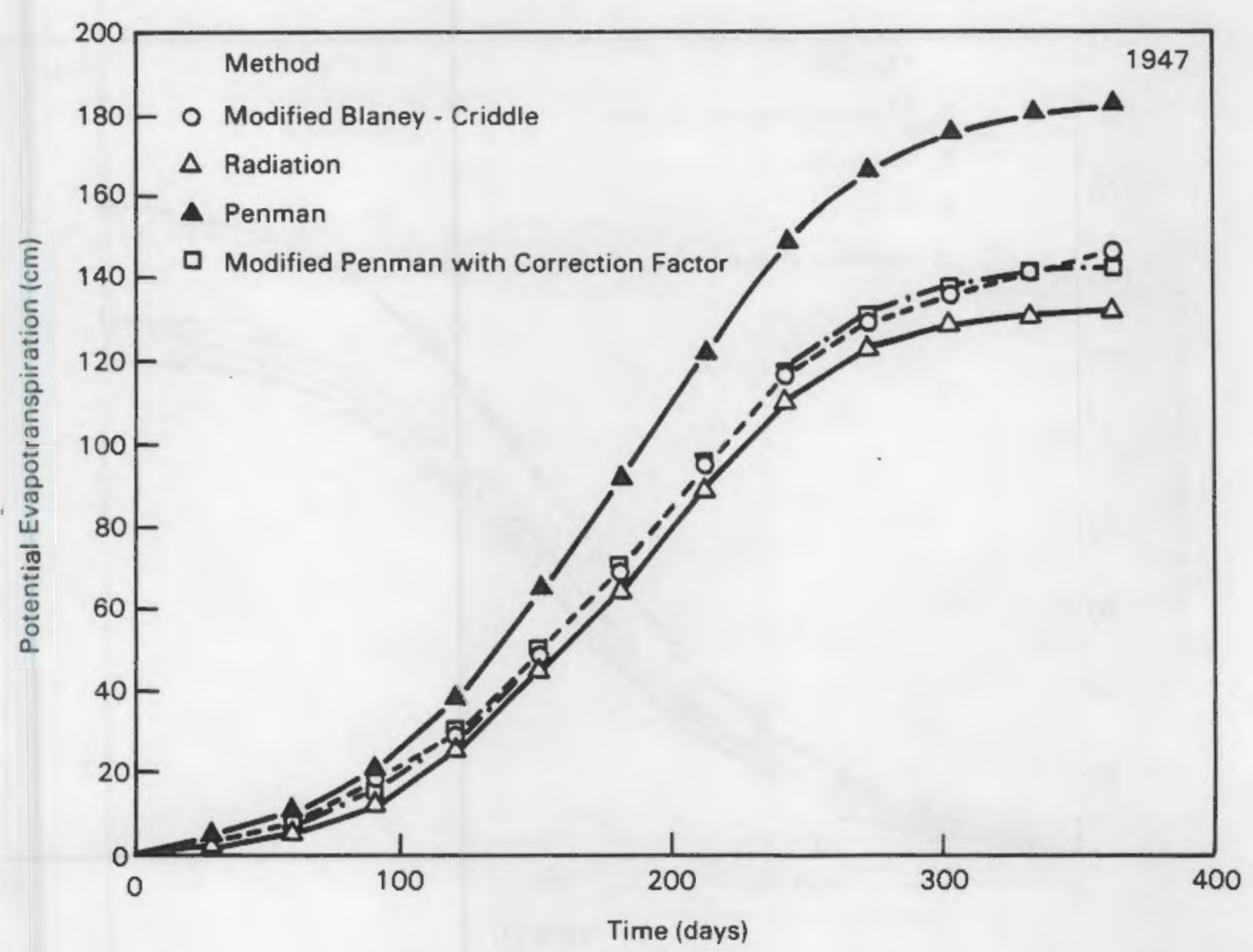

FIGURE 5.4. Cumulative Potential Evaporation by Four Methods for 1947 (After Gee and Simmons 1979)

and RAPS approaches. The first two approaches are based on HMS climatic data for the period 1912 to 1970, while the latter approach corresponds to the HMS climatic data for the period 1912 to 1980.

\subsubsection{Comparison of Long-Term Deep-Drainage Volumes Estimated by RAPS with Measured Volumes at the Hanford Facility}

This section (and Section 5.3.3.3) presents a comparison of long-term deep-drainage volumes that have been measured in the Hanford area with those estimated by the RAPS methodology. With this comparison, we can qualitatively demonstrate the applicability of applying the RAPS methodology to a semiarid or arid environment. This demonstration is important because many of the 


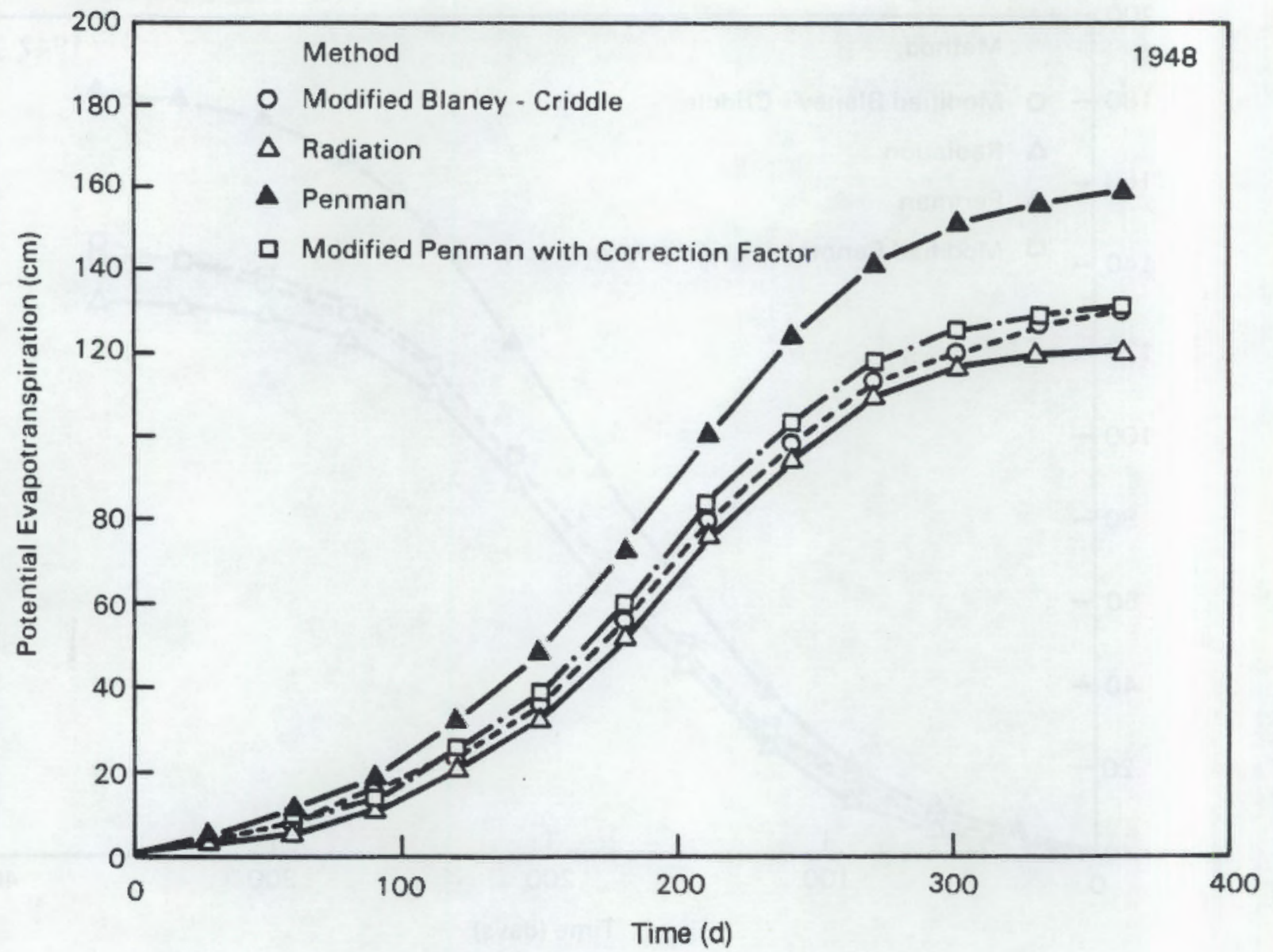

FIGURE 5.5. Cumulative Potential Evaporation by Four Methods for 1948 (After Gee and Simmons 1979)

techniques used in this analysis were originally developed for humid environments in which these methods have been shown to apply.

Gee and Jones (1985) note that recharge at the Hanford facility is known to vary, depending on the interrelationships of soil, plant, and climatic variables. Water that is not recycled by root water uptake or evaporation moves through the subsurface soil to the water table as recharge. Soil and vegetative types can significantly influence the ability of a waste site to impede the movement of water through the site. For example, the soil moisture capacity of a clay soil is larger than that of a coarse sandy soil, therefore resulting in a greater ability to "hold" more of the moisture, assuming all other conditions are equivalent. 


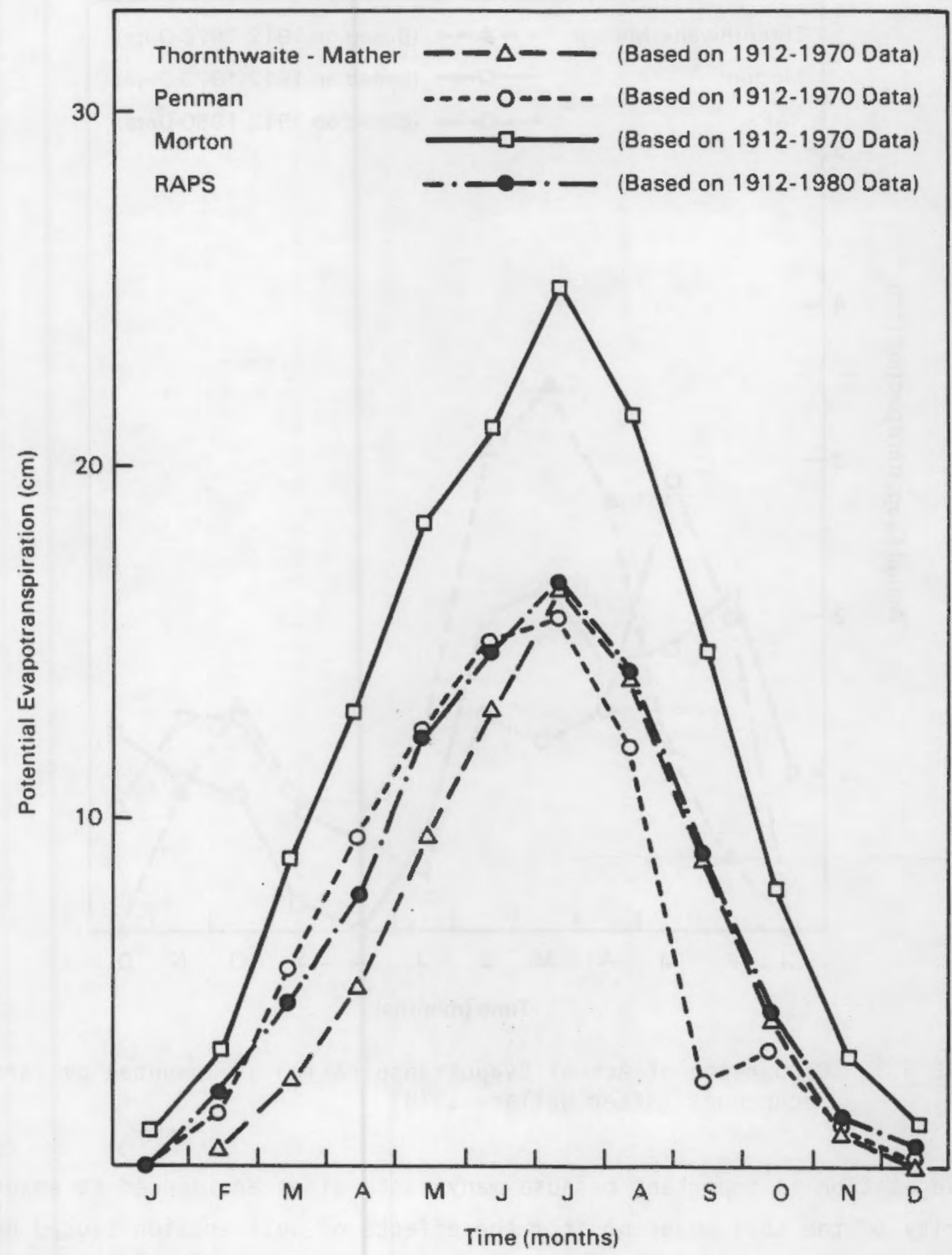

FIGURE 5.6. Comparison of Various Techniques for Estimating Potential Evapotranspiration (After Wallace 1978) 


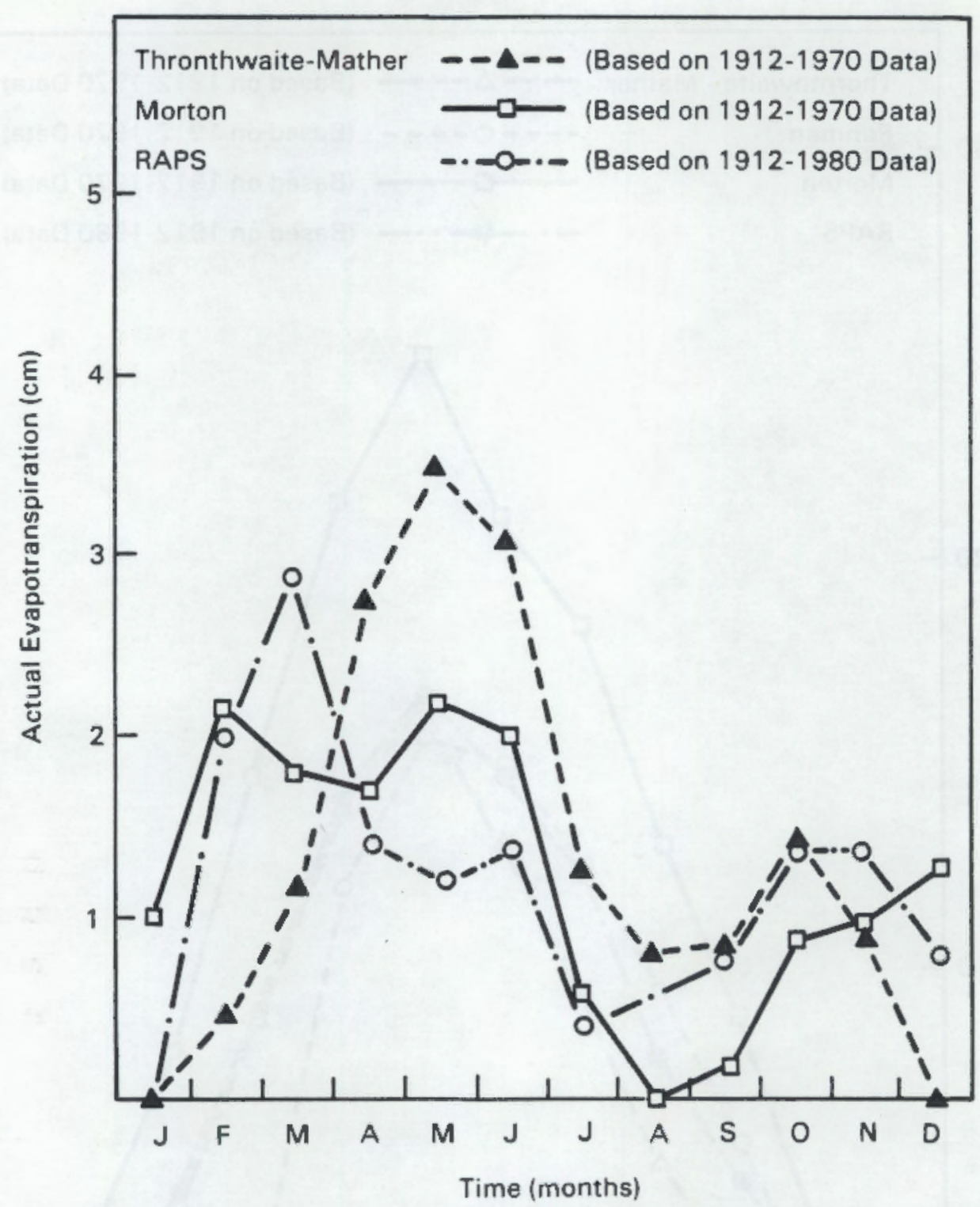

FIGURE 5.7. Comparison of Actual Evapotranspiration as Computed by Various Techniques (After Wallace 1978)

Vegetation is important because many waste sites are seeded to ensure the integrity of the soil covering from the effects of soil erosion caused by water and wind. However, the type of vegetation can affect the volume of water that reaches and passes through the waste. Deep-rooted vegetation (e.g., Russian thistle) can significantly increase a soil's moisture capacity over that of 
shallow-rooted vegetation (e.g., certain grasses). At many sites, shallowrooted grasses are used to stabilize the soil covering because the roots cannot reach the waste site proper.

Because of the variety in soil and vegetation types that exist in the Hanford area, a single value defining the deep drainage (i.e., recharge) through the soil is not possible. Gee and Jones (1985) estimate that the annual water recharge to the water table at the Hanford facility varies from 0 to $8.5 \mathrm{~cm}$ ( 0 to $3.3 \mathrm{in.}$ ), and these estimates depend on climatic conditions as well as soil and vegetative coverings. Table 5.3, as compiled by Gee and Jones (1985), shows estimates of recharge at a number of arid areas, including Hanford.

The RAPS methodology estimates deep drainage at the Hanford facility using the approach outlined in Section 5.2 and by whelan et al. (1987). As noted in Section 5.3.2, RAPS requires the user to supply monthly information pertaining to temperature, precipitation, wind speed, cloudiness, number of precipitation events, and minimum and maximum relative humidity; this information is presented in Table 5.1. Other information includes latitude, elevation of the weather station and the waste site, soil moisture capacity, overland runoff, curve number, and height of the tower measuring wind speeds; this information, except for the soil moisture capacity, is presented in Table 5.2.

The results of applying the RAPS methodology to the data sets outlined in Tables 5.1 and 5.2 are presented in Figure 5.8. The results are based on the elevation of the waste site equaling that of the HMS. Based on the RAPS analysis, Figure 5.8 shows the soil moisture capacity versus the deep-drainage volume curve for the Hanford area. As this figure indicates, the volume of water that is available to percolate through the partially saturated zone to the water table is a function of the moisture capacity of the soil. As noted in Section 5.3.2, the soil moisture capacity is a function of the available water (i.e., field capacity minus wilting point) and root zone depth.

Table 5.4 presents an example calculation for estimating the averageannual deep-drainage volume at the Hanford facility for a soil with a moisture capacity of $2.5 \mathrm{~cm}$ ( $1 \mathrm{in.)}$. These results (i.e., Table 5.4) are structured to coincide with the fourteen steps outlined in Section 5.2. For soil with a soil 
TABLE 5.3. Reported Estimates of Recharge at Selected Arid Sites [sources reported in Gee and Jones (1985)]

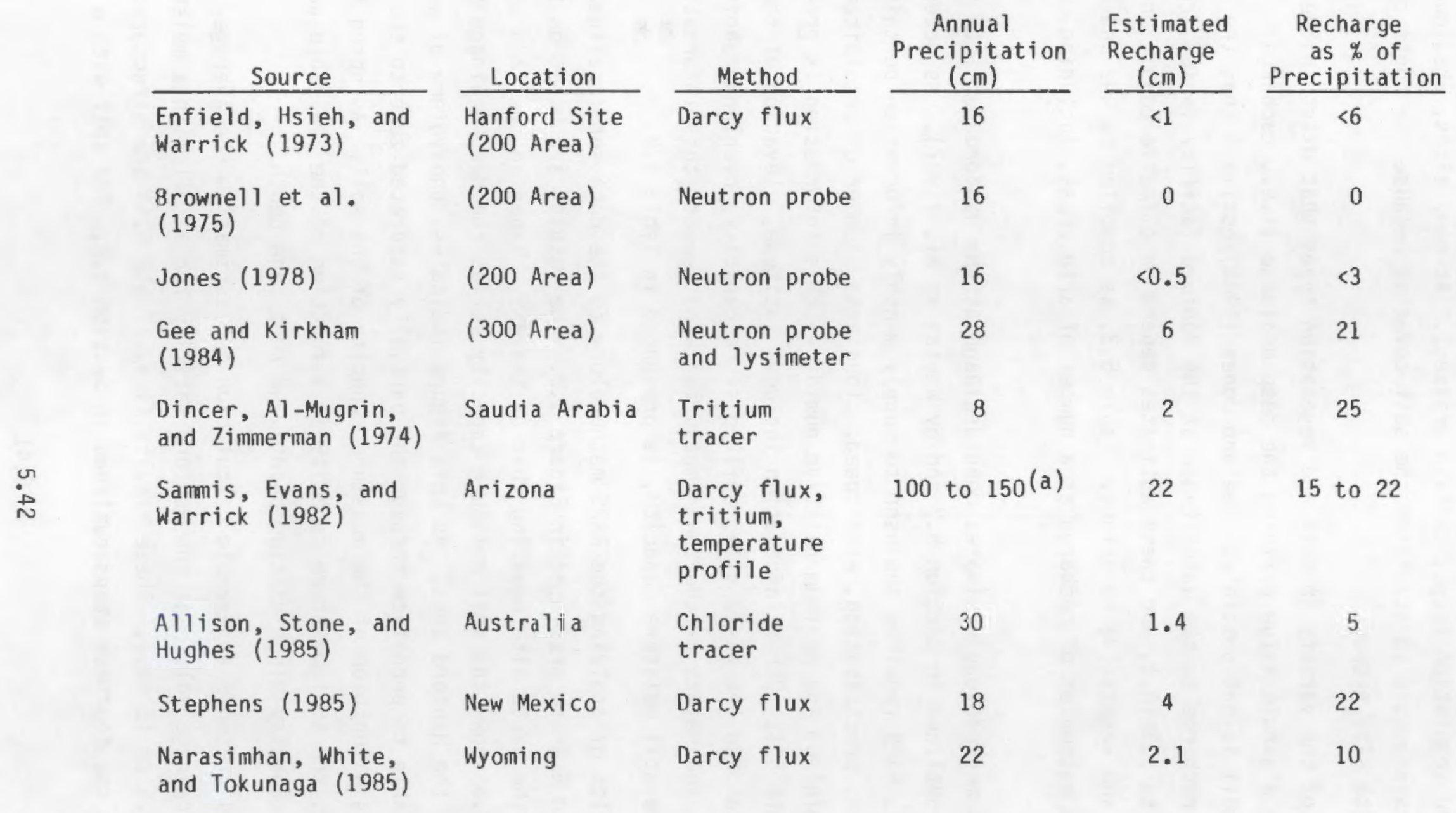

(a) Includes irrigation. 


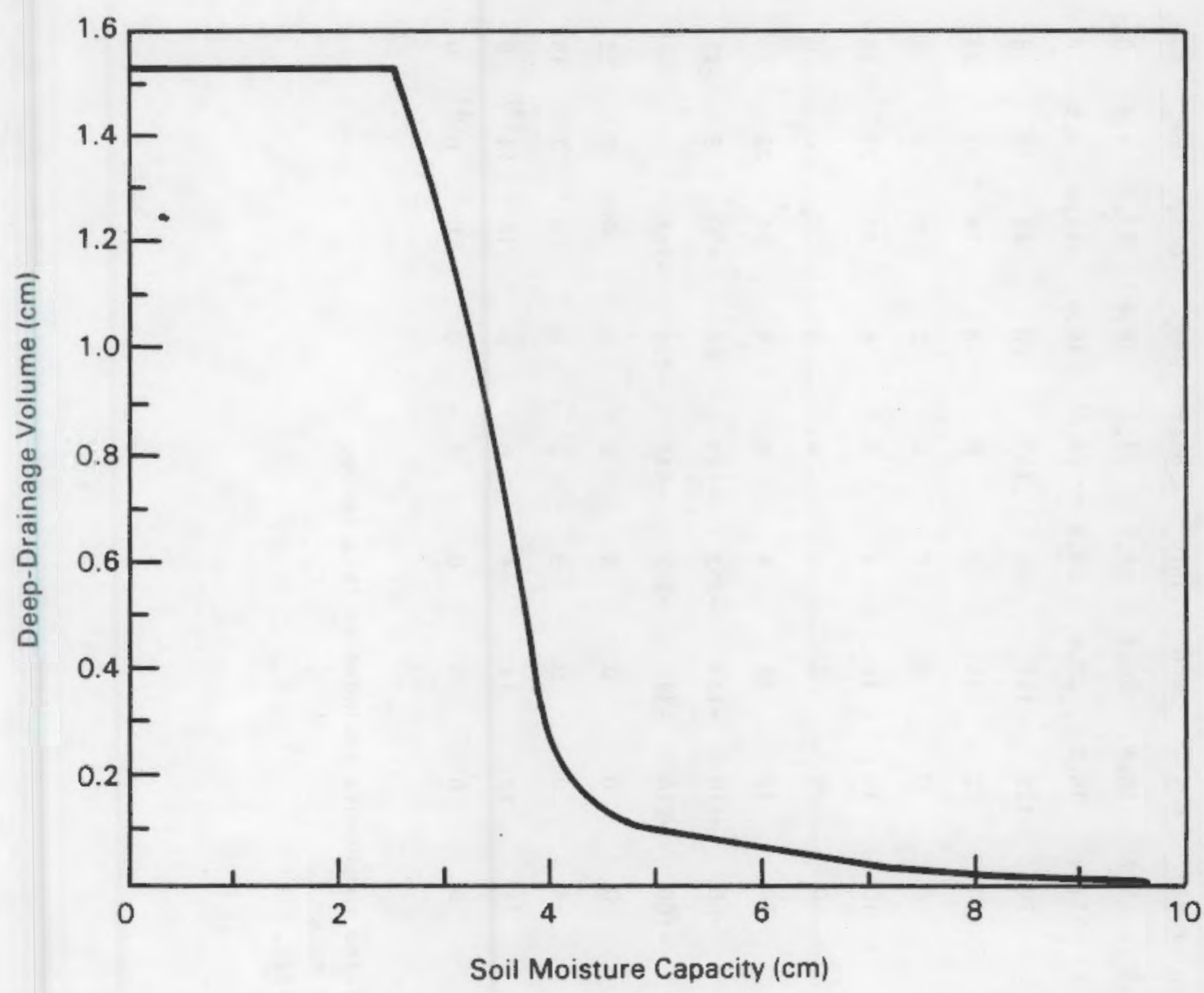

FIGURE 5.8. Soil Moisture Capacity Versus Deep-Drainage Volume at the Hanford Facility Using Historical (1912 to 1980) Hanford Meteorology Station Climatic Data

moisture capacity of $2.5 \mathrm{~cm}$ (1 in.), the results indicate that the long-term, average-annual, deep-drainage rate at this site in the Hanford facility is estimated as $1.5 \mathrm{~cm} /$ year ( $0.59 \mathrm{in./year)}$.

The results, presented in Figure 5.8 and Table 5.4, of the RAPS analysis qualitatively match the recharge values, reported by Gee and Jones in Table 5.3, for the Manford area for annual average precipitation of $16 \mathrm{~cm}$ (6.3 in.). Section 5.3.3.3 provides a quantitative comparison between measured, site-specific deep-drainage volumes and volumes simulated by the RAPS methodology. 


\section{TABLE 5.4. Average Annual Infiltration Volume Calculations Using the RAPS
Methodology at the Hanford Facility}

\begin{tabular}{|c|c|c|c|c|c|c|c|c|c|c|c|c|}
\hline \multirow[b]{2}{*}{ Parameter } & \multicolumn{12}{|c|}{ Month } \\
\hline & Jen. & feb. & March & April & May & June & July & August & Sep. & Oct. & Nov. & Dec. \\
\hline Unadjusted temperature & $-1.5^{(b)}$ & 2.4 & 7.3 & 11.7 & 16.4 & 20.7 & 24.7 & 23.5 & 18.4 & 11.7 & 4.3 & 0.4 \\
\hline Adjusted temperature & -1.4 & 2.5 & 7.4 & 11.9 & 16.5 & 20.9 & 24.8 & 23.6 & 18.6 & 11.8 & 4.5 & 0.5 \\
\hline Potentlal evapotranspiration & $0^{(b)}$ & 20 & 47 & 78 & 122 & 147 & 166 & 139 & 88 & 44 & 14 & 8 \\
\hline Precipltation as rainfall & 0 & 15 & 9 & 10 & 12 & 14 & 4 & 6 & 8 & 14 & 22 & 23 \\
\hline Preclpitation as snowfall & 23 & 0 & 0 & 0 & 0 & 0 & 0 & 0 & 0 & 0 & 0 & 0 \\
\hline Precipltation adjusted for snowmelt & 0 & 39 & 9 & 10 & 12 & 14 & 4 & 6 & 8 & 14 & 22 & 23 \\
\hline Overland runof $f$ & 0 & 0 & 0 & 0 & 0 & 0 & 0 & 0 & 0 & 0 & 0 & 0 \\
\hline Maximum potential Inflitration & 0 & 39 & 9 & 10 & 12 & 14 & 4 & 6 & 8 & 14 & 22 & 23 \\
\hline Potentlal infiltration & 0 & 19 & -38 & -68 & -110 & -133 & -162 & -133 & -80 & -30 & 8 & 15 \\
\hline Accumulated potential water loss & & $(-1)^{(c)}$ & -38 & -106 & -216 & -349 & -512 & -644 & -725 & -754 & & \\
\hline Soll molsture storage & 22 & 25 & 4 & 0 & 0 & 0 & 0 & 0 & 0 & 0 & 7 & 22 \\
\hline Change in soll molsture storage & 0 & 3 & -21 & -4 & 0 & 0 & 0 & 0 & 0 & 0 & 7 & 15 \\
\hline Actual evapotransplration & 0 & 20 & 29 & 14 & 12 & 14 & 4 & 6 & 8 & 14 & $14^{(d)}$ & 8 \\
\hline Infiltration volume & 0 & $15^{(d)}$ & 0 & 0 & 0 & 0 & 0 & 0 & 0 & 0 & $0^{(d)}$ & 0 \\
\hline
\end{tabular}

(a) See Whelan et al. (1987) for a complete explanation of the components Included in this table.

(b) Values in units of ${ }^{\circ} \mathrm{C}$ for temperature and $\mathrm{mm}$ for other terms.

(c) Starting point for accumulating negative water potentlals.

(d) Based on numbers that have been rounded of $f$. 


\subsubsection{Comparison of 1983 Deep-Drainage Volumes Estimated by RAPS with Measured Volumes at a Site on the Hanford Facility (a)}

Gee and Kirkham (1984) conducted a field study to measure and predict water movement under vegetated and bare soil at two nearby sites on the Hanford facility. This section describes their work and compares their measured results for deep drainage with those simulated by the RAPS methodology.

Description of the experiments conducted by Gee and Kirkham (1984). The years 1983 and 1984 are considered to be wet years in the Hanford area. Rainfall volume during 1983 was $28.1 \mathrm{~cm}$ (11.1 in.) and exceeded the long-term historical average $[15.9 \mathrm{~cm}(6.26 \mathrm{in.})]$ by 177\%; above-normal precipitation at the Hanford facility continued through the first half of 1984, exceeding the long-term average by 131\%. They note that in 1983, January, February, March, November, and December accounted for nearly $75 \%$ of the annual precipitation. To illustrate the dramatic change in the amount of precipitation, Figure 5.9 presents the temporal distribution of precipitation over the months of the year for 1) 1912 through 1980 as collected at the HMS, 2) 1983 as collected at the HMS, and 3) 1983 as collected at the vegetated site (the Grass Site).

The data used in the experiments conducted by Gee and Kirkham (1984) were collected by recording precipitation events; monitoring other meteorological variables, including air temperature, humidity, and wind speed; measuring the water content of the soil profile; and measuring evapotranspiration losses from lysimeters at the nearby Buried Waste Test Facility (BWTF) site. Additional climatic data, including solar radiation, were obtained from the HMS for 1983 and 1984. A climatic summary for 1983 as compiled at the HMS is presented in Table 5.5; only those parameters required as input to the RAPS methodology are presented.

The Grass Site is located in a slight depression that is approximately $900 \mathrm{~m}$ (3000 ft) wide and several thousand meters (a couple of

(a) This section is based on Gee and Kirkham (1984). 


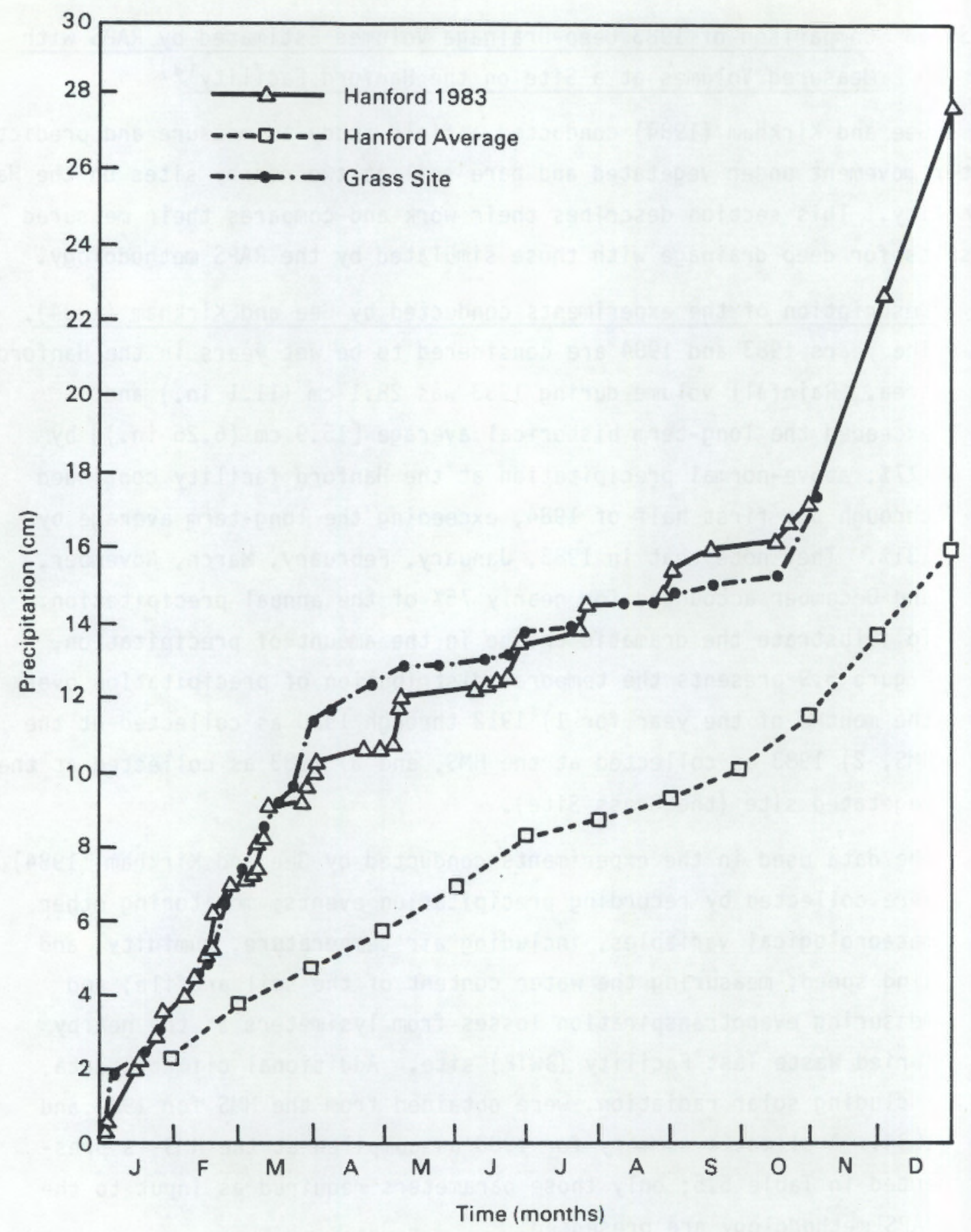

FIGURE 5.9. Precipitation at Grass Site and Hanford Meteorology Station During 1983 (After Gee and Kirkham 1984) 
TABLE 5.5. 1983 Climatologic Summary for the Hanford Area

\begin{tabular}{|c|c|c|c|c|c|c|c|c|c|c|c|c|}
\hline \multirow[b]{2}{*}{ Parameter } & \multicolumn{12}{|c|}{ Month } \\
\hline & Jan. & Feb. & March & Aprll & May & June & July & August & Sep. & oct. & Nov. & Dec. \\
\hline Temperature $\left({ }^{\circ} \mathrm{C}\right)$ & 3.1 & 4.9 & 9.2 & 10.8 & 17.7 & 18.6 & 21.8 & 23.6 & 16.5 & 11.4 & 6.4 & -6.0 \\
\hline Preclpitation (mm) & 37 & 35 & 25 & 11 & 13 & 17 & 8 & 3 & 12 & 13 & 54 & 54 \\
\hline WInd speed $(\mathrm{m} / \mathrm{s})$ & 3.2 & 3.4 & 3.9 & 3.6 & 4.8 & 4.8 & 4.8 & 4.0 & 3.7 & 2.5 & 3.5 & 2.5 \\
\hline Cloudiness (tenths) & 8.4 & 8.4 & 7.5 & 5.3 & 5.4 & 6.2 & 5.0 & 4.7 & 3.0 & 5.6 & 8.1 & 8.2 \\
\hline Number of precipitation events & 10 & 15 & 10 & 4 & 3 & 8 & 5 & 5 & 2 & 4 & 18 & 15 \\
\hline Average relative humldity (s) & 81.7 & 83.5 & 68.0 & 50.9 & 34.9 & 36.6 & 37.4 & 37.9 & 41.6 & 51.9 & 68.1 & 75.4 \\
\hline
\end{tabular}


miles) long. Several years ago, a range fire removed vegetation from the site, and brush growth now appears only at the burn area perimeter. The grasses that reappeared are typical of disturbed areas at the Hanford Site and are primarily cheatgrass and Sandburg bluegrass, comprising 35 and $27 \%$ of the total cover, respectively. Grass roots were not found below $1 \mathrm{~m}(3 \mathrm{ft})$.

Gee and Kirkham (1984) describe the soil as well drained and nearly uniform to a depth of $3.5 \mathrm{~m}(11.5 \mathrm{ft})$. The top $60 \mathrm{~cm}(2 \mathrm{ft})$ contain $79 \%$ sand, $17 \%$ silt, and $4 \%$ clay and is classified as a sandy loam; the next $2.9 \mathrm{~m}(9.5 \mathrm{ft})$ contain $92 \%$ sand, $5 \%$ silt, and $3 \% \mathrm{clay}$. A rock-gravel layer exists below this depth. Although a detailed description of the site without vegetation (the Bare Site) was not provided, they did classify it as having a sandy soil.

Gee and Kirkham (1984) measured evapotranspiration rates with the north and south weighing lysimeters located at the BWTF, $2 \mathrm{~km}$ (1.2 $\mathrm{mi}$ ) north of the Grass Site. The north weighing lysimeter was located on a bare soil surface, and the south weighing lysimeter was located on a surface covered with vegetation similar to that at the Grass Site. A complete description of the operation of these lysimeters as well as the details of the experiments is presented in Gee and Kirkham (1984).

Application of RAPS to the Grass and Bare Soil Sites for 1983 and 1984. The RAPS methodology was applied to the Grass and Bare Soil Sites described by Gee and Kirkham (1984) using the meteorological summaries compiled by the HMS for the years 1983 and 1984. The input requirements to RAPS are reviewed as follows:

- climatic data -- The climatic data for 1983 are presented in Table 5.5 .

- elevation of the test site and the HMS -- The elevation of the test site was approximated from a topographic map published by 
Tallman et al. (1979); the elevation of the site was estimated at $150 \mathrm{~m}(500 \mathrm{ft})$ above sea level. The elevation of the HMS is $223 \mathrm{~m}$ (733 ft) above sea level (Stone et al. 1983).

- runoff curve number -- The runoff curve number was estimated at 21. The curve number was determined from SCS (1972, 1982) and USBR (1977) using the assumptions outlined in Section 5.3.2. For more information on defining the curve number, see Whelan et al. (1987).

Because no calibration is necessary to apply the RAPS methodology, the data listed above represent the only requirements to implement RAPS.

Deep-Drainage volume results for 1983. Results associated with the RAPS analysis (i.e., solid line) are presented in Figure 5.10. This figure presents soil moisture capacity versus deep-drainage volume at the Grass and Bare Soil Sites in 1983 and is not associated with Table 5.4, although Table 5.4 presents example calculations for Hanford using average-annual climatic conditions from 1912 through 1980. To estimate the deep-drainage rates at these sites, the soil moisture capacity has to be estimated.

For the Grass Site, a field capacity of $13 \%(a, b)$ is estimated from a soil moisture release curve for Hanford area soils, developed by Sisson and Lu (1984); a wilting point of $5 \%(a, b)$ is estimated from Sisson and Lu (1984); and a root zone depth of $1 \mathrm{~m}(3 \mathrm{ft}$ ) is estimated from Gee and Kirkham (1984). From this information, the soil moisture capacity for the Grass Site is estimated as $8 \mathrm{~cm}$ ( $3 \mathrm{in.}$ ). Because the soil at the Bare Soil Site is classified as sandy and, more importantly, is void of vegetation (and, therefore has no root zone), the soil moisture capacity of the soil at the Bare Soil site defaults to $2.5 \mathrm{~cm}$ ( 1 in.). Based on these assumptions, the

(a) This value correlates with those in other references, such as Israelsen and Hansen (1962), Eagleson (1970), and Hanks and Ashcroft (1980).

(b) Suction head versus moisture content. 


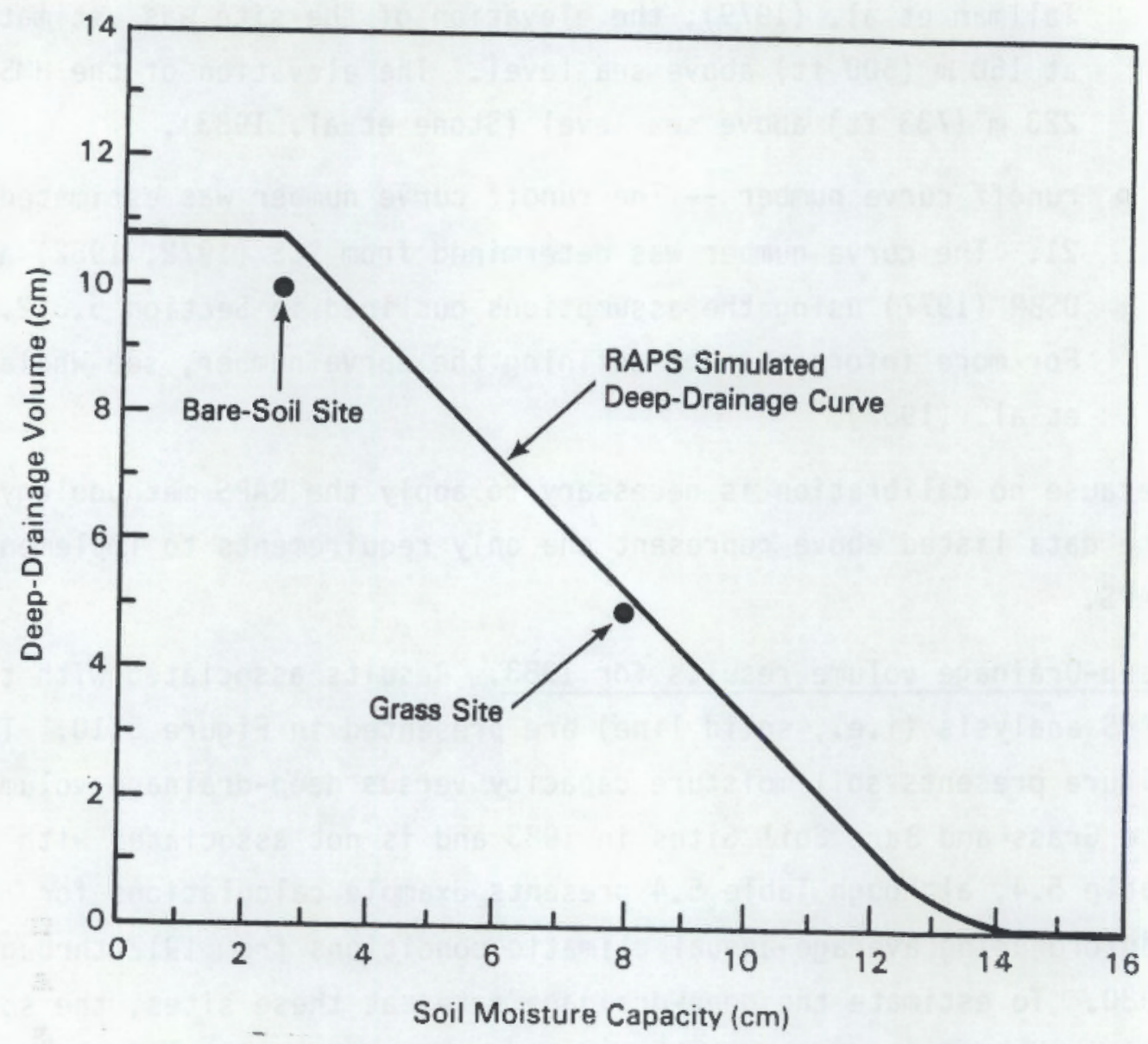

FIGURE 5.10. Soil Moisture Capacity Versus Deep-Drainage Volume at the Grass and Bare-Soil Sites on the Hanford Facility Using 1983 Hanford Meteorology Station Climatic Data

deep-drainage volumes at the Grass and Bare Soil Sites during 1983, as simulated by the RAPS methodology (see Figure 5.10), are estimated as $5.3 \mathrm{~cm}(2.1 \mathrm{in.})$ and $10.8 \mathrm{~cm}(4.25 \mathrm{in.})$, respectively.

Gee and Kirkham (1984) summarize their findings in the following:

Both direct measurements of actual drainage and indirect measurements of changes in moisture profiles confirmed that water moves below the root zone and is lost to deep drainage during periods of low evapotranspiration. Measurements indicated at that over $10 \mathrm{~cm}$ of drainage occurred during a 1-year period from bare sandy soil and over $5 \mathrm{~cm}$ of drainage from a grass-covered field site. 
Results of their analyses (i.e., data points) are plotted on Figure 5.10 .

Deep-drainage volume results for June 1983 through May 1984. Gee and Kirkham (1984) also measured deep-drainage volumes over the 1-year period from June 1983 through May 1984. For comparison with the Grass Site, they monitored the water that drained from the south weighing lysimeter at the BWTF site for the June 1983 through May 1984 test period. Although soil type and vegetation are slightly different at the BWTF and Grass Site, Gee and Kirkham (1984) note that water loss patterns should be similar. They also noted that for this 1-year period, "over $6 \mathrm{~cm}$ of drainage was measured at the SWL (south weighing lysimeter), in qualitative agreement with the fieldmeasured ... drainage for the grass site."

The RAPS methodology was also applied to the Grass Site for the period June 1983 through May 1984. Except for climatic data, the same input that was used for the 1983 calendar year simulation was used for this simulation. The climatic data were updated to include January 1984 through May 1984; this information is presented in Table 5.6. By again assuming a soil moisture capacity of $8 \mathrm{~cm}$ ( $3 \mathrm{in.}$ ), RAPS estimated the deep-drainage volume at this site to be $1 \mathrm{~cm}(0.4 \mathrm{in.})$. For the Bare Soil Site with a soil moisture capacity

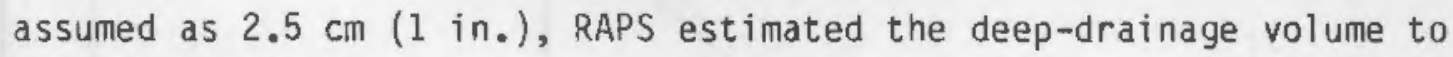
be $6.4 \mathrm{~cm}(2.5 \mathrm{in.})$.

TABLE 5.6. Climatologic Summary for the First 5 Months of 1984 for the Hanford Area

\begin{tabular}{|c|c|c|c|c|c|}
\hline Parameter & January & February & March & April & May \\
\hline Temperature $\left({ }^{\circ} \mathrm{C}\right)$ & -0.2 & 3.7 & 8.4 & 10.3 & 13.3 \\
\hline Precipitation (mm) & 6 & 24 & 26 & 15 & 14 \\
\hline Wind Speed (m/s) & 2.5 & 2.8 & 3.3 & 4.1 & 4.0 \\
\hline Cloudiness (tenths) & 7.1 & 8.4 & 6.7 & 6.8 & 6.4 \\
\hline Number of precipitation events & 4 & 14 & 12 & 5 & 7 \\
\hline Average relative humidity $(\%)$ & 74.7 & 67.3 & 58.1 & 49.5 & 44.3 \\
\hline
\end{tabular}


Actual evapotranspiration results. The actual evapotranspiration rates predicted by the RAPS methodology from June 1983 through May 1984 are compared with the evapotranspiration rates measured in the south weighing lysimeter at the BWTF Site. Gee and Kirkham (1984) published actual evapotranspiration rates only for the months January 1984 through April 1984. Figure 5.11 presents a comparison of the observed and simulated actual evapotranspiration rates for the first 4 months of 1984 .

Summary. Because of soil and plant characteristics, the results obtained by Gee and Kirkham (1984) are specific to the field piots studied. Although the RAPS methodology addresses these particular

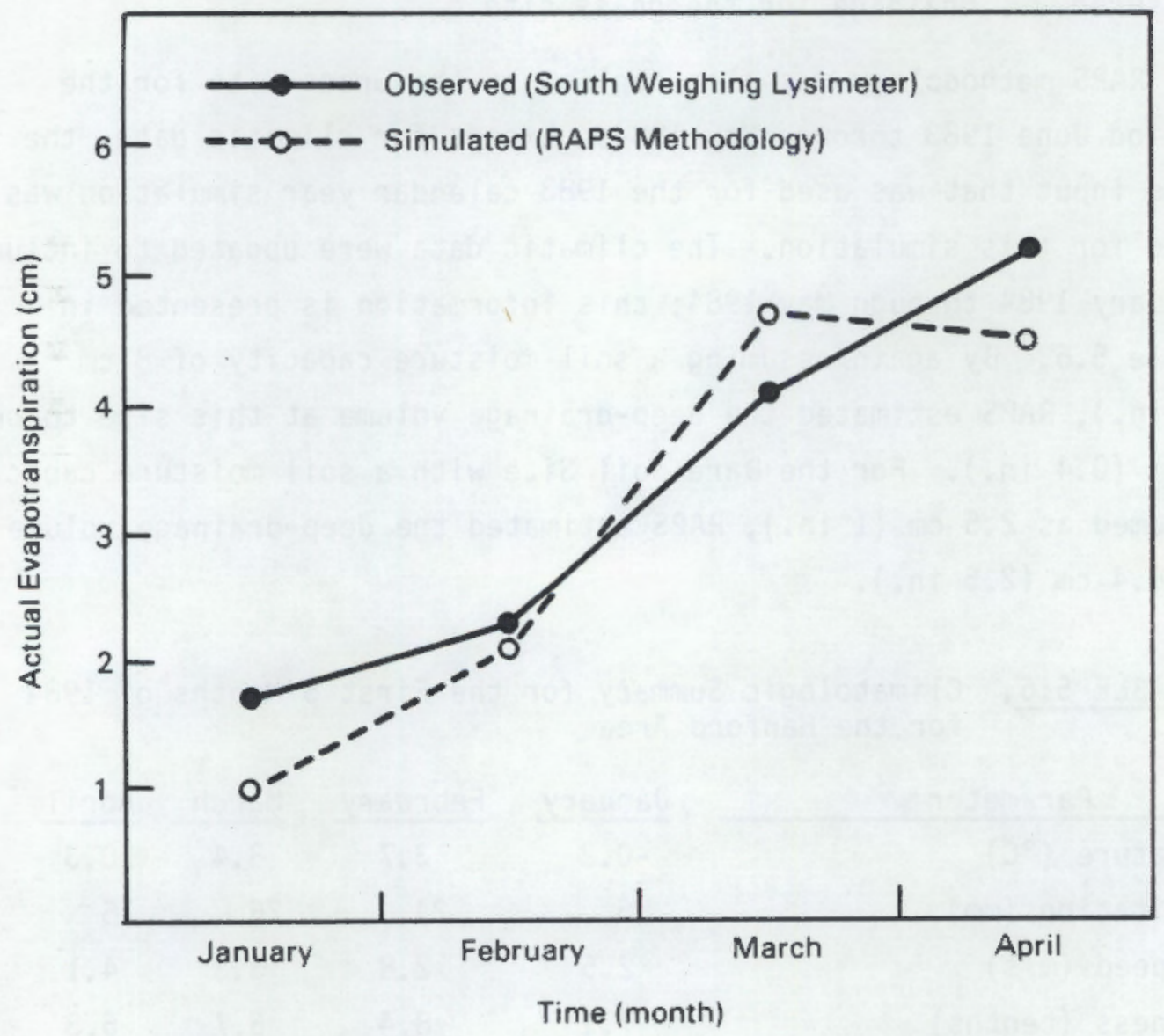

FIGURE 5.11. Comparison of Observed and Simulated Actual Evapotranspiration for the First 4 Months of 1984 at the Burial Waste Test Facility Site on the Hanford Facility 
sites also, RAPS represents a more general analysis and can only differentiate sites at Hanford facility through the soil moisture capacity parameter. In addition, although the simulated results of RAPS appear to reflect the conditions at the Hanford facility, the RAPS calculations are too coarse to accurately compute, in any consistent manner, deep-drainage patterns at various locations at the Hanford facility. It must be remembered that the RAPS methodology is composed of components that describe, in a very simple manner, highly complex phenomena associated with moisture movement in the partially saturated zone.

5.4 APPLICATION OF THE RAPS METHODOLOGY TO THE PARTIALLY SATURATED ZONE AT SITE 216-Z-1A

The 216-Z-1A waste disposal site at DOE's Richland Operations (i.e., Hanford) facility in Richland, Washington, is used to demonstrate the applicability of the partially saturated zone component of the RAPS methodology. The location of the 216-Z-1A waste site at the Hanford facility is shown in Figure 5.12. This site was selected for demonstration purposes because of the availability of information pertaining to construction, disposal history, and known spacial and temporal distributions of radionuclides beneath the site. The sections to follow describe the 216-Z-1A site and outline the results of previous studies performed to characterize the movement of contaminants below the site. The parameters used in the application of the methodology are described and quantified, and a comparison between monitored and simulated contaminant concentrations in the partially saturated zone beneath the $216-2-1 \mathrm{~A}$ site is presented.

\subsubsection{Description of Site 216-Z-1A}

The 216-z-1A underground disposal site was constructed in 1949 to receive radioactive waste generated from the analytical and development laboratories and process operations in the $Z$ plant (see Figure 5.12). The 216-Z-1A disposal site, described by Price et al. (1979), used an underground crib (i.e., a liquid dispersal system) to deposit liquid waste in cobble and coarse, sandy soil. The crib consisted of a tile drain field of 20-cm-diameter (8-in.-diameter) 


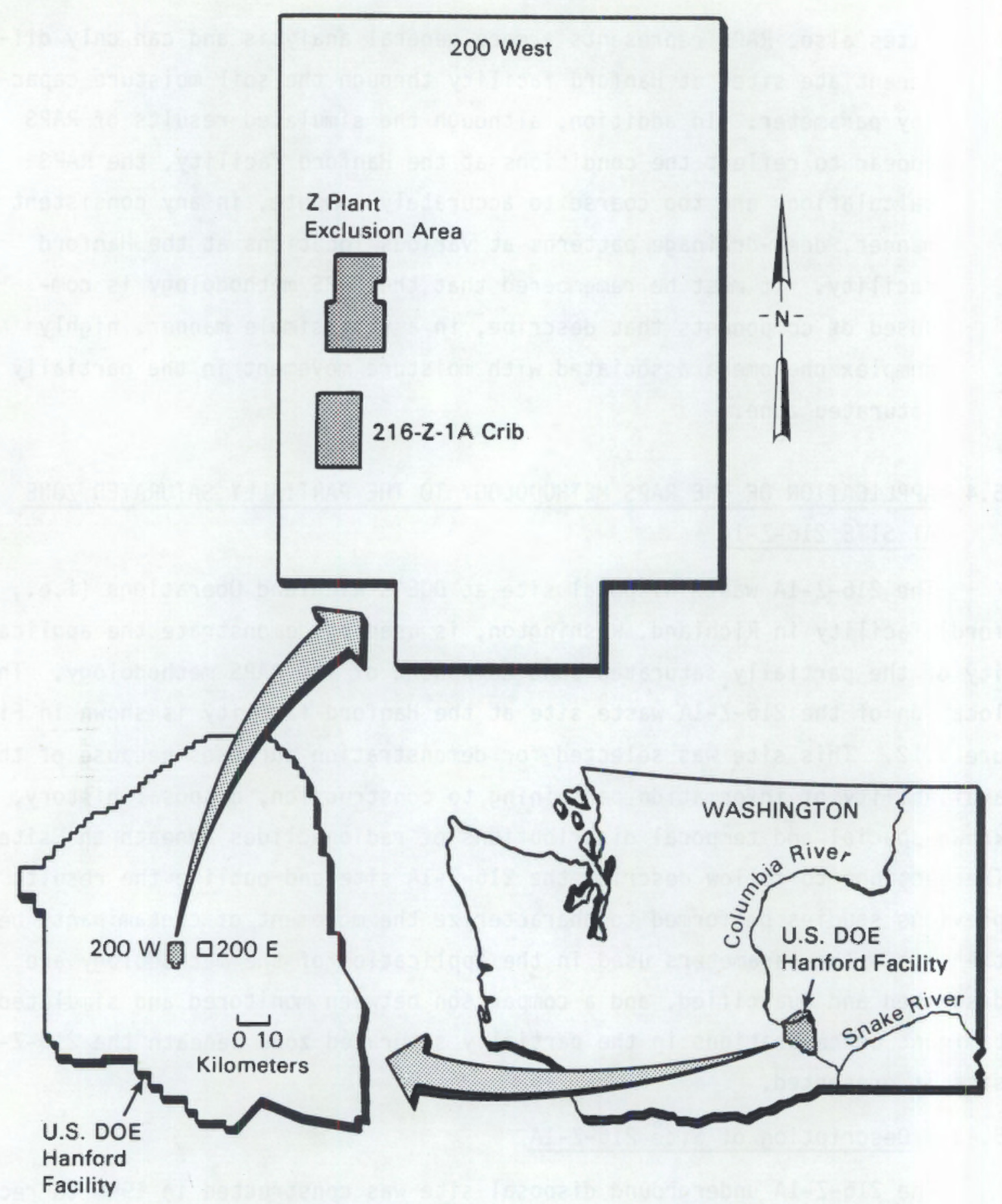

FIGURE 5.12. Location of the 216-2-1A Waste Site at the Hanford Facility 
vitrified clay pipe placed in a herringbone pattern. A continuous 79-m-long (260-ft-long) central distribution pipe, which connected fourteen 21-m-long (69-ft-long) secondary laterals, was segmented at 0.3-m (10-ft) intervals. The tile field rested on $1.2 \mathrm{~m}(3.9 \mathrm{ft})$ of cobble with a minimum slope of $1 \%$ and was overlain with $15 \mathrm{~cm}(5.9 \mathrm{in.})$ of cobbles and $1.5 \mathrm{~m}(4.9 \mathrm{ft})$ of sand and gravel (see Figure 5.13). The site excavation covered an area $60-m(200-f t)$ wide, $110-\mathrm{m}$ (360-ft) long and 5.8-m (9.2-ft) deep. Sloping side walls reduce the drain field floor to an area 35 by $84 \mathrm{~m}$ (120 by $280 \mathrm{ft}$ ). A layer of polyethylene covered by $30 \mathrm{~cm}$ (12 in.) of sand and gravel was added to the site in 1964 to prevent upward migration of waste liquid.

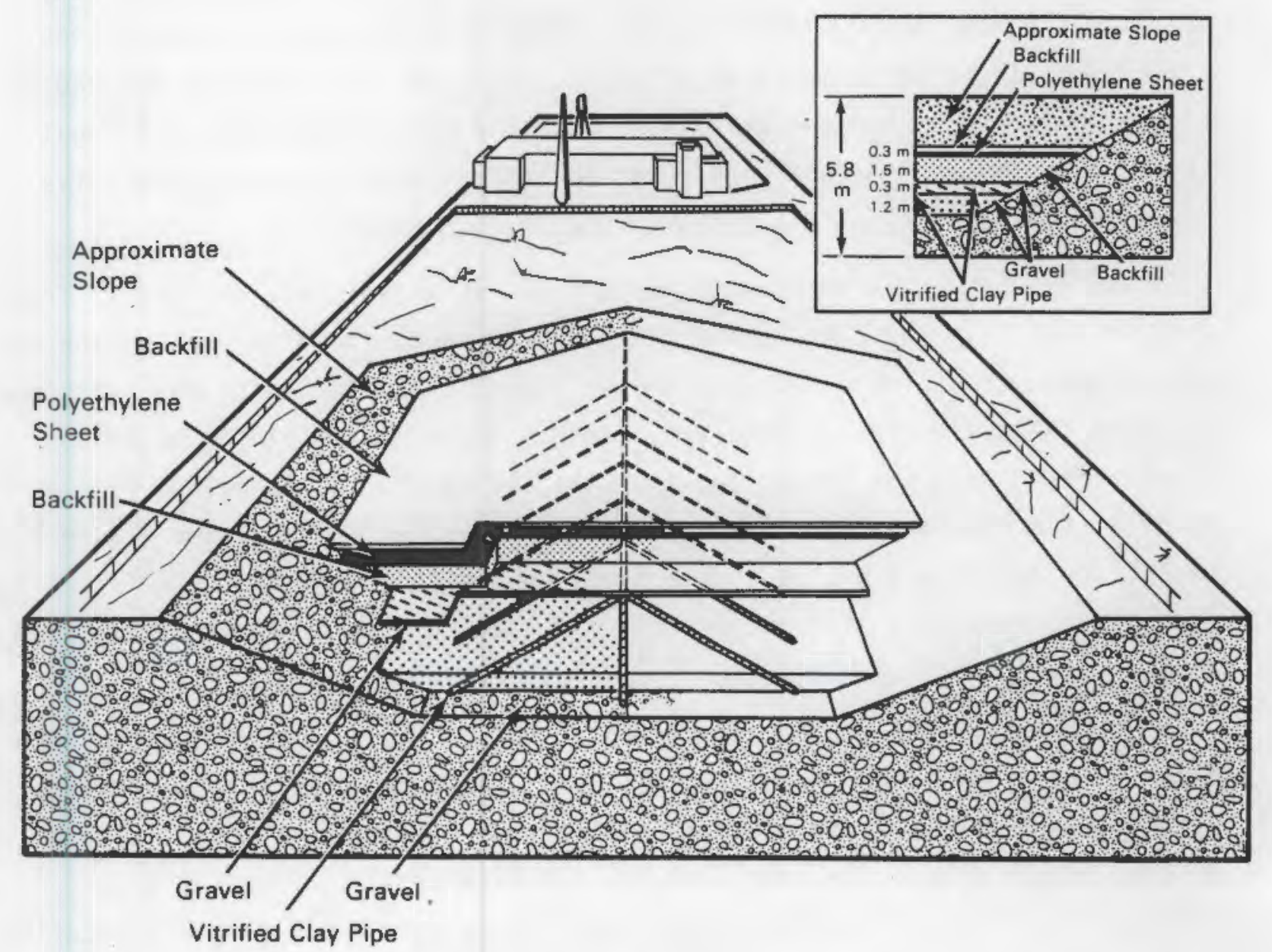

FIGURE 5.13. 216-Z-1A Crib Construction Details (After Price et al. 1979) 
From 1949 to 1959 the 216-Z-1A site received overflow from the 241-Z-361 settling tank via three adjacent underground cribs: $216-Z-1,216-Z-2$ and 216-Z-3 (Price et al. 1979; Kasper et al. 1979). An estimated $50 \mathrm{~g}$ (0.11 1b) of plutonium was disposed of to the 216-Z-1A crib along with 106 ( $2.64 \times$ $10^{5} \mathrm{gal}$ ) of a dilute, basic, aqueous solution. The site was inactive from 1960 until 1964, when it was reactivated to receive aqueous and organic waste from the Plutonium Reclamation Facility located in $\mathrm{Z}$ plant. This waste was a concentrated solution of nitrates with an average pH of 1.0 and was disposed of directly to the $216-\mathrm{Z}-1 \mathrm{~A}$ crib. From 1964 to $1969,57 \mathrm{~kg}$ (125.7 1b) of plutonium-239,240 and $1 \mathrm{~kg}(2.2 \mathrm{lb})$ of americium-241 were disposed of in $5.2 \times$ $10^{6}$ । $\left(1.37 \times 10^{6} \mathrm{gal}\right)$ of waste containing less than $5 \%$ organic waste, primarily carbon tetrachloride $\left(\mathrm{CCl}_{4}\right)$, tributylphosphate (TBP), and dibutyl butyl phosphonate (DBBP) (Price et al. 1979). The site was closed in 1969 after receiving a lifetime total of $57.05 \mathrm{~kg}(125.8 \mathrm{lb})$ plutonium-239,240 and $1 \mathrm{~kg}(2.2 \mathrm{lb})$ americium-241 released in 6.2 million liters $\left(1.63 \times 10^{6}\right.$ gal) of liquid waste. The $216-Z-1 A$ site received the nighest estimated cumulative transuranic inventory of all cribs on the Hanford Site.

The liquid wastes entered the tile field at three different points from 1964 to 1969. In 1966, the point of entry was moved from the head of the central distribution pipe (i.e., Point $A$ in Figure 5.14) to bypass the first onethird of the drain field. This was accomplished by installing a stainless steel pipe through the overburden and into the central distribution pipe at Point B (see Figure 5.14). The entrance was moved to Point C (see Figure 5.14) in 1967 to distribute wastes in the lower one-third of the drain field. A summary of the inventory of contaminants released from the tile field from 1949 to 1969 is presented in Table 5.7 .

Characterization studies performed on the 216-Z-1A crib (Price and Ames 1976; Price et a1. 1979; Kasper et al. 1979) indicate some movement of both plutonium-239,240 and americium-241 beneath the site. Numerous wells were drilled in and around the crib site for the 1979 study by Price et al. (1979). Figure 5.14 presents a plan view of the tile field and well locations at the 216-Z-1A site. The samples collected at this site were analyzed for their geological and radiological characteristics. The geological analysis 


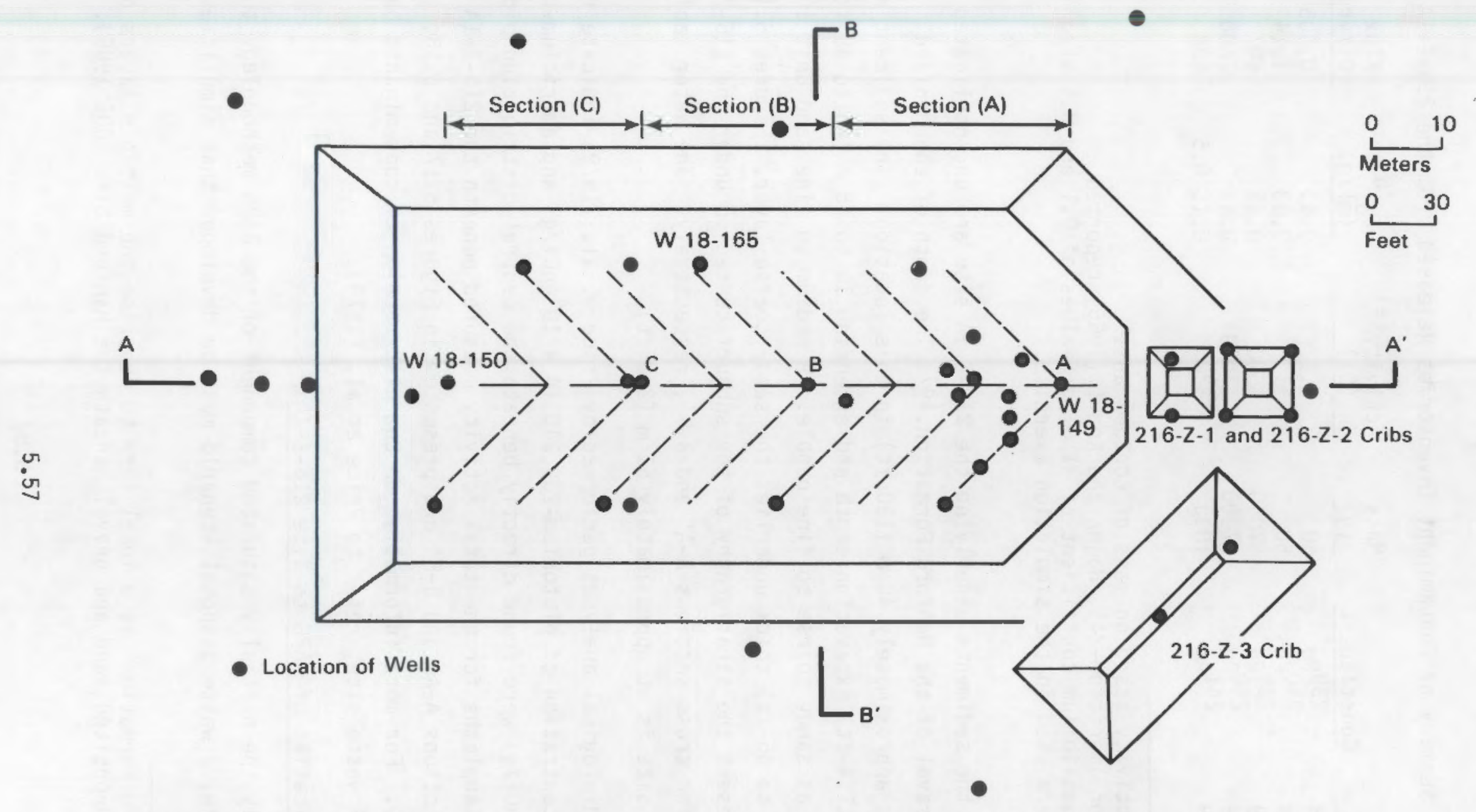

FIGURE 5.14. Plan View of Cribs, Tile Field, and Well Locations at the 216-Z-1A Waste Site (After Price et al. 1979) 
TABLE 5.7. Summary of Contaminant Inventories Released from the 216-2-1A Site

\begin{tabular}{|c|c|c|c|c|c|}
\hline Year & Constituent & $\begin{array}{c}\text { Mass } \\
(\mathrm{g}) \\
\end{array}$ & $\begin{array}{l}\text { Activity (a) } \\
\text { (Ci) }\end{array}$ & $\begin{array}{l}K_{d}(b) \\
(m l / g) \\
\end{array}$ & $\begin{array}{c}\text { Flux } \\
(\mathrm{Ci} / \mathrm{yr})\end{array}$ \\
\hline $\begin{array}{l}1949-59 \\
1949-59 \\
1964-69 \\
1964-69 \\
1964-69\end{array}$ & $\begin{array}{l}239 \mathrm{Pu} \\
240 \mathrm{Pu} \\
239 \mathrm{Pu} \\
240 \mathrm{Pu} \\
241_{\mathrm{Am}}\end{array}$ & $\begin{array}{l}50 \\
50 \\
57000 \\
57000 \\
1000\end{array}$ & $\begin{array}{l}3.1 \\
11 \\
3500 \\
13000 \\
3200\end{array}$ & $\begin{array}{l}0.63 \\
0.63 \\
0.63 \\
0.63 \\
0.1, \quad 0.5\end{array}$ & $\begin{array}{l}0.305 \\
1.14 \\
697 \\
2600 \\
638\end{array}$ \\
\hline
\end{tabular}

(a) Activity based on mass of contaminant.

(b) For americium-241, Hajek and Knoll (1966) reported an equilibrium coefficient of $<1 \mathrm{ml} / \mathrm{g}$; values of 0.1 and $0.5 \mathrm{ml} / \mathrm{g}$ were used in the simulation exercise.

showed that the sediments underlying the 216-Z-1A site are unconsolidated sand, silt, and gravel of the Hanford Formation. (a) The depth of the Hanford

Formation is approximately $40 \mathrm{~m}(130 \mathrm{ft})$ in this location. The sediment near the 5.8-m (17.4-ft) excavation depth and extending 10 to $15 \mathrm{~m}$ (33 to $49 \mathrm{ft}$ ) is categorized as sandy coarse to fine pebble. A medium to fine sand unit $10-m$ to $20-m$ (33-ft to 66-ft) thick underlies the sandy coarse layer. Figures 5.15 and 5.16 present the stratigraphy of the subsurface region under the $216-2-1 \mathrm{~A}$ waste site for cross sections $A-A^{\prime}$ and $B-B^{\prime}$, respectively. The water table beneath the site is at approximately $61 \mathrm{~m}(200 \mathrm{ft})$.

The radiological analyses performed by Price et al. (1979) indicate the highest concentration of plutonium-239,240 (4 $\left.\times 10^{4} \mathrm{nCi} / \mathrm{g}\right)$ and americium-241 $\left(2.5 \times 10^{3} \mathrm{nCi} / \mathrm{g}\right)$ were found directly beneath the central distribution pipe of the crib. Isopleths for the total activity measured beneath the 216-Z-1A site for cross sections $A-A^{\prime}$ and $B-B^{\prime}$ are presented in Figures 5.17 and 5.18, respectively. For more information on the distribution of contaminants beneath the 216-Z-1A waste site, refer to Price et al. (1979).

\subsubsection{Application of RAPS to Site 216-Z-1A}

To apply the partially saturated component of the RAPS methodology to the 216-Z-1A site, a waste disposal scenario must be developed that simplifies the

(a) 'Hanford Formation' is a local term to describe the multiple layers of flood-deposited sand and gravel beneath the Hanford Site (DOE 1986). 


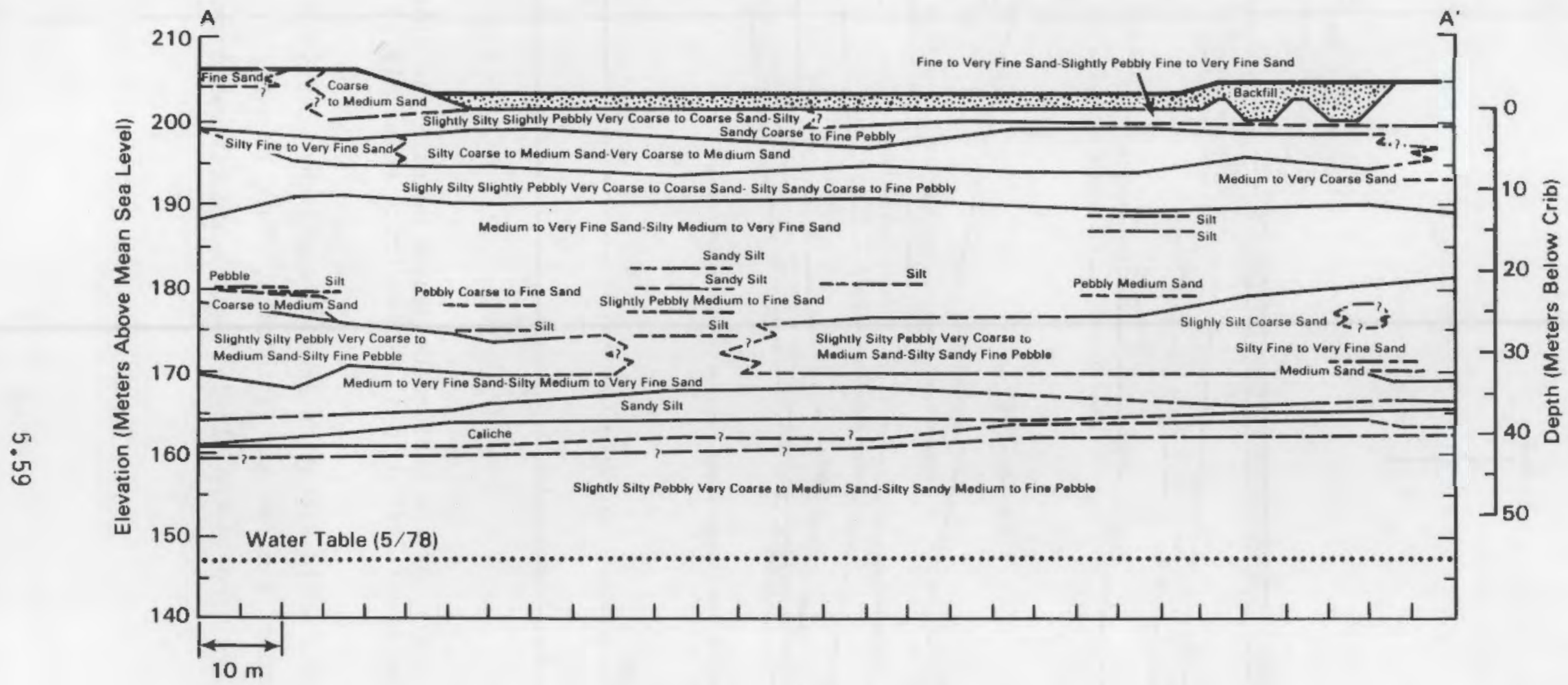

FIGURE 5.15. Stratigraphy of the Subsurface Region Reneath the 216-Z-1A Waste Site for Cross Section A-A' (After Price et a1. 1979) 


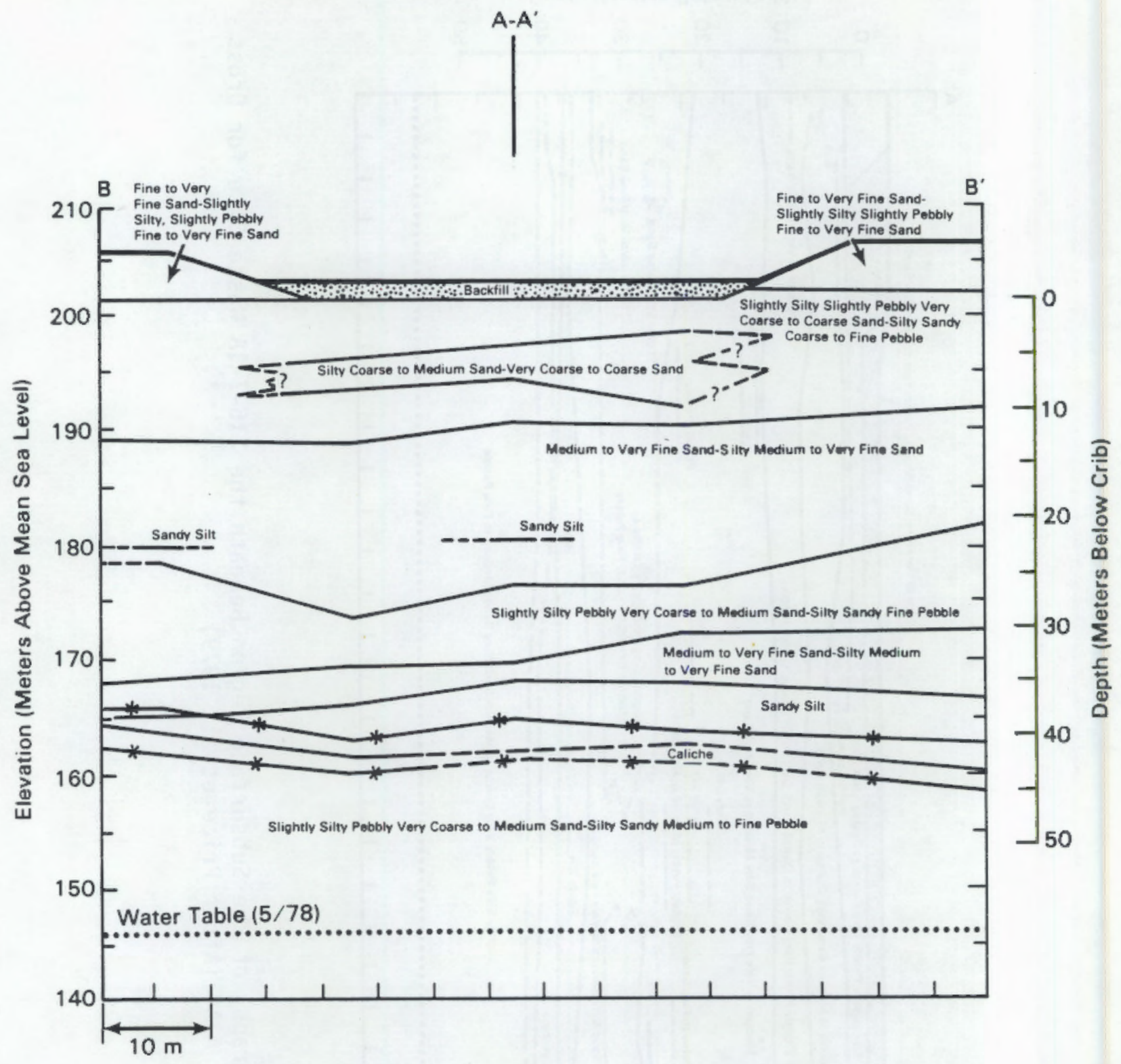

FIGURE 5.16. Stratigraphy of the Subsurface Region Beneath the 216-Z-1A Waste Site for Cross Section B-B' (After Price et al. 1979)

complexities of the real-world situation and addresses the most important parameters needed to model a hazardous waste site. This scenario is developed below and the parameters used in the 216-Z-1A model are discussed and quantified. 


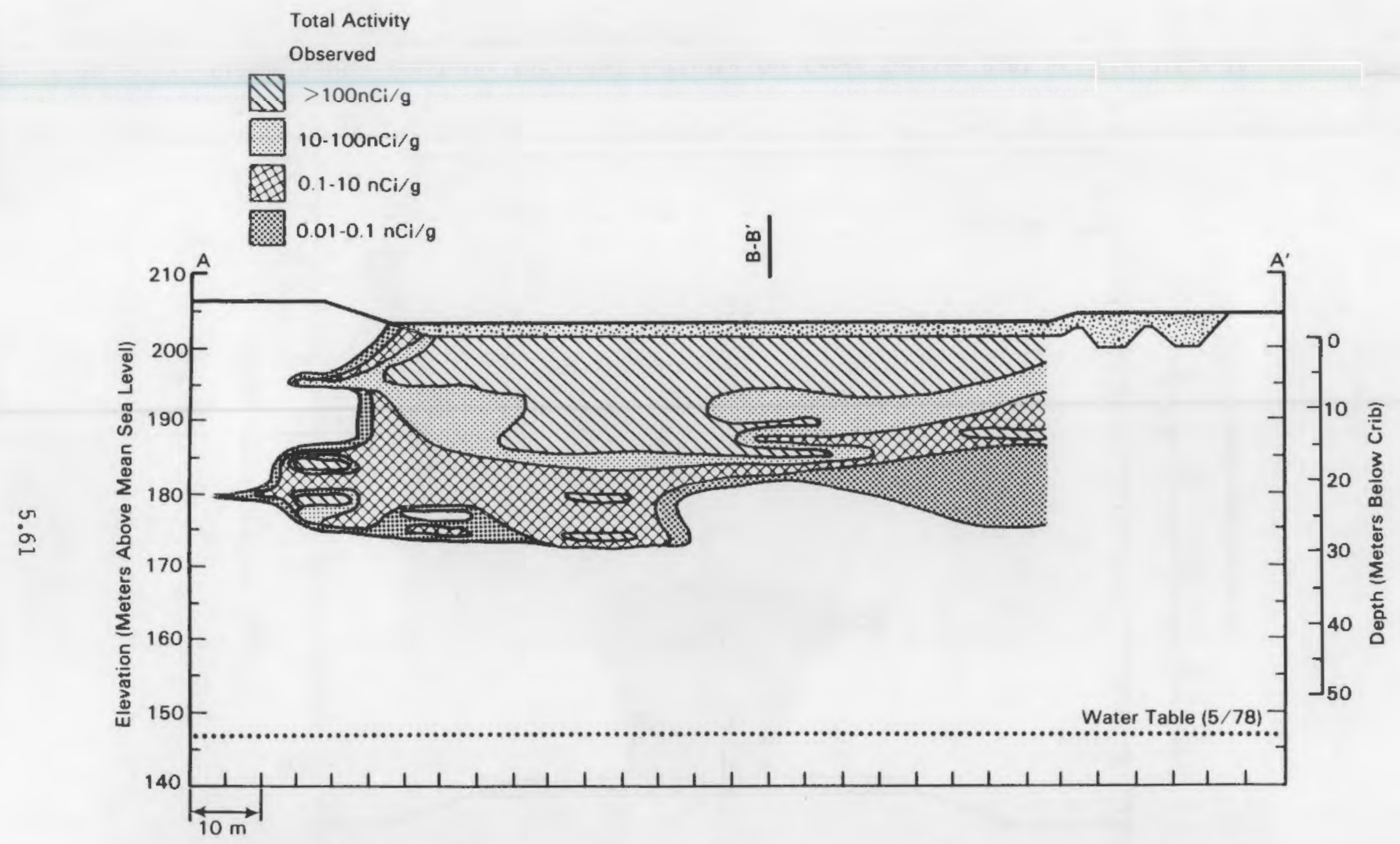

FIGURE 5.17. Isopleths for Total Activity for Cross Section A-A' at Site 216-Z-1A (After Price et al. 1979) 
$<1$

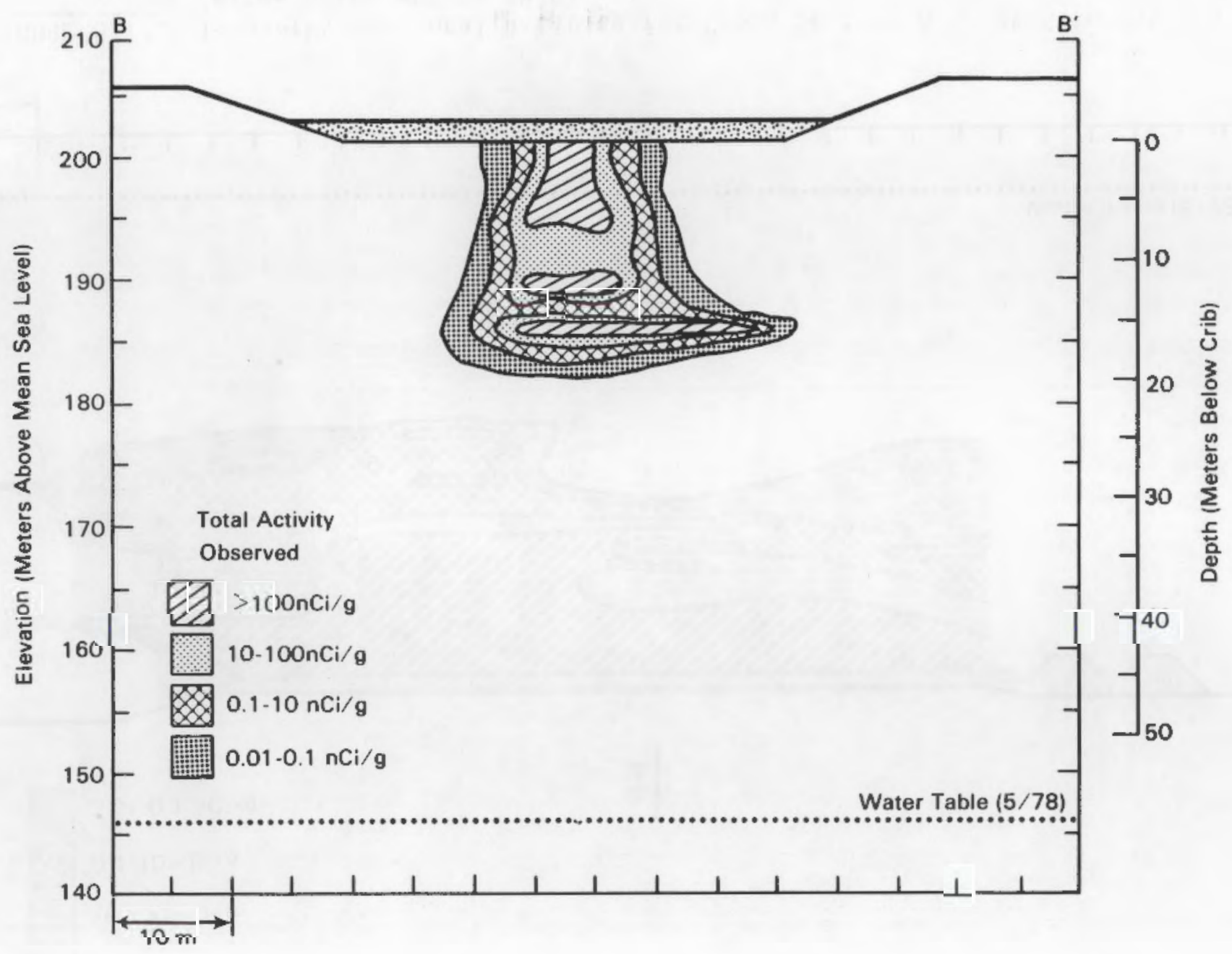

FIGURE 5.18. Isopleths for Total Activity for Cross Section B-B' at Site 216-Z-1A (After Price et al. 1979) 


\subsubsection{Scenario Development for Site 216-2-1A}

Much of the detail of the environmental setting and disposal history at the 216-Z-1A site is described in Section 5.4.1. The five areas of concern in assessing a hazardous waste site, as outlined in Chapter 3.0, are constituents of interest and form of the constituents, level of contamination, mechanism of release, source of the water transporting the contaminants, and the time frame over which the contaminants are released into the environment. These areas as they relate to the $216-Z-1 A$ site are:

1) constituents of interest and form of constituents -- The primary constituents of concern used in the assessment exercise are plutonium239,240 and americium-241; these constituents were chosen because monitored information was available for each constituent.

2) level of contamination -- The level of contamination is described by the inventory of constituents released from the 216-Z-1A crib site during the operational life of the site. The release of plutonium239,240 and americium-241 occurred in two separate incidents. The first release occurred from 1949 through 1959, while the second release occurred from 1964 through 1969. The inventory of constituents released during these incidents is presented in Table 5.7 .

3) mechanism of release -- The contaminants were contained in an aqueous waste that was directly discharged to the soil in the partially saturated zone beneath the 216-Z-1A waste site. Three points of entry were used to deliver the waste to a central distribution piping system, which then released the waste to the soil. The location of the three points of entry (i.e., Points A, B, and C) are illustrated in Figure 5.14 .

4) Source of water - The contaminants flowed to the disposal site as an aqueous solution that was primarily acidic with a pH of 1 . The waste flowed to the site via a settling tank and three other crib structures during the period from 1949 to 1959. From 1964 to 1969, the waste was released to the $216-Z-1 A$ crib directly from the plutonium processing plant. 
5) time frame -- The release of the contaminants is shown on an annual average basis in Table 5.7 .

Now that these five areas of concern have been addressed, the specific parameters relating to these areas can be defined.

\subsubsection{Quantification of Parameters for Site 216-Z-1A}

The parameters required for application of the partially saturated zone component of the RAPS methodology are discussed and defined below.

1) temporally distributed contaminant fluxes -- The temporally distributed fluxes represent the most important information used in this assessment exercise. Section 5.4.1 presents a summary of the masses of plutonium-239,240 and americium-241 that were released from the waste site during the operational life of the site. Because activity in terms of curies is required by the RAPS methodology, the annual average mass in terms of grams discharged from the waste site had to be converted to units of curies. The equation used to convert mass in grams to activity in curies is (Friedlander et al. 1964):

$$
\text { Activity in curies }=M \ln (2) \mathrm{N} / \mathrm{t}_{1 / 2}
$$

in which

$$
N=6.0225 \times 10^{23} / \text { atomic mass }
$$

$$
\text { where } \begin{aligned}
M & =\text { mass of constituent }(g) \\
N & =\text { number of radioactive atoms per unit mass } \\
t_{1 / 2} & =\text { decay half }-1 \text { ife of radionuclide }\left(y e a r^{-1}\right)
\end{aligned}
$$

Because no information was available to estimate the percentage of the total mass contributed by plutonium-239 and plutonium-240, each is assumed in the analysis to individually account for the total mass. The temporally distributed fluxes of plutonium-239,240 and americium-241 are 1isted in Table 5.7. 
2) decay rate -- The half-lives of plutonium-239, plutonium-240, and americium-241 are 24,400 years, 6,537 years, and 465.7 years, respectively (Weast 1984; Codell et al. 1982). Based on the first-order decay assumption for radioactivity, the corresponding decay rates for plutonium-239, plutonium- 240, and americium-241 are $2.84 \times 10^{-5}$ year ${ }^{-1}, 1.06 \times 10^{-4}$ year $^{-1}$, and $1.49 \times 10^{-3}$ year ${ }^{-1}$, respectively.

3) equilibrium coefficient -- The equilibrium coefficient $\left(K_{d}\right)$ attempts to describe that portion of contaminant moving with the groundwater and that portion adsorbing to the surrounding soil. It is defined as the ratio between the mass (or activity) of constituent per unit weight of soil and the mass (or activity) per unit volume of solution. Because the RAPS methodology assumes that an equilibrium coefficient $\left(K_{d}\right)$ represents a valid technique for redistributing a contaminant between particulate (i.e., $\mathrm{Ci} / \mathrm{g}$ ) and dissolved (i.e., $\mathrm{Ci} / \mathrm{ml}$ ) phases, the $\mathrm{K}_{\mathrm{d}}$ was used to convert particulate concentrations to concentrations of solutions that might be in contact with the sediments and assumed to be in chemical equilibrium with them. This was done for comparison purposes only. The comparison could also be made on the solid phase by calculating simulated solid-phase concentrations. Delegard and Barney (1983) performed several experiments using simulated wastes at Hanford to determine representative $k_{d} s$ for Hanford soil. In their tests, they varied the pH and organic composition of the waste. The $K_{d}$ for plutonium-239,240 ranged from $300 \mathrm{ml} / \mathrm{g}$ for a dilute, noncomplexed (i.e., with organics) waste to $0.63 \mathrm{ml} / \mathrm{g}$ for a concentrated, complexed waste. The waste solution that was discharged from the $216-Z-1 A$ waste site contained organics with a low $\mathrm{pH}$; therefore, it represented a concentrated, complexed

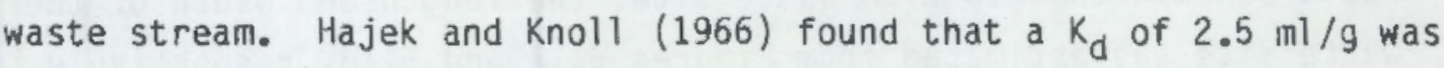
representative of the reaction between actual untreated $216-Z-1 A$ wastes and 216-z-1A sediments. Organic materials found in the waste, however, reduced the sorption of plutonium even further; therefore, for this assessment, a $K_{d}$ of $0.6 \mathrm{ml} / \mathrm{g}$ was used. This value would not necessarily accurately represent continued elution of ${ }^{239} \mathrm{Pu}$ through the sediment column because of waste-sediment interactions that have 
neutralized the acidic waste, resulting in precipitation of ${ }^{239} \mathrm{Pu}$ solid phases. Delegard et al. (1981) indicate that less than $1 \%$ of the plutonium in the $216-Z-1 A$ would be mobilized by natural environmental conditions. Delegard and Barney (1983) also performed several experiments to determine a representative $k_{d}$ for americium-241. For americium-24l, the $k_{d}$ ranged from $300 \mathrm{ml} / \mathrm{g}$ for a concentrated noncomplexed waste to $5.6 \mathrm{ml} / \mathrm{g}$ for a concentrated, complexed waste. Hajek and Knoll (1966) also performed analyses with americium-241 and Hanford soils. Their test results indicated a $k_{d}$ for americium-241 of less than $1 \mathrm{ml} / \mathrm{g}$ (i.e., < $1 \mathrm{ml} / \mathrm{g}$ ). Because Hajek and Knoll's (1966) $k_{d}$ value for americium-241 (i.e., < $1 \mathrm{ml} / \mathrm{g}$ ) tested lower than that of Delegard and Barney (1983) (i.e., $5.6 \mathrm{ml} / \mathrm{g}$ ), the Hajek and Knoll estimate was used in the assessment. Because Hajek and Knoll did not provide a precise value for the $K_{d}$, values of $0.1 \mathrm{ml} / \mathrm{g}$ and $0.5 \mathrm{ml} / \mathrm{g}$ were used to represent the $K_{d}$ for americium-241. Two $K_{d} s$ are used in the assessment to demonstrate the sensitivity of the methodology to $\mathrm{K}_{\mathrm{d}}$ selection.

4) length and width of waste site -- It is difficult to estimate a representative length and width of a herringbone tile field. The spacial distribution of the waste below this configuration greatly depends on which sections discharge the waste material. Because the spacial distribution of the contaminants below the waste site were available from supporting documentation (e.g., Price et al. 1979), a representative length and width of the waste site could be estimated. The area containing the leaching contaminated effluent is estimated from Figures 5.17 and 5.18. From the spacial distribution of the waste beneath the $216-Z-1 A$ waste site, the length and width of the waste site was estimated from Figures 5.17 and 5.18 , respectively, as being $79 \mathrm{~m}$ and $10 \mathrm{~m}$, respectively. If the spacial distribution of the contaminants below the site had been unavailable, the length and width would have been set equal to one-half the length and width of the tile field, respectively. This "rule-of-thumb" should provide an adequate representative area for the RAPS assessment. 
5) porosity -- Delegard and Barney (1983) suggested that a value of $38 \%$ is a typical value for porosity of Hanford soils.

6) bulk density -- the bulk density of the site can be computed from the porosity and by assuming a specific weight of the alluvial soil of $2.65 \mathrm{~g} / \mathrm{cm}^{3}$. The equation for computing bulk density is as follows: (a)

$$
B=(1-n) S_{w}
$$

where $B=$ bulk density $\left(\mathrm{g} / \mathrm{cm}^{3}\right)$

$n=$ porosity

$S_{w}=$ specific weight $\left(\mathrm{g} / \mathrm{cm}^{3}\right)$

7) field capacity -- Field capacity is defined as the soil water content of an initially well-watered soil that has drained by gravity to a nearly constant water content. Field capacity is a term used to describe the upper limit of soil moisture that is normally available for plant water uptake. This upper limit is defined as the water content in a uniform profile after wetting and draining has ceased (or is neglibibly small) under a surface condition with no evaporation. For some sandy soils, field capacity can be estimated to be a water content value that corresponds to a field matrix potential (i.e., negative of the suction head) of approximately $-100 \mathrm{~cm}$. The field capacity for this analysis is estimated from a soil moisture release curve developed by Sisson and Lu (1984) for a coarse alluvial Hanford soil. This moisture release curve is presented in Figure 5.19. From Figure 5.19, the field capacity is estimated to be $8 \%$ (volume basis).

(a) Normally, the porosity is determined from the bulk density. Specific weights (i.e., particle density) usually ${ }_{3}$ range between 2.6 to $2.8 \mathrm{~g} / \mathrm{cm}^{3}$. A commonly used value of $\mathrm{S}_{\mathrm{w}}$ is $2.65 \mathrm{~g} / \mathrm{cm}^{3}$, although some Hanford soils have been measured at $2.8 \mathrm{~g} / \mathrm{cm}^{3}$. 


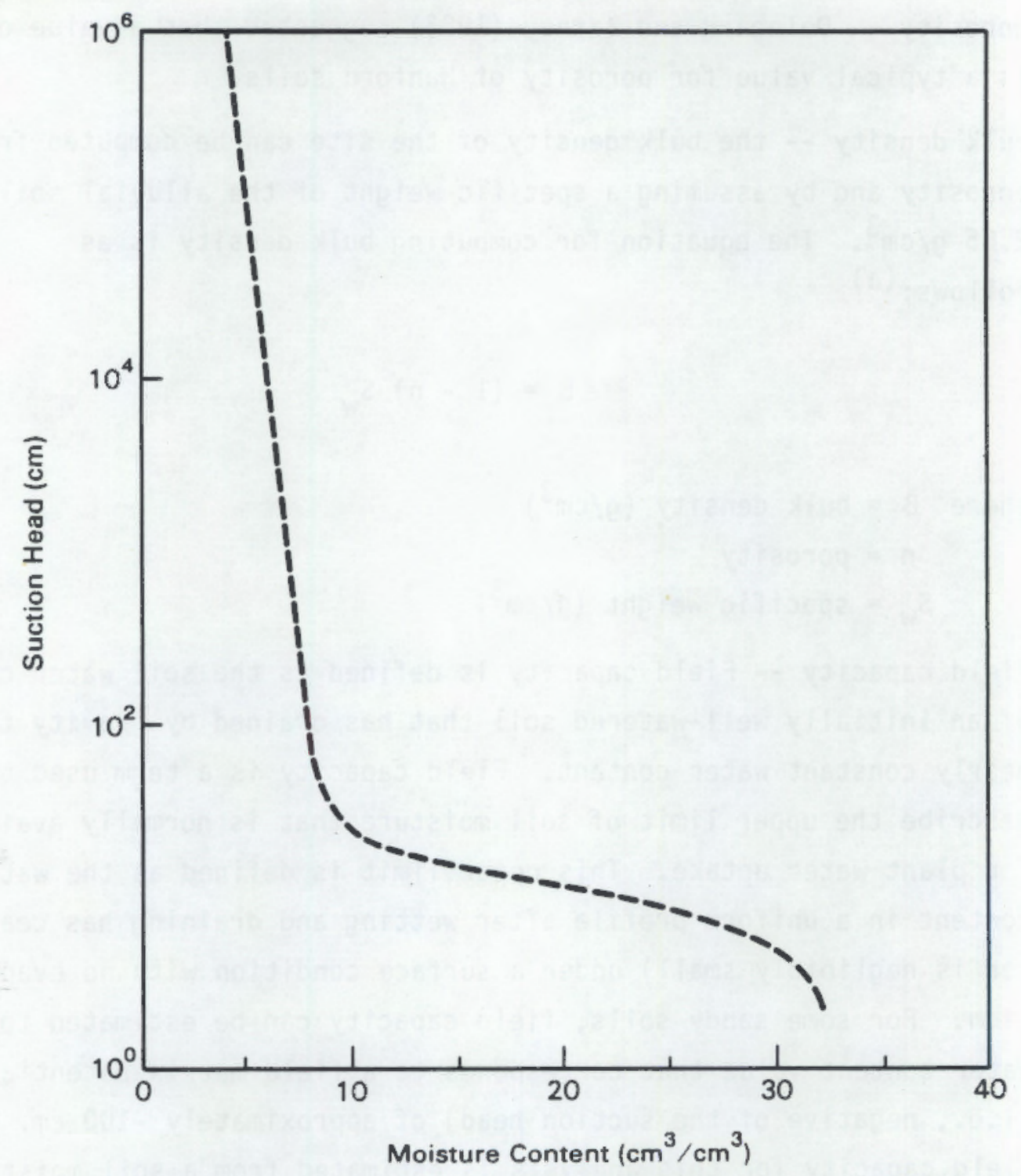

FIGURE 5.19. Moisture Release Curve (After Sisson and Lu 1984)

8) leach rate -- The leach rate of $0.36 \mathrm{~cm} / \mathrm{d}(0.14 \mathrm{in./d})$ was calculated from the maximum average annual flow of aqueous waste into the site (i.e., $1.04 \times 10^{6} 1$ year $\left(2.7 \times 10^{5} \mathrm{gal} /\right.$ year)) and the surface area of the site (i.e., $\left.790 \mathrm{~m}^{2}\left(8.5 \times 10^{3} \mathrm{ft}^{2}\right)\right)$.

9) Saturated hydraulic conductivity -- The saturated hydraulic conductivity value of $4320 \mathrm{~cm} /$ day was obtained from Sisson and Lu (1984) as representative of medium to course alluvial Hanford soils. 
10) longitudinal dispersivity -- Although a generalized theory to describe dispersivity has not yet been developed, according to EPA (1986) some investigators (e.g., Gelhar and Axness 1981) have reported simple, linear dependencies, based on mean travel distance, for dispersivity in the flow direction. Gelhar and Axness (1981), although not recommending a particular relationship, suggest that the dispersivity might be defined as being approximately equal to $10 \%$ of the mean travel distance. Given that a better approximation is unavailable at this time and that "EPA (U.S. Environmental Protection Agency) believes that this relationship is a reasonable approximation ..." (EPA 1986), this relationship is assumed for this assessment.

11) soil-type coefficient -- The soil type coefficient refers to the exponential parameter defined in Equation (5.26) (i.e., m). Clapp and Hornberger (1978) have defined this soil-type coefficient as a function of soil type. For alluvial material, their suggested value of 0.09 was used in the assessment.

A summary for the data employed as part of this assessment is presented in Table 5.8 .

\subsubsection{Results Associated with the Application of RAPS to Site 216-Z-1A}

The subsurface component of the RAPS methodology computes spacially and temporally distributed contaminant concentrations in the partially saturated zone beneath a hazardous waste site. Results of the application of the RAPS methodology to the 216-Z-1A site are presented in this section. The results of the assessment are presented in Figures 5.20 through 5.29. The results presented in these figures represent a snapshot in time. The temporal distribution of the concentration, as the contaminant passes a particular location, is unavailable. These results represent only the spacial distribution of the contaminant approximately 30 years after the initial release of the waste into the environment.

Figures 5.20 through 5.25 present observed and simulated isopleths (i.e., contours of constant concentration) for plutonium-239,240 and americium-241 for two different cross sections through the site: $A-A^{\prime}$ and $B-B^{\prime}$. The location of 
TABLE 5.8. Data for the 216-Z-1A Site Assessment

Parameter

Contaminant decay rate

Plutonium-239

Plutonium-240

Americium-241

Contaminant equilibrium coefficient

Plutonium-239,240

Americium-241

Leach rate

Saturated hydraulic conductivity

Bulk density

Porosity

Field capacity (by volume)

Longitudinal dispersivity

Soil-Type coefficient

Length of disposal site

Width of disposal site
Value

$2.84 \times 10^{-5} \mathrm{yr}^{-1}$

$1.06 \times 10^{-4} \mathrm{yr}^{-1}$

$1.49 \times 10^{-3} \mathrm{yr}^{-1}$

$$
0.63 \mathrm{ml} / \mathrm{g}
$$

0.1 and $0.5 \mathrm{ml} / 9$

$0.36 \mathrm{~cm} / \mathrm{d}$

$4320 \mathrm{~cm} / \mathrm{d}$

$1.65 \mathrm{~g} / \mathrm{cm}^{3}$

0.38

0.08

0.1 of depth

4.05

$79 \mathrm{~m}$

$10 \mathrm{~m}$

each cross section is illustrated in Figure 5.14. Figures 5.20 and 5.21 present isopleths for plutonium-239,240 for cross sections $A-A^{\prime}$ and $B-B^{\prime}$, respectively. Figures 5.22 and 5.23 present isopleths for americium-241, using a $K_{d}$ of $0.1 \mathrm{ml} / \mathrm{g}$, for cross sections $A-A^{\prime}$ and $B-B^{\prime}$, respectively. Figures 5.24 and 5.25 present isopleths for americium-241, using a $K_{d}$ of $0.5 \mathrm{ml} / \mathrm{g}$, for cross sections $A-A^{\prime}$ and $B-B^{\prime}$, respectively.

For the simulated results, $K_{d}$ affects travel time and prediction of the spacial distribution of the contaminant. As Figures 5.22 through 5.25 indicate, as $K_{d}$ increases, the contaminant's travel time increases and, as one moves farther from the site, the contaminant's concentration decreases. For the observed results, an increase in $K_{d}$ will result in a decrease in the observed concentration. Care, therefore, must be exercised when analyzing these results. 


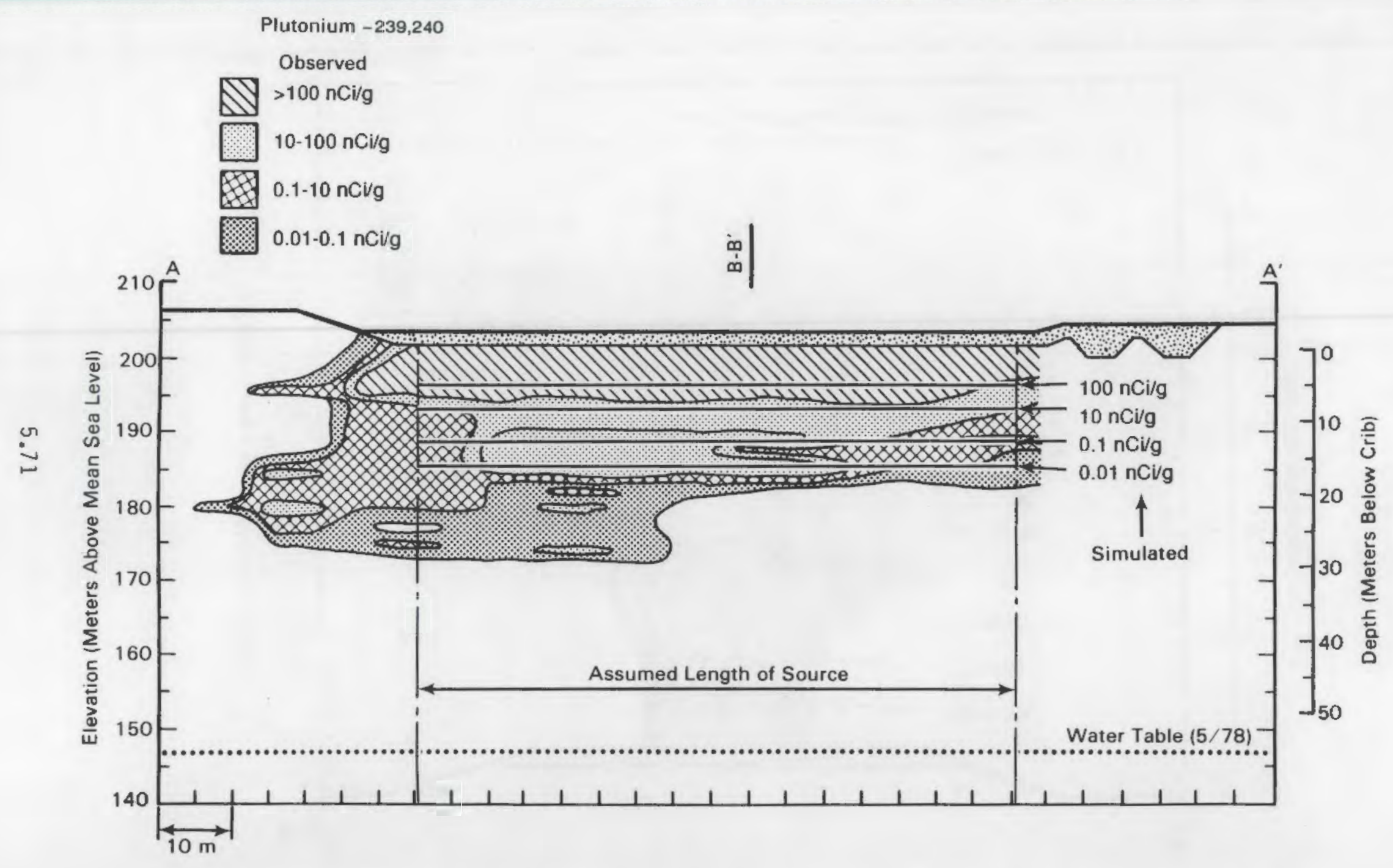

FIGURE 5.20. Plutonium-239,240 Isopleths for Cross Section A-A' at Site 216-Z-1A (After Price et al. 1979) 
我

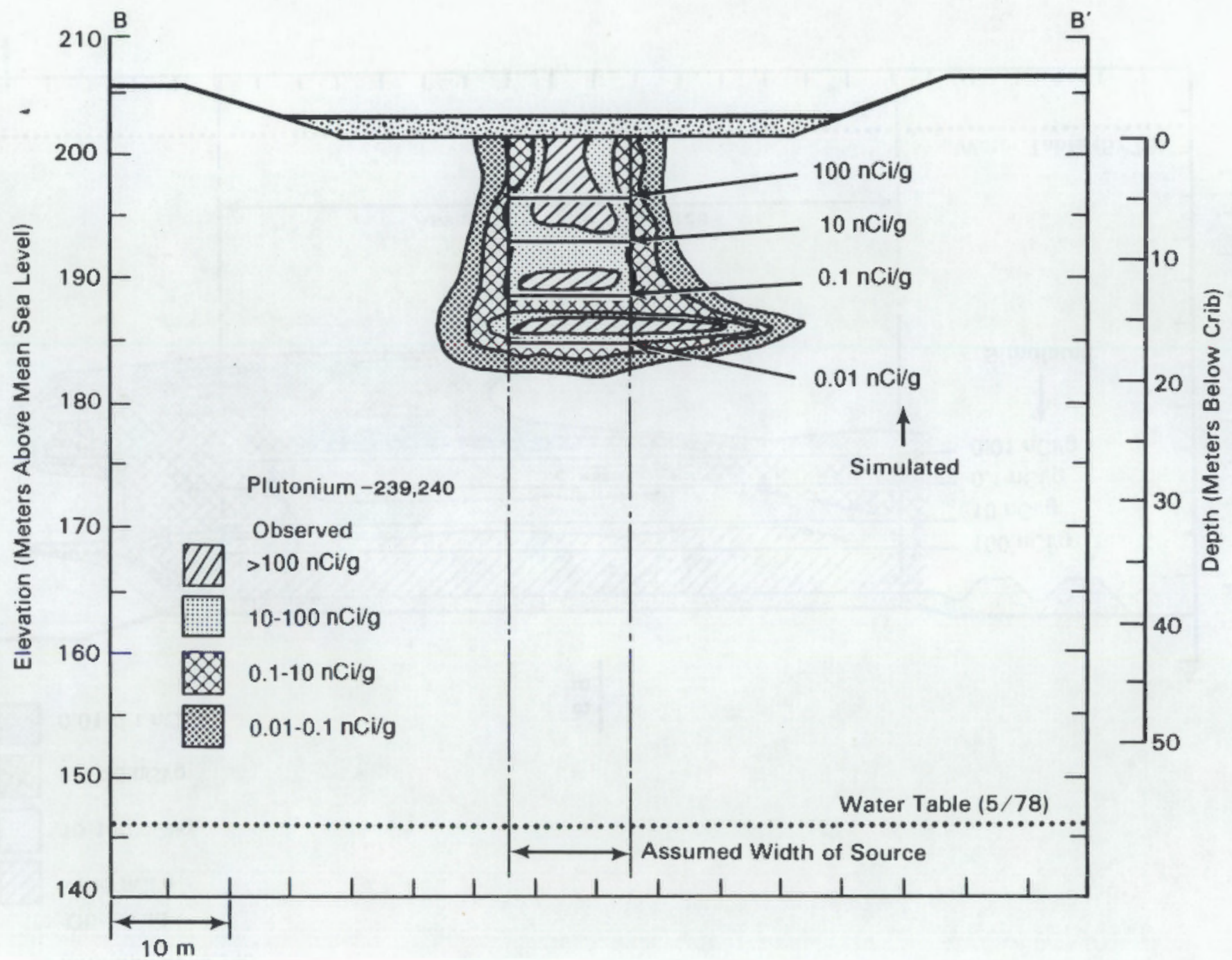

FIGURE 5.21. Plutonium-239,240 Isopleths for Cross Section B-B' at Site 216-Z-1A (After Price et al. 1979) 


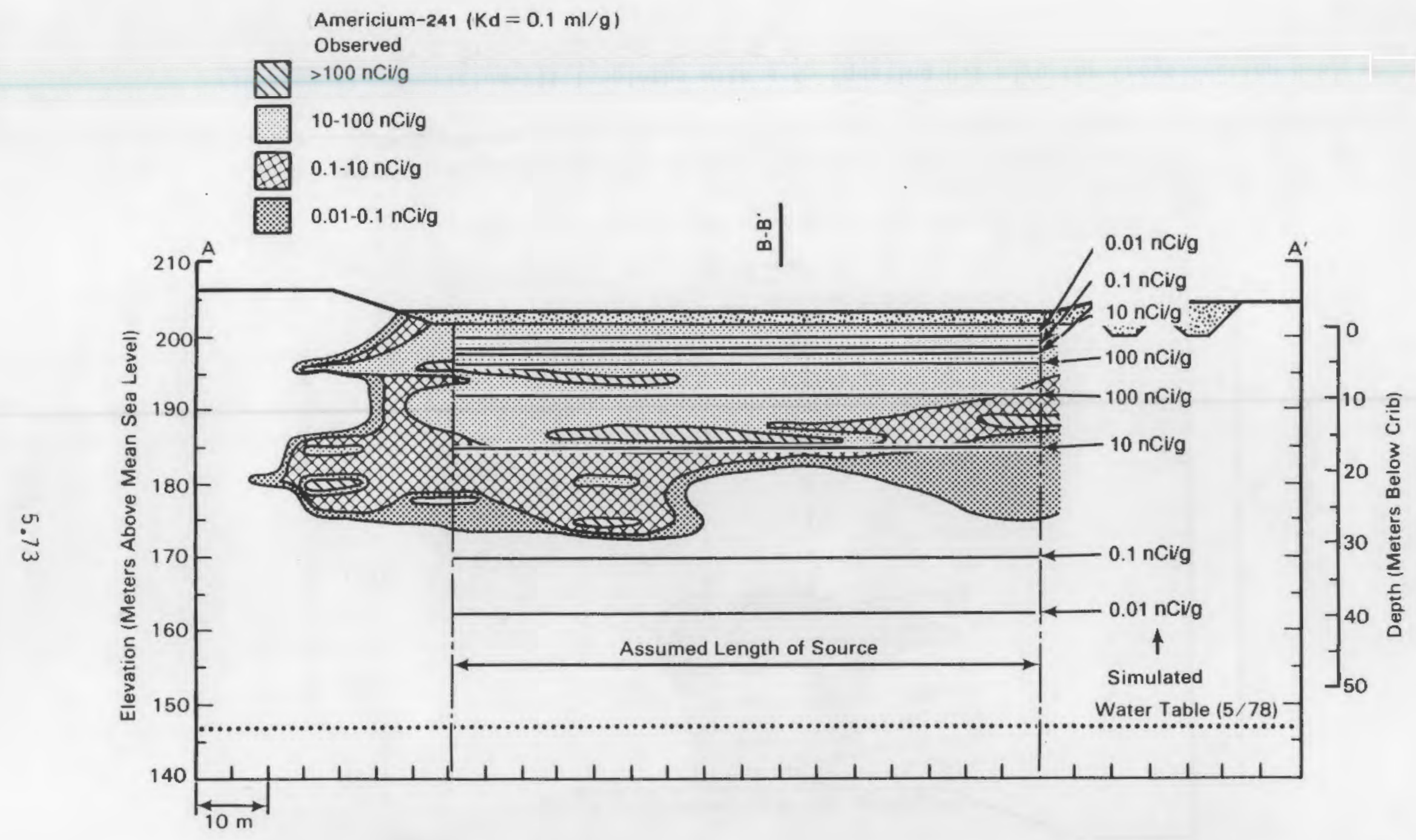

FIGURE 5.22. Americium-241 Isopleths with a $K_{d}$ Equaling $0.1 \mathrm{ml} / \mathrm{g}$ for Cross Section $A-A^{\prime}$ at Site 216-Z-1A (After Price et al. 1979) 


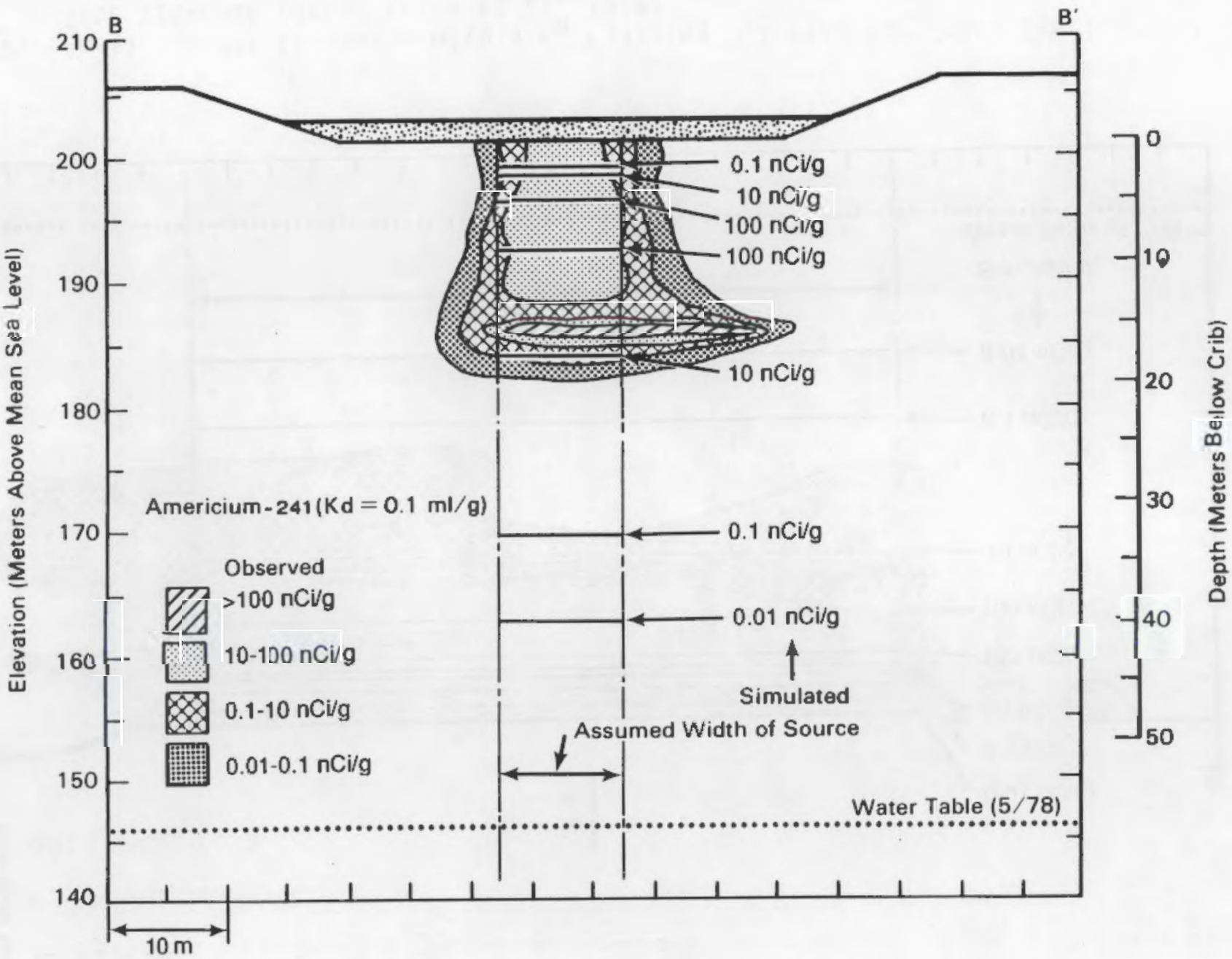

FIGURE 5.23. Americium-241 Isopleths with a $K_{d}$ Equaling $0.1 \mathrm{ml} / \mathrm{g}$ for Cross Section $B-B^{\prime}$ at Site 216-Z-1A (After Price et al. 1979) 


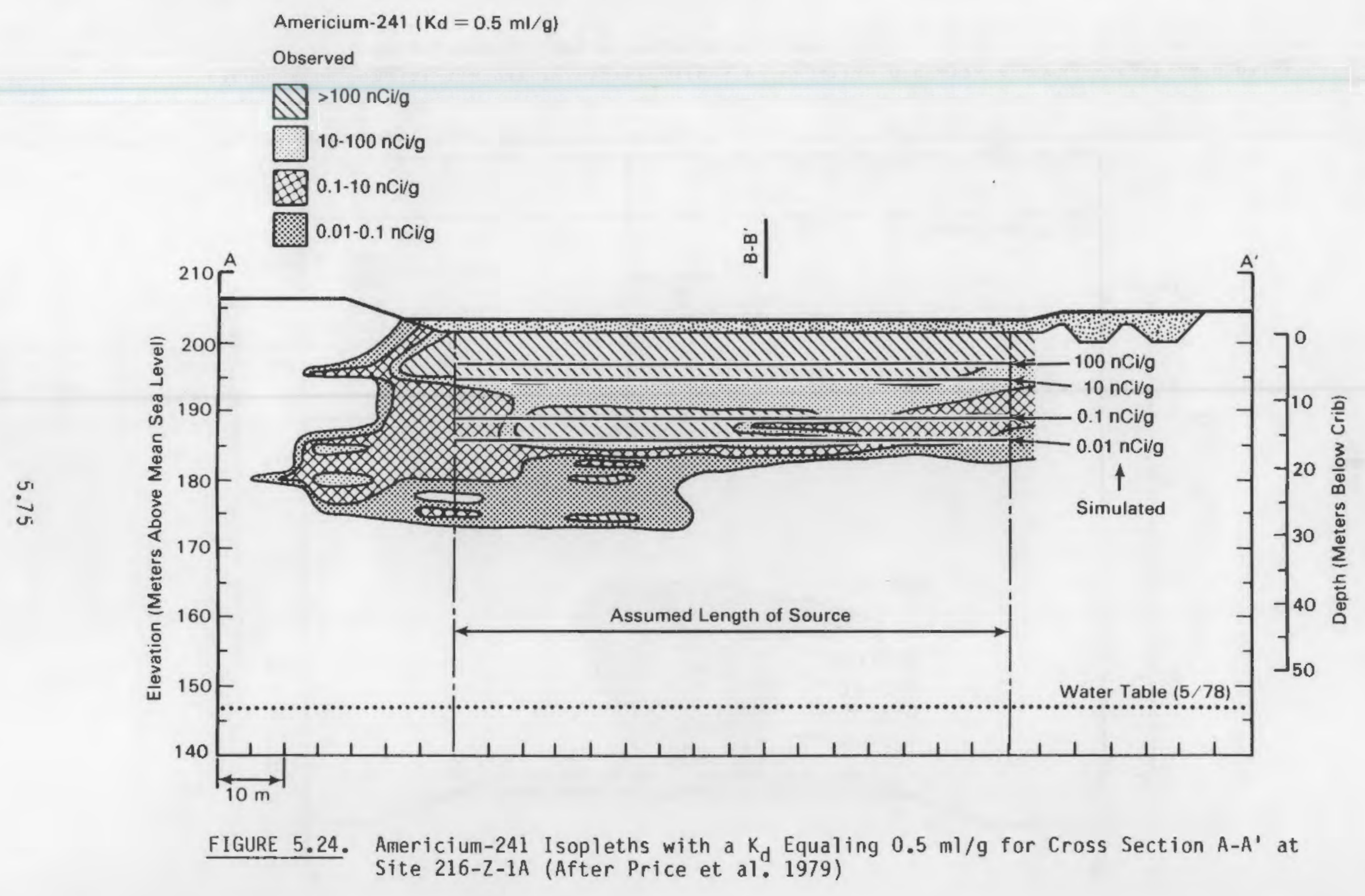




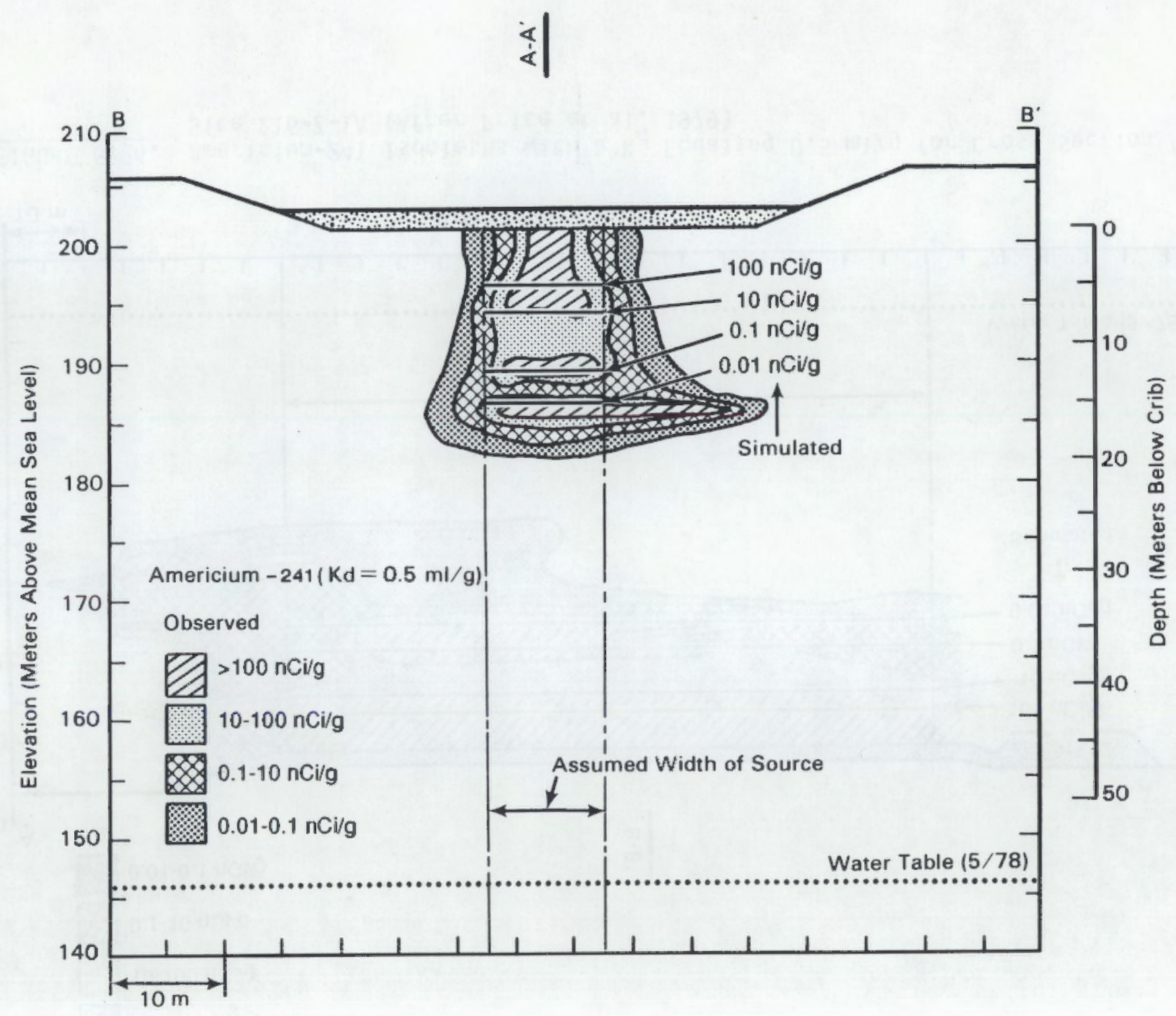

FIGURE 5.25. Americium-241 Isopleths with a $K_{d}$ Equaling $0.5 \mathrm{ml} / \mathrm{g}$ for Cross Section B-B' at Site 216-Z-1A (After Price et al. 1979) 


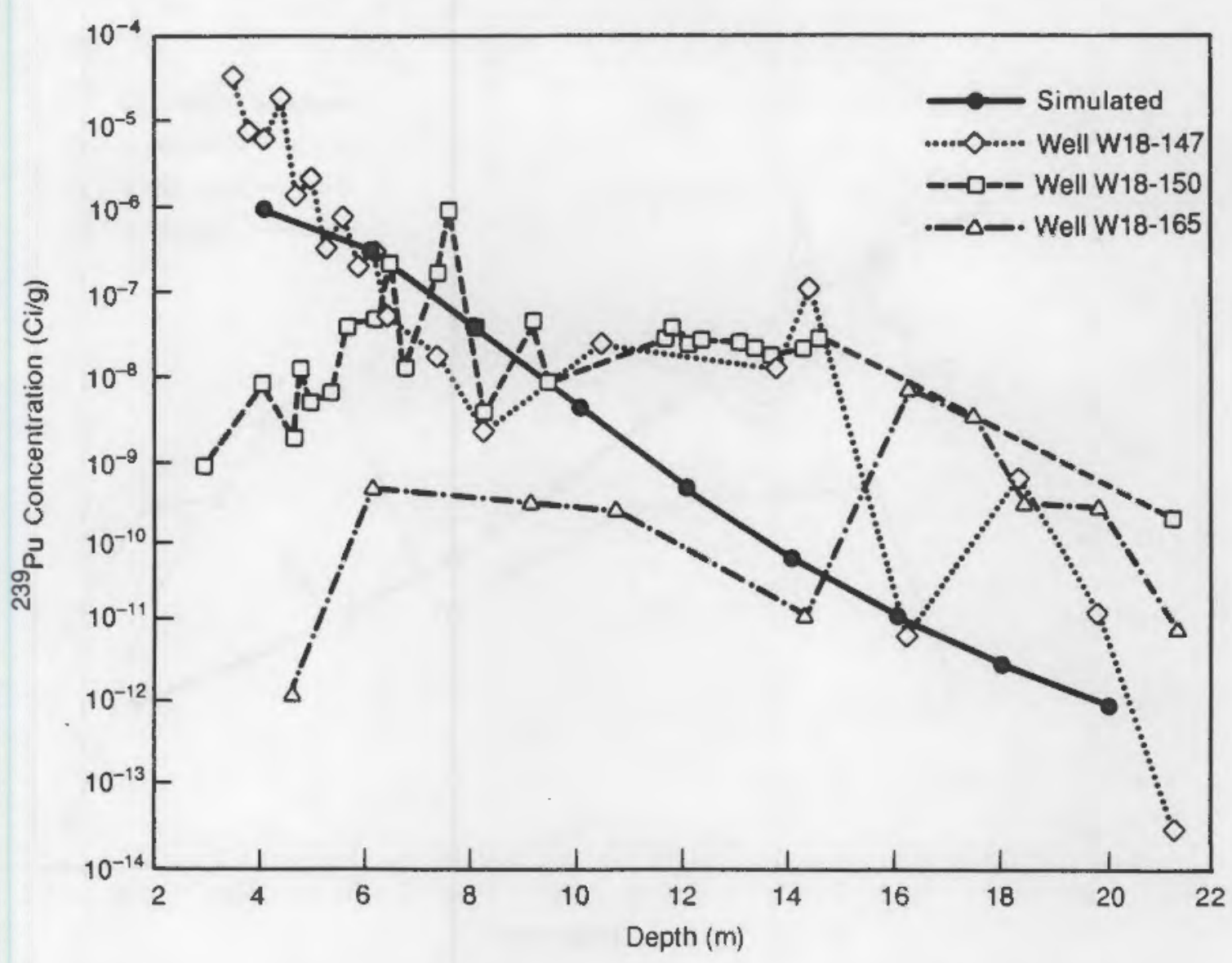

FIGURE 5.26. Simulated and Observed Spacially Varying Plutonium-239 Concentrations Beneath the 216-Z-1A Waste Site

Figures 5.26 through 5.29 present both observed and simulated concentrations as a function of depth for plutonium-239, plutonium-240, and americium241. Each figure presents observed concentrations at wells W18-149, W18-150, and W18-165. Wells W18-149 and w18-150 represent centrally located wells along the main branch of the tile field. Well w18-165 represents a peripheral well of the drain field. The location of each well is shown in Figure 5.14 .

Figures 5.26 and 5.27 present comparisons between simulated and observed plutonium-239 and plutonium-240 concentrations, respectively, as they vary with depth. Figures 5.28 and 5.29 compare simulated and observed americium-241 concentrations for $\mathrm{K}_{\mathrm{d}} \mathrm{s}$ of $0.1 \mathrm{ml} / \mathrm{g}$ and $0.5 \mathrm{ml} / \mathrm{g}$, respectively. Note in the latter two figures the effect the equilibrium coefficient has on the spacial 


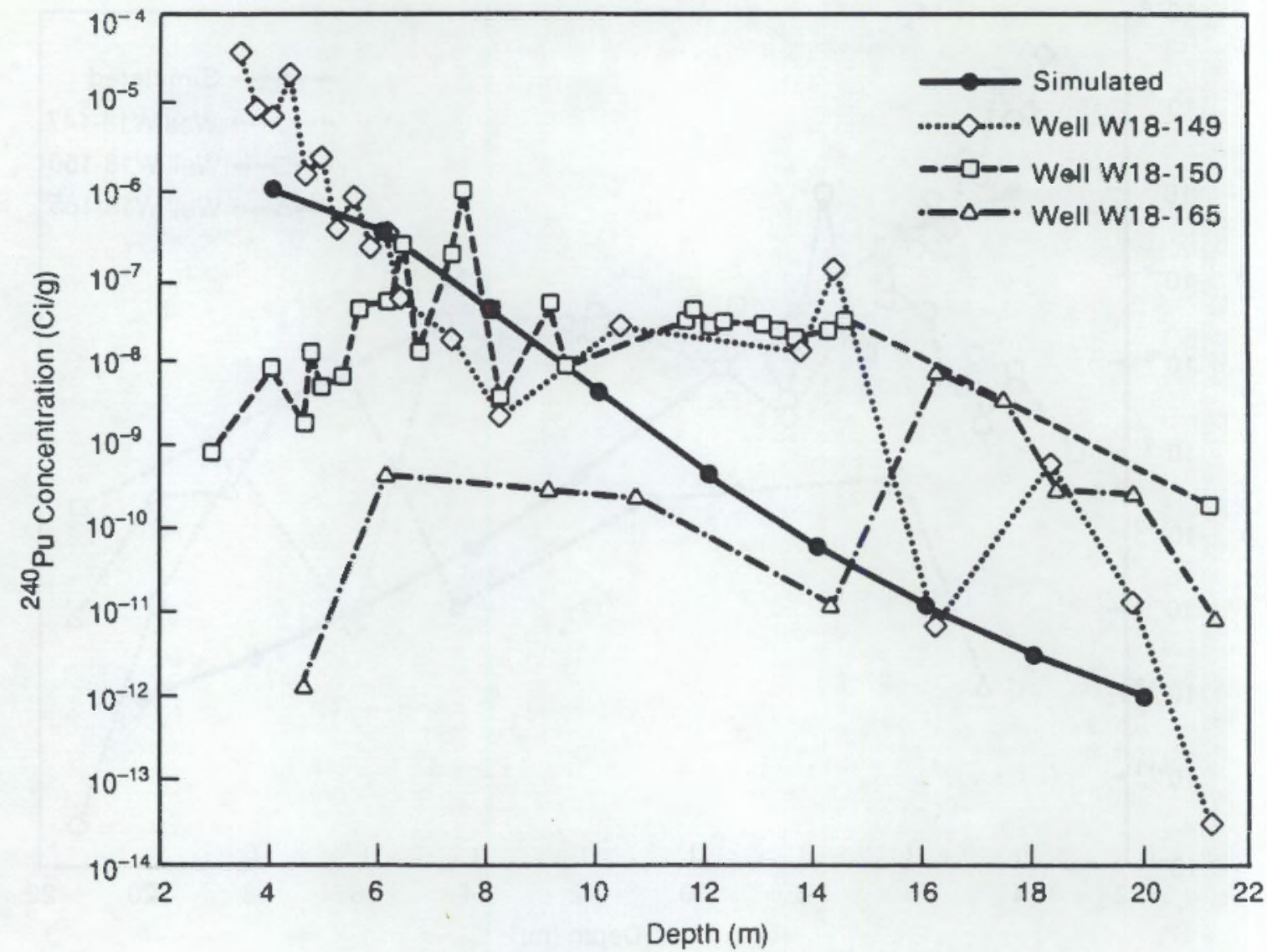

FIGURE 5.27. Simulated and Observed Spacially Varying Plutonium-240 Concentrations Beneath the 216-Z-1A Waste Site

distribution of the contaminant concentrations. In these figures, both the simulated and observed concentrations increase as the $k_{d}$ decreases (as one would expect).

\subsection{APPLICATION OF THE RAPS METHOOOLOGY TO THE PARTIALLY SATURATED ZONE AT SITE 216-Z-8}

The 216-Z-8 waste disposal site at DOE's Richland Operations (i.e., Hanford) facility in Richland, Washington, is also used to demonstrate the applicability of the partially saturated zone component of the RAPS methodology. Figure 5.30 shows the location of the $216-2-8$ waste site at the Hanford facility. This site was selected for demonstration purposes because of the availability of information pertaining to construction, disposal history, and 


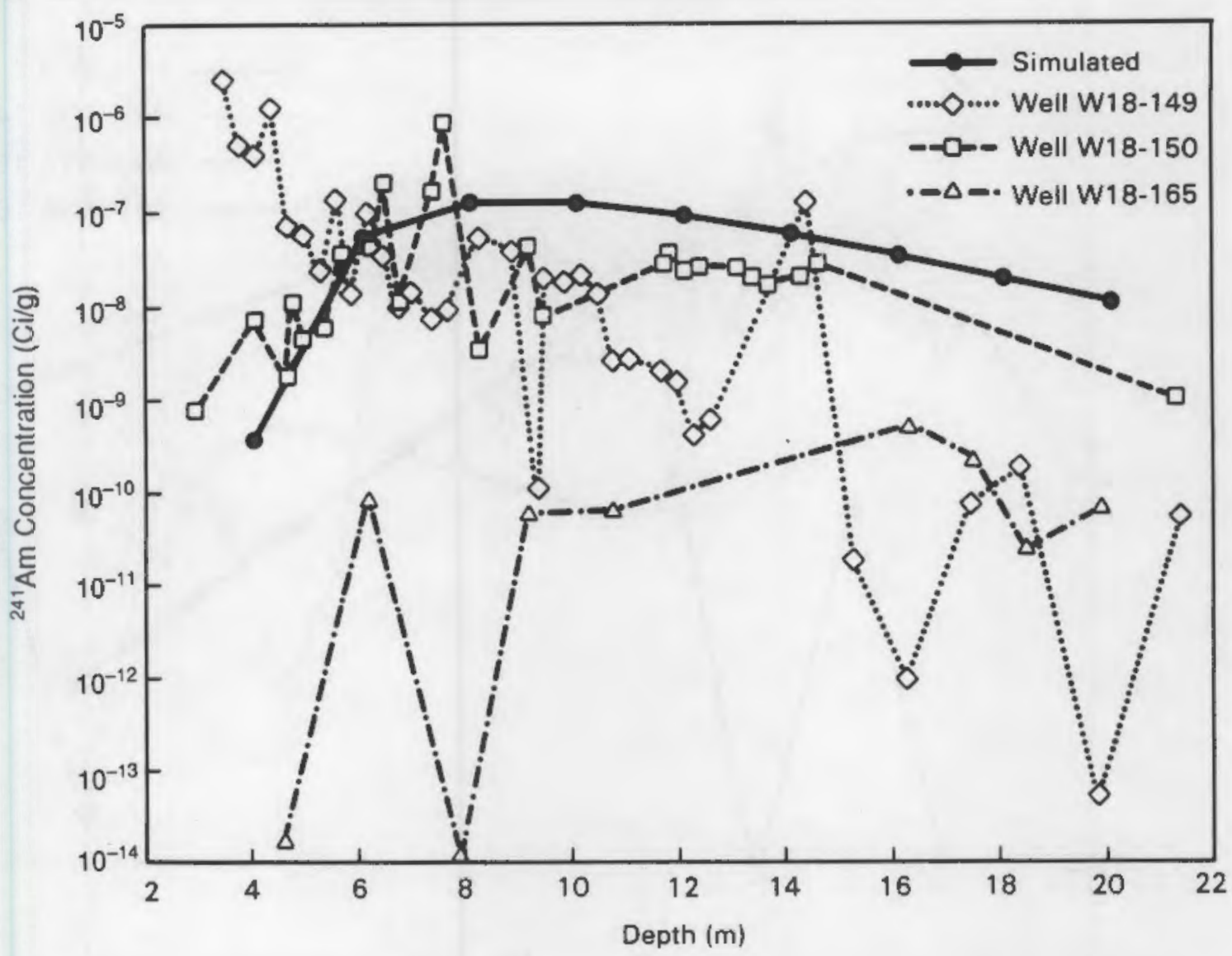

FIGURE 5.28. Simulated and Observed Spacially Varying Americium-241 Concentrations, with a $k_{d}$ Equaling $0.1 \mathrm{ml} / \mathrm{g}$, Beneath the 216-Z-1A Waste Site

known spacial and temporal distributions of radionuclides beneath the site. The sections to follow describe the $216-2-8$ site and outline the results of previous studies performed to characterize the movement of contaminants below the site. The parameters used in the application of the methodology are described and quantified, and a comparison between monitored and simulated contaminant concentrations in the partially saturated zone beneath the 216-2-8 site is presented.

\subsubsection{Description of Site 216-Z-8}

The 216-2-8 French drain underground disposal system consisted of a large settling tank that overflowed into a French drain. The disposal system is illustrated in Figure 5.31. Marratt et al. (1984) note that the French drain 


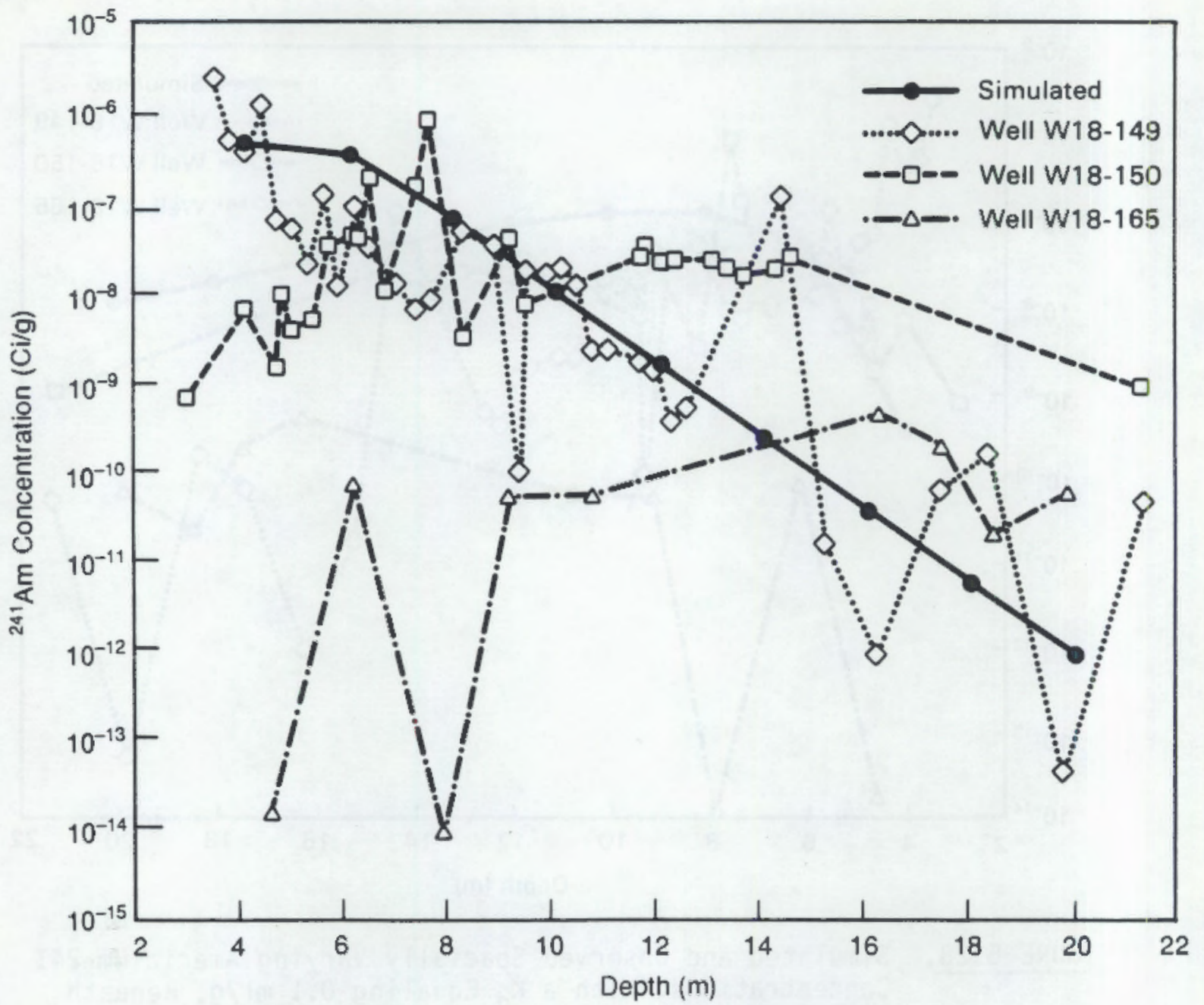

FIGURE 5.29. Simulated and Observed Spacially Varying Americium-241 Concentrations, with a $K_{d}$ Equaling $0.5 \mathrm{ml} / \mathrm{g}$, Beneath the $216-Z-1 A$ Waste Site

consists of two large-diameter, gravel-filled, vitrified clay pipes placed on end, end-to-end, over a gravel-filled excavation. The top of the drain was sealed with concrete to prevent the upward flow of waste solution. Figure 5.32 shows the French drain.

The 216-Z-8 underground waste disposal system discharged liquid waste from a 58,500-1 (15,456-gal) silica settling tank to the French drain that immediately allowed the waste to leach into the partially saturated zone below the site (see Figure 5.31). The French drain received filter cake backflush and rinse water from a plutonium reduction slag and crucible dissolution process in 


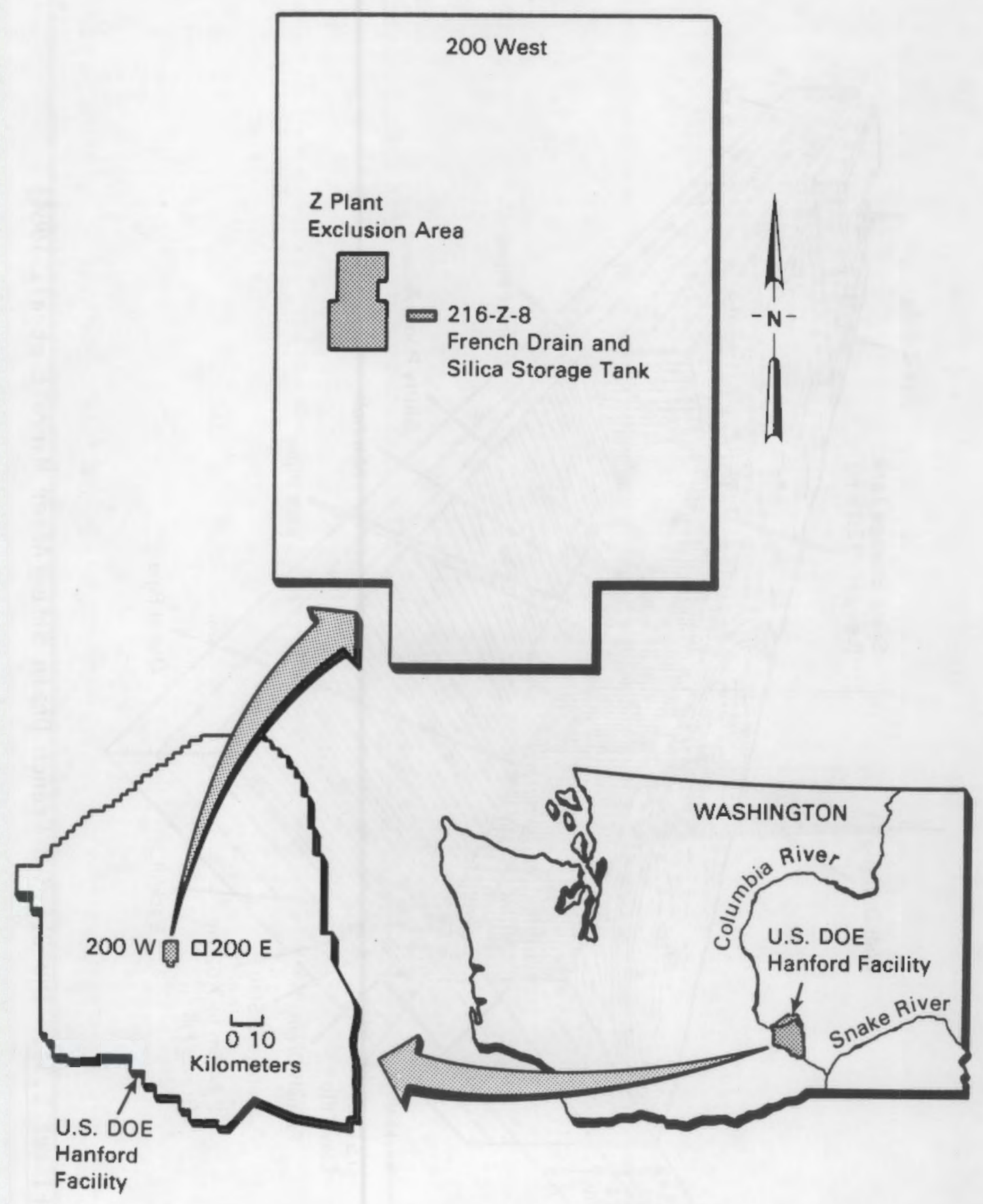

FIGURE 5.30. Location of the 216-Z-1A Waste Site at the Hanford Facility 


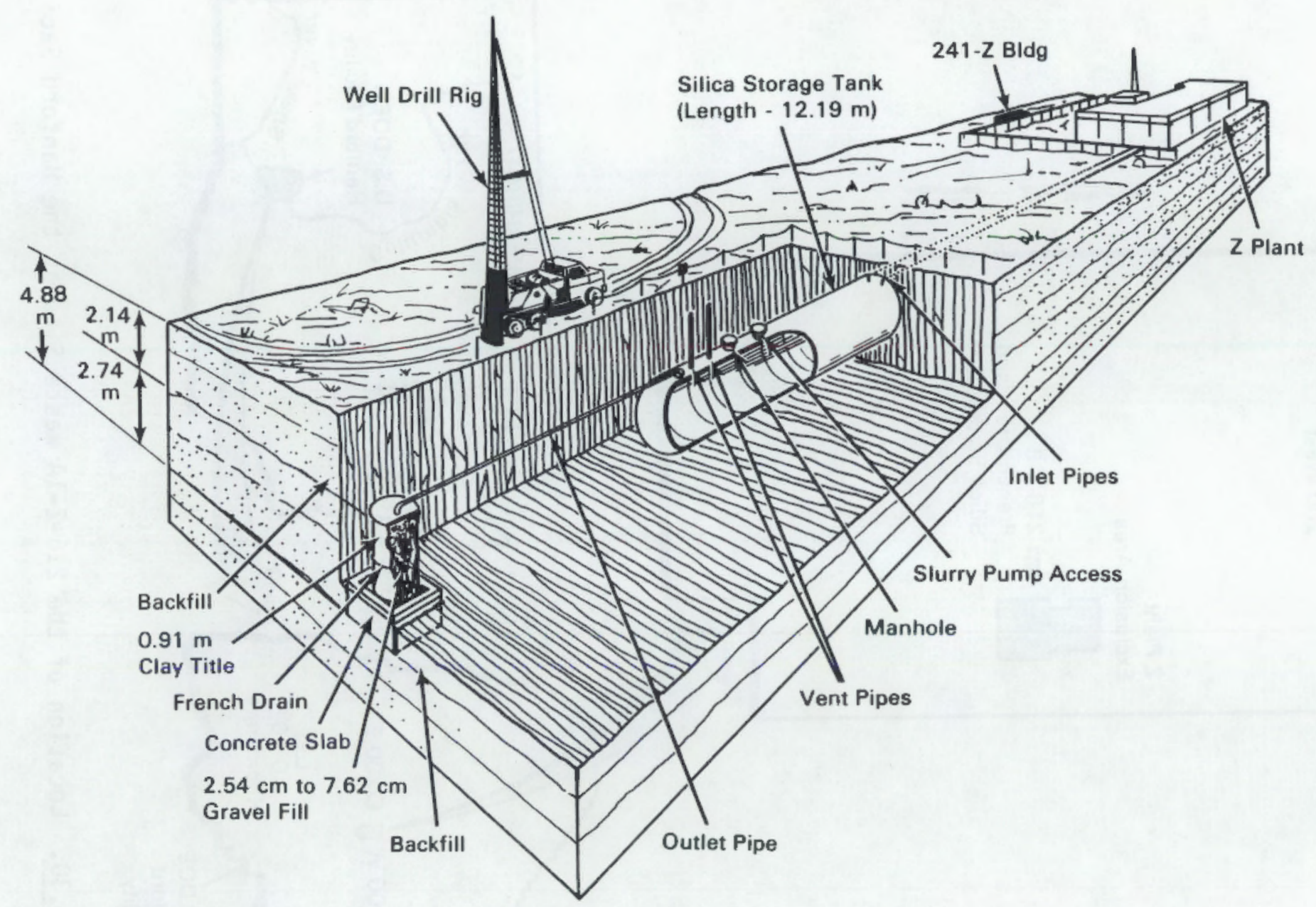

FIGURE 5.31. The 216-Z-8 French Drain Site (After Marratt et al. 1984) 


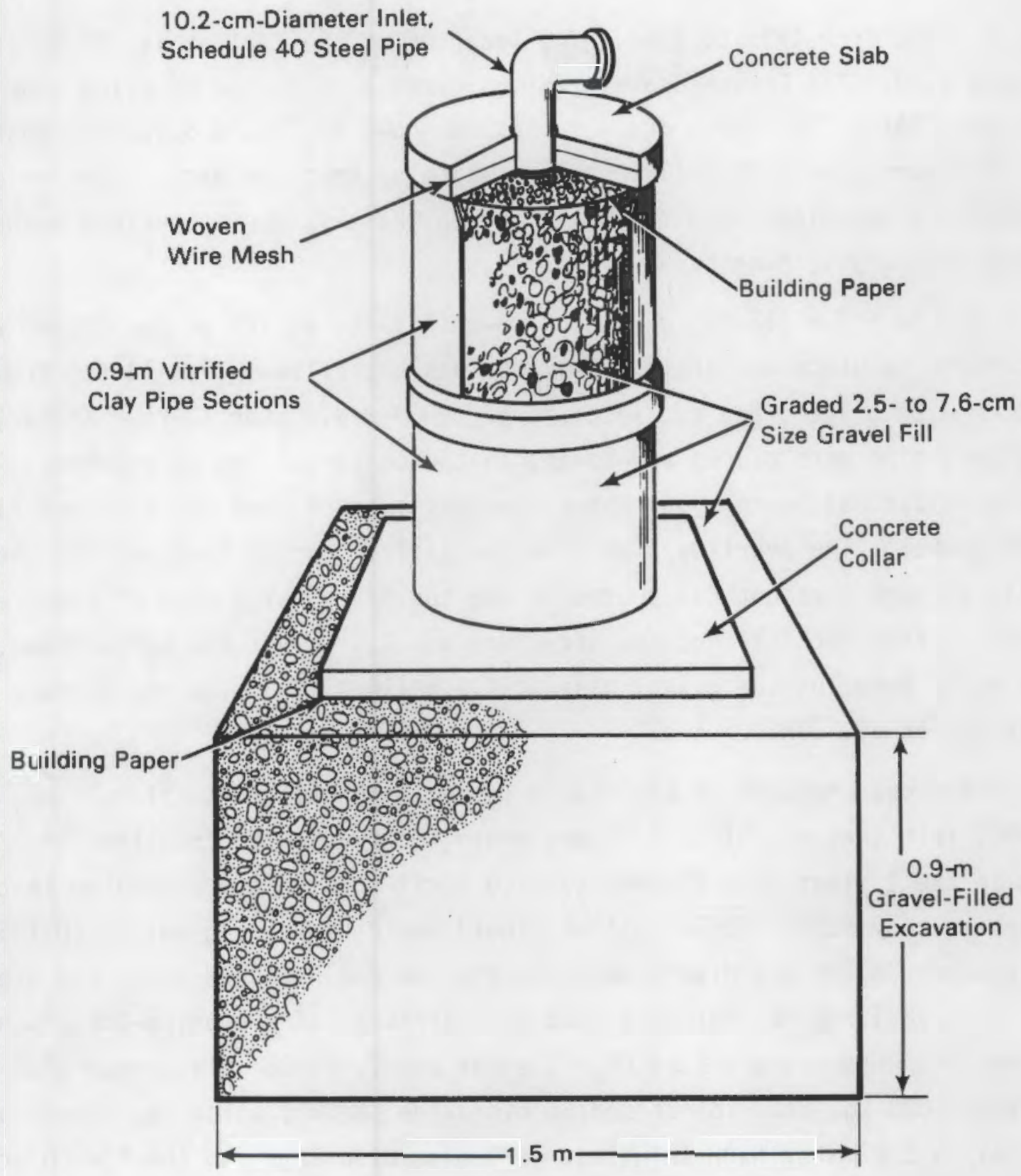

FIGURE 5.32. Schematic Diagram of the 216-Z-8 French Drain System (After Marratt et a1. 1984) 
the $Z$ plant from 1955 to 1962. The location of the $Z$ plant is illustrated in Figure 5.30. The French drain received overflow from the settling tank after October 1957. The French drain structure shown in Figure 5.32 was constructed to hold more than 1000 I (264 gal) of waste so that the waste solution could completely percolate into the soil beneath the site during periods between waste discharges (Marratt et al. 1984).

A site $5.3-\mathrm{m}(17-\mathrm{ft})$ deep and $1.5-\mathrm{m}(4.9-\mathrm{ft})$ square at the bottom was excavated to place the drain. The site was backfilled $0.9 \mathrm{~m}(3 \mathrm{ft})$ from the bottom with gravel, and two sections of a 0.9 -m-diameter (3-ft-diameter) clay vitreous pipe were placed end-to-end in the center of the excavation. A concrete collar was poured just above the gravel layer, and the pipe was filled with gravel. The overflow pipe from the silica storage tank entered the French drain through a cement cap poured at the top of the clay pipe of the French drain. After backfilling, the structure was $2.5 \mathrm{~m}(8.2 \mathrm{ft})$ below grade, with the waste entering the gravel base at $4.4 \mathrm{~m}(14.4 \mathrm{ft})$ below the surface (Marratt et al. 1984).

From measurements of the liquid level in the silica settling tank, DOE (1986) felt that the 216-Z-8 French drain received waste from the 234-5Z building in the $Z$ plant from October 1957 to April 1962. They estimated that approximately $9590 \mathrm{l}$ (2530 gal) of liquid waste containing $48.2 \mathrm{~g}(0.106 \mathrm{lb})$ of plutonium-238,239 was discharged into the 216-2-8 French drain. The Stenner et al. (1988) report indicated that the inventory of plutonium-239 discharged to the French drain was $2.76 \mathrm{Ci}$. Stenner et al. (1988) also noted that approximately $1000 \mathrm{~kg}(2200 \mathrm{lb})$ of sodium hydroxide $(\mathrm{NaOH})$, which represents approximately a $2.6 \mathrm{molar} \mathrm{NaOH}$ solution, were al so discharged to the French drain during this time.

Marratt et al. (1984) conducted a characterization study to determine the distribution of radionuclides beneath the French drain and to investigate a suspected leak in the settling tank. One well was drilled $1 \mathrm{~m}(3 \mathrm{ft})$ south of the drain, and radiological and geological analyses were performed. The soil immediately beneath the French drain was found to be composed of silty, sandy 
medium to fine pebble typical of the Hanford Formation(a) soils. The highest plutonium-239 concentration observed in the well was $4.62 \mathrm{nCi} / \mathrm{g}$ and occurred at a depth of $7.6 \mathrm{~m}(25 \mathrm{ft})$. From data collected from the well samples, they estimated that 4 to $5 \mathrm{~m}^{3}$ (5 to $7 \mathrm{yd}^{3}$ ) of radioactively contaminated sediments, at concentrations greater than or equal to $10 \mathrm{nCi} / \mathrm{g}$, lay directly underneath the French drain.

\subsubsection{Application of RAPS to Site $216-2-8$}

To apply the partially saturated component of the RAPS methodology to the 216-Z-8 site, a waste disposal scenario must be developed that simplifies the complexities of the real-world situation and addresses the most important parameters needed to model a hazardous waste site. This scenario is developed below and the parameters used in the 216-Z-8 model are discussed and quantified.

\subsubsection{Scenario Development for Site 216-z-8}

Much of the detail of the environmental setting and disposal history at the 216-Z-8 site is described in Section 5.5.1. The five areas of concern in assessing a hazardous waste site, as outlined in Chapter 3.0, are constituents of interest and form of the constituents, level of contamination, mechanism of release, source of the water transporting the contaminants, and the time frame over which the contaminants are released into the environment. These areas as they relate to the $216-Z-8$ site are:

1) constituents of interest and form of constituents -- Monitoring information was available, which identified plutonium-239 as the primary constituent of concern.

2) level of contamination -- The total inventory of plutonium-239 discharged into the French drain over a 5.1-year time span equalled 2.76 Ci (Stenner et al. 1988).

3) mechanism of release -- During the operational life of the site, 95901 (2530 gal) of an aqueous waste containing $2.76 \mathrm{Ci}$ of

(a) Hanford Formation is a local term used to describe the multiple layers of flood-deposited sand and gravel beneath the Hanford Site. 
plutonium-239 was directly released into the French drain, which had a diameter of $0.91 \mathrm{~m}(3 \mathrm{ft})$. The waste passed through $2.8 \mathrm{~m}(9.2 \mathrm{ft})$ of gravel before reaching the partially saturated zone.

4) source of water -- The waste stream originated in the 234-5Z building in the $Z$ Plant exclusion area and passed through a settling tank before reaching the $216-z-8$ French drain. The aqueous waste stream, therefore, represents the major source of the liquid transporting the plutonium-239 through the partially saturated zone.

5) time frame -- The level of contamination is averaged over the 5.5-year period from October 1957 to April 1962.

\subsubsection{Quantification of Parameters for Site 216-Z-8}

The parameters required for application of the partially saturated zone component of the RAPS methodology are:

1) temporally distributed contaminant fluxes -- The temporally distributed contaminant fluxes represent the most important information used in this assessment exercise. The mass flux was calculated as an annual average from the estimated activity of plutonium-239 discharged to the 216-Z-8 site from October 1957 through Apri1 1962, as reported by Marratt et al. (1984) and Stenner et al. (1988); that is, $2.76 \mathrm{Ci}$ over $5.5 /$ years.

2) decay rate -- The half-1 ife of plutonium- 239 is 24,400 years (Weast 1984, Codell et a1. 1982). Based on the first-order decay assumption for radioactivity, the corresponding decay rate for plutonium-239 is $2.84 \times 10^{-5} /$ year.

3) equilibrium coefficient -- As noted in Section 5.4.2.2, Delegard and Barney (1983) performed several experiments to determine representative $k_{d}$ values for various radionuclides leached through Hanford soils. As noted previously, they varied the $\mathrm{pH}$ and organic composition of the waste and estimated $k_{d}$ values for plutonium-239 from these tests. Because plutonium-239 was not discharged with organic material, the waste stream was classified as a noncomplexed solution. The inventory of $\mathrm{NaOH}$ in the waste stream also classified the waste 
stream as being between a dilute and concentrated solution. $A K_{d}$ equaling $71 \mathrm{ml} / \mathrm{g}$ was associated with the dilute solution, while the concentrated solution had a $K_{d}$ of $2.2 \mathrm{ml} / \mathrm{g}$. Because it represented a more conservative estimate, $2.2 \mathrm{ml} / \mathrm{g}$ was chosen to represent the equilibrium coefficient.

4) length and width of waste site -- Figure 5.32 indicates that the dimensions of the 216-Z-8 French drain system increase from top to bottom. The circular pipe on top has a diameter of $0.9 \mathrm{~m}(3 \mathrm{ft})$, resulting in a cross-sectional area of $0.64 \mathrm{~m}^{2}\left(6.8 \mathrm{ft}^{2}\right)$. The square base of the French drain is $1.5 \mathrm{~m}(4.9 \mathrm{ft})$ on side, resulting in a cross-sectional area of $2.25 \mathrm{~m}^{2}\left(24.2 \mathrm{ft}^{2}\right)$. The cross-sectional area of the base is, therefore, over 3.5 times as large as that of the standing pipe on top. Given that two sets of dimensions are available to describe the French drain system, the most conservative, but realistic, dimensions are associated with the standing circular pipe on top and were chosen to represent those of the French drain. A characteristic length and width, equaling $80 \mathrm{~cm}(2.6 \mathrm{ft})$, was computed by taking the square root of the cross-sectional area of the circular pipe.

5) porosity -- Because a representative porosity for the gravel used in the French drain was unavailable from site documents, the porosity of the gravel layer was estimated from Israelson and Hanson (1962) as equaling $30 \%$. Sisson and Lu (1984) reported a porosity of $32.5 \%$ for soils typical of those found below the French drain.

6) bulk density -- The bulk density can be estimated from Equation (5.36), a soil particle density of $2.65 \mathrm{~g} / \mathrm{cm}^{3}$, and the porosity of a particular soil. For the gravel layer used in the 
French drain, the bulk density was computed as $1.8 \mathrm{~g} / \mathrm{cm}^{3}$. (a) For the alluvial material below the French drain, the bulk density was estimated as $1.9 \mathrm{~g} / \mathrm{cm}^{3}$.

7) field capacity -- The field capacity for this analysis is estimated from the soil moisture release curve presented in Figure 5.19, as developed by Sisson and Lu (1984) for a coarse alluvial Hanford soil. From Figure 5.19, the field capacity is defined as $8 \%$ (volume basis), corresponding to a suction head of $100 \mathrm{~cm}$. Field capacity for the gravel layer was unavailable from site documents. Based on soil characteristics data published by Israelson and Hanson (1962), the field capacity of the gravel layer was assumed to be $6 \%$ (volume basis).

8) leach rate -- The leach rate of $0.79 \mathrm{~cm} / \mathrm{d}(0.31 \mathrm{in.} / \mathrm{d})$ was calculated from the maximum average annual flow of aqueous waste into the site (i.e., 95901 (2530 gal) over 5.1 years) and the cross-sectional area of the site (i.e., $\left.0.64 \mathrm{~m}^{2}\left(6.8 \mathrm{ft}^{2}\right)\right)$.

9) saturated hydraulic conductivity -- The saturated hydraulic conductivity value of $5360 \mathrm{~cm} / \mathrm{d}(2110 \mathrm{in./d})$ was obtained from Sisson and Lu (1984) and corresponded to the appropriate Hanford soil for which the porosity and bulk density were obtained. The saturated hydraulic conductivity value of $86,400 \mathrm{~cm} / \mathrm{d}$ was obtained for the gravel layer from Freeze and Cherry (1979).

10) longitudinal dispersivity -- As noted in Section 5.4.2.2, although a generalized theory to describe dispersivity has not yet been developed, EPA (1986) reports that some investigators (e.g., Gelhar and Axness 1981) have reported simple, linear dependencies, based on mean travel distance, for dispersivity in the flow direction. Gelhar and Axness, although not recommending a particular relationship, suggest that the dispersivity might be defined as being approximately equal

(a) Normally the porosity is determined from the bulk density. Specific weights (i.e., particle density) usually range between 2.6 to $2.8 \mathrm{~g} / \mathrm{cm}^{3}$. A commonly used value of $\mathrm{S}_{W}$ is $2.65 \mathrm{~g} / \mathrm{cm}^{3}$, although some Hanford soils have been measured at $2.8 \mathrm{~g} / \mathrm{cm}^{3}$. 
to $10 \%$ of the mean travel distance. Given that a better approximation is unavailable at this time and that "EPA (U.S. Environmental Protection Agency) believes that this relationship is a reasonable approximation ..." (EPA 1986), this relationship is assumed for this assessment.

11) Soil-type coefficient -- As noted in Section 5.4.2.2, the soil-type coefficient refers to the exponential parameter defined in Equation (5.26) (i.e., m). Clapp and Hornberger (1978) have defined this soil-type coefficient as a function of soil type. For alluvial material, their suggested value of 0.09 was used in the assessment. They did not, though, provide any values for soils with particle diameters larger than sand-sized particles. Although correlated relationships based on Clapp and Hornberger's (1978) data were investigated to estimate an appropriate value of a soil-type coefficient for gravel, no acceptable value was determined. Because an acceptable value for gravel was unavailable, it was assumed equivalent to that of sand (i.e., 0.09).

A summary for the data employed as part of this assessment is presented in Table 5.9.

\subsubsection{Results Associated with the Application of RAPS to Site 216-Z-8}

The subsurface component of the RAPS methodology computes spacially and temporally distributed contaminant concentrations in the partially saturated zone beneath a hazardous waste site. Results of the application of the RAPS methodology to the $216-\mathrm{Z}-8$ site are presented in this section. The results of the assessment are presented in Figure 5.33. The results presented in this figure represent a "snapshot" in time. The temporal distribution of the concentration, as the contaminant passes a particular location, is unavailable. These results represent only the spacial distribution of the contaminant approximately 27 years after the initial release of the waste into the environment.

For the simulated results, $K_{d}$ can affect the travel time and the prediction of the spacial distribution of the contaminant. As Figures 5.22 through 
TABLE 5.9. Data for the 216-Z-8 Site Assessment

Parameter

Contaminant decay rate

Contaminant equilibrium coefficient

Leach rate

Length of disposal site

Width of disposal site

Gravel Layer:

Saturated hydraulic conductivity

Bulk density

Longitudinal dispersivity

Porosity

Field capacity (by volume)

Soil-type coefficient

Sand Layer:

Saturated hydraulic conductivity

Bulk density

Longitudinal dispersivity

Porosity

Field capacity (by volume)

Soil-type coefficient

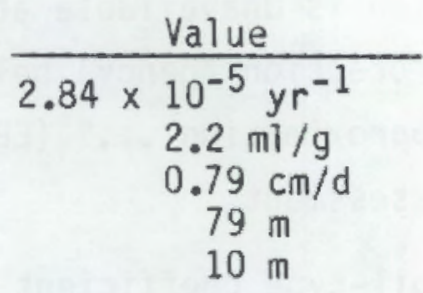

$86400 \mathrm{~cm} / \mathrm{d}$

$1.79 \mathrm{~g} / \mathrm{cm}^{3}$

0.1 of depth

0.30

0.06

4.05

5.25 indicate in the assessment of the $216-Z-1 A$ waste site, as $K_{d}$ increases, the contaminant's travel time increases and, as one moves farther from the site, the contaminant's concentration decreases. For the observed results, expressed in units of $\mathrm{Ci} / \mathrm{ml}$, an increase in $\mathrm{K}_{d}$ will result in a decrease in the observed concentration. Care, therefore, must be exercised when analyzing the results presented in Figure 5.33.

Although the simulated plutonium-239 concentrations are a couple of orders of magnitude above those of the observed concentrations, the actual discrepancy may not be as large as these results indicate. First, a conservative equilibrium coefficient was assumed for the waste stream. By assuming a slightly larger $K_{d}$, the predicted concentrations would be reduced and would more closely approach those of the observed concentrations. Second, the representative cross-sectional area of the waste site was conservatively chosen as being equal to the area of the standing pipe (see Figure 5.32) as opposed to being set equal to the area of the base of the French drain, whose area is over 3.5 times 


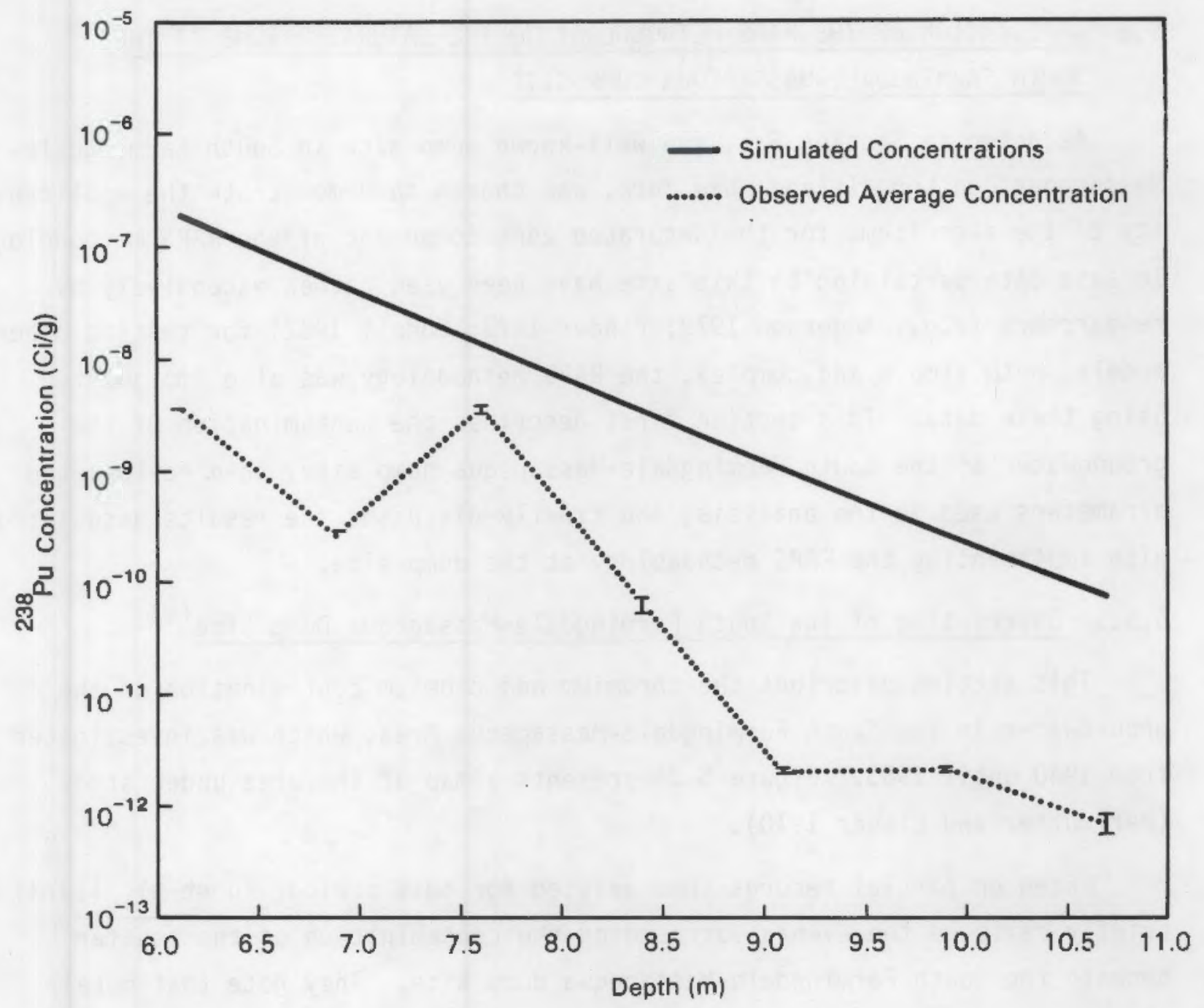

FIGURE 5.33. Simulated and Observed Spacially Varying Plutonium-239 Concentrations Beneath the 216-Z-8 Waste Site

that of the standing pipe. An increase in the representative cross-sectional area would have decreased the simulated contaminant concentrations beneath the French drain. Finally, the observed concentrations (in units of $\mathrm{Ci} / \mathrm{g}$ ) were collected at a well $1.5 \mathrm{~m}(4.8 \mathrm{ft})$ from the center of the French drain. The observed concentrations directly under the French drain are most likely higher than those measured in the nearby observation well and, therefore, higher than the observed concentrations plotted in Figure 5.33. 


\subsection{APPLICATION OF THE RAPS METHOOOLOGY TO THE SATURATEO ZONE AT THE SOUTH FARMINGDALE-MASSAPEQUA DUMP SITE}

As noted in Section 5.1, the well-known dump site in South FarmingdaleMassapequa, on Long Island, New York, was chosen to demonstrate the applicability of the algorithms for the saturated zone component of the RAPS methodology. Because data pertaining to this site have been used rather extensively by researchers (e.g., Anderson 1979; Pinder 1973; Codell 1982) for testing other models, both simple and complex, the RAPS methodology was also implemented using these data. This section first describes the contamination of the groundwater at the South Farmingdale-Massapequa dump site, then reviews the parameters used in the analysis, and finally discusses the results associated with implementing the RAPS methodology at the dump site.

5.6.1 Description of the South Farmingdale-Massapequa Durmp Site ${ }^{(a)}$

This section describes the chromium and cadmium contamination of the groundwater in the South Farmingdale-Massapequa Area, which was investigated from 1940 until 1963. Figure 5.34 presents a map of the area under study (Perlmutter and Lieber 1970).

Based on partial records that existed for this period, Ku et al. (1978) briefly reviewed the events surrounding the contamination of the aquifer beneath the South Farmingdale-Massapequa dump site. They note that metalplating waste had infiltrated through waste disposal basins from an industrial park in the South Farmingdale-Massapequa area into the upper glacial aquifer (i.e., water table) since the early 1940s. The resulting plume of altered groundwater with elevated chromium and cadmium levels extended approximately $1300 \mathrm{~m}$ (4265 ft) downgradient from the disposal basins and discharged into nearby Massapequa Creek (Ku et al. 1978).

Ku et al. (1978) also note that the alteration of the quality of the groundwater in the South Farmingdale-Massapequa area was first discovered in 1942 when elevated levels of chromium were detected (Davids and Lieber 1951,

(a) This section is based on Codell et al. (1982), Perlmutter and Lieber (1970), Pinder (1973), Lieber et al. (1964), Ku et al. (1978), and Anderson (1979). 


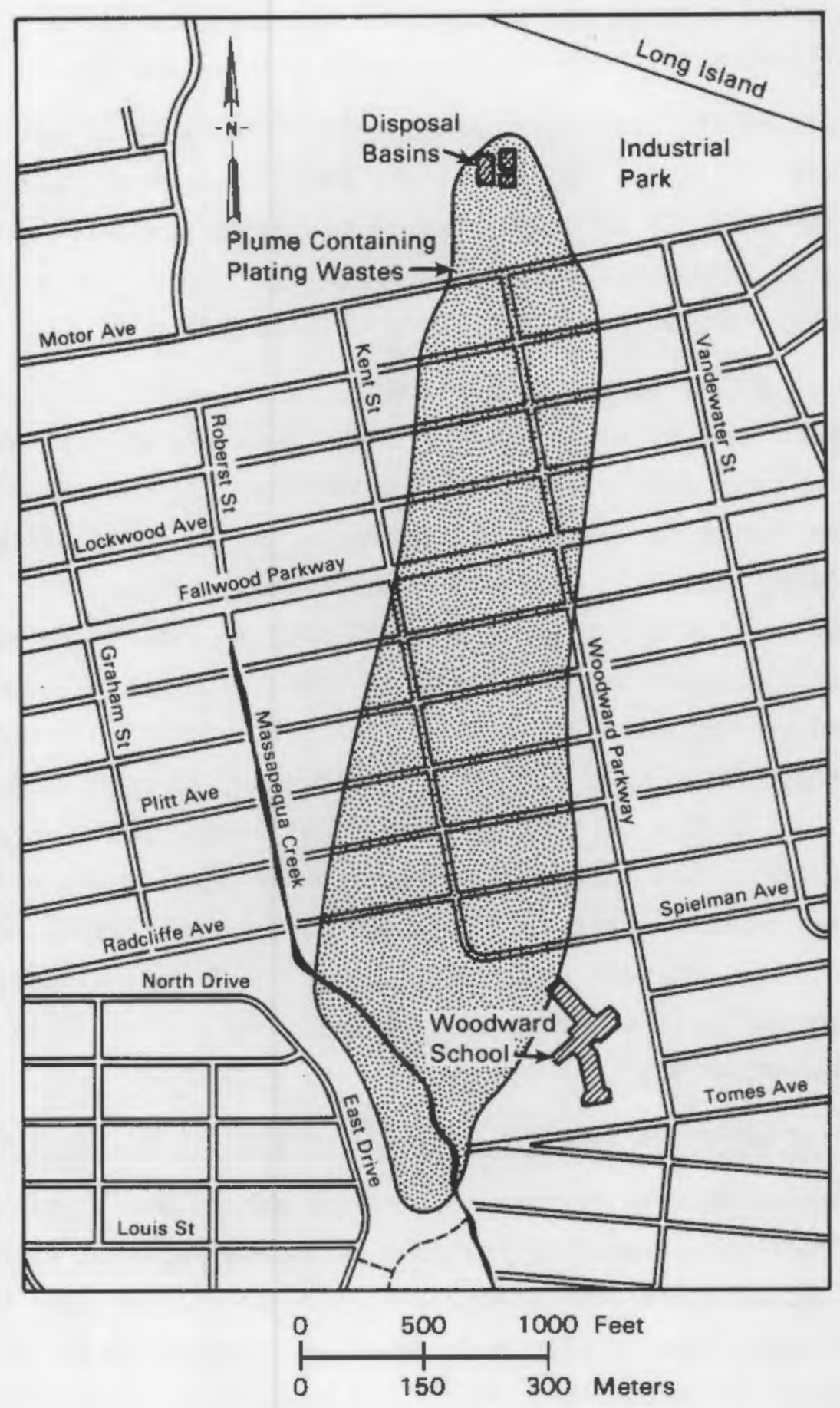

FIGURE 5.34. Measured Areal Extent of Contamination (After Perlmutter and Lieber 1970) 
after Ku et al. 1978). The contamination was attributed to the discharge of liquid industrial plating wastes into the disposal basins at the industrial park and subsequent leaching into the upper glacial aquifer.

The depth of the upper glacial aquifer in the area of concern ranges from 20 to $43 \mathrm{~m}$ (66 to $141 \mathrm{ft}$ ) (Codell et a1. 1982). Ku et a1. (1978) report that 1) the aquifer consists mainly of medium to course sand with lenses of fine sand and gravel, 2) porosity averages about $35 \%$, and 3 ) the average hydraulic conductivity is estimated to be $6.5 \mathrm{~m} / \mathrm{d}(260 \mathrm{ft} / \mathrm{d})$.

Codell et al. (1982), citing Perlmutter and Lieber (1970), note that records suggest that during the early 1940s, possibly as much as 1.1 million liters per day [0.3 mgd (million gallons per day)] of contaminated effluent was pumped at the industrial park. The amount of contaminated effluent recharged in the following decade is uncertain, but probably ranged from an estimated low of about 0.08 million liters per day ( $0.02 \mathrm{mgd})$ in 1957 to an estimated high of 0.49 million liters per day ( $0.13 \mathrm{mgd})$ in 1953 . The estimated recharge of contaminants and cooling water in 1963 was about 0.19 million liters per day $(0.05$ mgd). It is estimated that during the early $1940 \mathrm{~s}$ as much as 0.8 to $1.1 \mathrm{mil}$ lion liters ( 0.2 to 0.3 million gallons) of effluent, containing about $24 \mathrm{~kg}$ (52 1b) of chromium and smaller amounts of other metals, was discharged daily into the upper glacial aquifer. Perlmutter and Lieber (1970) mention that a 1953 sample of the effluent contained $1.2 \mathrm{mg} / 1(1.2 \mathrm{ppm})$ of cadmium. In 1949, a chromium-removal unit was installed at the plant. Since then, chromium leaching information has been scarce.

\subsubsection{Application of RAPS to the South Farmingdale-Massapequa Dump Site}

This section briefly reviews methods for manipulating available data and converting complex real-world situations to more simplified scenarios that are more consistent with the limitations and assumptions that form the basis of the RAPS methodology. This section also describes the parameters of interest and modeling results and presents a comparison between monitored and simulated contaminant concentrations in the aquifer surrounding the site. 


\subsubsection{Scenario Development for the South Farmingdale-Massapequa Dump Site}

Section 5.6.1 briefly describes the events that led to the contamination of the groundwater at the South Farmingdale-Massapequa dump site. Although the data from the site are limited, there is enough information to estimate the source term and address the five areas of critical concern outlined in Chapter 3.0. The five critical areas, as they relate to the South FarmingdaleMassapequa dump site, are as follows:

1) constituents of interest and form of constituents -- The constituents of interest are hexavalent chromium and cadmium. The constituents are part of a liquid effluent waste stream that was discharged directly to a holding basin.

2) level of contamination -- Although the exact flux and concentration of each constituent was not in the supporting documentation, enough information was in the reports to estimate the contaminant flux rates to and corresponding concentrations in the aquifer. The method used to estimate the contaminant fluxes and concentrations will be presented in Section 5.6.2.2.

3) mechanism of release -- The liquid effluent discharged to the holding basin was the fluid transporting the chromium and cadmium to the subsurface aquifer.

4) source of water -- The liquid effluent discharged to the holding basin was also the source of "water" transporting the constituents to the saturated subsurface aquifer. The liquid flux was the driving force behind the movement of the contaminants.

5) time frame -- The contaminants were discharged to the holding basin over a 23-year period. The distribution of the contaminant fluxes over this time can be estimated from site documents; the method used for estimating the contaminant fluxes will be presented in Section 5.6.2.2.

Once the five areas of concern have been addressed, the specific parameters used in the assessment can be defined. The various methods used to 
define these parameters are outlined in detail and illustrate how data can be manipulated to meet input requirements of the RAPS methodology.

\subsubsection{Quantification of Parameters for the South Farmingdale-Massapequa Dump Site}

The values of the parameters used in the analysis are those used by codell et al. (1982) and Pinder (1973) and reported by Anderson (1979). The value for each parameter used in the assessment is identified below, along with a brief explanation of how the parameter was defined:

1) temporally distributed contaminant fluxes -- The temporally distributed fluxes are the most important information used in this assessment exercise. Although they are not specifically identified in the supporting documentation, they can be calculated from it.

Given the background information presented in Section 5.6.1, the effluent concentration and leach rate of chromium in the early 1940s were 20.8 to $31.2 \mathrm{mg} / 1(20.8$ to $31.2 \mathrm{ppm})$ and $8.62 \times 10^{6} \mathrm{~g} /$ year $\left(1.90 \times 10^{4} \mathrm{lb} /\right.$ year $)$, respectively. The early 1940 s are assumed as 1940 to 1943. A range in values for the effluent concentration and leach rate of chromium depends upon the recharge rate assumed for the analysis (see Section 5.6.1).

From 1944 to 1949 the assumed recharge rate of effluent was based on the 1953 value of $0.49 \mathrm{milli}$ ion liters per day $(0.13 \mathrm{mgd})$. The rate of $1.1 \mathrm{milli}$ on liters per day $(0.3 \mathrm{mgd})$ was not used because it only pertained to the early 1940s. The concentration for the period 1944 to 1949 was based on that of the early 1940s, because the chromiumremoval unit had not yet been installed.

For the years after 1949, Pinder (1973) suggested that an assumed reduced chromium effluent of $10 \mathrm{mg} / 1$ (10 $\mathrm{ppm})$ produced results consistent with the effluent analyses obtained during a sampling program conducted in 1962. Using this information, the leachate from 1950 to 1953 was assumed to be $1.79 \times 10^{6} \mathrm{~g} /$ year $\left(3.94 \times 10^{3} \mathrm{1b} /\right.$ year $)$. The effluent concentration and leach rates of chromium in 1957 were assumed to be $10 \mathrm{mg} / 1$ (10 ppm) and $2.74 \times 10^{5} \mathrm{~g} /$ year $(6.03 \mathrm{x}$ 
$10^{2} \mathrm{ib} /$ year), respectively. This was based upon a recharge rate of 0.08 million liters per day $(0.02 \mathrm{mgd})$. The concentration and leach rates in 1963 were assumed to be $10 \mathrm{mg} / 1$ (10 ppm) and $6.88 \mathrm{x}$ $10^{5} \mathrm{~g} /$ year $\left(1.51 \times 10^{3} \mathrm{lb} /\right.$ year $)$, respectively; this value was based upon the recorded recharge rate of 0.19 million liters per day (0.05 mgd).

Fewer data were available for cadmium than for chromium. As noted earlier, Perlmutter and Lieber (1970) reported that a 1953 sample of the effluent contained $1.2 \mathrm{mg} / 1(1.2 \mathrm{ppm})$ of cadmium. Based upon this information, it was assumed that the cadmium concentration in the effluent remained constant at $1.2 \mathrm{mg} / 1(1.2 \mathrm{ppm})$ and that the recharge rate of effluent as the same as that assumed for chromium. Under these circumstances, the leach rates of cadmium were $4.96 \mathrm{x}$ $10^{5} \mathrm{~g} /$ year $\left(1.09 \times 10^{3} \mathrm{lb} /\right.$ year $)$ for 1940 to $943,2.15 \times 10^{5} \mathrm{~g} /$ year $\left(4.73 \times 10^{2} \mathrm{lb} /\right.$ year $)$ for 1944 to $1953,3.32 \times 10^{4} \mathrm{~g} /$ year (73.0 1b/year) for 1957 , and $8.30 \times 10^{4} \mathrm{~g} /$ year $(183 \mathrm{lb} /$ year $)$ for 1963.

Finally, it was assumed for chromium and cadmium that a linear relationship for the source function extended during the time spans of 1953 to 1957 and 1957 to 1963. Although this assumption may be incorrect, no better relationship is known. The temporal variations of the source functions for cadmium and chromium are presented in Figures $5.35 \mathrm{a}$ and $5.35 \mathrm{~b}$, respectively.

2) degradation rate -- Because hexavalent chromium and cadmium do not degrade in the environment, the degradation rates were assumed to be zero. If the geochemistry at the site had dictated that these contaminants would precipitate out of solution and remain in that state, a pseudodegradation rate could have been assigned to each constituent. Because there is no indication in the supporting documentation of this occurring and because a zero degradation rate represents a conservative assumption, the degradation rate for each constituent is assumed to be zero. 

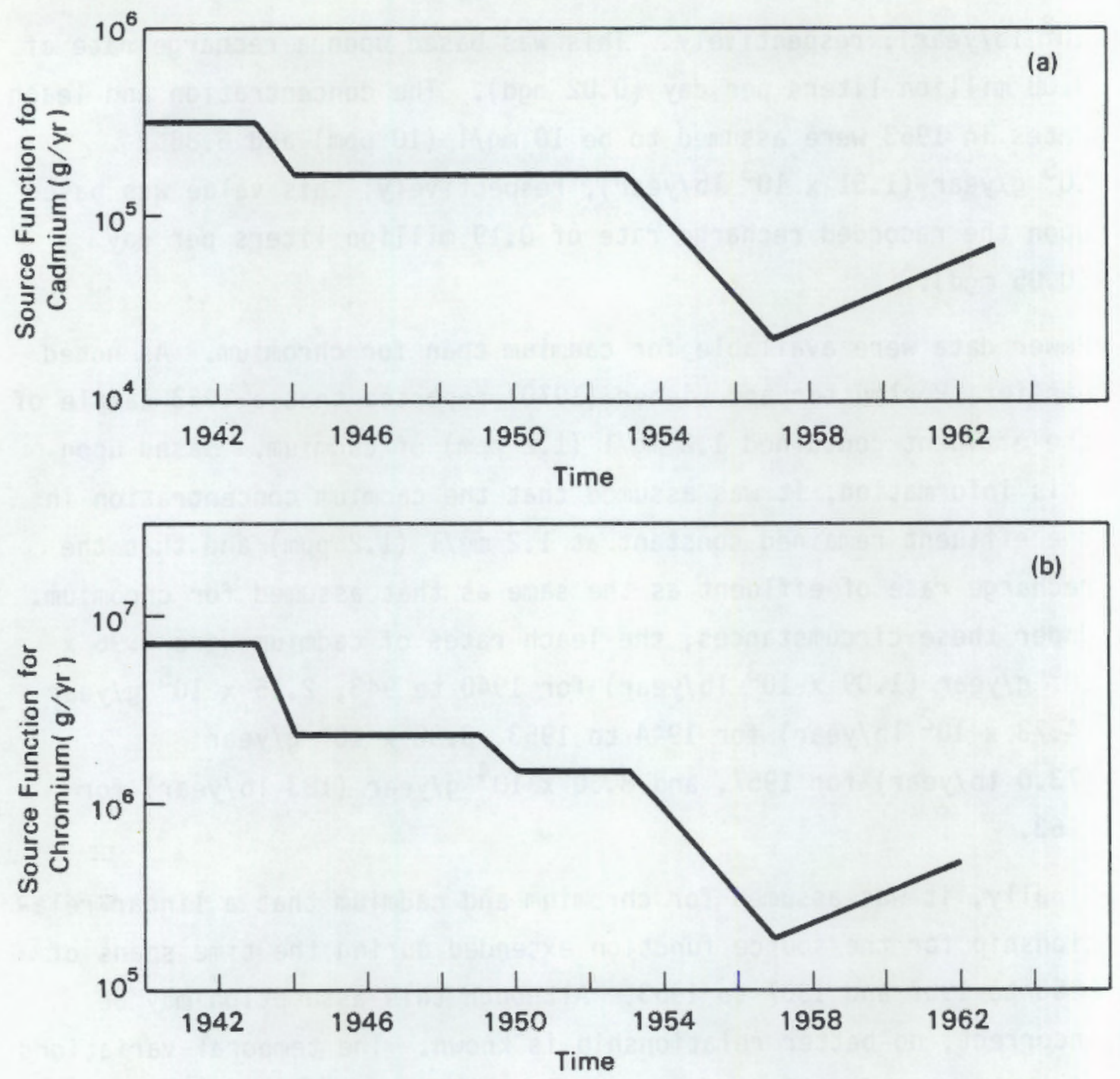

FIGURE 5.35. Source Function for (a) Cadmium and (b) Chromium

3) equilibrium coefficient for hexavalent chromium and cadmium -Callahan et al. (1979) note that the hexavalent form of chromium is quite soluble, existing in solution as a complex ion, and is not sorbed to any significant degree by clays or hydrous metal oxides. Rai et al. (1984) note, though, that the adsorptive behavior of hexavalent chromium in soil is not well documented. They also note that several column attenuation studies have indicated qualitatively that chromate is relatively mobile through soil. Because little is 
known about the behavior of the hexavalent chromium at the site and because assuming zero for the equilibrium coefficent is conservative, the equilibrium coefficent is assumed to be zero.

Callahan et al. (1979) note that compared to other heavy metals cadmium is relatively mobile, although it does have adsorptive properties. Rai et al. (1984) state that the adsorptive behavior of cadmium is a function of the cation exchange capacity of the soil; the $\mathrm{pH}$; the percent of organic material; the amounts of aluminum, calcium, and zinc present; complexation by organic 1igands; and the competition with other cations for adsorption sites. Because little is known about the geochemical behavior of cadmium at the site, and because an equilibrium coefficent of zero is conservative, the equilibrium coefficent is assumed to be zero.

4) length and width of waste site -- The horizontal extent of the leaching contaminated effluent is unknown. Perlmutter and Lieber (1970) have mentioned indirectly that the area source, as represented by the recharge-basin complex, could be described as an area with a diameter of $61 \mathrm{~m}(200 \mathrm{ft})$. Based on this assumption, the length and width of the area source were assumed to be $54 \mathrm{~m}$ (177 ft) (i.e., the square root of the area).

5) aquifer thickness -- According to Perlmutter and Lieber (1970), the aquifer ranged in thickness between 20 and $43 \mathrm{~m}$ (66 and $141 \mathrm{ft}$ ). Although both of these aquifer depths have been addressed in the analysis, the smaller value would be used in any exposure and health effects assessment exercise.

6) porosity -- Perlmutter and Lieber (1970), Pinder (1973), Ku et al. (1978), and Anderson (1979) indicate that the porosity of the saturated aquifer is $35 \%$. 
7) bulk density -- The bulk density at the site can be computed from from the porosity, assuming a specific weight of the alluvial soil of $2.65 \mathrm{~g} / \mathrm{cm}^{3}$.(a) From Equation (5.36), the bulk density of the soil was estimated as $1.77 \mathrm{~g} / \mathrm{cm}^{3}$.

8) Groundwater flow velocity -- Perlmutter and Lieber (1970) estimated the groundwater velocity as being between $15 \mathrm{~cm} / \mathrm{d}(5.9 \mathrm{in.} / \mathrm{d})$ and 46 $\mathrm{cm} / \mathrm{d}$ (18 in./d), whereas Pinder (1973) suggested a value of $43.2 \mathrm{~cm} / \mathrm{d}$ (17 in./d). Pinder's value of $43.2 \mathrm{~cm} / \mathrm{d}(17 \mathrm{in./d})$ was assumed for this exercise (Perlmutter and Lieber 1970; Pinder 1973).

9) longitudinal, lateral (transverse), and vertical dispersivities -Pinder (1973) noted that in the absence of measured values for these properties for the study area, estimates based on tests conducted in similar material could be used. Anderson (1979) notes that a trialand-error procedure by Pinder (1973) (using Pinder's numerical model) was employed to update these values, and the measured chromium concentration distribution was satisfactorily reproduced, with a longitudinal dispersivity of $21.3 \mathrm{~m}$ and a transverse dispersivity of $4.27 \mathrm{~m}$. The vertical dispersivity was assumed to equal that of the lateral dispersivity.

The data employed for this simulation are summarized in Table 5.10.

5.6.3 Results Associated with the Application of RAPS to the South Farmingdale-Massapequa Dump Site

The subsurface component of the RAPS methodology calculates the concentrations at points downgradient of an area source in a uniform aquifer, using anaiytical solutions to the equations of mass transfer for conservative substances in a porous medium. This component was employed in the onsite modeling of chromium and cadmium contamination of the groundwater in the mouth FarmingdaleMassapequa area, Nassau County, New York. The results of the model simulation are presented in Figures 5.36 through 5.39.

(a) Nornally the porosity is determined from the bulk density. Specific weights (i.e., particle density) usually range betweeg 2.6 to $2.8 \mathrm{~g} / \mathrm{cm}^{3}$. A commonly used value of specific weight is $2.65 \mathrm{~g} / \mathrm{cm}^{3}$. 
TABLE 5.10. Data for the South Farmingdale-Massapequa Chromium-Cadmium Site Modeling

\begin{tabular}{|c|c|}
\hline Parameter & Value \\
\hline Contaminant degradation rate & $0 y r^{-1}$ \\
\hline Contaminant equilibrium coefficient & $0 \mathrm{ml} / \mathrm{g}$ \\
\hline Groundwater velocity & $43.2 \mathrm{~cm} / \mathrm{d}$ \\
\hline Aquifer thickness & $2000 \mathrm{~cm}$ to $4300 \mathrm{~cm}$ \\
\hline$x$-Direction dispersivity & $2130 \mathrm{~cm}$ \\
\hline$y$-Direction dispersivity & $427 \mathrm{~cm}$ \\
\hline$z$-Direction dispersivity & $427 \mathrm{~cm}$ \\
\hline Bulk density & $1.72 \mathrm{~g} / \mathrm{cm}^{3}$ \\
\hline Length of disposal site & $5400 \mathrm{~cm}$ \\
\hline Width of disposal site & $5400 \mathrm{~cm}$ \\
\hline Porosity & 0.35 \\
\hline
\end{tabular}

The solid curve in each figure represents the simulated results when the aquifer was $20 \mathrm{~m}(66 \mathrm{ft})$ thick, while the broken curve represents the simulated results when the aquifer was $43 \mathrm{~m}(141 \mathrm{ft})$ thick. The $20-\mathrm{m}(66-\mathrm{ft})$ and $43-\mathrm{m}$ (141-ft) values represent the minimum and maximum saturated aquifer thicknesses. The shaded area in each figure represents the range of the observed contaminant concentrations reported by Perimutter and Lieber (1970). This observed range is presented to show that the concentration is not uniformly distributed in any direction within the aquifer. Thus, the measured concentration depends on the location and the time the sample was taken. The observed data have not been averaged because such averaging could be distorted to produce desired results. Finally, the simulated range (solid and broken curves) is presented because the aquifer thickness varied from $20 \mathrm{~m}(66 \mathrm{ft})$ to $43 \mathrm{~m}$ (141 ft) within the simulation area.

Figures 5.36 and 5.37 illustrate temporal and spacial variations in chromium concentration. Both figures present the same results, but in different forms. Note that chromium samples were not regularly collected until 1949. Figure 5.36 presents the temporal variation in chromium concentration at five locations downgradient of the area source. It also presents the simulated 


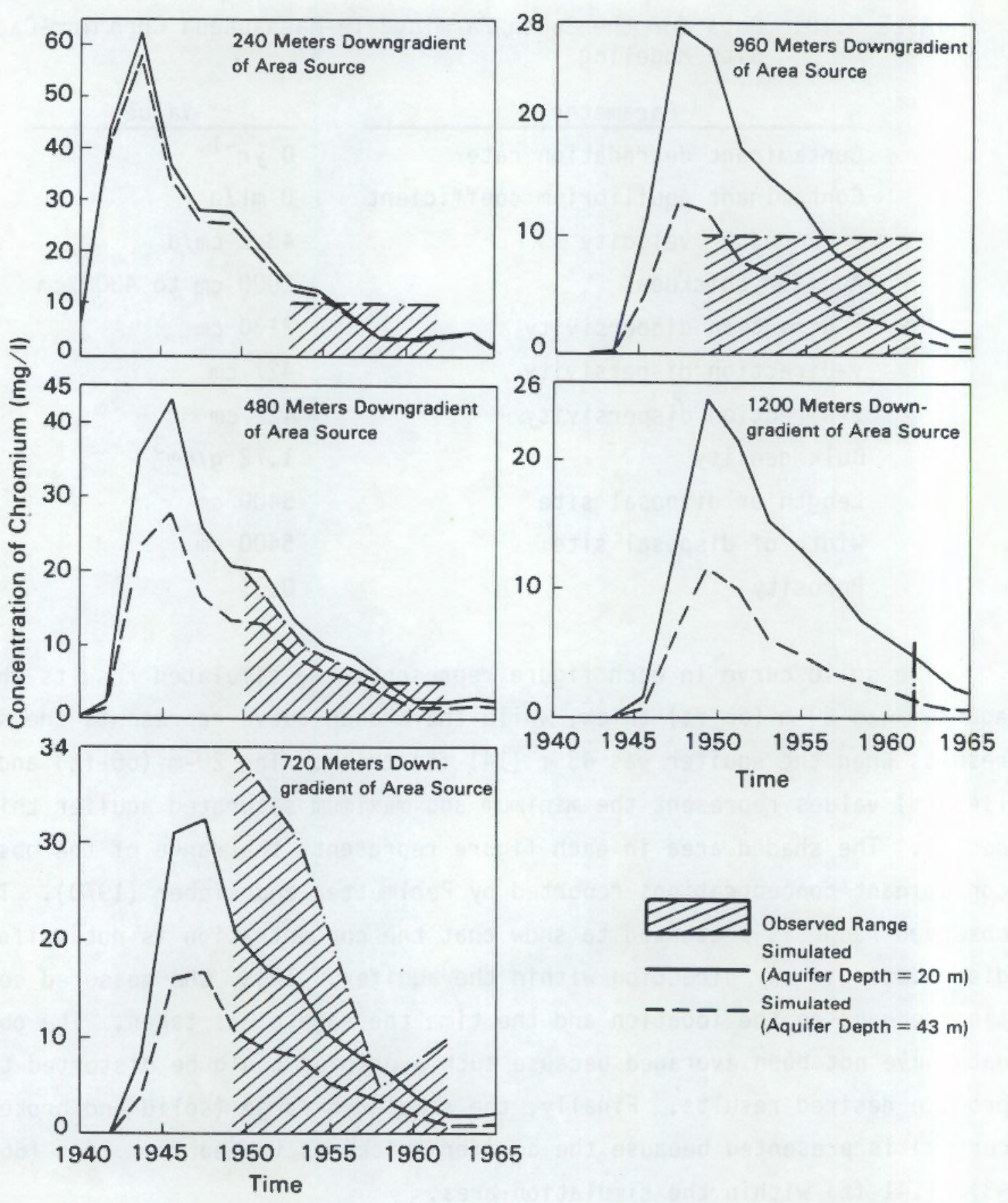

FIGURE 5.36. Temporal Variation in the Chromium Concentration at Different Locations Downgradient of the Area Source 

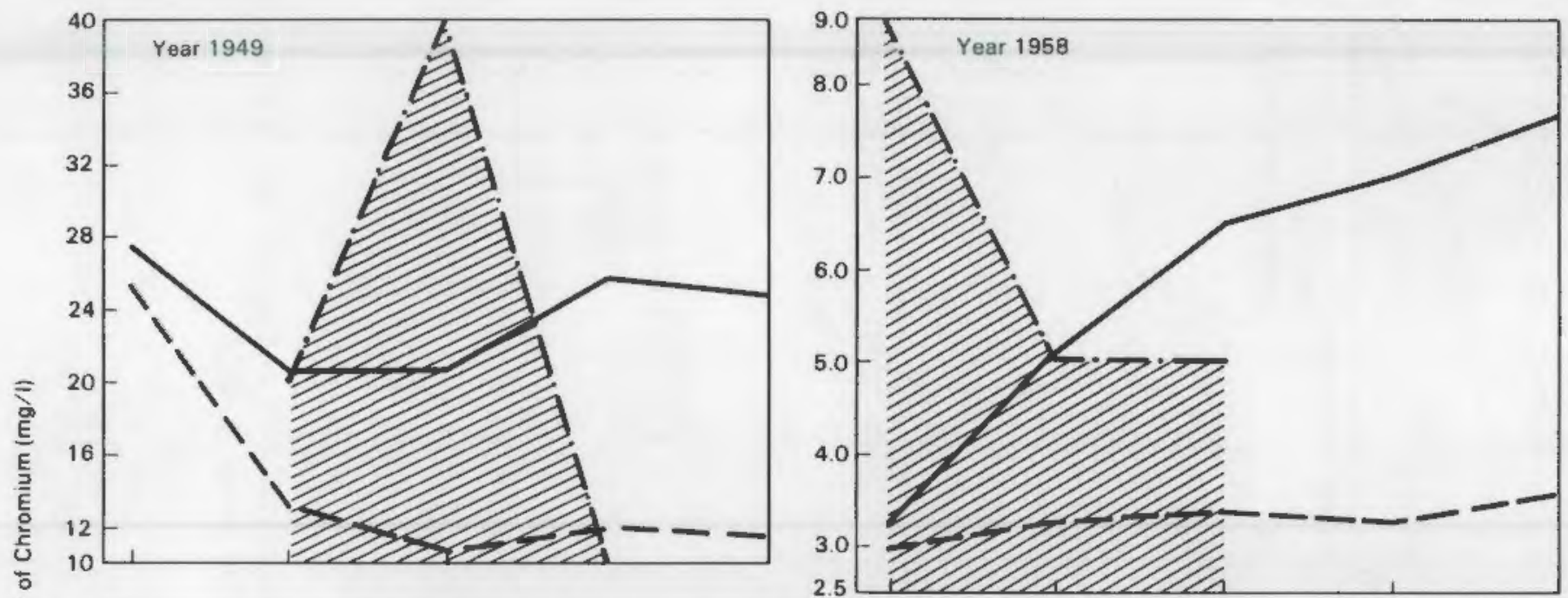

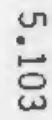
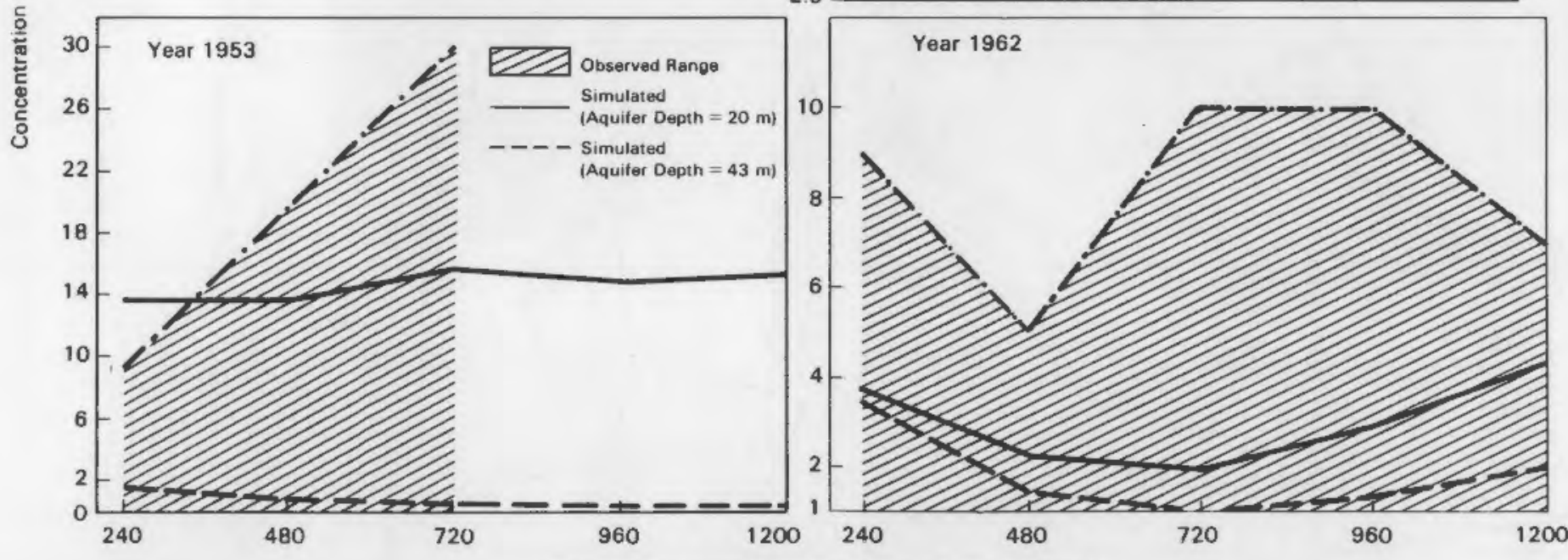

Distance Downgradient From Area Source (meters)

FIGURE 5.37. Spatial Variations in the Chromium Concentration for the Years 1949, 1953, 1958, and 1962 


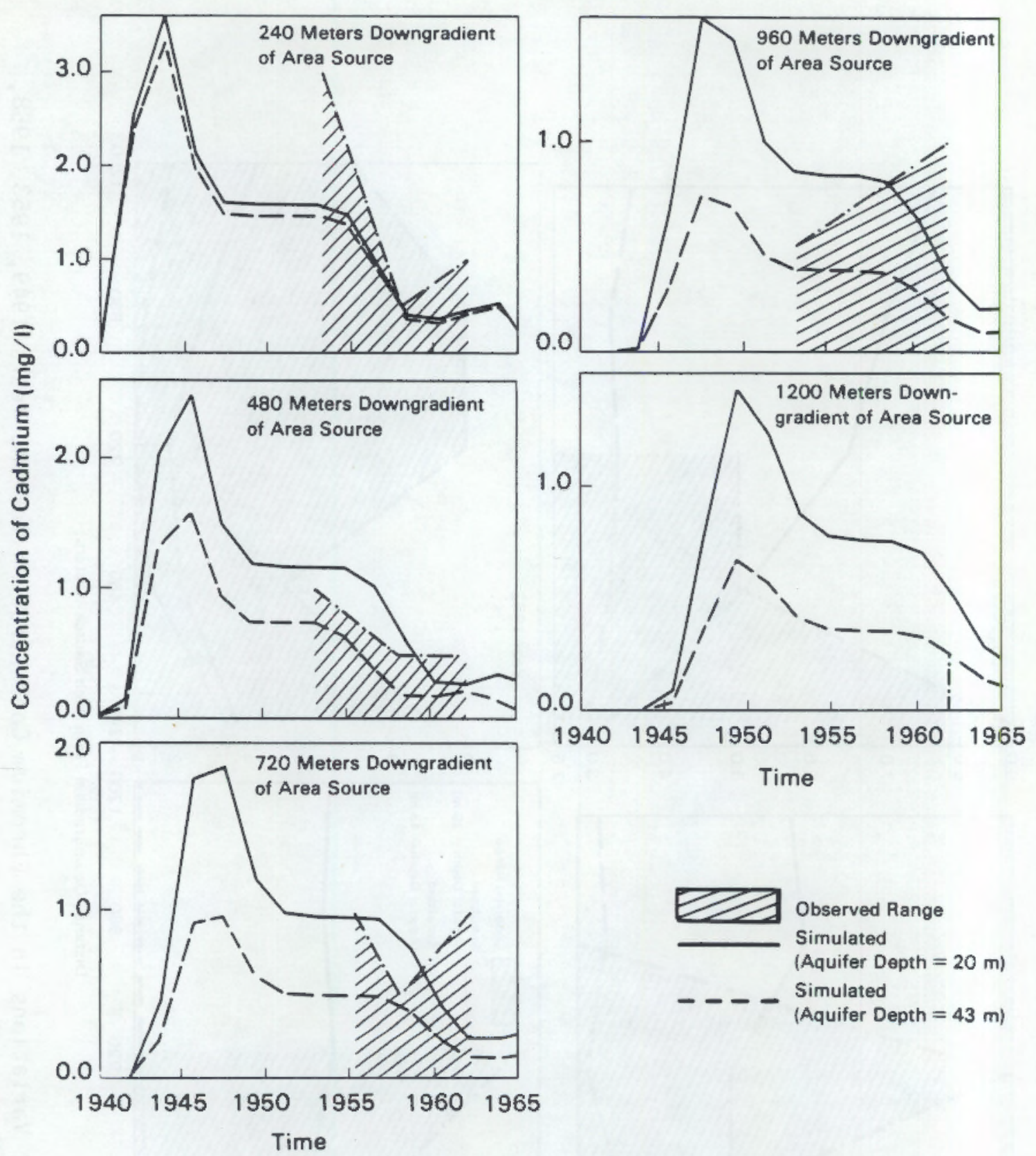

FIGURE 5.38. Temporal Variation in the Cadmium Concentration at Different Locations Downgradient of the Area Source 


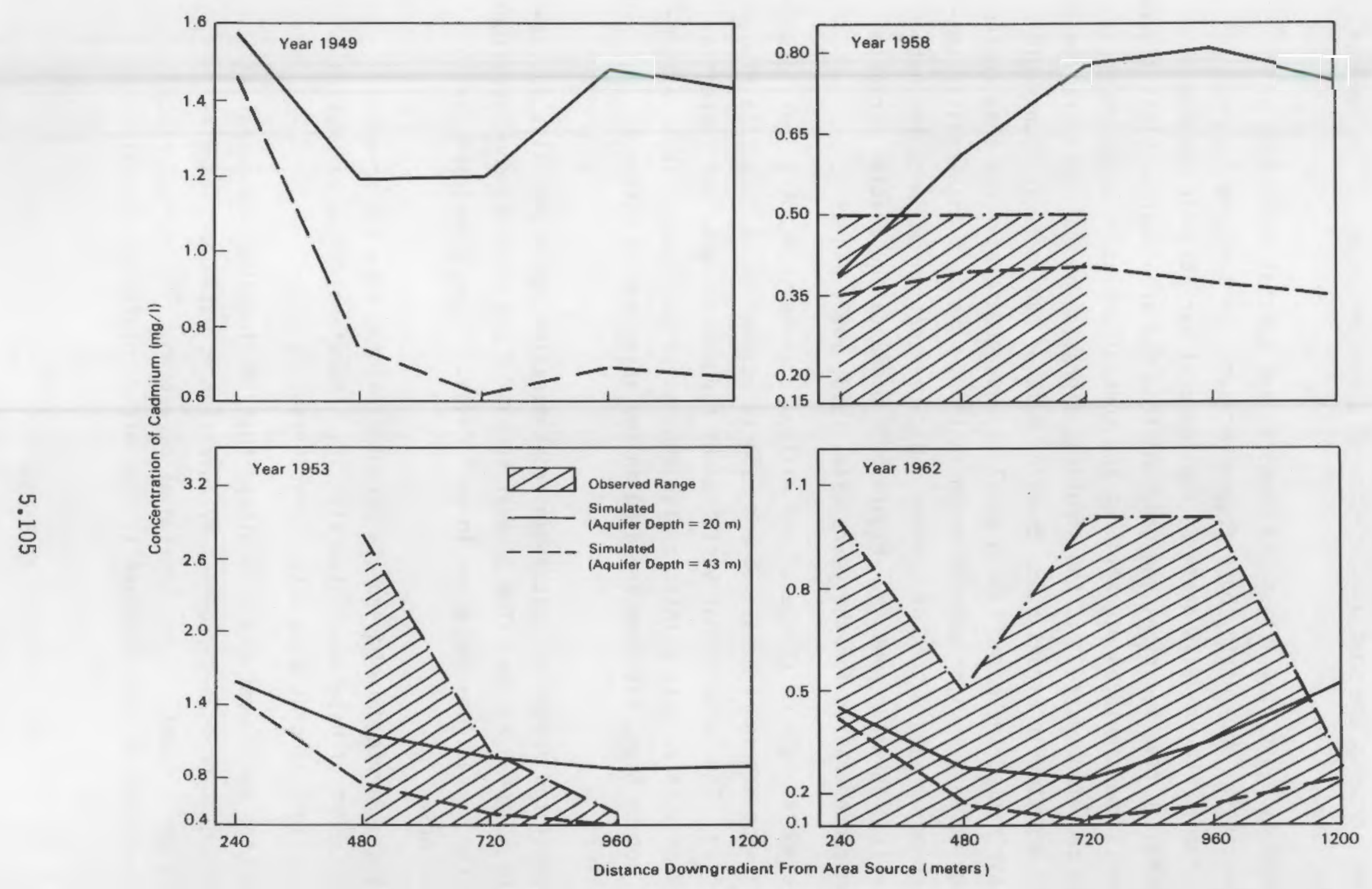

FIGURE 5.39. Spatial Variation in the Cadmium Concentration for the Years 1949, 1953, 1958, and 1962 
migration of the contaminant as it moves downgradient from the area source. Figure 5.37 presents the spatial variation of chromium concentration for the years 1949, 1953, 1958, and 1962.

Figures 5.38 and 5.39 illustrate temporal and spacial variations in cadmium concentration. Again, both figures present the same results, but in different forms. Figure 5.38 presents the temporal variation in cadmium concentration at five locations downgradient from the area source. This figure also presents the simulated migration of the contaminant as it moves downgradient from the area source. If the simulated migration of the concentration is accurately depicted in Figure 5.38, then the bulk of the contamination would a) ready have passed the point $1200 \mathrm{~m}$ (3937 ft) downgradient of the area source before regular sampling for cadmium began in 1953. The fact that regular sampling of chromium before that of cadmium indicates that chromium contamination was initially of greater concern. Figure 5.39 presents the spatial variation of cadmium concentration for the years 1949, 1953, 1958, and 1962.

The temporal rate of change of the maximum observed concentrations between sampled data points in Figures 5.36 and 5.38 is assumed to be 1 inear in Figures 5.37 and 5.39. The longitudinal variation of the maximum observed concentrations between sampled data points is also assumed to be linear. These assumptions may not be true, but they are used in the absence of a better relationship.

The predicted ranges of contaminant concentrations were generally equivalent to the measured ranges. The general trends of the observed concentrations are reflected in the computed plots in most cases. These trends are due to several factors:

1) The South Farmingdale-Massapequa chromium-cadmium site had an adequate amount of data associated with it. Therefore, input parameters were defined according to site characteristics.

2) Perlmutter and Lieber (1970) indicate that the longitudinal extent of the plume is principally caused by advection of water and its dissolved constituents in the horizontal direction. The average rate and direction of such movement is controlled chiefly by natural 
velocities and flow patterns. Perlmutter and Lieber also note that the advection is fairly uniform throughout most of the plume, and that the only significant hydraulic barrier to longitudinal growth observed was the discharge zone of Massapequa Creek (see Figure 5.34). These flow properties are well suited to this model.

3) Enough information was available to adequately describe the tabular source function (see Figure 5.35 ) because simulated contaminant levels tended to reflect variations in observed contaminant levels. Note that the tabular source function has a significant impact on the contaminant concentration hydrograph.

4) The dispersion and adsorption-desorption mechanisms were insignificant relative to the advection process (Perlmutter and Lieber 1970).

5) Contaminant degradation is not an important factor in determining contaminant levels.

\subsection{REFERENCES}

Andersen, M. P. 1979. "Using Models to Simulate the Movement of Contaminants through Groundwater Flow Systems." CRC Critical Review in Environmental Control, November, pp. 97-156.

Blaney, H. F., and W. D. Criddle. 1950. Determining Water Requirements in Irrigated Areas from Climatological and Irrigation Data. USDA(SCS)TP-96, U.S. Department of Agriculture, Washington, D.C.

Bretz,. H. 1923. "The Channel Scablands of the Columbia Plateau." J. Hydrol. $31: 617-649$.

Calkins, F. C. 1905. Geology and Water Resource of a Portion of East Central Washington. U.S. Geological Survey Water-Supply Paper 118, Washington, D. C.

Callahan, M. A., M. W. Slimak, N. W. Gabel, I. P. May, F. Fowler, J. R. Freed, P. Jennings, R. L. Durfee, F. C. Whitmore, B. Maestri, W. R. Mabey, B. R. Holt, and C. Gould. 1979. Water-Related Environmental Fate of 129 Priority Pollutants -- Volume I: Introduction and Technical Background, Metals and Inorganics, Pesticides and PCBS. EPA-440/4-79-029a, National Technical Information Service, Springfield, Virginia.

Campbel1, G. S. 1974. "A Simple Method for Determining Unsaturated Conductivity from Moisture Retention Data." Soil Sci. 117:311-314. 
Clapp, R., and G. M. Hornberger. 1978. "Empirical Equations for Some Soil Hydraulic Properties." Water Resour. Res. 14(4):601-604.

Codell, R. B., K. T. Key, and G. Whelan. 1982. A Collection of Mathematical Models for Dispersion in Surface Water and Groundwater. NUREG-0868, U.S. Nuclear Regulatory Commission, Washington, D.C.

Dass, P., G. R. Tamke, and C. M. Stoffel. 1977. "Leachate Production at Sanitary Landfills." J. Environ. Eng. Div., Proceedings of the American Society of Civil Engineers, 103(EEG). New York, New York.

Davids, H. W., and M. Lieber. 1951. "Underground Contamination by Chromium Wastes." Water and Sewage Works. 98(12):528-534.

Delegard, C. H., and G. S. Barney. 1983. Effects of Hanford High-level Waste Components on Sorption of Cobolt, Strontium, Neptunium, Plutonium, and Americium on Hanford Sediments. RHO-RE-ST-1 P, Rockwell Hanford Operations, Energy Systems Group, Richland, Washington.

Delegard, C. H., S. A. Gallagher, and R. B. Kasper. 1981. "Saturated Column Leach Studies: Hanford 216-Z-1A Sediment." RHO-SA-210, Research and Engineering. Health, Safety, and Environment. Energy Systems Group. Rockwell Hanford Operations, Richland, Washington.

DOE. 1986. Disposal of Hanford Defense High-Level, Transuranic, and Tank Wastes. Draft Envi ronmental Impact Statement, VoT. 3. DOE/EIS-0113, U.S. Department of Energy, Richland, Washington.

Doorenbos, J., and W. 0. Pruitt. 1977. Crop Water Requirements. FAO Irrigation and Drainage Paper (Revised), Food and Agriculture Organization of the United Nations, Rome.

Eagleson, P. S. 1970. Dynamic Hydrology. McGraw-Hill, Inc., New York.

EPA. 1986. "Hazardous Waste System Land Disposal Restrictions; Proposed Rule." Part III. U.S. Environmental Protection Agency, 40 CFR (260) Fed. Reg. 1601-1766, (January 14, 1986).

Fenn, D. G., K. J. Hanley, and T. V. DeGeare. 1975. Use of the Water Balance Method for Predicting Leachate Generation from Solid Waste Disposal Sites. SW-168, U.S. Environmental Protection Agency, Washington, D.C.

Freeze, R. A., and J. A. Cherry. 1979. Groundwater. Prentice-Hall, New York, 604 p.

Friedlander, G., J.W. Kennedy, and J. M. Miller. 1964. Nuclear and Radiochemistry. (2nd Ed.) John Wiley \& Sons, Inc., New York.

Gardner, W. R. 1960. "Soil Water Relations in Arid and Semi-Arid Conditions." UNESCO 15:37-61. 
Gardner, W. R., D. Hillel, and Y. Benyamini. 1970. "Postirrigation Movement of Soil Water, 1. Redistribution." Water Resour. Res. 6:851-861.

Gee, G. W., and T. L. Jones. 1985. Lysimeters at the Hanford Site: Present Use and Future Needs. PNL-5578, Pacific Northwest Laboratory, Richland, Washington.

Gee, G. W., and R. R. Kirkham. 1984. Arid Site Water Balance: Evapotranspiration Modeling and Measurements. PNL-5177, Pacific Northwest Laboratory, Richland, Washington.

Gee, G. W., and C. S. Simmons. 1979. Characterization of the Hanford 300 Area Burial Grounds: Task III - Fluid Transport and Modeling. PNL-2921, Pacific Northwest Laboratory, Richland, Washington.

Gelhar, L. W., and C. L. Axness. 1981. Stochastic Analysis of Macrodispersion in Three-dimensionally Heterogeneous Aquifers. Report No. H-8, Hydrology Research Program, Geophysical Research Center, Research and Development Division, New Mexico Institute of Mining and Technology, Socorro, New Mexico.

Hajek, B. F., and K. C. Knoll. 1966. Disposal Characteristics of Plutonium and Americium in High Salt Acid Waste. BNWL-CC-649, Battelle, Pacific Northwest Laboratories, Richland, Washington.

Hanks, R. J., and G. L. Ashcroft. 1980. Applied Soil Physics. Springer Verlag, New York.

Hillel, D. 1980. Fundamentals of Soil Physics. Academic Press, New York.

Israelsen, 0. W., and V. E. Hansen. 1962. Irrigation Principles and Practices. John Wiley and Sons, Inc., New York.

Kasper, R. B., S. M. Price, M. K. Additon, R. M. Smith, G. V. Last, and G. L. Last. 1979. Transuranic Distribution Beneath a Retired Underground Disposal Facility, Hanford Site. RHO-SA-131, Rockwell Hanford Operations, Energy Systems Group, Richland, Washington.

Kent, K. M. 1973. A Method for Estimating Volume and Rate of Runoff in Small Watersheds. SCS-TP-149, U.S. Department of Agriculture, Soil Conservation Service, Washington, D.C.

Kocker, A. E., and A. T. Strahorn. 1919. Soil Survey of Benton County, Washington. U.S. Department of Agriculture, Washington, D.C.

Ku, H. F. H., B. G. Katz, D. J. Sulam, and R. K. Krulikas. 1978. "Scavenging of Chromium and Cadmium by Aquifer Material-South Farmingdale-Massapequa Area, Long Island, New York." Groundwater 16:112.

Lieber, M., N. M. Perlmutter, and H. L. Frauenthal. 1964. "Cadmium and Hexavalent Chromium in Nassau County Groundwater." Amer. Water Works Assoc. J. 50(6):739-747. 
Linsley, R. K., and J. B. Franzini. 1972. Water-Resources Engineering. McGraw-Hill, Inc., New York.

Linsley, R. K., Jr., M. A. Kohler, and J. L. H. Paulhus. 1975. Hydrology for Engineers. McGraw-Hill, Inc., New York.

Makkink, G. F. 1957. "Testing the Penman Formula by Means of Lysimeters," J. Inst. Water Eng. 11:277-290.

Marratt, M. C., R. B. Kasper, and A. E. Van Luik. 1984. The 216-Z-8 French Drain Characterization Study. RH0-RE-EV-46 P, Rockwell Hanford Operations, Waste Management Systems Engineering Department, Research and Engineering, Richland, Washington.

Merriam, J. C., and J. P. Budalda. 1917. "Age of Strata Referred to in the Ellensburg Formation in the White Bluffs of the Columbia River." Bulletin of Geology for the University of California, 10(15):255.

Mockus, V. 1971. "Estimation of Direct Runoff from Snowmelt." In SCS National Engineering Handbook, Section 4: Hydrology. U.S. Department of Agriculture, Soil Conservation Service, Washington, D.C.

Morton, F. I. 1971. "Catchment Evaporation and Potential Evaporation--Further Development of a Climatologic Relationship". Jour. Hydrol. 12(2):81-99.

Morton, F. I. 1975. "Estimating Evaporation and Transpiration from Climatological Observations." Jour. Appl. Meteor. 14(4):488-497.

Morton, F. I. 1976. "Climatological Estimates of Evapotranspiration." Proc. ASCE, Jour. Hydraulics Div. 102(HY3):275-290.

NDAA. 1984. Local Climatological Data: Annual Summaries for 1983. National Oceanic and Atmospheric Administration, National Environmental Satellite, Data, and Information Service, National Climatic Data Center, Asheville, North Carolina.

Parker, G. G., and A. M. Piper. 1949. Geologic and Hydrologic Features of the Richland Area, Washington, Relevant to the Disposal of Wastes at the Hanford Directed Operations of the Atomic Energy Commission. U.S. Geological Survey WP-7, Washington, D.C.

Penman, H. L. 1948. "Natural Evaporation from Open Water, Bare Soil, and Grass." Proc. R. Soc. (Lond.) 193:120-145.

Perlmutter, N. M., and M. Lieber. 1970. Disposal of Plating Waste and Sewer Contaminants in Ground Water and Surface Water, South Farmingdale-Massapequa Area, Nassau County, New York. U.S. Geological Survey Water-Supply Paper 1979-G, U.S. Geological Survey, Washington, D.C.

Pinder, G. F. 1973. "A Galerkin-Finite Element Simulation of Ground-Water Contamination of Long Island, New York." Water Resour. Res. 9(6):1657-1669. 
Price, K. R., J. M. V. Carlile, R. L. Dirkes, R. E. Jaquish, M. S. Trevathan, and R. K. Woodruff. 1985. Environmental Monitoring at Hanford for 1984. PNL-5407, Pacific Northwest Laboratory, Richland, Washington.

Price, S. M., and L. L. Ames. 1976. "Characterization of Actinide Bearing Sediments Underlying Liquid Waste Disposal Facilities at Hanford." In: Transuranium Nuclides in the Environment. International Atomic Energy Agency, Vienna.

Price, S. M., R. B. Kasper, M. K. Additon, R. M. Smith, and G. V. Last. 1979. Distribution of Plutonium and Americium Beneath the 216-Z-1A Crib: A Status Report. RH0-ST-17, Rockwell Hanford Operations, Earth Sciences Group, Research Department, Richland, Washington.

Rai, D., J. M. Zachara, A. P. Schwab, R. L. Schmidt, D. C. Girvin, and J. E. Rogers. 1984. Attenuation Rates, Coefficients, and Constants in Leachate Migration: A Critical Review. EPRI-EA-3356. Prepared by Battelle, Pacific Northwest Laboratories for the Electric Power Research Institute, Palo Alto, California.

Rosenberg, N. J. 1974. Microclimate, The Biological Environment. John Wiley \& Sons, New York.

Russe11, I. C. 1903. A Geological Reconnaissance in Central washington. U.S. Geological Survey Bul Tetin 108. Washington, D.C.

SCS. 1972. "Hydrology Guide for Use in Watershed Planning." SCS National Engineering Handbook, Section 4: Hydrology, Supplement A. U.S. Department of Agriculture, Soil Conservation Service, Washington, D.C.

SCS. 1982. SCS National Engineering Handbook, Section 4: Hydrology. Update). U.S. Department of Agriculture, Soil Conservation Service, $(1982$ Washington, D.C.

Selim, H. M., and R. S. Mansel1. 1976. "Analytical Solution of the Equation for Transport of Reactive Solutes Through Soils." Water Resour. Res. $12(3): 528-532$.

Simmons, C. S., and G. W. Gee. 1981. Simulation of Water Flow and Retention in Earthen Cover Materials Overlying Uranium Mill Tailings. UMT/0203, U.S. Department of Energy, Washington, D.C.

Sisson, J. B., and A. H. Lu. 1984. Field Calibration of Computer Models for Application to Buried Liquid Discharges: A Status Report. RH0-ST-46 P, Rockwell Hanford Operations, Engineering Department, Engineering and Research Function, Richland, Washington.

Smith, G. 0. 1903. Geology and the Physiography of Central Washington. U.S. Geological Survey Professional Paper 19, Washington, D.C. 
Stenner, R. D., K. H. Cramer, K. A. Higley, S. J. Jette, D. A. Lamar, T. J. Mclaughl in, D. R. Sherwood, and N. C. Van Houten. 1988. Hazard Ranking System Evaluation of CERCLA Inactive Waste Sites at Hanford. Vol. 2. PNL-6456, Pacific Northwest Laboratory, Richland, Washington.

Stone, W. A., J. M. Thorp, D. P. Gifford, and D. J. Hoitink. 1983. Climatological Summary for the Hanford Area. PNL-4622, Pacific Northwest Laboratory, Richland, Washington.

Stone, W. A., D. E. Jenne, and M. J. Thorp. 1972. Climatology of the Hanford Area. BNWL-1605, Pacific Northwest Laboratory, Richland, Washington.

Tallman, A. M., K. R. Fecht, M. C. Marratt, and G. V. Last. 1979. Geology of the Separation Areas, Hanford Site, South-Central Washington. RHO-ST-23, Rockwell Hanford Operations, Earth Sciences Group, Research Department, Richland, Washington.

Thornthwaite, C. W., and J. R. Mather. 1955. "The Water Balance." Publications in Climatology, Vol. VIII, No. 1, Drexel Institute of Technology, Laboratory of Climatology, Centerton, New Jersey.

Thornthwaite, C. W., and J. R. Mather. 1957. "Instructions and Tables for Computing Potential Evapotranspiration and the Water Balance." In Publications in Climatology, Vol. X, No. 3. Orexel Institute of Technology, Laboratory of Climatology, Centerton, New Jersey.

USBR. 1977. Design of Smal1 Dams. U.S. Department of the Interior, Bureau of Reclamation, Washington, D.C.

Viessman, W., Jr., J. W. Knapp, G. L. Lewis, and T. E. Harbaugh. 1977. Introduction to Hydrology. Harper and Row, New York.

Wallace, R. W. 1978. A Comparison of Evapotranspiration Estimates Using DOE Hanford Climatologic Data. PNL-2698, Pacific Northwest Laboratory, Richland, Washington.

Walton, W. C. 1970. Groundwater Resources Evaluation. McGraw-Hill, New York.

Waring, G. A. 1913. Geology and Water Resources of a Portion of South Central Washington. U.S. Geological Survey Water-Supply Paper 316, Washington, D.C.

Weast, R. C. (ed). 1984. CRC Handbook of Chemistry and Physics. CRC Press, Boca Raton, Florida.

Whel an, G., B. L. Steelman, D. L. Strenge, and J. G. Droppo. 1986. "Overview of the Remedial Action Priority System (RAPS)." In Pollutants in a Multimedia Environment, ed. Y. Cohen, pp. 191-227. Plenum Press, New York. 
Whel an, G., D. L. Strenge, J. G. Droppo, B. L. Steelman and J. W. Buck 1987. The Remedial Action Priority System (RAPS): Mathematical Formulations. PNL6200 , Prepared for the Office of Environment, Safety, and Health, U.S. Department of Energy, Washington, D.C., by Pacific Northwest Laboratory, Richland, Washington.

Whelan, G., S. M. Brown, D. L. Strenge, A. P. Schwab, and P. J. Mitchell. 1988. Contaminant Assessment Modeling Under the Resource Conservation and Recovery Act. EA-5342, Electric Power Research Institute, Palo A1to, California.

Yeh, G. T. 1981. AT123D: Analytical Transient One-, Two-, and ThreeDimensional Simulation of Waste Transport in the Aquifer System. ORNL-5602, Oak Ridge National Laboratory, Oak Ridge, Tennessee.

Yeh, G. T., and y. Tsai. 1976. "Analytical Three-Dimensional Transient Modeling of Effluent Discharges." Water Resour. Res. 12(3):533-540. 



\subsection{ATMOSPHERIC COMPONENT OF THE RAPS METHODOLOGY}

\subsection{INTRODUCTION}

The RAPS atmospheric pathway model includes components for modeling of contaminant emission, movement, dilution, and deposition. These components were tested by applying the model at selected DOE sites.

Two cases were selected for this testing effort. The first case was a large area source of a particulate contaminant, which allowed the virtual area and particle suspension routines to be tested. The second case was a site with detailed stack release and monitoring data so that the ability of the RAPS routines to predict air and surface concentrations from routine stack releases could be tested.

The B-C cribs site at the DOE Hanford facility was selected to test the surface-particulate suspension component of RAPS. The suspension of radioactive materials from areas with surface contamination has historically been expressed in terms of a resuspension parameter that relates surface concentration to the air concentration directly over the contaminated surface. The RAPS code is tested by comparing resuspension parameters derived from the RAPS output with resuspension parameters measured in past studies at Hanford.

The Mound facility in Ohio was selected to test the air and surface concentration outputs of the RAPS code for a site with stack releases. This testing application of RAPS differs from a ranking application as a component of the RAPS methodology. The RAPS methodology is designed to provide relative rankings of sites at a facility, and considers only one source at a time. However monitoring data represent the cumulative impact of all emissions from the facility. To obtain an output from RAPS that represents a cumulative impact, a single combined source term is used for the stack releases at the Mound facility.

\subsection{MATHEMATICAL FORMULATIONS}

The formulations for the atmospheric pathway include components for computing emission, transport and dispersion, and deposition rates. The RAPS 
model uses different formulations depending on the nature of the release. For a stack or vent release, the model includes initial dispersion and plume rise formulations. For an area release, the model includes an initial dispersion formulation. The same transport, dispersion, and deposition routines are used in all cases.

For all emission-based atmospheric transport scenarios, RAPS requires the definition of an atmospheric release rate. One option for defining the suspended particle flux from an exposed contaminated area is to compute the emission rate using input surface and site characteristics. A computed soil emission rate based on these characteristics is referred to as both suspension and resuspension. The term "resuspension" derives from nuclear applications involving suspension of radioactive materials previously deposited from the air. Because the component is also able to treat surface contamination not deposited from the air (e.g., a spill of materials onto a surface), its primary name is the suspension component.

The outputs of the atmospheric component of RAPS are predicted air and surface concentrations. The air concentration computation includes emission, transport and dispersion, and depletion (from deposition) rates. The surface concentrations are computed as the accumulation of material caused by deposition processes.

\subsubsection{Particle Suspension Component}

The suspension of respirable particles (those with diameter less than $10 \mu \mathrm{m})$ from contaminated areas at DOE sites may be calculated using empirical relationships based on studies of wind erosion and surface disruption. The RAPS outputs for suspension from contaminated surface areas are expressed in terms of an airborne soil concentration normalized to a unit surface contamination. These soil concentration arrays are converted to arrays of contaminant concentrations using the fraction of surface contamination in the suspended soil. 
The computation of the suspension of contaminants from a surface into the atmosphere requires both contaminant and site data. These data are used first to define which formulations apply to the site and second to compute the suspension rates.

The RAPS methodology for computing suspension rates is an adaptation of the methodology proposed by Cowherd et al. (1984) for rapid computation of potential long-term impacts from spills of hazardous materials. This methodology includes formulations for suspension by winds, vehicular traffic, and other physical disturbances of the surface.

This section describes tests of the wind suspension component. The wind suspension of surface material appeared to be a potential mechanism for suspension of surface materials at the selected DOE facility. Although the facility, for the sake of this test, was assumed not to have any suspension by vehicles or other physical disturbances, RAPS does have formulations for computing such emissions from mechanical surface disturbances.

Cowherd et al. (1984) define the steps for determining potential respirable particulate emission from wind erosion. The soil particle size distribution, apparent roughness of the site, vegetation cover, presence of a crust on the soil, and presence of nonerodible elements (e.g., large stones) are used to define the potential for suspension. Depending on the results of this procedure, the site is characterized as having 1) unlimited erosion potential, 2) limited erosion potential, or 3 ) no erosion potential.

The methodology uses different formulations for the two cases with wind erosion potential. For the no erosion potential, Cowherd et al. (1984) suggest that if the site is completely covered with vegetation or if there is a thick crust and no mechanical disturbances occur at the site, it can be assumed that no contaminants are suspended. However, for certain contaminants, even very small suspension rates from well-stabilized surfaces may be significant. Testing was needed to determine if the erosion formulations give reasonable results over the range from bare, unstabilized surfaces to well-stabilized surfaces. 
The potential for wind erosion is quantified in terms of a threshold friction velocity. The greater the value of the threshold friction velocity for a site, the lower the potential for particle suspension. The threshold friction velocity for the contaminated area is determined by knowing the mode of the aggregate size distribution and using a formula derived from the graphical relationship given in Cowherd et al. (1984),

$$
u^{\star}=\exp [0.4118428 \log (X)+4.1671713]
$$

where $u^{*}=$ threshold friction velocity $(\mathrm{cm} / \mathrm{s})$

$X$ = aggregate size distribution.

If there are any nonerodible elements in the contaminated area, a correction factor must be applied to the threshold friction velocity computed with Equation (6.1). This correction factor is based on the fraction of surface coverage. This factor is based on graphical results given by Cowherd et al. (1984), derived from wind tunnel studies by Marshall (1971). As the silhouette area of nonerodible elements increases, so does the threshold friction velocity.

Once the threshold friction velocity has been determined, the erosion potential of the contaminated area can be classified by calculating the critical friction velocity at a given height above the surface using the equation

$$
u^{\prime}=r u_{c}^{*} \log \left(Z / Z_{0}\right)
$$

where $u^{\prime}=$ critical friction velocity at $7-m$ height $(\mathrm{cm} / \mathrm{s})$

$r=$ von Karman constant (0.4; dimensionless)

$u_{c}^{*}=$ corrected threshold friction velocity $(\mathrm{cm} / \mathrm{s})$

$Z=$ reference height above the surface $(7.0 \mathrm{~m})$

$Z_{0}=$ surface roughness height $(\mathrm{m})$. 
The value of $Z$ is usually $7 \mathrm{~m}$; the surface roughness height of the site, Zo, is related to the size and spacing of the roughness elements in the area. Figure 6.1 illustrates Zo for various surfaces (Cowherd and Guenther 1976).

Once the critical friction velocity has been calculated, the erosion potential of the area can be determined. If the critical friction velocity is less than $75 \mathrm{~cm} / \mathrm{s}$, the area has unlimited erosion potential; otherwise the area has limited erosion potential.

For estimating particulate emissions from a contaminated area having limited wind-erosion potential, the following equation is used to predict potential emissions:

$$
E 10=0.83\left[f p(u)(1-v) /(P E / 50)^{2}\right]
$$

where $E 10=$ annual average emission rate per unit surface area $\left(\mathrm{mg} / \mathrm{m}^{2} / \mathrm{hr}\right)$

$f=$ frequency of mechanical disturbances (number $/ \mathrm{mo}$ )

$u=$ observed maximum wind speed for periods between disturbances $(\mathrm{m} / \mathrm{s})$

$$
\begin{aligned}
P(u)= & \text { erosion potential }\left(\mathrm{g} / \mathrm{m}^{2}\right) \\
v= & \text { vegetation coverage on surface (fraction) } \\
P E= & \text { Thornthwaite's Precipitation Evaporation (PE) Index } \\
& \text { (dimensionless) }
\end{aligned}
$$

The frequency of disturbances per month, $f$, is defined as the number of actions that could expose fresh surface material. A disturbance could be vehicular traffic, plowing or turning of the soil, or mining or construction. The erosion potential, $p(u)$, depends on the maximum wind speed, $u$, so that

$$
\begin{array}{ll}
p(u)=6.7\left(u-u^{\prime}\right) & \text { if } u>u^{\prime} \\
p(u)=0.0 & \text { if } u<u^{\prime}
\end{array}
$$

The vegetation fraction varies from 0 for bare ground to 1 for total coverage. The Thornthwaite's PE Index is used as a moisture-correction 


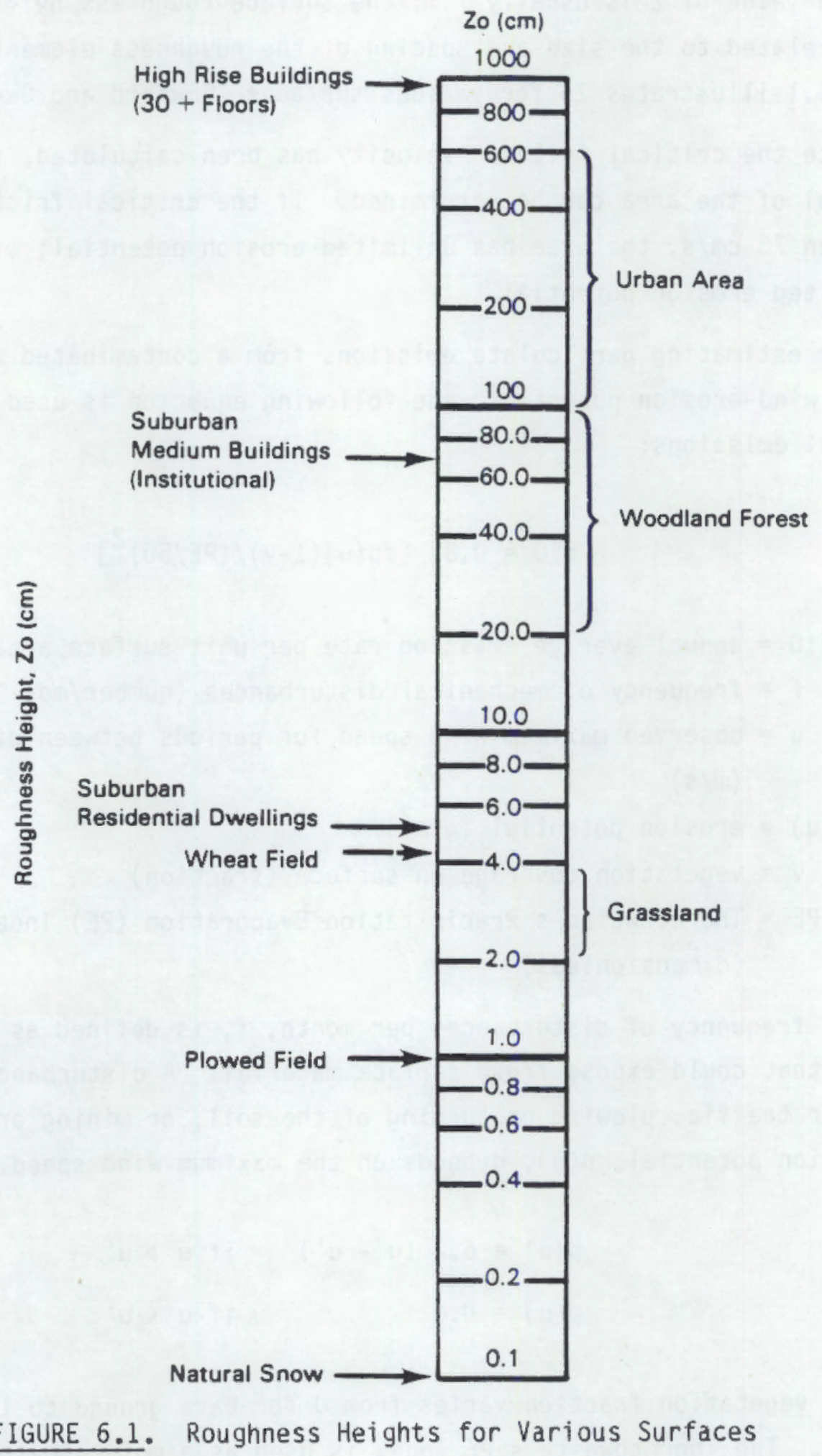

6.6 
parameter for wind-generated emissions. Cowherd et al. (1984) provide a map with values of $P E$ for all regions in the contiguous United States.

For an area with unlimited erosion potential, the relationship for the surface emission rate is

$$
E 10=0.036(1-v)\left(\bar{u} / u^{\prime}\right)^{3} F(x)
$$

where $\bar{u}=$ mean annual wind speed $(\mathrm{m} / \mathrm{s})$

$F(x)=$ integration function.

The vertical flux of particles smaller than $10 \mu \mathrm{m}$ in diameter is assumed to be proportional to the cube of the horizontal wind speed. This relationship was originally developed from measurements made by O'Brien and Rindlaub (1936) in studies at the mouth of the Columbia River and later measurements made by Bagnold (1941) in the Egyptian desert. Chepil (1951) found this same relationship using results from wind-tunnel experiments.

The integration function $F(x)$ comes from the cubic relationship of the vertical transport of particles and the wind speed. It is defined in graphical format by Cowherd et al. (1984). This relationship can be broken into the following four discrete parts:

$$
\begin{array}{ll}
F(x)=0.0 & \text { if } x<0.0 \\
F(x)=1.91 & \text { if } 0.0<x<0.5 \\
F(x)=1.9-(x-0.5) 0.6 & \text { if } 0.5<x<1.0 \\
F(x)=1.6-(x-1.0) 1.3 & \text { if } 1.0<x
\end{array}
$$

where $x=0.886 u^{\prime} / \bar{u}$.

Similar formulations are used to compute emissions per unit area for mechanical disturbances. However, mechanical disturbances were not computed in the selected test case.

Once the emission factors for wind erosion have been determined, the emission rates for respirable particles can be calculated from the relationship 


$$
R 10=E 10 \mathrm{area} / \mathrm{cpr}
$$

where $R 10=$ emission rate for wind erosion $(\mathrm{g} / \mathrm{s})$

area $=$ area of source contamination $\left(\mathrm{m}^{2}\right)$

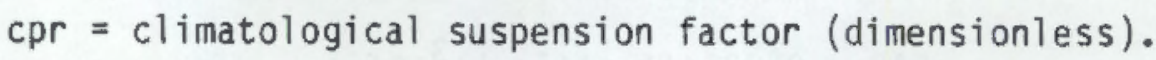

The climatological suspension factor allows for the frequency of suspension conditions to be included. This factor is based on regional factors tabulated by Cowherd et al. (1984) based on output from a series of runs of the Industrial Source Complex-Long Term (ISCLT) model (Bowers et al. 1979).

The total emission rate is the sum of the wind-erosion and mechanicaldisturbance emission rates. The total emission rate is used as input to the atmospheric dispersion, transport, and deposition model described in Section 6.2.2.

This atmospheric model determines air and surface concentrations of the suspended soil materials. The concentrations resulting from the suspension of a specific surface contaminant, e, are computed using the following equations:

$$
\begin{aligned}
& c_{e}=\alpha_{s} \\
& s_{e}=\alpha_{s}
\end{aligned}
$$

where $c_{e}=$ airborne contaminant concentration $\left(\mathrm{g} / \mathrm{m}^{3}\right)$

$C_{s}=$ airborne soil concentration $\left(\mathrm{g} / \mathrm{m}^{3}\right)$

$\alpha=$ mass fraction of contaminant in the suspended surface soil $(\mathrm{g} / \mathrm{g})$

$S_{e}=$ surface concentration of deposited contaminant $\left(\mathrm{g} / \mathrm{m}^{2}\right)$

$S_{S}=$ surface concentration of deposited soil material $\left(\mathrm{g} / \mathrm{m}^{2}\right)$

Historically, a resuspension factor has been used at Hanford in reporting the results of studies of airborne suspension of particles by wind action (and other means) from a contaminated surface. The resuspension factor is defined as the ratio of air concentration and source-area surface concentration, 


$$
K=C_{e} / S_{e}
$$

where $K=$ resuspension factor $\left(m^{-1}\right)$.

Although a resuspension factor is not explicitly used, RAPS outputs can be interpreted in terms of equivalent factors for comparison with the results of past Hanford studies.

\subsubsection{Dispersion, Transport, and Deposition}

The prediction of contaminant movement through the atmospheric pathway uses algorithms that address atmospheric suspension and emission of contaminants at a site and the subsequent transport, diffusion, and deposition of these airborne contaminants. Input to the model includes site-specific climatological information, such as wind speed and direction, stability, and precipitation. Output from the model consists of average air and surface contaminant levels.

Once contaminated material is airborne, it is transported and dispersed by air movements. The contaminant will be carried by the winds, and the atmospheric contaminant concentration will be reduced by dispersion and deposition processes.

The relative importance of the atmospheric pathway is controlled by a combination of local topographic and climatological influences. Controlling parameters include distance and direction from the inactive waste site and local wind conditions and stability. Because dispersion is strongly a function of the downwind distance, the physical distances between the contaminant site and potential areas of impact are of prime importance. The local frequencies of wind directions, particularly in areas where winds are topographically channeled, are important in calculating the exposure and risk associated with the atmospheric pathway.

A standard, straight-line, sector-averaged Gaussian model was selected as the basis of the atmospheric pathway model. Such a model meets the RAPS objective of assessing the long-term, average risk from the various inactive waste sites. This model provides a consistent framework for computing average 
exposures and incorporates the major factors that control the emission, transport and dispersion, and deposition of various contaminants.

The sector-averaged atmospheric model is particularly applicable in RAPS because it allows long-term site data to be incorporated directly. The sectoraveraged model computes long-term average exposures by a weighted summation of exposures. These exposures span a matrix of cases covering a range of combinations of atmospheric stability, wind speed, and wind direction. Climatological data, representing average, long-term conditions, are used to define the frequency of occurrence of each case in the computation.

No single, simple atmospheric model can be expected to be equally applicable to all sites. The sector-averaged Gaussian model is best applied to a site located on a flat, uniform plane. It is used only as an approximation for sites located on other types of terrain.

Although atmospheric influences on sites in complex terrain or on coastlines are quite different from those on sites located on a flat, uniform plane, the use of a straight-line Gaussian model will generally provide reasonable exposure estimates to the first major terrain feature. As the regional influences become more important at greater distances, the straight-line Gaussian model becomes less accurate.

In applying the sector-averaged model to sites in complex terrain, careful attention is needed to ensure that the estimate of risk is reasonable. For example, it may be appropriate to adjust some of the inputs for sites in complex terrain to reflect local wind fields. A terrain interaction option can be used to account for the potential of plume interaction with local topography. A local channeling option can be used to approximate the atmospheric exposures at sites where the emissions may be carried by local winds channeled by terrain.

The Gaussian diffusion equation for the concentrations of a contaminant in a plume downwind of a continuous point source release has been given by Slade (1968) as 


$$
\begin{aligned}
& C_{k}=\frac{Q_{k}}{2 \pi \sigma_{y} \sigma_{z} \bar{u}} \exp \left[-y^{2} /\left(2 \sigma_{z}^{2}\right)\right] \\
& \left(\exp \left[-(z-H)^{2} /\left(2 \sigma_{z}^{2}\right)\right]+\exp \left[-(z+H)^{2} /\left(2 \sigma_{z}^{2}\right)\right]\right)
\end{aligned}
$$

where $C_{k}=$ time-averaged value of concentration for contaminant form $k\left(\mathrm{~g} / \mathrm{m}^{3}\right)$

$Q_{k}=$ amount of material released from a point source of contaminant form $k(g / s)$

$k=$ index on elemental contaminant form $[k=1,2, \ldots, p ; p=$ number of forms representing a gaseous state and $\left(p^{-1}\right)$ ranges of particle sizes]

$x, y, z=$ positions in a Cartesian coordinate system that are oriented such that the $x$ axis is in the direction of the mean horizontal wind vector, the $y$ axis is crosswind, and the $z$ axis is vertical height above local ground level (m)

$\sigma_{y}=$ standard deviation of the distribution of material in a plume in the $y$ direction ( $m$ )

$\sigma_{z}=$ standard deviation of the distribution of material in a plume in the $z$ direction $(m)$

$\bar{u}=$ average value of wind speed in the $x$ direction at the height of the plume centerline $(\mathrm{m} / \mathrm{s})$

$H=$ height of release over local ground level (m).

The crosswind integrated concentration from a continuous source is obtained by integrating Equation (6.11) with respect to the crosswind distance (y) from - B to $+B$ :

$$
\begin{aligned}
& C W I=\frac{Q_{k}}{\sqrt{2 \pi} \sigma_{z} \bar{u}} \\
& \left(\exp \left[-(z-H)^{2} /\left(2 \sigma_{z}^{2}\right)\right]+\exp \left[-(z+H)^{2} /\left(2 \sigma_{z}^{2}\right)\right]\right)
\end{aligned}
$$


where CWI $=$ crosswind integrated concentration (i.e., that perpendicular to wind direction) $\left(\mathrm{g} / \mathrm{m}^{2}\right)$.

The frequency of combinations of wind speeds, wind directions, and diffusion rates can be summarized in a joint frequency table of speed, direction, and stability. The sector-averaged concentration for one set of wind speed, direction, and stability conditions is given by

$$
\begin{aligned}
& C_{i j k}(x, z)=Q_{k} R_{k}(x)\left(\frac{1}{2 \pi}\right)^{1 / 2} \frac{1}{j_{i} \sigma_{z_{j}}{ }^{2} \pi x / n} \\
& \left(\exp \left[-(z-H)^{2} /\left(2 \sigma_{z_{j}}^{2}\right)\right]+\exp \left[-(z+H)^{2} /\left(2 \sigma_{z_{j}}^{2}\right)\right]\right)
\end{aligned}
$$

where $C_{i j k}(x, z)=$ sector-averaged atmospheric concentrations for wind speed $i$, stability condition $j$, and contaminant form $k$ for the downwind distance $x$ and height $z$ above local ground level $\left(\mathrm{g} / \mathrm{m}^{3}\right)$

$i=$ index on wind speed $(i=1,2, \ldots . m ; m=$ number of wind speed $\mathrm{cl}$ asses)

$j=$ index on stability conditions $(j=1,2, \ldots, n ; n=$ number of stability conditions)

$R_{k}(x)=$ plume source depletion fraction as a function of downwind distance $x$ for contaminant form $k$ (dimensionless)

$u_{i}=$ wind-speed central value for wind-speed interval class i $(\mathrm{m} / \mathrm{s})$

$\sigma_{z_{j}}=$ standard deviation of concentration in the vertical dimension for stability class $j(m)$

$n=$ number of wind direction sectors $(n=16)$ (dimensionless)

$(2 \pi x / n)=$ sector width.

The indexed variables are defined in terms of central values for each frequency class of atmospheric conditions. The removal of the contaminant from the atmospheric plume, by various depletion processes, is computed using the equation 


$$
R_{k}(x)=r c d w
$$

where fractional losses are defined as

$$
\begin{aligned}
& r=\text { radioactive decay term (dimensionless) } \\
& c=\text { chemical decay term (dimensionless) } \\
& d=\text { dry deposition loss term (dimensionless) } \\
& w=\text { wet deposition loss term (dimensionless). }
\end{aligned}
$$

The central wind speed, $u_{j}$, in a wind-speed category is not directly applicable to the movement of an atmospheric plume in the region of interest. The wind speed must be adjusted for differences in height and local surface roughness. The atmospheric component of RAPS uses relationships from the atmospheric surface-layer similarity theory given by Paulson (1970), Businger et al. (1971), and Hanna et al. (1982) to compute an equivalent central wind speed at plume height for each wind-speed category. To provide a height adjustment of the wind speed as a continuous function of the local surface roughness, these relationships are used in preference to less general power-law approximations (Irwin et al. 1979). (a)

The local surface roughness is characterized by a surface roughness length. Table 6.1 shows examples of the magnitude of this parameter for various surface covers (see also Figure 6.1). The surface roughness lengths in

TABLE 6.1. Typical Surface Roughness Lengths

\begin{tabular}{lcc}
\multicolumn{1}{c}{ Surfaces } & \multicolumn{2}{c}{$\begin{array}{c}\text { Roughness } \\
\text { Length }(\mathrm{cm})\end{array}$} \\
\cline { 1 - 1 } Snow, sea, desert & 0.005 to 0.03 \\
Lawn & 0.1 \\
Grass $(5 \mathrm{~cm})$ & 1 to 2 \\
Grass (tall) & 4 to 9 \\
Mature root crops & 14 \\
Low forest & 50 \\
High forest & 100 \\
Urban area & 100
\end{tabular}

(a) Irwin, J. S., S. E. Gryning, A. A. M. Holtslay and B. Sivertsen. 1985. Atmospheric Modeling Based on Boundary Layer Parameterization. Draft Report. U.S. Environmental Protection Agency, Washington, D.C. 
the region surrounding the release are used to account directly for local influences in both dispersion and dry deposition computations.

The average air concentration, $c(x, z)$ in $g / m^{3}$, at ground level $(z=0)$ for a population located a certain distance and direction from the waste site is computed as the sum of the concentrations over the $i, j$, and $k$ indices, as given by

$$
C(x, z)=\sum_{i=1}^{n} \sum_{j=1}^{m} \sum_{k=1}^{p}\left[f_{i j} C_{i j k}(x, z)\right]
$$

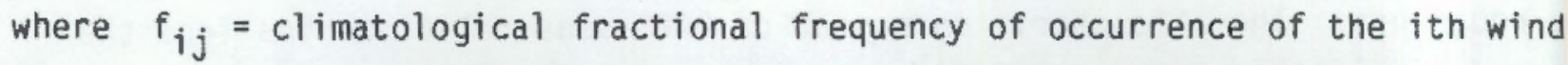
speed and jth stability class conditions within the specified direction (dimensionless)

$n, m, p=$ number of wind speed, stability, and contaminant forms, respectively.

Deposition to surfaces can occur as the result of either wet or dry deposition processes. Wet deposition is the scavenging of the contaminant by precipitation or cloud droplets. Dry deposition is the direct deposition of the airborne contaminant onto a surface by such processes as impaction, sorption, and gravitational settling. The total deposition at a specified location is computed as the sum of the wet and dry deposition fluxes to the surface:

$$
T(x, z)=\sum_{i=1}^{n} \sum_{j=1}^{m} \sum_{k=1}^{p}\left[f_{i j} D_{i j k}(x, z)+g w_{i j k}(x, z)\right]
$$

where $T(x, z)=$ total surface concentration $\left(\mathrm{g} / \mathrm{m}^{2}\right)$

$$
\begin{aligned}
D_{i j k}(x, z)= & \text { dry deposition flux }\left(\mathrm{g} / \mathrm{m}^{2}\right) \\
g= & \text { climatologic fractional frequency of occurrence of the indexed } \\
& \text { precipitation conditions within the specified direction } \\
& \text { (dimensionless) } \\
W_{i j k}(x, z)= & \text { wet deposition flux for wind speed } i \text {, stability class } j, \text { and } \\
& \text { contaminant form } k\left(g / \mathrm{m}^{2}\right) .
\end{aligned}
$$


The value for dry deposition $\left[D_{i j k}(x, z)\right]$ is computed from the sectoraveraged concentrations given in Equation (6.13) using the equation

$$
D_{i j k}(x, z)=\frac{C_{i j k}(x, z) T}{R_{i j k}}
$$

where $R_{i j k}=$ dry deposition resistance for wind speed $i$, stability class $j$, and contaminant $k(s / m)$

$$
T=\text { time period for deposition (s). }
$$

The value for wet deposition is given by

$$
W_{i j k}(x, z)=g T \int_{D}^{Z} L C_{i j k}(x, z) d z
$$

where $Z=$ depth of the wetted plume layer $(m)$

$L=$ scavenging coefficient $\left(s^{-1}\right)$.

The atmospheric transport, dispersion, and deposition computations account for the size of the source by modifying the initial dispersion. A typical width for the source is used to define a virtual distance of travel for computing initial vertical dispersion.

The RAPS atmospheric component uses six atmospheric-stability classes to characterize the dispersion rates. The atmospheric-stability classes are designated by the letters A to $F$ (S1ade 1968) and are commonly referred to as the Pasquill-Gifford Stability Categories. Classes A, B, and C stand for very unstable, unstable, and slightly unstable conditions, respectively; $D$ stands for neutral conditions; and $E$ and $F$ stand for stable and very stable conditions, respectively. Dispersion is fastest under very unstable conditions (Class A) and slowest under very stable conditions ( $\mathrm{Cl}$ ass $\mathrm{F}$ ).

The Pasquill-Gifford dispersion curves used in the atmospheric component of RAPS are expressed as a function of elapsed travel time for the plume. This 
travel time is computed as the sum of the travel times over various local surfaces, thus directly allowing for local wind shear effects in the dispersion computation.

Radioactive materials with short half-lives decay significantly while still airborne. The radioactive decay plume depletion term $(r)$ in Equation (6.14) is computed assuming exponential decay. A similar approach is used for the chemical decay term.

As shown in Equation (6.17), the dry deposition rate is computed using a value for total resistance $\left(R_{i j k}\right)$. The total resistance, which is the inverse of the deposition velocity, is computed at each point as the sum of the atmospheric and surface resistances:

$$
R_{i j k}=R_{a_{i j k}}+R_{s_{i j k}}
$$
where $R_{a_{i j k}}=$ atmospheric resistance for wind speed $i$, stability class $j$,

$R_{s_{i j k}}=$ surface resistance for wind speed $i$, stability class $j$, and contaminant $k(\mathrm{~s} / \mathrm{m})$.

The atmospheric resistance represents the resistance to the transfer of a contaminant from the atmospheric layer to the ground surface. The RAPS formulations for atmospheric resistance are based on micrometeorological relationships (Paulson 1970; Businger et a1. 1971; Golder 1972). These formulations allow the atmospheric resistance to vary with the wind speed, stability, and upwind surface roughness. The surface resistance is a function of the surface roughness and the properties of the contaminants. For particulate matter, the gravitational term is included in the empirical curves used to define the resistances (Sehmel and Hodgson 1980).

For dry deposition, a mass budget approach is used to compute the source depletion fraction [i.e., parameter $d$ in Equation (6.14)]. Although these fractions are applied as a source depletion model such as the one given in Slade (1968), the surface depletion effects documented by Horst (1984) are accounted for in the RAPS dry deposition model by the atmospheric resistances. 
The computation of the atmospheric resistance term is based on assuming empirical shapes of micrometeorological profiles such that the RAPS model accounts for equilibrium effects of surface depletion under a 10-m height.

The climatological scavenging of contaminants is calculated by RAPS using an approach suggested by Slinn (1976). This climatological calculation provides an order-of-magnitude estimate of wet deposition rates. This computation accounts for the major factors affecting the wet deposition rate for the various combinations of releases and receptors between sites.

Wet deposition is computed as the integral of the concentration over height in Equation (6.18) using Equation (6.11). The result, as given by Hanna et al. (1982) for the wet flux $\left(F_{\text {wet }}\right)$, is

$$
F_{\text {wet }}=\frac{\Lambda Q_{k}}{\sqrt{2 \pi} \sigma_{y_{j}} u_{i}}
$$

Equation (6.20), converted to a sector-averaged form for the total deposition, is expressed as

$$
W_{i j k}=\frac{\Lambda Q_{0} R_{k} 8 g T}{u_{i} \pi x}
$$

The scavenging coefficient is defined for a specified volume of a plume as the ratio of airborne contaminant removed by precipitation scavenging to the airborne contaminant concentration. The scavenging coefficient varies with the rainfall type and rate, saturation conditions, and contaminant characteristics. The model assumes a neutral stability for all precipitation conditions. The wet deposition plume depletion term [w in Equation (6.14)] is obtained using

$$
w=\exp (-L \times / U)
$$

In summary, the atmospheric pathway component of the RAPS model takes into account local site influences. The region around the site is assigned one of 
four roughness classes to define local dispersion rates. The atmospheric and surface deposition concentrations are computed using these dispersion coefficients plus climatological site data. Major removal and decay mechanisms are incorporated in the atmospheric component of RAPS. These computations are formulated to provide reasonable estimates of contaminant deposition rates as input to the overland transport and exposure assessment components of RAPS.

\subsection{SUSPENSION COMPUTATION TEST APPLICATION}

An area on the DOE's Hanford Site was selected for testing the surface particulate suspension computation of the atmospheric pathway code. To test the model outputs in a situation where nonzero data exist for comparisons, the suspension from a contaminated area was computed as it existed in the past at a time when it was the subject of intensive field and modeling efforts.

This special computation was made only for testing purposes. Application of the RAPS methodology at the Hanford Site for a current ranking of facilities will give quite different results, since the surface contamination at the site has largely been eliminated.

\subsubsection{Site Description}

The contaminated area selected is the B-C cribs area. The B-C cribs area was an active, unlined waste trench for supernatant liquids containing active cesium $\left({ }^{137} \mathrm{Cs}\right)$ and strontium $\left({ }^{90} \mathrm{Sr}\right)$.

The area surrounding the B-C cribs became contaminated in the late 1950s after active disposal ceased and animals began burrowing into the contaminated undersoil. The exposed soil and material became a salt lick for local animals and this allowed the contamination to spread farther. When the spread of contamination was discovered, the site was classified as a radiation zone. The burrow holes were sealed and routine surveillance was started. Figure 6.2 is a 1975 map of the controlled B-C cribs area showing contaminated areas, nearby roads, air sampling locations, and fire breaks. The contaminated area is subdivided into two zones; zone $A$ is the more highly contaminated area located within the larger, overall area of contamination, zone B. 


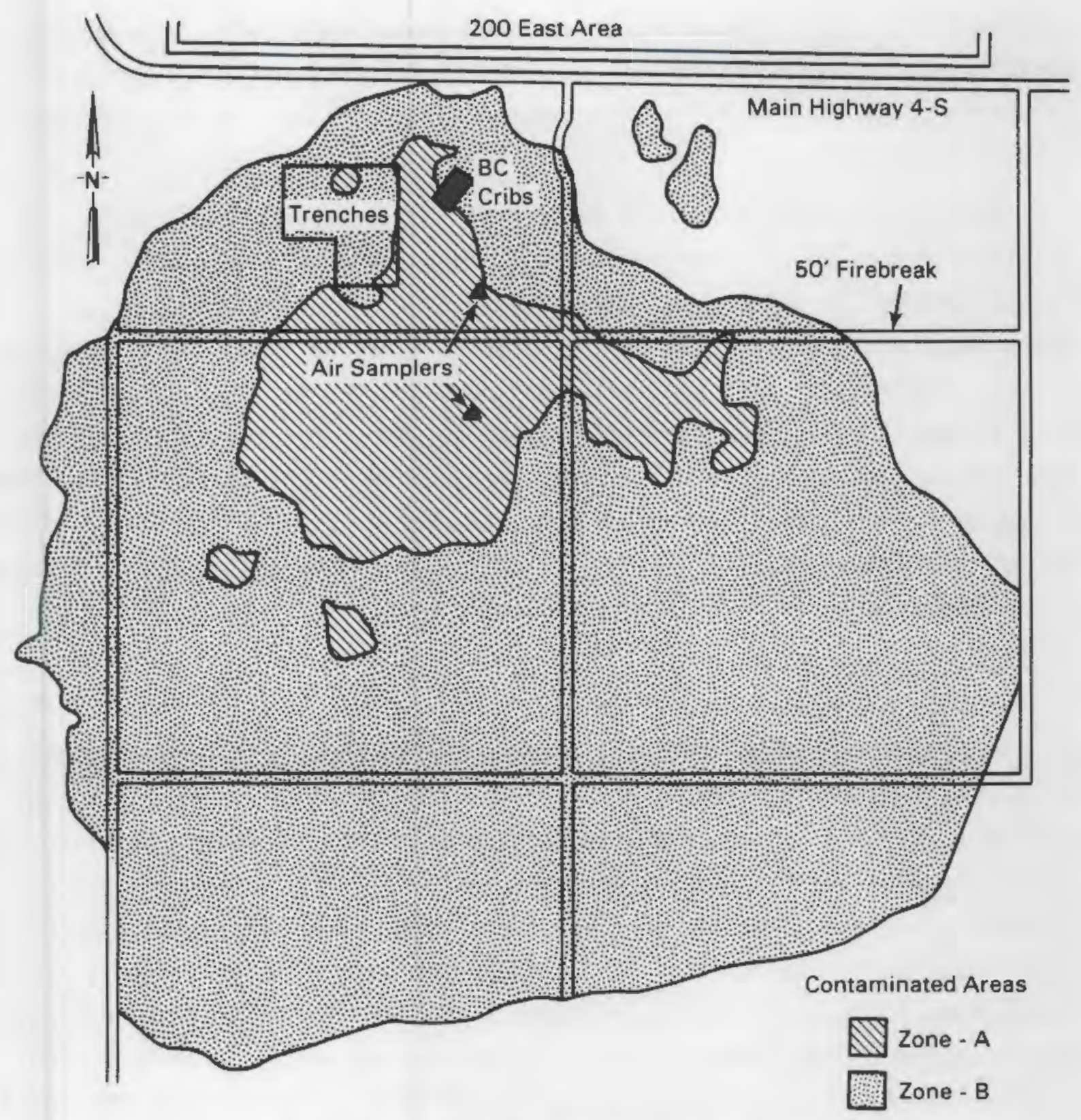

FIGURE 6.2. B-C Cribs Controlled Area

The contaminated area covered about 2000 acres of land near the center of the Hanford Site. The contamination was estimated to be 14 curies of ${ }^{137} C_{s}$ and 81 curies of ${ }^{90} \mathrm{Sr}$, mainly associated with animal waste.

Since the discovery and sealing of the contaminated area, no additional spread of contamination by biological or meteorological mechanisms has been 
detected. The contaminated animal wastes were removed. Routine environmental surveillance included contaminant air samples, monthly radiation surveys, bimonthly groundwater samples, and semiannual biological samples (0'Farrell and Gilbert 1975).

Range fires occur from time to time at Hanford; current management practices are aimed at preventing a major range fire over this area. Mishima (1964) studied the potential for resuspension of surface contaminants in a fire and found that less than $0.1 \%$ of the material would be injected into the air by a fire. However, he also concluded that once the vegetation had been removed from the surface by fire, the wind erosion potential for the site would become very great. Therefore 50-ft firebreaks were added to the area to reduce the chance of a fire spreading through the area (see Figure 6.2). As part of the current model testing, the hypothetical case of a bare, unstabilized surface is included for comparison with the resuspension rates indicated by Mishima's studies.

A detailed modeling effort of the suspension potential of the B-C cribs area was conducted by Horst (1976). Horst used gridded aerial survey data from the B-C cribs area to define a detailed grid of surface concentrations. He predicted downwind air concentrations using a Gaussian dispersion surface suspension model. Horst's model treats suspension as a positive surface source and deposition as a negative surface source term. Air concentrations normalized to surface emission rates are computed for the stability classes. This computation is based on the observed horizontal distribution of the surface contamination and an assumed ratio of deposition velocity to the mean wind speed. To simplify the calculations, the air concentration is assumed to be uniform in the crosswind direction and the source term is a constant.

Figure 6.3 is a detailed contour map from Horst (1976) of the results from a 1975 aerial survey of the B-C cribs area. This map provides considerable detail on the extent and distribution of the contamination. The dotted boundary marks the area that was gridded for Horst's model runs. Table 6.2 gives the values for the letters used to label contours in Figure 6.3 . 


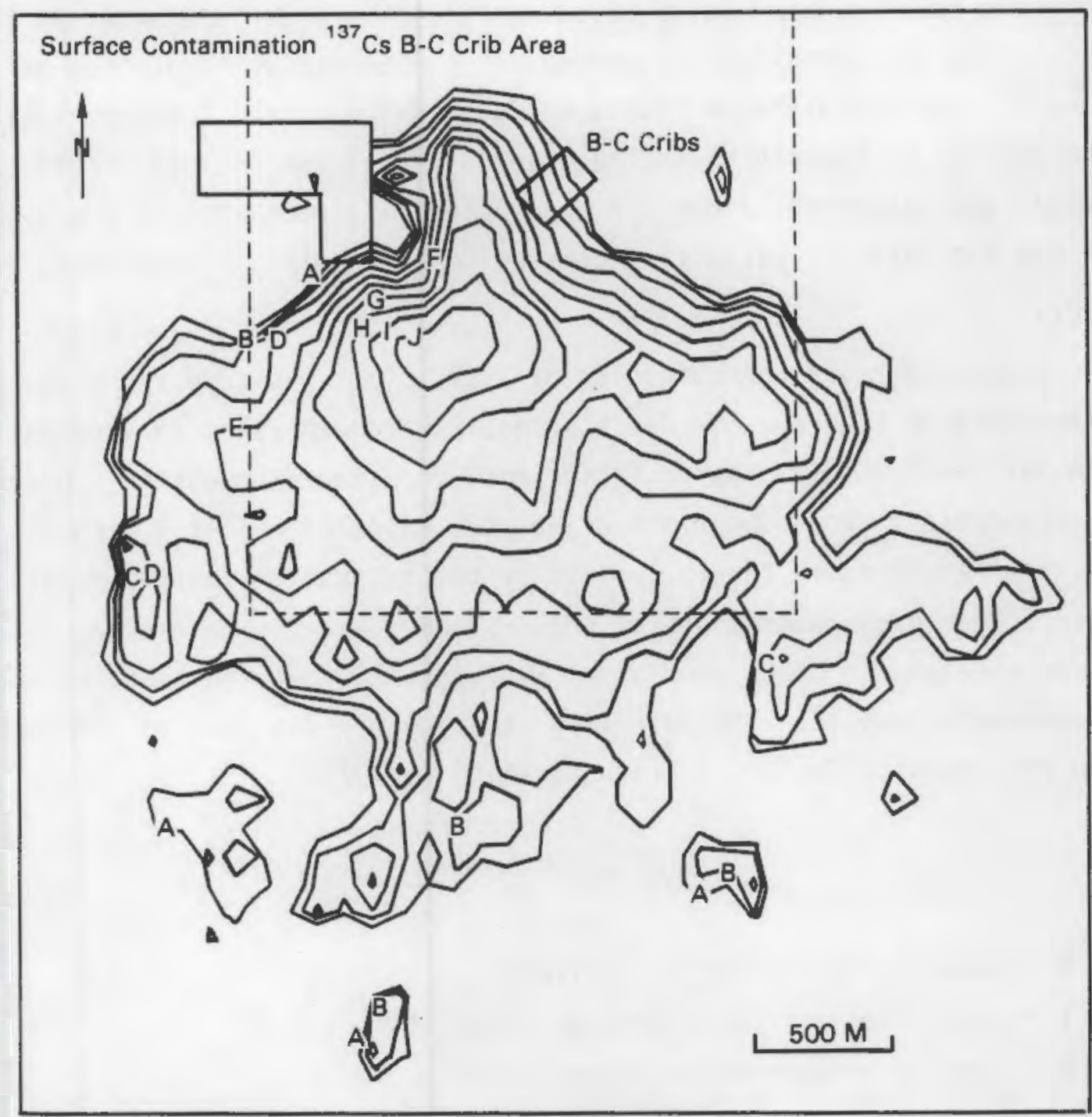

FIGURE 6.3. Contours of ${ }^{137}$ CS Surface Contamination in the B-C Cribs Controlled Area (Horst 1976)

TABLE 6.2. Surface Contamination Labels For Figure $6.3\left(\mu \mathrm{Ci} / \mathrm{m}^{2}\right)$

\begin{tabular}{|c|c|c|c|}
\hline Label & Value & Label & value \\
\hline A & 0.12 & $F$ & 0.88 \\
\hline B & 0.18 & G & 1.33 \\
\hline C & 0.26 & $H$ & 2.00 \\
\hline D & 0.40 & I & 3.00 \\
\hline$E$ & 0.59 & $\mathrm{~J}$ & 4.50 \\
\hline
\end{tabular}


Horst's results from a simplified surface flux model are shown in Figure 6.4, where the normalized suspended air concentration is plotted as a function of downwind distance from a uniform area source. The numerical solution values for no deposition (solid lines), deposition (dashed lines), and analytical approximation values for deposition (discrete points) are given in Figure 6.5 for Pasguill (stability classes) A (unstable), D (neutral), and F (stable).

An average surface contamination of $1.29 \mu \mathrm{Ci} / \mathrm{m}^{2}$ was computed from the digitized data in Figure 6.3. Horst's results are expressed in a normalized fashion such that a resuspension factor must be assumed to obtain a predicted air concentration. For comparison of Horst's detailed modeling with the RAPS output, the resuspension factor implied by the outputs of the two models was computed. Reasonable magnitudes of the implied resuspension factors relative to values obtained in other studies at Hanford will indicate that the models show comparable outputs. The following relationship was used to compute the implied resuspension factor, $K$, [see Equation (6.10)]:

$$
K=C /(Y * G)
$$

where $C=$ mean air concentration $\left(\mu \mathrm{C} / \mathrm{m}^{3}\right)$

$Y=$ normalized air concentration (dimensionless)

$G=$ surface contamination value $\left(\mu \mathrm{C} i / \mathrm{m}^{2}\right)$.

The mean air concentration, $C$, is computed by the RAPS code as described below. The normalized air concentration is taken from Horst's results as given in Figure 6.4, with a deposition velocity to wind speed ratio of $10^{-2}$ (Horst 1976). The neutral stability curve was selected as representing average conditions.

Values for the resuspension factor reported in the literature show variation over 11 orders of magnitude. This wide range appears to reflect real differences over different kinds of surfaces (Slinn 1976). A smaller range of resuspension factors for wind erosion from natural surfaces has been reported for Hanford. Healy and Fuquay (1959), Mishima (1964, 1973), Bruns (1976), and 


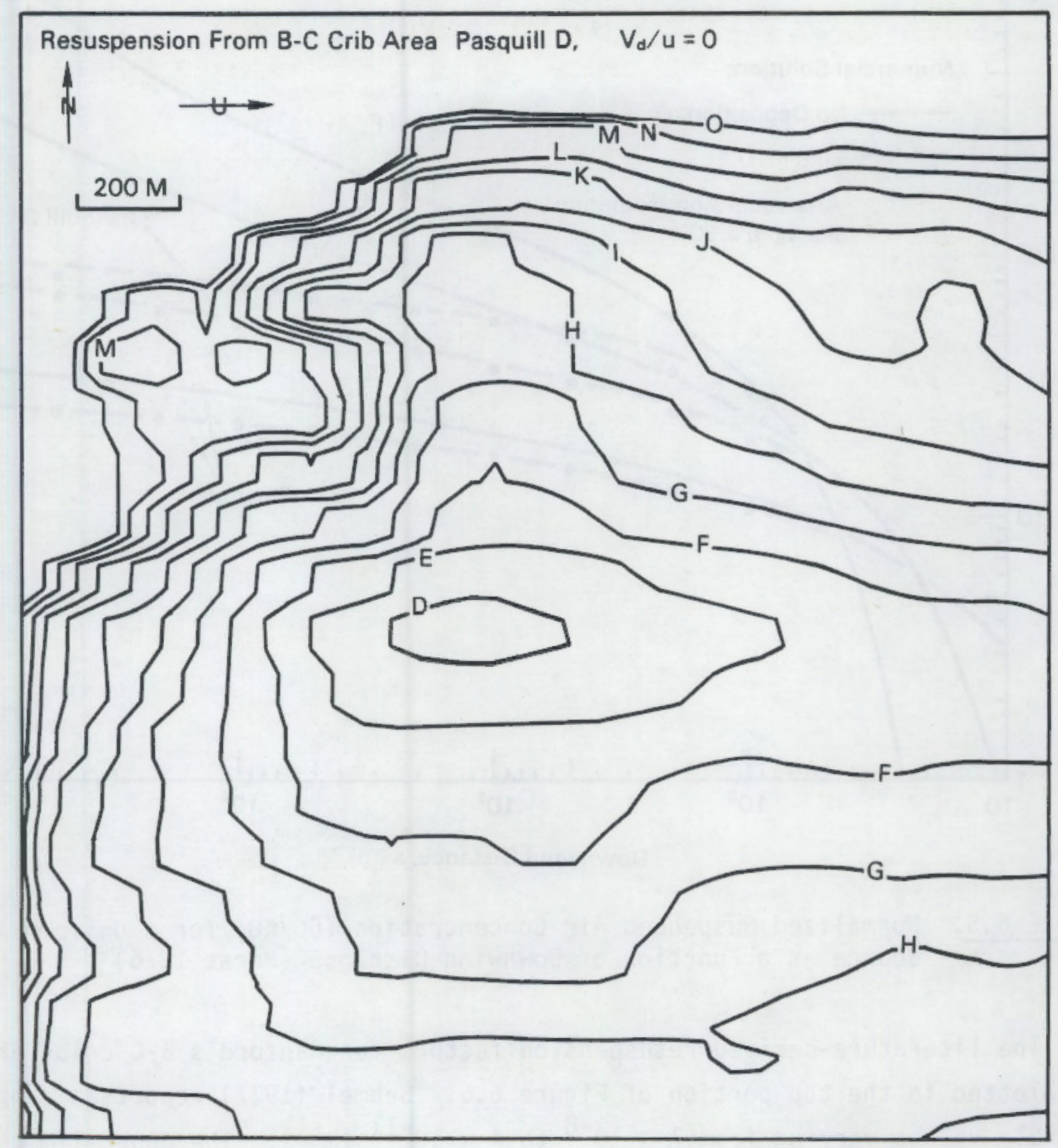

FIGURE 6.4. Contours of Normalized Suspended Air Concentration $\bar{U} \mathrm{C} / \mathrm{K}$ in the B-C Cribs Controlled Area (Horst 1976)

Sehmel (1977) have provided various values for resuspension factors at Hanford. These studies were mainly concerned with defining the suspension potential for the B-C cribs area. 


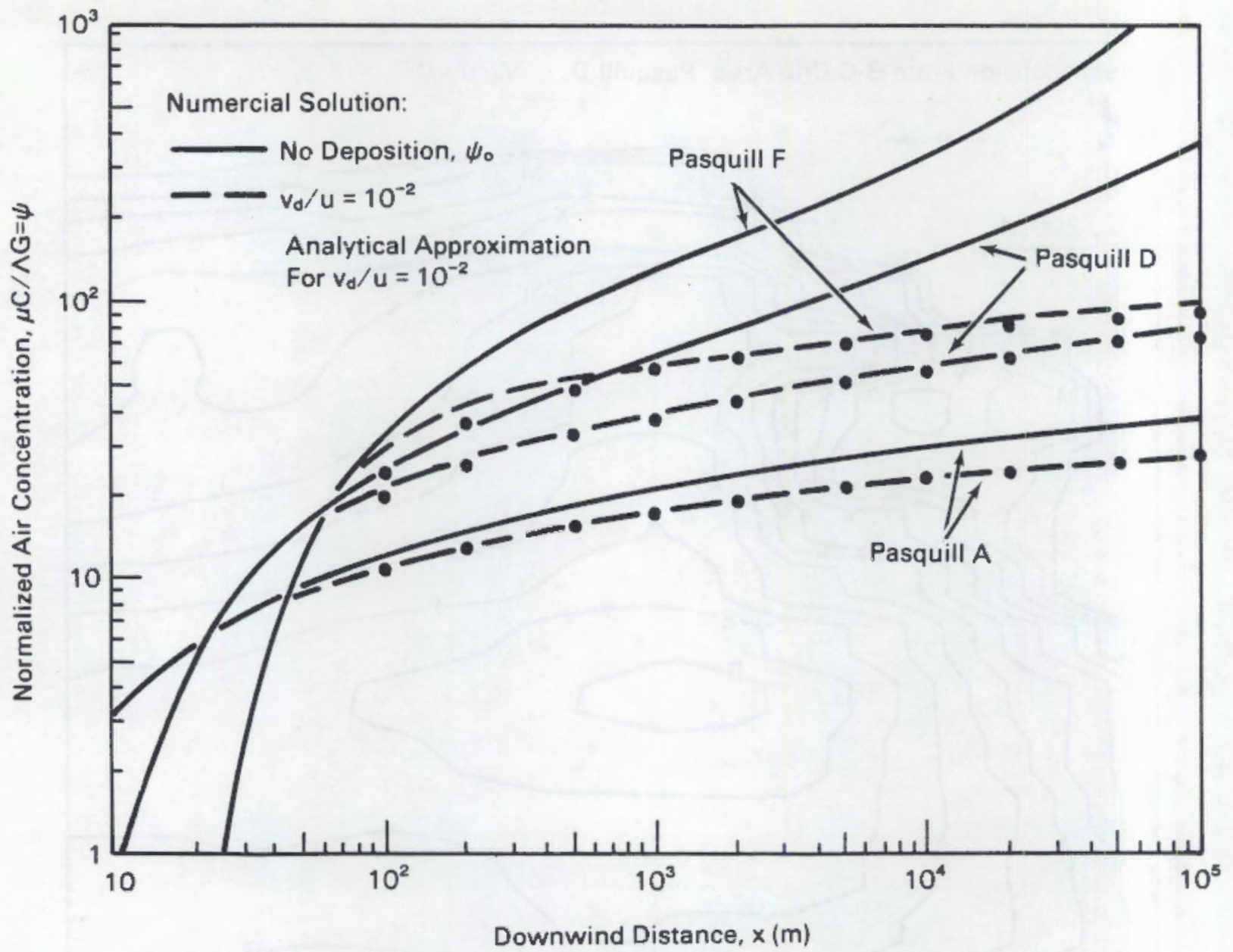

FIGURE 6.5. Normalized Suspended Air Concentration ( $\bar{U} \mathrm{C} / \mathrm{KG}$ ) for a Uniform Area Source as a Function of Downwind Distance (Horst 1976)

The 1 iterature-derived resuspension factors for Hanford's B-C cribs area are plotted in the top portion of Figure 6.6. Sehmel (1977) reports a range of possible values varying from $7 \times 10^{-8}$ to $4 \times 10^{-11}\left(\mathrm{~m}^{-1}\right)$. The upper limit of this range corresponds to values from range fire tests done by Mishima (1973) and field measurements made in the $B-C$ cribs area (before stabilization) by Healy and Fuquay in 1959. The lower limit corresponds to results of studies based on aerial measurements made after the area had been stabilized (Bruns 1976).

Because different techniques and assumptions were used to compute resuspension factors in these various studies, the question of equivalence of the reported resuspension factors arises. Although some part of the variation 


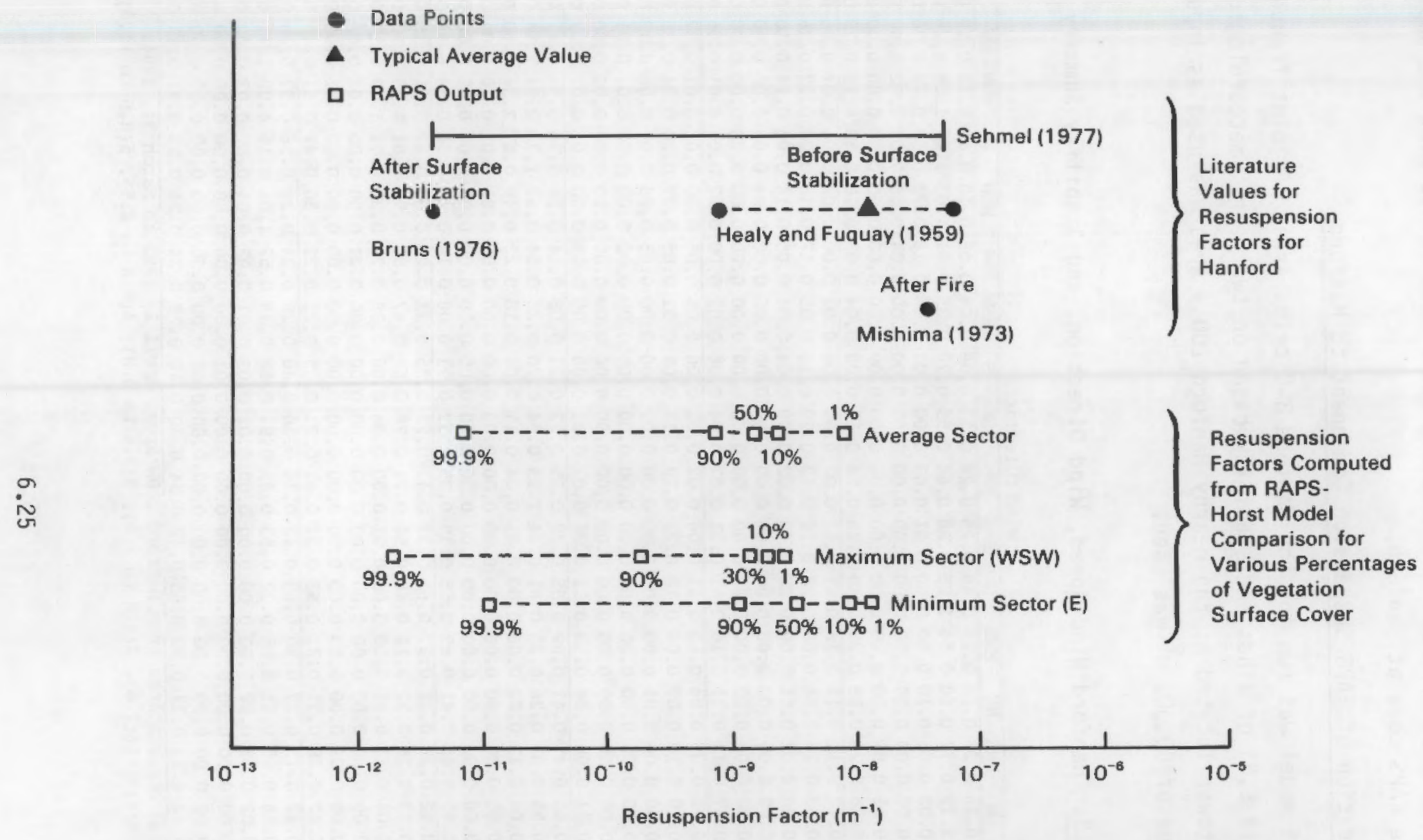

FIGURE 6.6. Comparison of Resuspension Factors 
is likely to be the result of differences in experiment designs, these reported resuspension factors represent the best available data for testing the application of the RAPS code at Hanford.

\subsubsection{Application of RAPS Suspension Component to Hanford}

The RAPS model was run for the Hanford B-C cribs area. A joint frequency summary (Table 6.3) of winds and stability based on two years' meteorological data from a tower located at the nearby Hanford $200 \mathrm{~W}$ Area was used as input. A surface area of $60,000 \mathrm{~m}^{2}$ was used.

TABLE 6.3. Hanford Wind Speed, Wind Direction, and Stability Summary

Stab-

ility wind (b) Wind Direction

Class Range ${ }^{(b)}$ N NNE NE ENE E ESE SE SSE S SSA SW WSW W WNW NW NNW

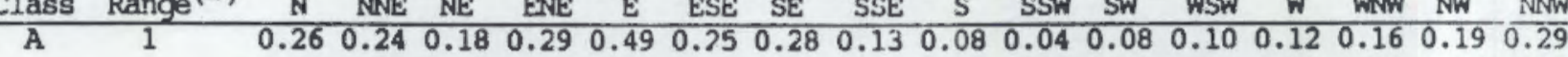

$\begin{array}{llllllllllllllllll}2 & 1.19 & 0.77 & 0.60 & 0.54 & 1.25 & 0.88 & 0.64 & 0.59 & 0.70 & 0.35 & 0.61 & 1.03 & 1.07 & 1.06 & 1.26 & 0.96\end{array}$

$\begin{array}{lllllllllllllllllllllllllllll}3 & 0.02 & 0.05 & 0.10 & 0.00 & 0.00 & 0.01 & 0.01 & 0.00 & 0.01 & 0.05 & 0.18 & 0.73 & 0.59 & 0.78 & 0.70 & 0.02\end{array}$

$\begin{array}{llllllllllllllllllllllllll}4 & 0.00 & 0.00 & 0.00 & 0.00 & 0.00 & 0.00 & 0.00 & 0.00 & 0.00 & 0.00 & 0.04 & 0.06 & 0.01 & 0.02 & 0.00 & 0.00\end{array}$

$\begin{array}{llllllllllllllllllllllll}5 & 0.01 & 0.01 & 0.00 & 0.00 & 0.00 & 0.00 & 0.00 & 0.00 & 0.00 & 0.00 & 0.00 & 0.00 & 0.00 & 0.00 & 0.00 & 0.00\end{array}$

$\begin{array}{lllllllllllllllllll}6 & 0.26 & 0.24 & 0.18 & 0.29 & 0.49 & 0.25 & 0.28 & 0.13 & 0.08 & 0.04 & 0.08 & 0.10 & 0.12 & 0.16 & 0.19 & 0.29\end{array}$

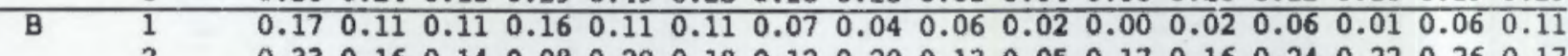

$\begin{array}{llllllllllllllllll}2 & & 0.33 & 0.16 & 0.14 & 0.08 & 0.28 & 0.18 & 0.12 & 0.20 & 0.13 & 0.05 & 0.17 & 0.16 & 0.24 & 0.22 & 0.26 & 0.17\end{array}$

$\begin{array}{llllllllllllllllllllllllll}3 & 0.00 & 0.02 & 0.01 & 0.00 & 0.00 & 0.00 & 0.02 & 0.00 & 0.04 & 0.04 & 0.05 & 0.14 & 0.05 & 0.14 & 0.10 & 0.00\end{array}$

$4 \quad \begin{array}{lllllllllllllllllllllll}4 & 0.00 & 0.00 & 0.00 & 0.00 & 0.00 & 0.00 & 0.00 & 0.00 & 0.00 & 0.00 & 0.00 & 0.04 & 0.01 & 0.00 & 0.00 & 0.00\end{array}$

$\begin{array}{llllllllllllllllllll}5 & 0.00 & 0.00 & 0.00 & 0.00 & 0.00 & 0.00 & 0.00 & 0.00 & 0.00 & 0.00 & 0.00 & 0.00 & 0.00 & 0.00 & 0.00 & 0.00\end{array}$ $\begin{array}{llllllllllllllllllll}6 & 0.17 & 0.11 & 0.11 & 0.16 & 0.11 & 0.11 & 0.07 & 0.04 & 0.06 & 0.02 & 0.00 & 0.02 & 0.06 & 0.01 & 0.06 & 0.11\end{array}$

\begin{tabular}{lllllllllllllllllll} 
& 6 & 0.17 & 0.11 & 0.11 & 0.16 & 0.11 & 0.11 & 0.07 & 0.04 & 0.06 & 0.02 & 0.00 & 0.02 & 0.06 & 0.01 & 0.06 & 0.11 \\
\hline $\mathrm{C}$ & 1 & 0.11 & 0.08 & 0.04 & 0.13 & 0.11 & 0.06 & 0.02 & 0.01 & 0.08 & 0.05 & 0.05 & 0.00 & 0.01 & 0.01 & 0.07 & 0.02
\end{tabular}

$\begin{array}{llllllllllllllllllll}0.10 & 0.10 & 0.07 & 0.04 & 0.18 & 0.22 & 0.19 & 0.13 & 0.06 & 0.01 & 0.05 & 0.07 & 0.20 & 0.34 & 0.25 & 0.1\end{array}$

$\begin{array}{llllllllllllllllllllllll}3 & 0.00 & 0.00 & 0.01 & 0.00 & 0.00 & 0.00 & 0.00 & 0.02 & 0.00 & 0.00 & 0.05 & 0.08 & 0.07 & 0.08 & 0.13 & 0.02\end{array}$

$\begin{array}{llllllllllllllllllllllllllll}4 & 0.00 & 0.00 & 0.00 & 0.00 & 0.00 & 0.00 & 0.00 & 0.00 & 0.00 & 0.00 & 0.00 & 0.00 & 0.00 & 0.01 & 0.01 & 0.00\end{array}$

$\begin{array}{llllllllllllllllllll}5 & 0.00 & 0.00 & 0.00 & 0.00 & 0.00 & 0.00 & 0.00 & 0.00 & 0.00 & 0.00 & 0.00 & 0.00 & 0.00 & 0.00 & 0.00 & 0.00\end{array}$

$\begin{array}{lllllllllllllllllllll}6 & 0.11 & 0.08 & 0.04 & 0.13 & 0.11 & 0.06 & 0.02 & 0.01 & 0.08 & 0.05 & 0.05 & 0.00 & 0.01 & 0.01 & 0.07 & 0.02\end{array}$

\begin{tabular}{llllllllllllllllllllll} 
& 0 & & 0.11 & 0.08 & 0.04 & 0.13 & 0.11 & 0.06 & 0.02 & 0.01 & 0.08 & 0.05 & 0.05 & 0.00 & 0.01 & 0.01 & 0.07 & 0.02 \\
\hline & 1 & & 0.65 & 0.45 & 0.41 & 0.69 & 0.55 & 0.39 & 0.35 & 0.22 & 0.21 & 0.08 & 0.14 & 0.14 & 0.36 & 0.54 & 0.41 & 0.39
\end{tabular}

$\begin{array}{lllllllllllllllllll}2 & & 0.59 & 0.52 & 0.26 & 0.25 & 0.61 & 0.64 & 1.23 & 0.54 & 0.70 & 0.26 & 0.54 & 0.67 & 1.73 & 2.84 & 2.14 & 0.60\end{array}$

$\begin{array}{llllllllllllllllllllll}3 & & 0.04 & 0.12 & 0.02 & 0.00 & 0.00 & 0.01 & 0.04 & 0.11 & 0.06 & 0.18 & 0.23 & 0.49 & 0.67 & 2.36 & 0.60 & 0.01\end{array}$

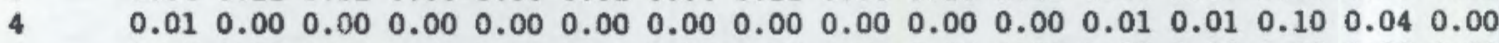

$\begin{array}{lllllllllllllllllllll}5 & 0.00 & 0.00 & 0.00 & 0.00 & 0.00 & 0.00 & 0.00 & 0.00 & 0.00 & 0.00 & 0.00 & 0.00 & 0.00 & 0.00 & 0.00 & 0.00\end{array}$

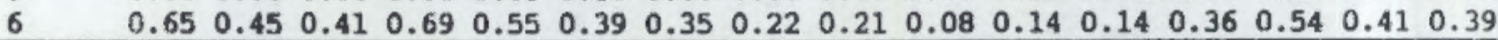

\begin{tabular}{llllllllllllllllllll}
\hline & 6 & 1 & & 0.42 & 0.28 & 0.31 & 0.37 & 0.63 & 0.37 & 0.41 & 0.21 & 0.35 & 0.21 & 0.22 & 0.30 & 0.47 & 0.51 & 0.35 & 0.46
\end{tabular}

$\begin{array}{llllllllllllllllllll}2 & & 0.33 & 0.25 & 0.12 & 0.11 & 0.48 & 0.54 & 0.71 & 0.78 & 0.66 & 0.47 & 0.56 & 0.92 & 4.01 & 4.15 & 1.53 & 0.49\end{array}$

$\begin{array}{lllllllllllllllllllllll}3 & 0.04 & 0.13 & 0.01 & 0.00 & 0.00 & 0.01 & 0.00 & 0.04 & 0.06 & 0.08 & 0.24 & 0.35 & 0.71 & 1.19 & 0.17 & 0.00\end{array}$

$\begin{array}{llllllllllllllllllllllllllll}4 & 0.00 & 0.00 & 0.00 & 0.00 & 0.00 & 0.00 & 0.00 & 0.00 & 0.00 & 0.00 & 0.01 & 0.00 & 0.00 & 0.02 & 0.00 & 0.00\end{array}$

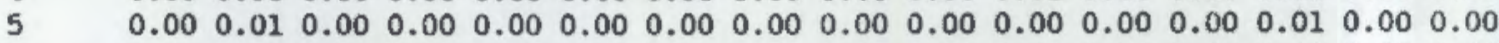
\begin{tabular}{llllllllllllllllllll}
6 & & 0.42 & 0.28 & 0.31 & 0.37 & 0.63 & 0.37 & 0.41 & 0.21 & 0.35 & 0.21 & 0.22 & 0.30 & 0.47 & 0.51 & 0.35 & 0.46 \\
\hline
\end{tabular}

$\begin{array}{llllllllllllllllllll}\text { F } & 1 & & 0.42 & 0.13 & 0.27 & 0.30 & 0.65 & 0.42 & 0.34 & 0.30 & 0.40 & 0.28 & 0.24 & 0.24 & 0.56 & 0.37 & 0.48 & 0.31\end{array}$

$\begin{array}{llllllllllllllllllll}2 & 0.16 & 0.06 & 0.01 & 0.05 & 0.22 & 0.53 & 0.89 & 0.94 & 0.62 & 0.38 & 0.52 & 1.01 & 4.16 & 4.08 & 1.41 & 0.28\end{array}$

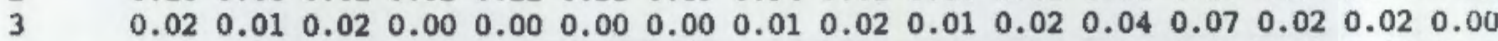

$4 \quad \begin{array}{llllllllllllllllllllllll}4 & 0.00 & 0.00 & 0.00 & 0.00 & 0.00 & 0.00 & 0.00 & 0.00 & 0.01 & 0.00 & 0.00 & 0.00 & 0.00 & 0.00 & 0.00 & 0.00\end{array}$

$\begin{array}{lllllllllllllllllllllllll}5 & 0.00 & 0.00 & 0.00 & 0.00 & 0.00 & 0.00 & 0.00 & 0.00 & 0.00 & 0.00 & 0.00 & 0.00 & 0.00 & 0.00 & 0.00 & 0.00\end{array}$

$\begin{array}{lllllllllllllllllll}6 & 0.42 & 0.13 & 0.27 & 0.30 & 0.65 & 0.42 & 0.34 & 0.30 & 0.40 & 0.28 & 0.24 & 0.24 & 0.56 & 0.37 & 0.48 & 0.31\end{array}$

(a) Meteorological wbservations fram Hanford 200 area, April 1, 1982 to March $31,1984$.

(b) Wind Ranges $(\mathrm{m} / \mathrm{s})$ : $1(\langle 1.8), 2(1.8$ to 3.6$), 3(3.6$ to 5.8$), 4(5.8$ to 8.5$), 5(8.5$ to 11.0$), 6(\rangle 11.0)$. 
The RAPS model can calculate concentrations for emissions in three different particle radius sizes $(7.5,3.0$, and $0.3 \mathrm{~m})$. Studies have indicated that suspended radioactive materials at Hanford (and other sites) tend to be asso-

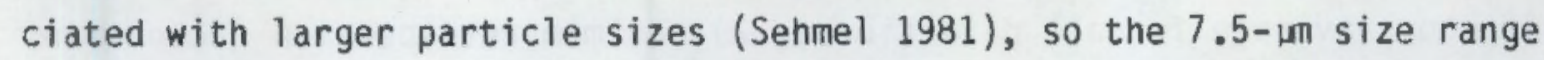
values were used to compute resuspension factors. Another choice of particle range would change the predicted concentrations only slightly and would not significantly affect the comparison results given below.

Because Hanford resuspension factors are available for various states of stabilization, RAPS model runs were made with different values for the percentage of vegetation cover. To simulate a post-fire condition with an unstabilized surface, vegetation covers of $10 \%$ and $1 \%$ were used. Vegetation covers of $90 \%$ and $99.9 \%$ were used to represent a well-stabilized surface. A $50 \%$ value for the vegetation cover represents a typical, intermediate case.

An equivalent resuspension factor could not be computed from the RAPS output alone because the surface contamination was defined as radioactivity per area rather than radioactivity per volume. To compute airborne radioactivity concentrations, Equation (6.8) requires that the radioactive contamination per volume of soil be known. The conversion of surface contamination values to volume contamination values requires that a certain thickness be assumed for the surface layer.

The output comparisons can be used to compute an implied thickness for the surface layer. Taking the case of an unstabilized surface with a resuspension factor of $1.1 \times 10^{-7} \mathrm{~m}^{-1}$ (Figure 6.6), the average concentration computed by RAPS at 200 in for a $1 \%$ vegetation cover $\left(2.6 \times 10^{-6} \mathrm{~g} / \mathrm{m}^{3}\right)$ and a typical Hanford bulk soil density $\left(1.4 \times 10^{6} \mathrm{~g} / \mathrm{m}^{3}\right)$ results in an estimate of a 10 - to $20-\mu \mathrm{m}$ surface thickness. This thickness represents the value that would be used in the source concentration conversion to have the RAPS outputs exactly agree with the historical estimates of suspension rates at Hanford.

The air concentrations computed by RAPS for $200 \mathrm{~m}$ downwind of the modeled area are used in Equation (6.23) to compute equivalent resuspension factors implied by the comparison of the two models. 
RAPS output provides concentrations in the sixteen direction sectors around the site. The resuspension factors computed for the comparison of the RAPS and Horst models are reported here for three cases: 1) average resuspension factor (average for all directions), 2) maximum resuspension factor (in sector to east) and 3) minimum resuspension factor (in the sector to westsouthwest). These cases define the range of the computed values for various directions.

The resuspension ratios implied by the comparison of models outputs are presented in the lower portion of Figure 6.6. The resuspension values for a range of vegetation cover percentages are given for the minimum average sector and maximum sector values.

\subsubsection{Discussion of Suspension Testing Results}

The magnitudes and range of resuspension factors computed with the RAPS model compare quite well with the resuspension factors that have been derived in past field and modeling studies at Hanford. Because the RAPS formulations were not based on the Hanford studies, this test result independently confirms the applicability of the RAPS suspension formulations.

The RAPS resuspension factors based on a vegetation cover of $99.9 \%$ are of the same order of magnitude as those reported from past studies of wellstabilized surfaces at Hanford. The equivalence of model results with the B-C cribs resuspension factor measured by Bruns (1976) after surface stabilization shows that the RAPS suspension formulation provides credible results when applied to sites with a high percentage of vegetation cover. In this test, the model was able to provide reasonable estimates of the very low emission rates expected from well-stabilized surfaces.

The RAPS resuspension factors calculated for the sparser vegetation covers of $50 \%, 10 \%$, and $1 \%$ runs are all within an order of magnitude. The average sector resuspension value given a vegetation cover of $1 \%$ is $9.3 \times 10^{-8} \mathrm{~m}^{-1}$, which is equivalent to the results of Mishima (1973) for a range fire (7 $x$ $10^{-7} \mathrm{~m}^{-1}$ ). If the air concentration from the sector with the maximum value is

used to compute the resuspension factor, a value of $1.1 \times 10^{-7} \mathrm{~m}^{-1}$ is obtained. 
The RAPS suspension formulations are a generalized method of accounting for differences in suspension influences between sites. The testing results show that the RAPS formulations for wind suspension of particles simulate documented surface emission rates at the DOE facility. This favorable comparison held over the range from well-stabilized to unstabilized surfaces.

\subsection{TRANSPORT, DISPERSION, AND DEPOSITION AT THE MOUND FACILITY}

This section provides background information related to atmospheric releases from the operations at the Mound facility. Additional information on this facility may be found in other sections of this document.

\subsubsection{The Mound Facility}

The Mound facility is government owned and is operated by the Monsanto Research Corporation for the U.S. Department of Energy. The Mound facility began operations in 1949, manufacturing nonnuclear weapons components and tritium-containing nuclear weapons components. Production activities are conducted in 105 buildings.

The Mound facility is located on 306 acres in southern Montgomery County in southwestern Ohio. It lies at the southern boundary of the city of Miamisburg and $0.93 \mathrm{~km}(0.58 \mathrm{mi})$ due east of the Great Miami River. The site is $16 \mathrm{~km}$ (10 $\mathrm{mi})$ south-southwest of Dayton, Ohio, and $50 \mathrm{~km}(31 \mathrm{mi})$ northnortheast of Cincinnati. Additional information on the location and setting of the Mound facility is given in Section 3.3.2.

A network of 20 ambient-air monitoring stations and an onsite meteorological tower monitor air concentrations for the Mound facility. Figure 6.7 shows the locations of these stations. Five of the air monitoring stations are located onsite. The other 15 air monitoring stations are located offsite in the region surrounding the facility at various distances. The farthest is a single station $44.8 \mathrm{~km}$ (28 $\mathrm{mi})$ from the Mound facility. 


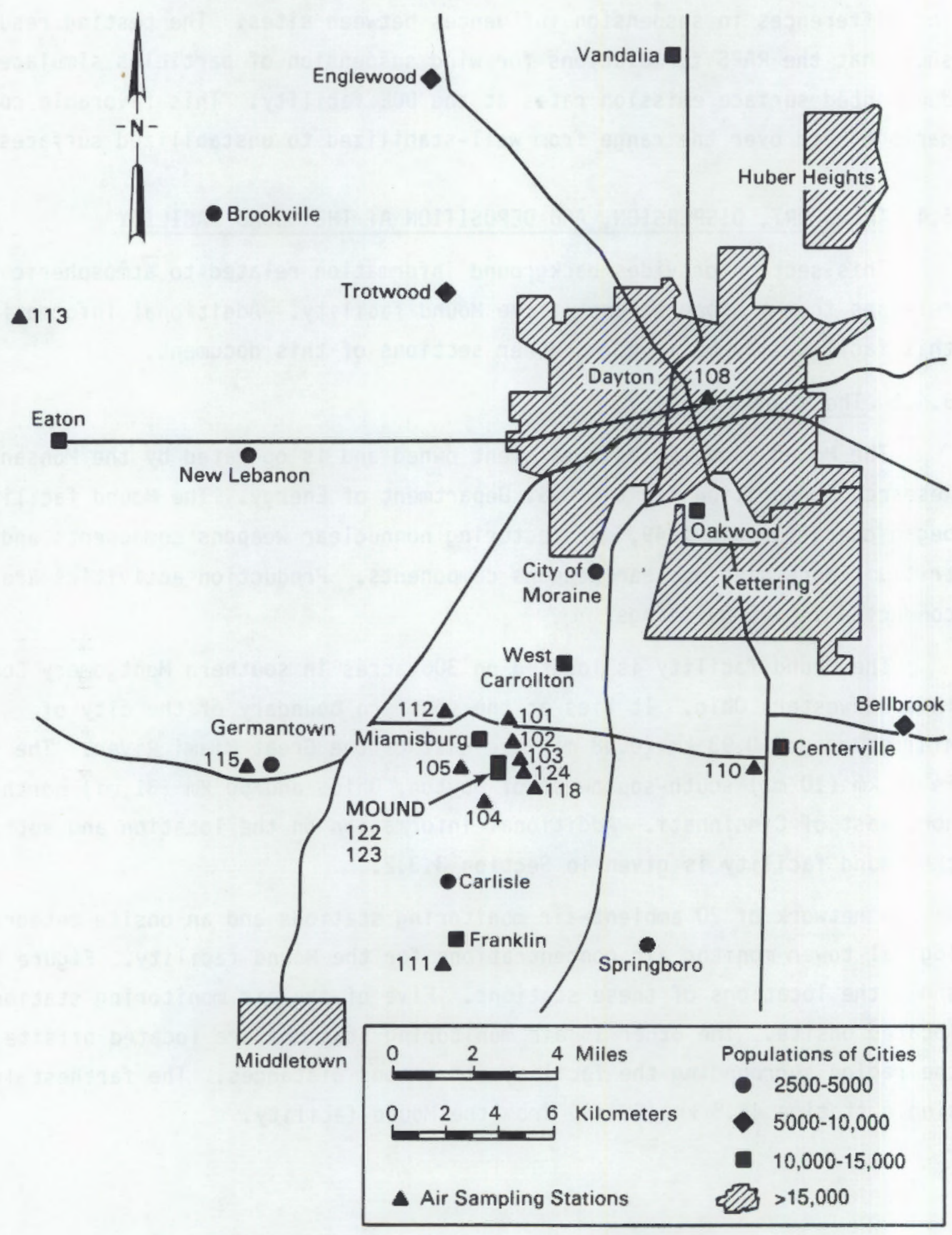

FIGURE 6.7. Locations of Mound Air-Monitoring Stations 


\subsubsection{Atmospheric Transport and Dispersion Climatology}

The location of the Mound facility provides complex influences on the local atmospheric transport and dispersion climatology. The facility is located at the top and side of a bluff adjacent to the Great Miami River. The facility's location on the inside of a gentle curve in the river valley includes a small sidewall valley imbedded in the bluff. In addition to the larger-scale winds, the local winds are expected to be influenced by drainage flows associated with the river valley as well as by the sidewall valley.

Onsite wind statistics for a 4-year period reported by Carfagno and Farmer (1986) are given in Table 6.4 and plotted in Figure 6.8. The wind data were collected from sensors $50 \mathrm{~m} \mathrm{high}$ on a tower. This height is typical for the Mound facility's stacks. A second wind rose, from the Wright-Patterson Air Force Base located about $19 \mathrm{~km}$ (12 $\mathrm{mi}$ ) northeast of the Mound facility, is included in Figure 6.8 for comparison. The winds onsite are similar to those represented by the more detailed wind rose based on 5 years of meteorological observations at the official Dayton U.S. Weather Bureau Station located near Vandalia, Ohio, $19 \mathrm{~km}(12 \mathrm{mi})$ north of the Mound facility. Table 6.5 contains the Dayton wind rose data for each of the six stability classes.

The onsite winds are measured at the height at which Mound stack releases are likely. Releases from vents and other low-elevation sources may be influenced by wake effects or shallow drainage flow effects. Local dispersion patterns for low-elevation releases may differ from the pattern for the stack releases.

\subsubsection{Radioactive Atmospheric Releases}

Activities at the Mound facility are sources of radioactive air emissions to the atmosphere. Plutonium is used as a heat source for radioisotope thermoelectric generators manufactured at Mound. Tritium is separated and enriched at the Mound facility. Atmospheric emissions of Pu and tritium that occur as a result of these activities and related operations are routinely monitored. 
TABLE 6.4. Average Winds at the Mound Facility, by Sector(a)

\begin{tabular}{|c|c|c|}
\hline Direction & $\begin{array}{c}\text { Frequency } \\
(\%)\end{array}$ & $\begin{array}{c}\text { Average } \\
\text { Wind Speed } \\
\text { (m/s) }\end{array}$ \\
\hline N & 4.2 & 4.3 \\
\hline NNE & 4.5 & 4.1 \\
\hline NE & 4.9 & 4.0 \\
\hline ENE & 4.9 & 4.0 \\
\hline$E$ & 4.5 & 4.1 \\
\hline ESE & 4.1 & 3.9 \\
\hline SE & 4.4 & 4.1 \\
\hline SSE & 4.7 & 4.2 \\
\hline S & 6.0 & 4.4 \\
\hline SSW & 9.7 & 5.0 \\
\hline SW & 12.4 & 5.6 \\
\hline WSW & 8.7 & 5.2 \\
\hline W & 5.4 & 5.0 \\
\hline WNW & 5.3 & 5.1 \\
\hline NW & 6.0 & 4.7 \\
\hline NNW & 4.4 & 4.4 \\
\hline CALM & 6.1 & 0.0 \\
\hline TOTAL & 100.0 & - \\
\hline AVERAGE & - & 4.4 \\
\hline
\end{tabular}
(a) Based on a 4-year (1981 to 1984) summary of winds at 50-m height from Carfagno and Farmer (1986).

Because extensive emission and environmental monitoring data are available for both materials, ${ }^{238} \mathrm{Pu}$ and tritium were selected for testing the application of RAPS at Mound. Monitoring data are available for operations from 1974 to the present. The data for 1985 were used to test the application of RAPS.

Studies at Mound have documented the surface soil concentrations of $\mathrm{Pu}$ both onsite and offsite. Assuming that the offsite surface concentrations are 
$\dot{\omega}_{\omega}^{0}$

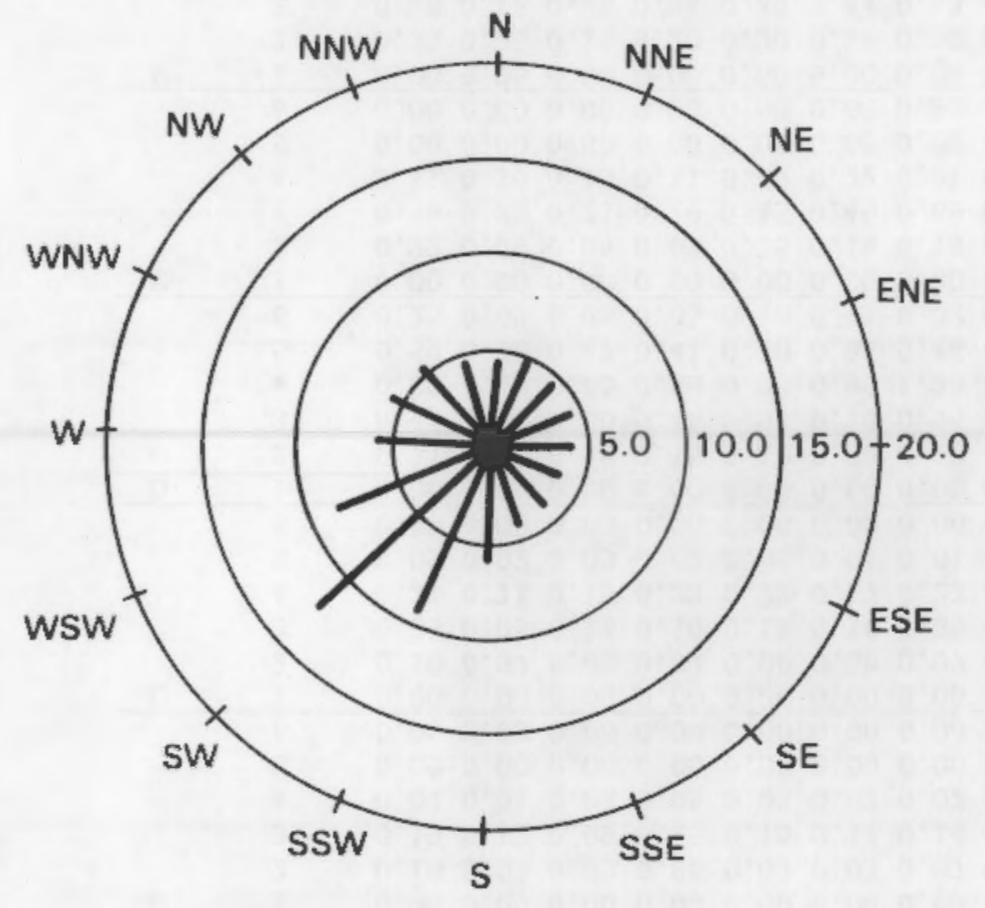

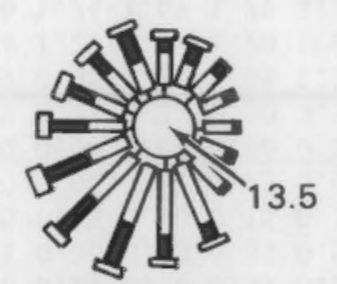

All Observations

(97.033)
Surface Wind Speed, mph $13^{4-12^{13-24}} 25+$

(\%) Calm

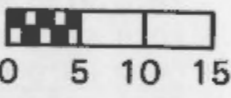

$\%$ Frequency

FIGURE 6.8. Wind Roses for Mound and Wright-Patterson Air Force Base 
TABLE 6.5. Dayton Wind Speed, Wind Direction, and Stability Summary

Stab-

\begin{tabular}{|c|c|c|c|c|c|c|c|c|c|c|c|c|c|c|c|c|c|}
\hline & & & & & & & & & & & & & & & & & \\
\hline lass & Range $^{(D)}$ & $\mathbf{N}$ & NNE & $\mathrm{NE}$ & ENE & $\tau$ & ESE & $\mathrm{SE}$ & SSE & $\mathbf{S}$ & SSW & SW & WSW & $\mathbf{W}$ & WNW & $\mathrm{NW}$ & NiNW \\
\hline & & 0.00 & 0.00 & 0.00 & 0.00 & 0.00 & 0.00 & 0.00 & $0 . \overline{0}$ & 0.00 & 0.00 & & 0.00 & & 0.00 & 0.00 & 0.00 \\
\hline & 2 & 0.02 & 0.00 & 0.02 & 0.01 & 0.02 & 0.01 & 0.01 & 0.00 & 0.05 & 0.01 & 0.01 & 0.02 & 0.02 & 0.04 & 0.02 & \\
\hline & 3 & 0.01 & 0.00 & 0.00 & 0.01 & 0.02 & 0.01 & 0.01 & 0.01 & 0.02 & 0.02 & 0.01 & 0.05 & 0.06 & 0.01 & 0.02 & 0.02 \\
\hline & 4 & 0.00 & 0.00 & 0.00 & 0.00 & 0.00 & 0.00 & 0.00 & 0.00 & 0.00 & 0.00 & 0.00 & 0.00 & 0.00 & 0.00 & 0.00 & 0.00 \\
\hline & 5 & 0.00 & 0.00 & 0.00 & 0.00 & 0.00 & 0.00 & 0.00 & 0.00 & 0.00 & 0.00 & 0.00 & 0.00 & 0.00 & 0.00 & 0.00 & 0.00 \\
\hline & 6 & & 0.00 & & & & & & 0.00 & 0.00 & & & & & & & \\
\hline B & 1 & 0.00 & 0.00 & 0.00 & 0.00 & 0.00 & 0.00 & 0.00 & 0.00 & 0.00 & 0.00 & 0.00 & 0.00 & 0.00 & 0.00 & 0.00 & 0.00 \\
\hline & 2 & 0.10 & 0.03 & 0.05 & 0.06 & 0.09 & 0.03 & 0.07 & 0.08 & 0.15 & 0.04 & 0.07 & 0.11 & & & & 0.07 \\
\hline & 3 & 0.19 & 0.12 & 0.09 & 0.15 & 0.15 & 0.14 & 0.14 & 0.12 & 0.21 & 0.11 & 0.25 & 0.30 & 0.27 & 0.12 & 0.12 & 0.14 \\
\hline & 4 & 0.04 & 0.01 & 0.03 & 0.05 & 0.03 & 0.02 & 0.02 & 0.02 & 0.02 & & & & & & & 0.02 \\
\hline & 5 & 0.00 & 0.00 & & 0.00 & 0.00 & 0.00 & 0.00 & 0.00 & 0.00 & 0.00 & 0.00 & 0.00 & & & & 0.00 \\
\hline & $=$ & 0.00 & 0.00 & 0.00 & 0.00 & 0.00 & 0.00 & 0.00 & 0.00 & 0.00 & 0.00 & 0.00 & 0.01 & 0.00 & 00 & 0.00 & 0.00 \\
\hline C & 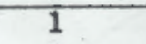 & 0.00 & 0.00 & 0.00 & 0.00 & 0.00 & 0.00 & 0.00 & 0.00 & & & 0.00 & & & & & 0.00 \\
\hline & 2 & 0.10 & 0.07 & 0.05 & 0.07 & 0.08 & 0.08 & 0.07 & 0.03 & 0.10 & 0.05 & 0.07 & 0.10 & 0 & 11 & 05 & 0.07 \\
\hline & 3 & 0. & 0.09 & 0. & 0.10 & 0.18 & 0.14 & 0. & 0.18 & 0.30 & 0 & & & & & & \\
\hline & 4 & 0.21 & 0.11 & 0.19 & 0.22 & 0.22 & 0.17 & 0.23 & 0.17 & 0.51 & 0. & 0.63 & 0 & 0 & 0 & 0 & 0.25 \\
\hline & & 0.05 & 0.02 & 0.03 & 0.02 & 0.05 & 0.01 & 0.01 & 0.02 & 0.05 & 0.05 & 0. & 0 & & & 10 & 0.01 \\
\hline & 6 & 0.00 & 0.00 & 0.00 & 0.00 & 0.00 & 0.00 & 0.00 & 0.00 & 0.00 & 0.1 & 0.01 & & & 0 & 0 & 0. \\
\hline D & & 0.00 & 0.00 & 0.00 & 0.00 & 0.00 & 0.00 & 0.00 & 0.00 & 0.00 & 0.00 & 0.00 & 0. & 5 & 10 & 0 & $\overline{0} . \overline{00}$ \\
\hline & & 0. & 0.19 & & 0 . & 0.18 & & & & & & & & & & & 0.15 \\
\hline & 3 & 0.90 & 0.42 & 0.50 & 0.46 & 0.51 & 0.70 & 0.95 & 0.65 & 1.39 & 0.65 & 0.69 & 0.85 & 1 & 0 & 0.71 & 0.57 \\
\hline & 4 & 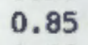 & 0.42 & & 0. & 0.90 & & & 0.74 & & & & & & & & 0.63 \\
\hline & & 0.59 & 0.36 & 0.47 & 0.41 & 0.70 & 0.61 & 0.46 & 0.38 & 2.56 & 1.74 & 1.67 & 1. & 3 & 1 & 1.21 & 0.63 \\
\hline & 6 & & 0. & & 0. & 0. & & & & & & & & & & & 0. \\
\hline E & & & 0.00 & 0 . & 0. & 0.00 & & 0.00 & 0.00 & 0.00 & 0.00 & 0. & 0 & & 0 & 0.00 & 0 . \\
\hline & 2 & 0.22 & 0.09 & 0.09 & 0.09 & 0.15 & 0.14 & 0.14 & 0.15 & 0.23 & 0. & 0. & 0 & 0 & & 0 & 0. \\
\hline & 3 & & 0. & & & 0.43 & & & & & & & & & & & \\
\hline & 4 & 1 & 0.10 & 0. & 0. & 0.22 & & & & & & 0. & 0 & & 0 & 0 & 0. \\
\hline & & & & & & & & & & & & & & & & & \\
\hline & 6 & & 0.00 & & 0.00 & 0.00 & & & 0.00 & & & & & & & & \\
\hline & 1 & & 0.00 & 0.00 & 0.00 & 0.00 & 0.00 & 0.00 & 0.00 & & 0.00 & & & & & & 0 \\
\hline & & & 0.28 & & & & & & & & & & & & & & \\
\hline & 3 & 0 & 0. & & & & & & & & & & & & & & \\
\hline & & & 0. & & & & & & & & & & & & & 0 & 0. \\
\hline & 5 & & 0.00 & & 0.00 & 0.00 & & & 0.00 & & & & & & 0. & 0.00 & 0.0 \\
\hline & 6 & 0.00 & 0.00 & 0.00 & 0.00 & 0.00 & 0.00 & 0.00 & 0.00 & & & & & & 0.00 & 0.00 & 0.0 \\
\hline
\end{tabular}

(a) Meteorological observations from Dayton, Ohio, Jan.1, 1970 to Dec.31, 1974.

(b) Wind Ranges $(\mathrm{m} / \mathrm{s})$ : $1(\langle .8), 2(.8$ to 2.2$), 3(2.2$ to 3.8$), 4(3.8$ to 6.0$), 5(6.0$ to 11.0$), 6(>11.0)$. 
mainly the result of air-to-surface deposition processes, these surface concentration data provide a means of checking the deposition portion of the RAPS model.

In addition, the contaminated surface area is a potential source of resuspended airborne Pu. Although RAPS can compute a source term for such an area, surface characteristics data are insufficient to make this computation a useful test of the model. (In the formal application of RAPS to a facility, such a computation would be made using data collected for the purpose.)

\subsubsection{Application of RAPS To Mound's Stack Releases}

The selection of meteorological data for input to RAPS turned out to be a useful exercise. The only onsite data (Table 6.4) consisted of average frequencies and magnitudes of winds as functions of wind direction; no onsite data for atmospheric stability or the distribution of wind speeds are available. A complete joint frequency summary of wind speed, direction, and stability was prepared from data from the Dayton weather station (Table 6.5). The RAPS methodology was tested by using both the onsite and the regional data. Both data sets were used to identify how the use of 1 imited data affects the application of RAPS.

Conventional wisdom for application of models like RAPS is that the more detailed meteorological data set should be used. If major differences between the data sets are noted, the more complete set might be adjusted to agree with the less detailed but nearer-site data. However, given the similarity of these two wind roses, no adjustment of data is indicated for the Dayton data to be applied to the Mound facility.

The average annual precipitation of $10.31 \mathrm{~cm}$ (40.59 in.) used was based on the 30-year record at Miamisburg, Ohio. The region receives a mixture of thunderstorms and stratus storms; therefore, a moderate rainfall intensity of $0.5 \mathrm{~cm} / \mathrm{hr}$ was used.

Surface roughness lengths were determined for the site and surrounding region from photographs, topographical maps, and land-use maps. The roughness elements varied from $200 \mathrm{~cm}$ for populated areas to $80 \mathrm{~cm}$ for areas with a mixture of farmlands and trees. 
RAPS in its current form is designed to model one source at a time. However, contaminants may be released from several stacks at the Mound facility. Therefore, to apply RAPS at this site, all stack releases were combined into a single stack release from a central point within the Mound facility. Mound facility stack data were provided by D. Carfagno. (a) Table 6.6 contains these data. A set of typical stack parameters was defined: a stack height of $46 \mathrm{~m}$ $(150 \mathrm{ft})$, a stack diameter of $1.5 \mathrm{~m}(5 \mathrm{ft})$, and an exit velocity of $10 \mathrm{~m} / \mathrm{s}$ (2000 ft/min).

The total 1985 emissions of ${ }^{238} \mathrm{Pu}$ and tritium to the air were $5.1 \times$ $10^{-6} \mathrm{Ci}$ and $4795 \mathrm{Ci}$, respectively (Carfagno and Farmer 1986). These values were used as a source term to allow comparison with the 1985 air monitoring data contained in the same report.

Table 6.7 lists the measured concentrations of ${ }^{238} \mathrm{Pu}$ in air at offsite locations in 1985 (Carfagno and Farmer 1986). The locations refer to the monitoring sites shown in Figure 6.7. Table 6.8 lists measured concentrations of tritium oxide in air at offsite locations in 1985 (Carfagno and Farmer 1986).

TABLE 6.6. Mound Stack Data

\begin{tabular}{|c|c|c|c|}
\hline $\begin{array}{l}\text { Stack } \\
\text { Name }\end{array}$ & $\begin{array}{c}\text { Stack Height } \\
{[m(\mathrm{ft})]}\end{array}$ & $\begin{array}{l}\text { Exit Diameter } \\
{[\mathrm{m}(\mathrm{ft})]}\end{array}$ & $\begin{array}{l}\text { Exit Velocity } \\
{[\mathrm{m} / \mathrm{s}(\mathrm{ft} / \mathrm{min})]}\end{array}$ \\
\hline$H H$ & $23(75)$ & $0.9(3.0)$ & $3.7(739)$ \\
\hline NCOPF & $40(130)$ & $0.7 \quad(2.33)$ & $14.0 \quad(2763)$ \\
\hline SM-PP & $61(200)$ & $1.8(6.0)$ & $6.1(1220)$ \\
\hline SWIC & $40(130)$ & $0.9(3.0)$ & $12.5(2480)$ \\
\hline$T$-WEST & $61(200)$ & $2.4(8.0)$ & $4.1(808)$ \\
\hline HEFS & $45(148)$ & $2.0(6.5)$ & $8.8(1732)$ \\
\hline WDALR & $15(48)$ & $1.2(4.0)$ & $6.8(1321)$ \\
\hline WDAHR & $15(48)$ & $0.6(2.0)$ & $2.8(555)$ \\
\hline WDSS & $15(50)$ & $0.3(1.0)$ & $16.4(3220)$ \\
\hline
\end{tabular}

(a) Letter from 0. Carfagno (Monsanto Research Corporation) to G. Whelan (Pacific Northwest Laboratory), dated August 22, 1986. 
TABLE 6.7. Concentrations of ${ }^{238} \mathrm{Pu}$, Including Environmental Levels in Air at Offsite Sampling Locations in 1985 (From Carfagno and Farmer 1986)

\begin{tabular}{|c|c|c|}
\hline Location & $\begin{array}{c}\text { Number } \\
\text { of } \\
\text { Samples } \\
\end{array}$ & $\begin{array}{c}{ }^{238} \mathrm{Pu} \\
\left(10^{-18} \mu \mathrm{C} i / \mathrm{mL}\right) \\
\text { Average }(\mathrm{a}, \mathrm{b})\end{array}$ \\
\hline 101 & 3 & $2.6 \pm 5.36$ \\
\hline 102 & 4 & $8.19 \pm 9.14$ \\
\hline 103 & 4 & $6.5 \pm 5.88$ \\
\hline 104 & 4 & $1.88 \pm 1.3$ \\
\hline 105 & 4 & $2.62 \pm 4.19$ \\
\hline 108 & 4 & $0.2 \pm 0.25$ \\
\hline 110 & 4 & $0.18 \pm 0.17$ \\
\hline 111 & 4 & $0.35 \pm 0.16$ \\
\hline 112 & 4 & $0.99 \pm 1.89$ \\
\hline 115 & 4 & $0.08 \pm 0.17$ \\
\hline 118 & 4 & $11.0 \pm 11.0$ \\
\hline 119 & 4 & $0.15 \pm 0.13$ \\
\hline 122 & 12 & $8.58 \pm 6.64$ \\
\hline 123 & 12 & $40.3 \pm 62.7$ \\
\hline 124 & 12 & $13.8 \pm 9.43$ \\
\hline
\end{tabular}

(a) Lower detection limit (LDL) for monthly values of ${ }^{238} \mathrm{Pu}$ in air is $0.69 \times 10^{-18} \mu \mathrm{Ci} / \mathrm{ml}$; for quarterly values, $0.14 \times 10^{-18} \mu \mathrm{Ci} / \mathrm{mi}$. Lower deteçtion limit for monthly values of $239,240 \mathrm{Pu}$ in air is $\left.0.38 \times 10^{-18} \mu \mathrm{Ci} / \mathrm{m}\right]$; for quarterly values, $0.08 \times 10^{-18} \mathrm{Li} / \mathrm{ml}$.

(b) Error limits are estimates of the standard error of the estimated means at the $95 \%$ confidence level. 
TABLE 6.8. Incremental Concentrations of Tritium 0xide in Air at Offsite Sampling Locations in 1985 (From Carfagno and Farmer 1986)

\begin{tabular}{|c|c|c|c|c|}
\hline \multirow[b]{2}{*}{ Location } & \multirow{2}{*}{$\begin{array}{c}\text { Number } \\
\text { of } \\
\text { Samples } \\
\end{array}$} & \multicolumn{3}{|c|}{$\begin{array}{l}\text { Tritium 0xide } \\
(10-12 \mu C i / m l)\end{array}$} \\
\hline & & Minimum (a) & Maximum $(a)$ & Average $(a, b, c)$ \\
\hline 101 & 42 & e.1. & 40.4 & $17.4 \pm 3.98$ \\
\hline 102 & 51 & 3.94 & 70.9 & $29.2 \pm 5.03$ \\
\hline 103 & 52 & e.1. & 43.6 & $10.9 \pm 3.57$ \\
\hline 104 & 52 & e.1. & 52.3 & $9.39 \pm 4.08$ \\
\hline 105 & 49 & e.1. & 26.6 & $4.89 \pm 3.09$ \\
\hline 108 & 50 & e.1. & 21.2 & $2.3 \pm 2.91$ \\
\hline 110 & 49 & e.1. & 26.2 & $0.99 \pm 2.72$ \\
\hline 111 & 51 & e.1. & 20.8 & e.1. \\
\hline 112 & 52 & e.1. & 19.5 & $2.45 \pm 2.81$ \\
\hline 115 & 45 & e.1. & 11.6 & e.1. \\
\hline 118 & 50 & e.1. & 31.7 & $6.49 \pm 3.1$ \\
\hline 122 & 51 & e.1. & 68.3 & $11.7 \pm 4.79$ \\
\hline 123 & 52 & e.l. & 116.0 & $20.2 \pm 6.62$ \\
\hline 124 & 50 & e.1. & 55.5 & $18.2 \pm 4.04$ \\
\hline
\end{tabular}

(a) Average environmental level (e.l.) subtracted from the data.

(b) Lower detection limit (LDL) for tritium oxide in air is $14 \times 10^{-12} \mu \mathrm{Ci} / \mathrm{ml}$.

(c) Error limits are estimates of the standard error of the estimated means at the $95 \%$ confidence level.

Figure 6.9 illustrates modeled and monitored ${ }^{238} \mathrm{Pu}$ concentrations for 1985. The computed values are based on the assumption of a release with plume rise from a typical Mound facility stack. The concentrations computed using onsite and Dayton meteorological data differ slightly but are essentially equivalent. The computed and monitored concentrations are within the same order of magnitude.

Given the complexity of atmospheric transport and dispersion processes at the Mound facility, the RAPS model could be underestimating ground-level 


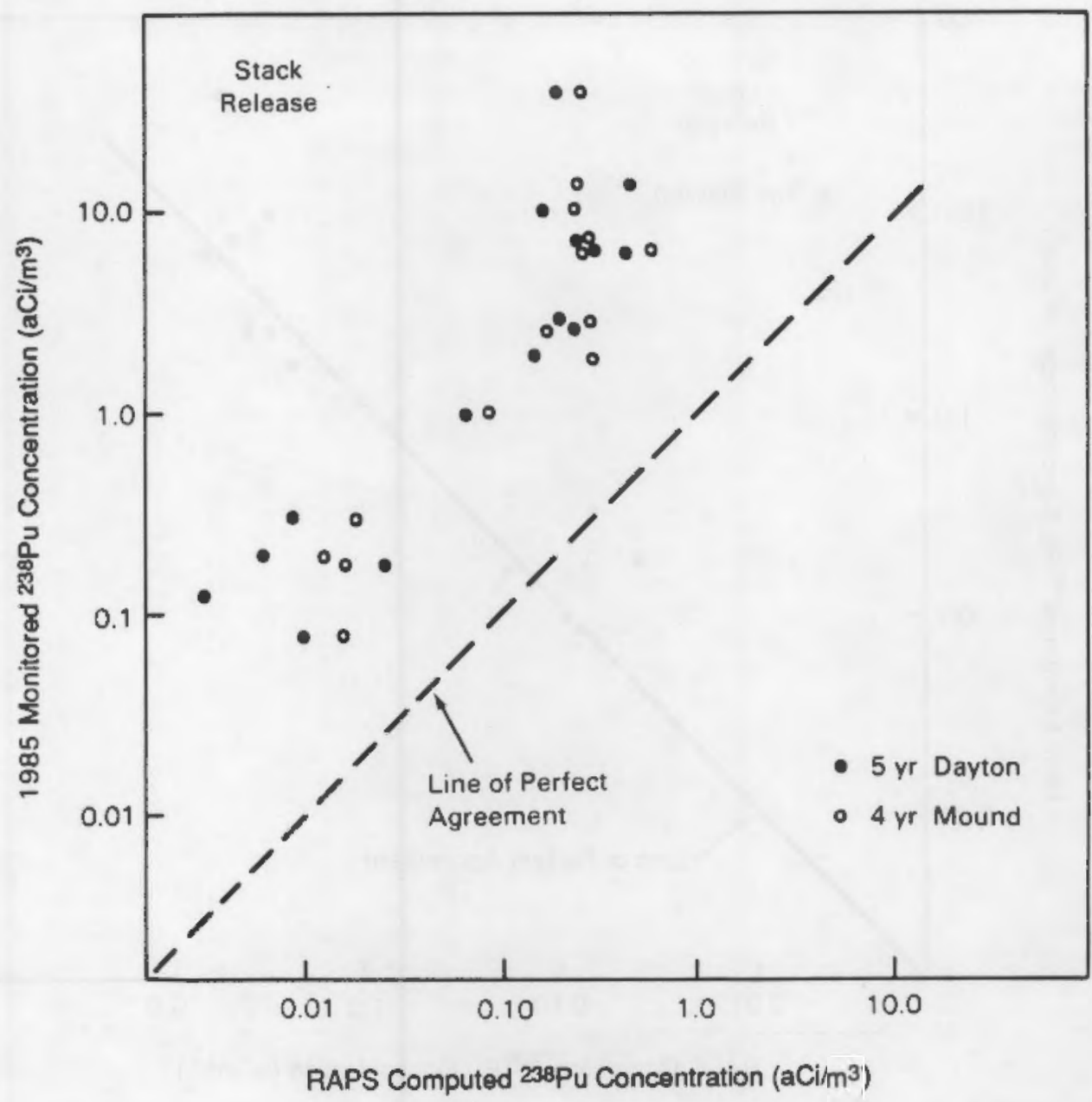

FIGURE 6.9. Comparison of Computed and Monitored ${ }^{238} \mathrm{Pu}$ Air Concentrations for 1985 Operations at Mound, Based on a Typical Stack Release

concentrations by assuming elevated releases. Therefore, an additional test was made for the limiting case with all releases modeled as ground-level releases. The results are shown in Figure 6.10. A comparison of Figures 6.9 and 6.10 shows that the ${ }^{238} \mathrm{Pu}$ concentrations computed are sensitive to the initial release assumptions and that assumption of a ground-level release provides a better fit with monitored ${ }^{238} \mathrm{Pu}$ data than the assumption of a stack release.

Figure 6.11 illustrates how monitored and modeled concentrations based on a stack release varied with downwind distance. Figure 6.12 presents the same 


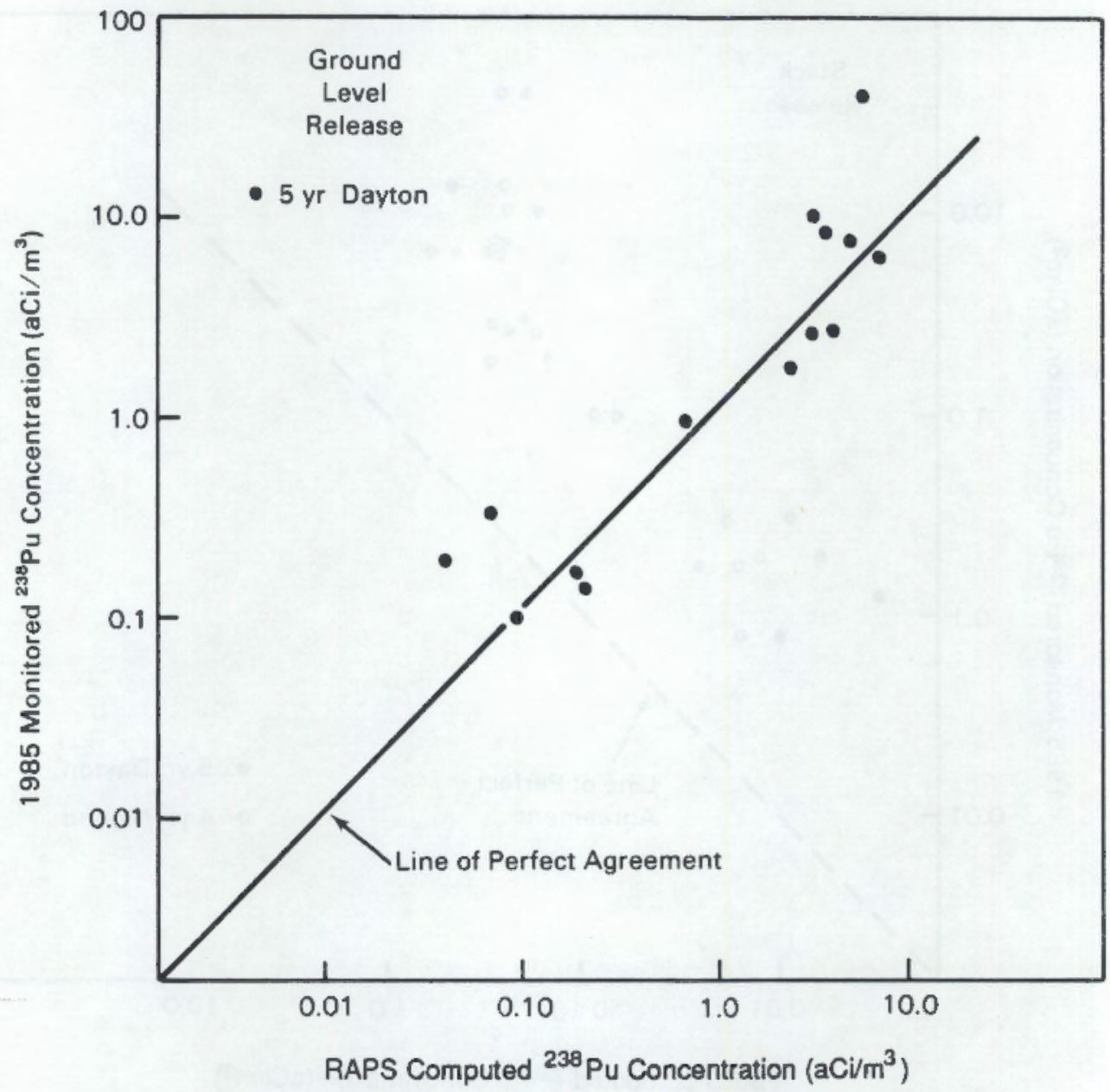

FIGURE 6.10. Comparison of Computed and Monitored ${ }^{238} \mathrm{Pu}$ Air Concentrations for 1985 Operations at Mound, Based on a Ground-Level Release

information for a ground-level release assumption. The modeled results are given for the sectors with the highest and lowest computed concentrations as well as the average sector. Those monitoring sites that are very close to the Mound facility are plotted at a distance of $1.0 \mathrm{~km}$.

Figure 6.13 contains a comparison of the computed and monitored incremental tritium air concentrations based on the assumption of a stack release. For comparison with monitoring data, a tritium dioxide emission fraction of 0.55 is assumed. The RAPS output for a nondepositing gas was selected as being appropriate for tritium. The tritium results show a strong relationship between 


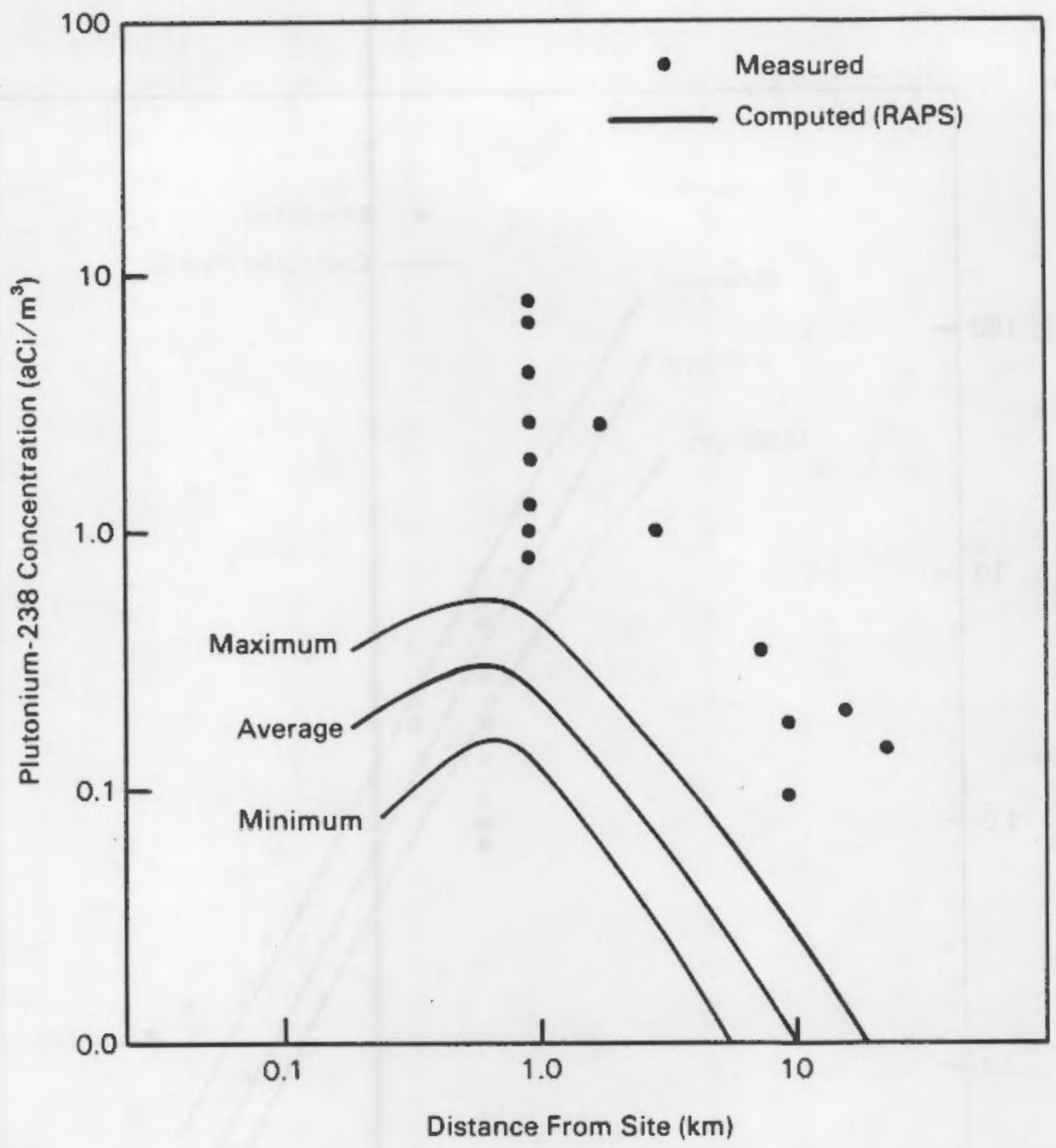

FIGURE 6.11. Computed and Monitored ${ }^{238} \mathrm{Pu}$ Air Concentrations as a Function of Downwind Distance for 1985 Operations at Mound, Based on a Typical Stack Release

computed and monitored values as seen above for the ${ }^{238} \mathrm{Pu}$ comparisons. The scatter is about the same, although the RAPS model consistently overpredicts for tritium rather than underpredicts as it did for ${ }^{238} \mathrm{Pu}$.

The RAPS-predicted ${ }^{238} \mathrm{Pu}$ surface concentrations were compared with surface contamination measurements in the region surrounding the Mound facility (DOE 1979). Figure 6.14 shows these data obtained mainly during 1977. At offsite locations, these data represent the long-term accumulation of $\mathrm{Pu}$ from plant 


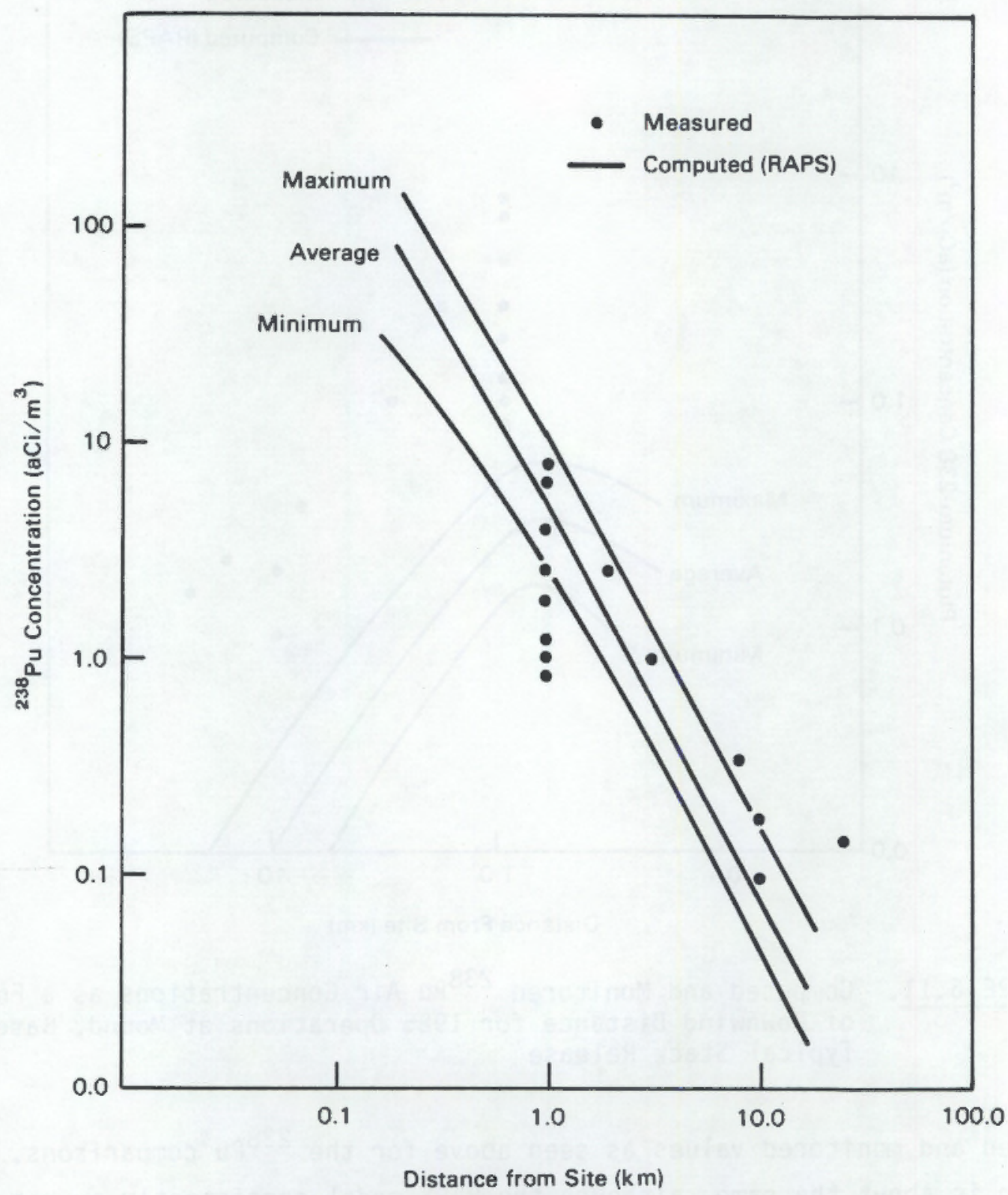

FIGURE 6.12. Computed and Monitored ${ }^{238} \mathrm{Pu}$ Air Concentrations as a Function of Downwind Distance for 1985 Operations at Mound, Based on a Ground-Level Release

operations previous to 1977. Plutonium-238 is deposited by wet and dry procsses and removed by resuspension processes. 


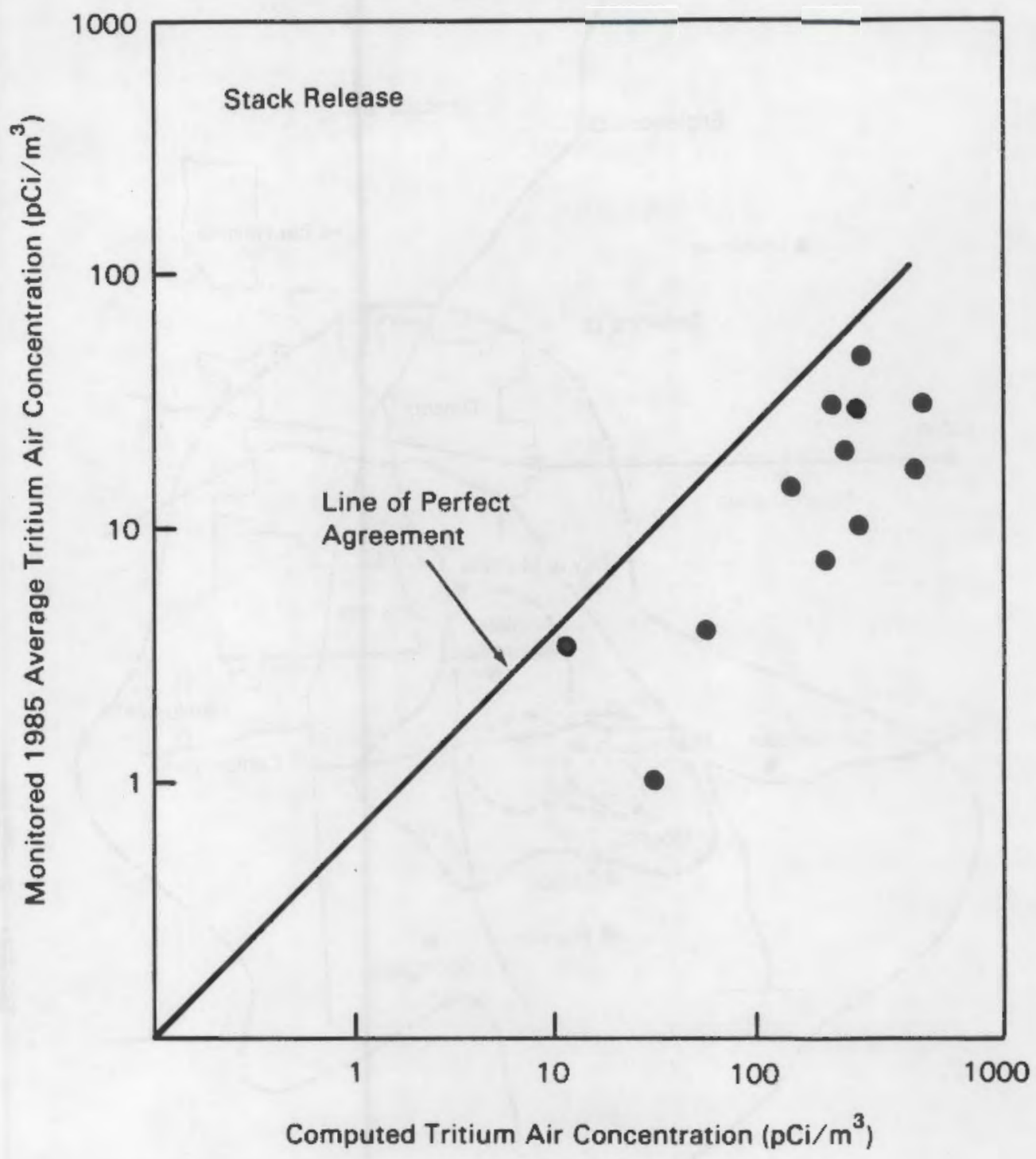

FIGURE 6.13. Comparison of Computed and Monitored Tritium Air Concentrations for 1985 Operations at Mound, Based on a Typical Stack Release

The values from the northeast sector were selected for comparing the measured and predicted values. Table 6.9 contains the Pu deposition rates predicted for 1 year of operation (1985) as a function of distance. Although the variation with distance is quite similar to that shown in Figure 6.14, the magnitudes for one annual cycle of deposition are, as expected, much smaller than the values measured.

To predict similar deposition values for all plant operations before 1977 requires that a source term be defined. Total stack emission rates of $65 \mu \mathcal{C} i$ 


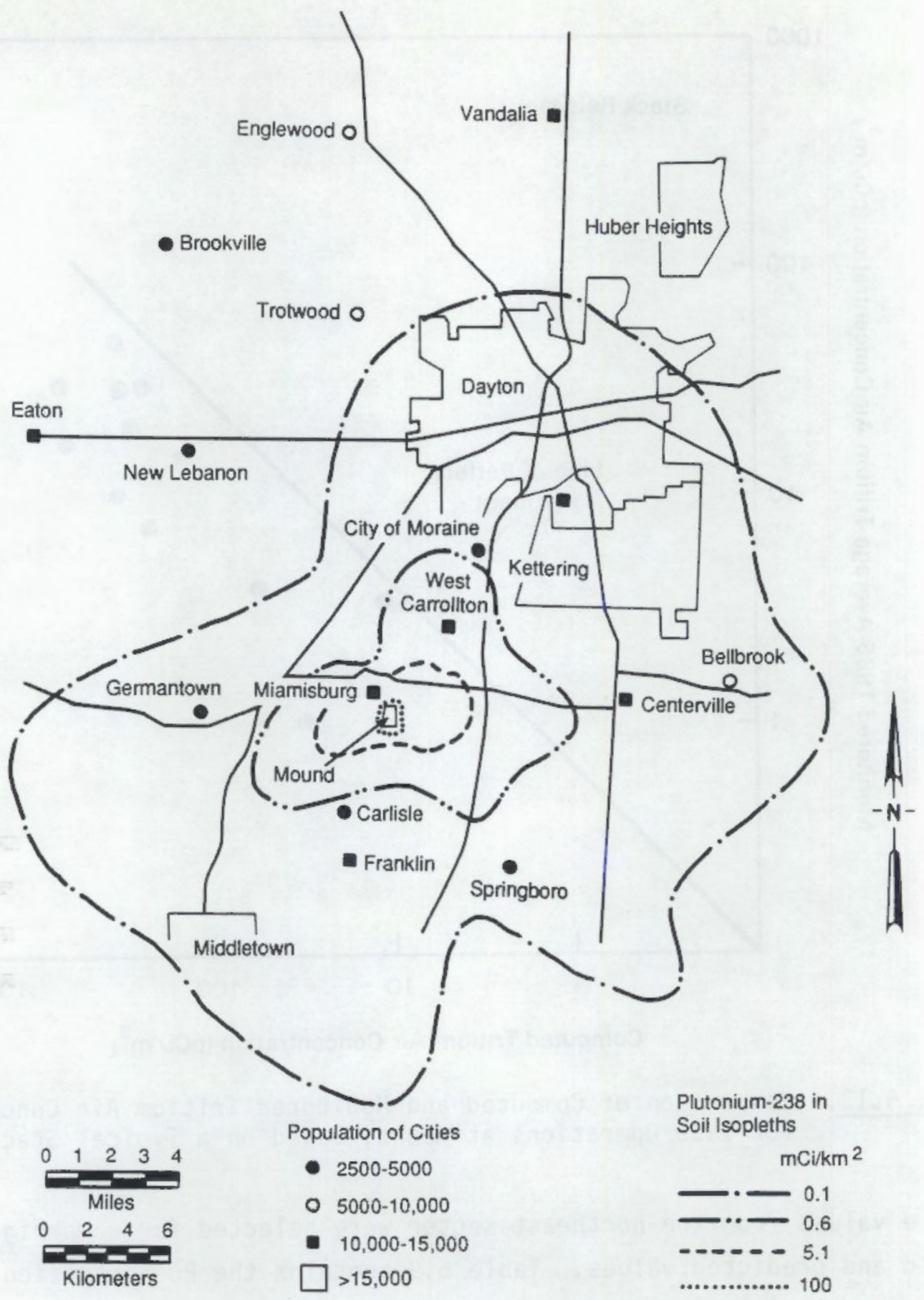

FIGURE 6.14. Distribution of Surface Contamination at Mound

are reported for the years 1974, 1975, and 1976 (Carfagno and Westendorf 1974; Carfagno and Robinson 1975; Farmer et al. 1976). To allow a comparison to be made, it was assumed that this rate of ${ }^{238} \mathrm{Pu}$ emission applied to the 28 years of operations before 1977. The available documentation did not state in which 
TABLE 6.9. Total Annual ${ }^{238} \mathrm{Pu}$ Deposition, Computed for

the Year 1985 for the Northeast Sector

\begin{tabular}{cccc}
$\begin{array}{c}\text { Distance } \\
\text { Downwind } \\
(\mathrm{km})\end{array}$ & $\begin{array}{c}\text { Stack } \\
\text { Release } \\
\left(\mathrm{mCi} / \mathrm{km}^{2}\right)\end{array}$ & $\begin{array}{c}\text { Ground Level } \\
\text { Release } \\
\left(\mathrm{mCi} / \mathrm{km}^{2}\right)\end{array}$ \\
\cline { 1 - 1 } 0.20 & & $3.4 \times 10^{-5}$ & $5.5 \times 10^{-3}$ \\
0.78 & $2.6 \times 10^{-5}$ & $4.0 \times 10^{-4}$ \\
2.35 & $6.7 \times 10^{-6}$ & $5.5 \times 10^{-5}$ \\
6.6 & $1.3 \times 10^{-6}$ & $9.3 \times 10^{-6}$ \\
18.3 & $3.0 \times 10^{-7}$ & $1.6 \times 10^{-6}$
\end{tabular}

years of operation ${ }^{238} \mathrm{Pu}$ emissions did occur or whether such emissions were greater or less than those reported. Given that newer control technology has progressively tended to reduce emissions from operations like those at the Mounds facility, the expected trend is that the earlier emission rates would have been greater than later rates.

Tables 6.10 and 6.11 contain comparisons of the computed and measured values for the stack release and ground-level release assumptions, respectively. It is assumed that no ${ }^{238} \mathrm{Pu}$ is lost from the surface -- once it is deposited, it is assumed to stay on the surface. Although a fraction of the deposited ${ }^{238} \mathrm{Pu}$ may represent background values, that fraction of the measured values is expected to be quite small. This conclusion is based on the strong dependence between the ${ }^{238} \mathrm{Pu}$ concentrations and distance from the Mound facility, as shown in Figure 6.14 .

The current emissions from the Mound stacks are expected to have particles with a typical radius of about $0.3 \mu m$. Emissions in the early years of operations may have had larger particle sizes as a result of different filtration technology or practices. Tables 6.10 and 6.11 contain comparisons for emission assumptions of both 0.3 - and 7.5-um particles.

All of the modeled values are much less than the measured values. However, the values agree within one or two orders of magnitude for the 7.5-umradius particle stack release and 0.3 - $m$ m-radius particle ground-level release. Given the uncertainty in the definition of the total emission rate, agreement in absolute magnitude is not expected. The fact that the application 
TABLE 6.10. Comparison of Computed Total ${ }^{238} \mathrm{Pu}$ Deposition with Measured Soil Concentrations in the Northeast Sector, Assuming a Stack Release $(\mathrm{a})$

\begin{tabular}{|c|c|c|c|c|c|}
\hline \multirow{2}{*}{$\begin{array}{c}\text { Distance } \\
\text { Downwind } \\
(\mathrm{km}) \\
\end{array}$} & \multirow{2}{*}{$\begin{array}{c}\text { Measured } \\
\text { Concent ration } \\
\left(\mathrm{mCi} / \mathrm{km}^{2}\right) \\
\end{array}$} & \multicolumn{2}{|c|}{$\begin{array}{l}\text { Emission Assumption of } \\
0.3-\mu m-R a d i u s \text { Particles }\end{array}$} & \multicolumn{2}{|c|}{$\begin{array}{l}\text { Emission Assumption of } \\
7.5 \text {-um-Radius Particles }\end{array}$} \\
\hline & & $\begin{array}{l}\text { Concentration } \\
\left(\mathrm{mCi} / \mathrm{km}^{2}\right) \\
\end{array}$ & Ratio (b) & $\begin{array}{c}\text { Concentration } \\
\left(\mathrm{mCi} / \mathrm{km}^{2}\right)\end{array}$ & Ratio(b) \\
\hline 0.20 & 100.0 & 0.023 & 4350.0 & 5.1 & 20.0 \\
\hline 0.78 & 50.0 & 0.017 & 2880.0 & 0.47 & 107.0 \\
\hline 2.35 & 5.0 & 0.0044 & 1130.0 & 0.92 & 54.0 \\
\hline 6.6 & 0.6 & 0.00091 & 661.0 & 0.0119 & 47.0 \\
\hline 18.3 & 0.1 & 0.00020 & 495.0 & 0.0013 & 9.4 \\
\hline
\end{tabular}

(a) Based on Dayton meteorological data; measured values were obtained from DOE (1979: Figure 3.14).

(b) Ratio of measured to computed values.

TABLE 6.11. Comparison of Computed Total ${ }^{238} \mathrm{Pu}$ Deposition with Measured Soil Concentrations in the Northeast Sector, Assuming a Ground-Level Release ${ }^{(a)}$

\begin{tabular}{|c|c|c|c|c|c|}
\hline \multirow{2}{*}{$\begin{array}{c}\text { Distance } \\
\text { Oownwind } \\
\text { (km) } \\
\end{array}$} & \multirow{2}{*}{$\begin{array}{c}\text { Measured } \\
\text { Concentration } \\
\left(\mathrm{mCi} / \mathrm{km}^{2}\right) \\
\end{array}$} & \multicolumn{2}{|c|}{$\begin{array}{l}\text { Emission Assumption of } \\
0.3-\mu m-R a d i u s \text { Particles }\end{array}$} & \multicolumn{2}{|c|}{$\begin{array}{l}\text { Emission Assumption of } \\
7.5 \text { - un-Radius Particles }\end{array}$} \\
\hline & & $\begin{array}{l}\text { Concentration } \\
\left(\mathrm{mCi} / \mathrm{km}^{2}\right)\end{array}$ & Ratio (b) & $\begin{array}{l}\text { Concentration } \\
\left(\mathrm{mCi} / \mathrm{km}^{2}\right)\end{array}$ & Ratio(b) \\
\hline 0.20 & 100.0 & 3.63 & 28.0 & 22.4 & 4.2 \\
\hline 0.78 & 50.0 & 0.27 & 188.0 & 0.35 & 142.0 \\
\hline 2.35 & 5.0 & 0.040 & 139.0 & 0.011 & 470.0 \\
\hline 6.6 & 0.6 & 0.0061 & 98.0 & 0.00037 & 1560.0 \\
\hline 18.3 & 0.1 & 0.0011 & 94.0 & 0.0000011 & 8550.0 \\
\hline
\end{tabular}

(a) Based on Dayton Meteorological data; measured values were obtained from DOE (1979: Figure 3.14).

(b) Ratio of measured to commuted values.

of the RAPS model to the Mound facility appeared to underpredict ${ }^{238} \mathrm{Pu}$ air concentrations by about a factor of ten implies that it will similarly underpredict deposition rates. 


\subsubsection{Discussion}

The limited onsite and complete regional meteorological data sets gave essentially equivalent results. Thus RAPS could be applied to the stack releases at the Mound facility using only the available onsite meteorological data.

The stack parameters chosen are a compromise between the two $61-m$ (200-ft) stacks, which accounted for $84.8 \%$ of reported $\mathrm{Pu}$ emissions during 1985 , and the other, shorter stacks that accounted for the remaining $15.2 \%$. The use of a single emission source to represent a number of stack releases will mainly affect the concentrations computed in the immediate vicinity of the facility. With distance from the site, the specific release characteristics become progressively less important.

The meteorological complexity of this facility makes topographic lowering of the height of elevated plumes a possibility. A model run assuming groundlevel release represents the extreme case of no stack or plume rise. This latter case was tested not because such a situation is expected to occur, but to provide data points representing the most extreme case of plume downwash.

The concentrations predicted for ${ }^{238} \mathrm{pu}$ assuming an elevated plume were about an order of magnitude smaller than the monitored values, but both varied identically with distance from the facility. A similar result occurred for the tritium comparisons, except that the predicted values for tritium were about an order of magnitude larger than the monitored values. These differences are within the order-of-magnitude accuracy expected for the model at a site with complex dispersion influences.

The consistent underprediction of ${ }^{238} \mathrm{Pu}$ concentrations at all distances suggests that the cause is not random variability. The better agreement obtained when a ground-level release was assumed suggests that the plumes may be downwashed by the local topography. It is also possible that the stack sampling underestimated the emission rate or that another source, such as resuspension of surface materials, may be involved.

As compelling as the plume downwash argument seems for the ${ }^{238} \mathrm{Pu}$ comparisons, the consistent overprediction of tritium using the assumption of an 
elevated plume shows the RAPS model is not consistently underpredicting environmental concentrations when applied to the Mound stack emissions. Thus, taking the results as a whole, the assumption of a stack release with plume rise appears to be appropriate for this application.

The comparisons of surface concentrations of ${ }^{238} \mathrm{Pu}$ show that the RAPS model does predict the observed patterns of long-term deposition in the region around the Mound facility. Although the surface concentrations are consistently underpredicted by the RAPS model, the uncertainties in the definition of the emissions makes absolute agreement unlikely. Although the case based on the assumption of a ground-level release of 7.5-ım particles does not simulate the observed environmental variation, the case based on the assumption of a ground-level release of $0.3-\mu m$ particles does. The assumption of an elevated plume with either size particle results in outputs that simulate the environmental variations reasonably well.

The comparisons using the atmospheric components show the RAPS model is able, when emission rates have been reported, to predict the environmental concentrations within an order of magnitude of those observed. In addition, the comparisons show that the RAPS model is able to predict the observed environmental variations quite accurately.

\subsection{REFERENCES}

Bagnold, F. A. 1941. The Physics of Blown Sand and Desert Dunes. Chapman and Hal 1, London.

Bowers, J. F., J. R. Bjorklund, and C. S. Cheney. 1979. Industrial Source Complex (ISC) Dispersion Model User's Guide. EPA-450/2-77-018, U.S. Environmental Protection Agency, Research Triangle Park, North Carolina.

Bruns, L. E. 1976. "Aerial Gamma Survey by Helicopter to Measure Surficial Contamination." In Atmosphere - Surface Exchange of Particles and Gaseous Pollutants, (1974) ERDA Symposium Series, No. 38, pp. 675-688. CONF-740921, National Technical Information Service, Springfield, Virginia.

Businger, J. A., J. C. Wyngaard, Y. Izumi, and E. F. Bradley. 1971. "Flux Profile Relationships in the Atmospheric Surface Layer." J. Atmos. Sci. $28: 181$. 
Carfagno, D. G., and B. M. Farmer. 1986. Environmental Monitoring at Mound: 1985 Report. MLM-3349, Environmental Section of the Administration Department at Monsanto Research Corporation, Miamisburg, Ohio.

Carfagno, D. G., and B. Robinson. 1975. Annual Environmental Monitoring Report: Calendar Year 1974. MLM-2232, Environmental Section of the Administration Department at Monsanto Research Corporation, Miamisburg, Ohio.

Carfagno, D. G., and W. H. Westendorf. 1974. Annual Environmental Monitoring Report: Calendar Year 1973. MLM-2142, Environmental Section of the Administration Department at Monsanto Research Corporation, Miamisburg, Ohio.

Chepi1, W. S. 1951. "Properties of Soil Which Influences Wind Erosion: I. The Governing Principle of Surface Roughness." Soil Sci. 69:142-162.

Cowherd, C., and C. Guenther. 1976. Development of a Methodology and Emission Inventory for Fugitive Dust for the Regional Air Pollution Study. Prepared for U.S. Environmental Protection Agency, Office of Air and Waste Management, Office of Air Quality Planning and Standards, Research Triangle Park, North Carolina.

Cowherd, C., G. E. Muleski, P. J. Englehart, and D. A. Gillette. 1984. Rapid Assessment of Exposure to Particulate Emissions from Surface Contamination Sites. Final Report EPA Contract 68-03-3116, Project 7972-L. Prepared for the U.S. Environmental Protection Agency by Midwest Research Institute, Kansas City, Missouri.

DOE (Department of Energy). 1979. Environmental Impact Statement -- Mound Facility, Miamisburg, Ohio. DOE/EIS-00140-0, U.S. Department of Energy, Washington, D.C.

Farmer, B. M., B. Robinson, and 0. G. Carfagno. 1976. Annual Environmental Monitoring Report: Calendar Year 1975. MLM-2317, Environmental Section of the Administration Department at Monsanto Research Corporation, Miamisburg, Ohio.

Golder, D. 1972. "Relationships Among Stability Parameters in the Surface Layer." Boundary-Layer Meteor. 3:47-58.

Hanna, S. R., G. A. Briggs, and R. P. Hosker. 1982. Handbook on Atmospheric Diffusion. DOE/TIC-11223, U.S. Department of Energy, Washington, D.C.

Healy, J. W., and J. J. Fuquay. 1959. "Wind Pickup of Radioactive Particles from the Ground." In Progress in Nuclear Energy, Series XII Vol. I-Health Physics, Pergamon Press, Oxford.

Horst, T. W. 1976. The Estimation of Air Concentration Oue to the Suspension of Surface Contamination by the Wind. BNWL-2047, Prepared for the U.S. Air Force by Battelle, Pacific Northwest Laboratories, Richland, Washington. 
Horst, T. W. 1984. "The Modification of Plume Models to Account for Dry Deposition." Boundary-Layer Meteor. 30:413-430.

Marshal1, J. 1971. "Orag Measurements in Roughness Arrays of Varying Density and Distribution." Agri. Meteor. 8:269-292.

Mishima, J. 1964. A Review of Research on Plutonium Releases During Overheating and Fires. HW-83668, Hanford Laboratories, Richland, Washington.

Mishima, J. 1973. "Distribution of Cs-137 Activity During a Range Fire in the B-C Controlled Area." In Pacific Northwest Laboratory Monthly Activities Report, September 1973: Division of Production and Materials Management and Hanford Plant Assistance Program, p. 13. BNWL-1792, Pacific Northwest Laboratory, Richland, Washington.

O'Brien, M. P., and B. D. Rindlaub. 1936. "The Transportation of Sand by Wind." Civil Eng. 6:325.

0'Farre11, T. P., and R. 0. Gilbert. 1975. "Transport of Radioactive Materials by Jackrabbits on the Hanford Reservation." Health Phys. 29:9-15.

Paulson, C. A. 1970. "The Mathematical Representation of Wind Speed and Temperature Profiles in the Unstable Atmospheric Surface Layer." J. Appl. Meteor. 9:857.

Sehmel, G. A. 1977. Radioactive Particle Resuspension Research Experiments on the Hanford Reservation. BNWL-2081, Pacific Northwest Laboratory, Richland, Washington.

Sehmel, G. A. 1981. "Airborne Plutonium Transported During Southwesterly Winds Near the Hanford Prosser Barricade." In Pacific Northwest Laboratory Annual Report for 1980 to the DOE Assistant Secretary for Environment. PNL-3700 PT3, Pacific Northwest Laboratory, Richland, Washington.

Sehme1, G. A., and W. J. Hodgson. 1980. "A Model for Predicting Ory Deposition of Particles and Gases to Environmental Surfaces." In Implications of the Clear Air Amendments of 1977 and of Energy Considerations for Air Pollution Control, W. Licht, ed., Vol. 26, No. 196. American Institute of Chemical Engineers, New York.

Slade, D. H. 1968. Meteorology and Atomic Energy. TID-24190, National Technical Information Service, Springfield, Virginia.

Slinn, W. G. N. 1976. "Ory Deposition and Resuspension of Aerosol Particles A New Look at Some 01d Problems." In Atmosphere-Surface Exchange of Particulate and Gaseous Pollutants. ERDA Symposium Series 38, pp. 1-40. CONF740921, National Technical Information Service, Springfield, Virginia. 


\subsection{EXPOSURE AND HEALTH EFFECTS COMPONENT OF THE RAPS METHODOLOGY}

\subsection{INTRODUCTION $(\mathrm{a})$}

The exposure pathway and health effects components of the RAPS methodology estimate how much individuals in a defined population group will be exposed and the potential health effects from such exposure to chemical and radioactive contaminants. The primary exposure modes considered are inhalation, external exposure (including dermal contact), and ingestion. The exposure analysis begins from the environmental concentrations predicted by analyses of the four environmental pathways. The exposure analysis produces an estimate of the uptake by individuals in the exposed population group. The uptake estimate is then used in the health-effects analysis to determine the Hazard Potential Index (HPI) for each contaminant at the site.

The mathematical models for the exposure pathway analysis were selected for easy application to a variety of sites. The analysis itself is designed to represent the important site parameters affecting exposure without requiring onerous input data or complex analyses. As such, the analysis is much simpler than a detailed environmental assessment that might be performed in conjunction with a detailed site analysis.

The exposure pathways by which contaminants may reach the individual resulting in human exposures are illustrated by a schematic diagram and flow diagram in Figures 7.1 and 7.2 , respectively. In Figure 7.2 , rectangles indicate processes and hexagons indicate contaminant concentrations, either in environmental media or in parts of the exposure network. The following exposure pathways are represented in this figure:

- inhalation -- primary mode of exposure from the atmospheric transport pathway

(a) For more information on the HPI, refer to Chapter 2.0. 


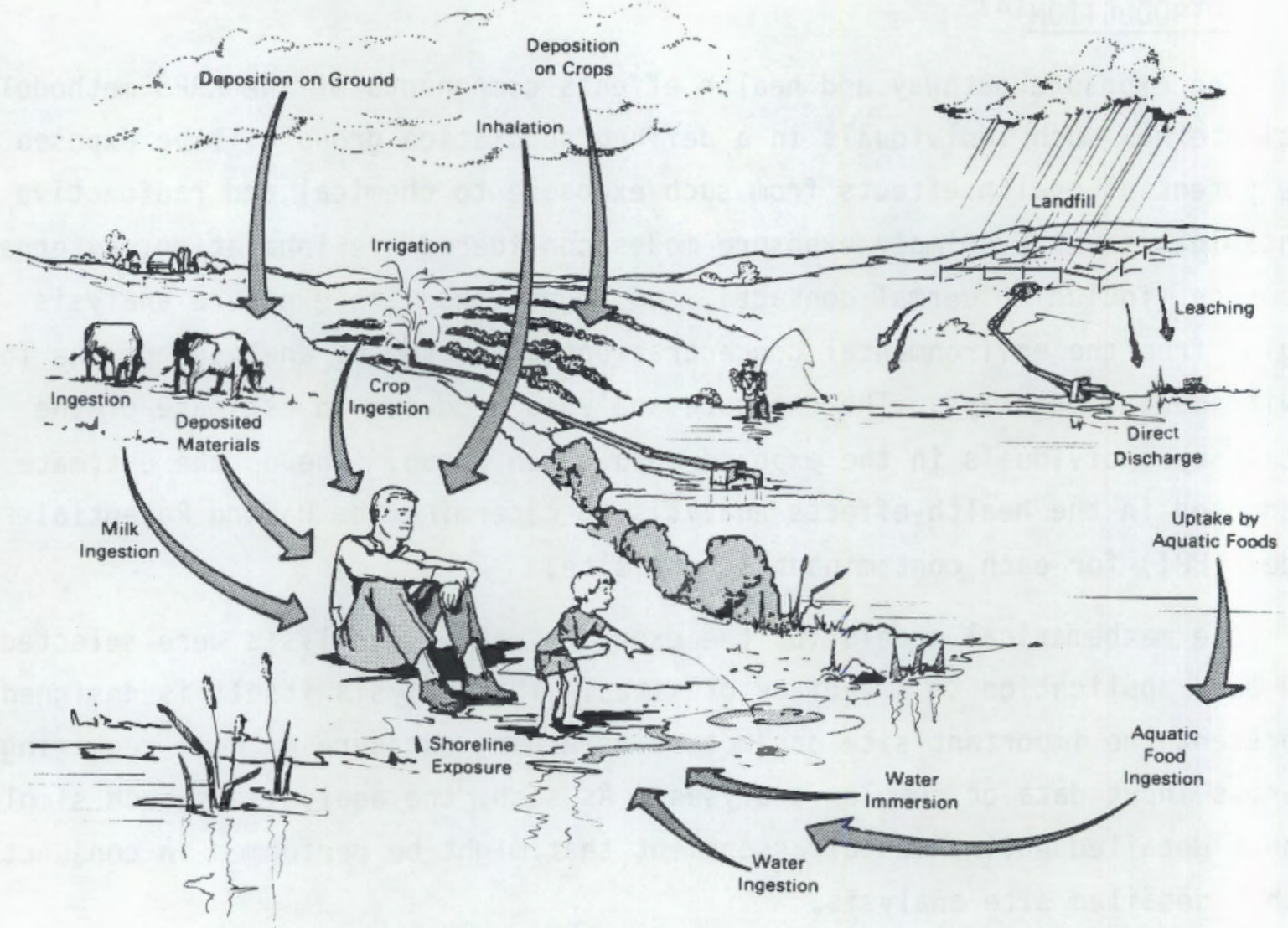

FIGURE 7.1. Exposure Pathways to Humans (After Whelan et al. 1987)

- drinking-water ingestion -- mode of exposure from groundwater, surface water, and overland transport pathways

- aquatic-food ingestion -- mode of exposure from eating fish and shellfish produced in contaminated waters; in other words, exposure derived from the surface water or overland transport pathways

- crop ingestion -- mode of exposure through eating foods grown on farmlands contaminated by atmospheric transport and deposition or by irrigation using contaminated water derived from the water transport pathways 


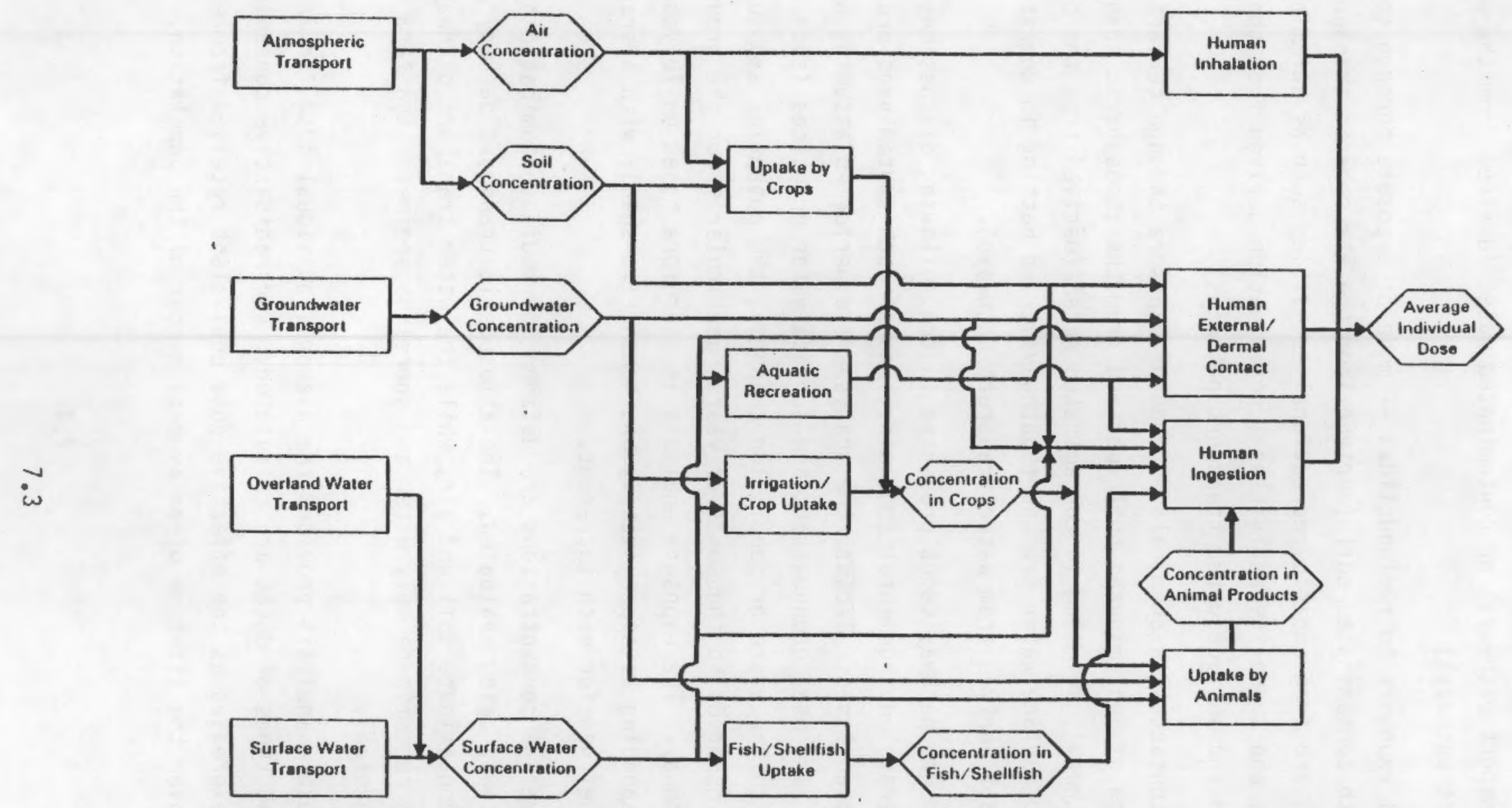

FIGURE 7.2. Exposure Pathways Considered by RAPS (After Bolten et al. 1983; Whelan et al. 1987) 
- animal-product ingestion -- mode of exposure through eating the products of animals fed contaminated crops (contamination derived from all transport pathways) or contaminated water (derived from the water transport pathways)

- external exposure to radionuclides -- mode of exposure through contact with contaminated soil (derived from the atmospheric transport pathway) and from aquatic recreational activities such as swimming, boating, and shoreline activities (contamination derived from the overland and surface water transport pathways)

- dermal contact with chemicals -- mode of exposure through contact and ingestion of contaminated soil (derived from the atmospheric transport pathway), swimming in contaminated water (derived from the overland and surface water transport pathways), and bathing in domestic water (all derived from water transport pathways).

The exposure pathway codes presented in the following discussions use the long-term average environmental concentrations of each contaminant provided by the transport analyses. Because the analyses are performed assuming no changes from current land use, groundwater, and surface water practices (such as remedial actions to the waste or population changes), the potential exposures may continue for hundreds to thousands of years, particularly for the groundwater transport pathway. The exposure analysis is therefore based on 70-year increments (corresponding to approximately one human life span), with average concentrations defined for each increment.

These average concentrations are defined for media contaminated by the transport pathway being evaluated. The atmospheric transport pathway can potentially contaminate soil and air, while the water transport pathways are considered to contaminate only water and shoreline sediment (and farm soil through irrigation).

The exposure analysis provides the average individual dose for each contaminant. Two types of doses are calculated. For radioactive contaminants, the dose is expressed as the effective dose equivalent received from each contaminant over the lifetime of an average member of the population. For 
chemical contaminants, dose is expressed as average daily intake (per unit body weight) of each contaminant by an average member of the population. The basic equations for the two types of contaminants are identical; the differences in dose types are handled through definition of dose conversion factors.

The exposure analysis is performed for one transport pathway, one usage location, and one 70-year period at a time. The term 'usage location' refers to a point in the environment where air, soil, or water may become contaminated and cause the exposure of a local population group. The doses from each contaminant are evaluated for each calculation. The calculated doses are then used in the health impact evaluation, in which a composite hazard potential index is determined for each contaminant. The hazard potential index includes contributions from all transport pathways, usage locations, and time periods.

This chapter presents a comparison between monitored and simulated food product concentrations for an actual contaminated environment. As noted in Chapter 1.0, the purpose of the comparison is to demonstrate the applicability of the RAPS methodology at established facilities that have monitored the release of contaminants into the environment. Because the Mound facility has historical records of environmental measurements for tritium and ${ }^{238} \mathrm{Pu}$ taken at various locations in the environment, it was chosen to test portions of the exposure pathway component. Although it would be desirable to test the entire exposure pathway and health effects components, no data base exists on which to perform such a comparison. Therefore, the present analysis is limited to testing those few portions of the exposure pathway component for which data do exist.

The remainder of this chapter is divided into four sections. First, the mathematical formulations associated with the exposure pathway analyses of RAPS are described. Second, the application of the RAPS exposure pathway component to a selected pathway at the Mound facility is presented. Third, the results of the comparison are summarized. Finally, the references cited in the chapter are listed. 


\subsection{MATHEMATICAL FORMULATIONS ASSOCIATED WITH THE EXPOSURE PATHWAY COMPONENT OF THE RAPS METHODOLOGY}

The following subsections (i.e., Sections 7.2.1 through 7.2.8) briefly discuss the routes of exposure addressed by the RAPS methodology. Because not all of the exposure pathways are tested in this chapter, details of the mathematical expressions for only those exposure pathways tested using the Mound facility data are given in the following discussions. These pathways are contamination of fish from surface water transport (Section 7.2.3) and contamination of grass and vegetables from airborne transport (Section 7.2.4). Summary descriptions are given for other pathways, details of which are available from Whelan et al. (1987).

\subsubsection{Inhalation}

The average daily intake from inhaling contaminated air is calculated from the average individual ventilation rate (inhalation volume rate) and the average air concentration at the location of exposure. The dose from inhalation is then calculated from the daily intake by multiplying by an inhalation dose conversion factor (rem/70 years per $\mathrm{pCi}$ inhaled for radionuclides and $\mathrm{kg}^{-1}$ for chemicals).

\subsubsection{Drinking-water Ingestion}

Exposure to contaminants via the drinking-water ingestion pathway may result from the groundwater, surface water, or overland transport pathways. (The overland transport pathway may contribute to contamination in surface water systems and thus contribute indirectly to drinking-water ingestion.) The dose from ingesting water is calculated from the water concentration, the water ingestion rate, a water-treatment purification factor, and a decay correction (for radioactive or unstable contaminants).

The water-treatment purification factor accounts for removal of contaminants during water treatment at municipal water-supply facilities. If the water is not treated, then the purification factor is unity. The average daily water intake rate is assumed to be $2 \mathrm{l} / \mathrm{d}$. Inadvertent ingestion of water during bathing is discussed separately in Section 7.2.7. 


\subsubsection{Aquatic-Food Ingestion}

Ingestion of contaminated aquatic foods is an exposure pathway considered for the surface water and overland transport pathways. For the RAPS analysis, two types of aquatic foods are considered: fish and invertebrates. Fish represent those organisms living in free-flowing waters; invertebrates represent those organisms living in or feeding on sediments. The contaminant concentration in these organisms is related to the contaminant water concentration by bioaccumulation factors. The average individual dose from ingestion of aquatic foods is calculated using the water concentration and uptake rates as follows:

$$
D a_{i}=\sum_{f=1}^{n}\left[U_{f} \quad C w_{i} B_{i f} \quad D f_{i} \exp \left(-\lambda_{i} t_{f}\right)\right]
$$

where Dai $=$ average individual dose from ingestion of aquatic foods for contaminant $i(\mathrm{mg} / \mathrm{kg} / \mathrm{d}$ or $\mathrm{rem} / 70$ year)

$n=$ number of aquatic foods considered (in this case, $n=2$ )

$f=$ index on aquatic food types

$U_{f}=$ average consumption rate of aquatic food for individuals in the population $(\mathrm{kg} / \mathrm{d})$

$\mathrm{Cw}_{\mathrm{j}}=$ average water concentration of contaminant $\mathrm{i}(\mathrm{mg} / 1$ or $\mathrm{pCi} / 1$ )

$B_{i f}=$ bioaccumulation factor for contaminant $i$ and aquatic food $(1 / \mathrm{kg})$

$D f_{i}=$ ingestion dose conversion factor $\left(\mathrm{rem} / \mathrm{pCi}\right.$ or $\mathrm{kg}^{-1}$ )

$\lambda_{i}=$ environmental degradation or radiological decay constant for contaminant $i\left(d^{-1}\right)$

$t_{f}=$ average time for decay from food harvest to consumption for aquatic food type $f(d)$.

The ingestion dose factor for chemicals is the inverse of the average adult body weight $(70 \mathrm{~kg})$. Equation $(7.1)$ converts daily intake $(\mathrm{mg} / \mathrm{d})$ to average individual dose $(\mathrm{mg} / \mathrm{kg} / \mathrm{d})$. Default values for consumption rates are taken from NRC (1977). The default values correspond to daily intake rates of $0.0027 \mathrm{~kg} / \mathrm{d}$ for invertebrates and $0.065 \mathrm{~kg} / \mathrm{d}$ for fish.

Bioaccumulation factors from models derived for use in radiological analysis are available from NRC (1977) for all elemental chemicals. For chemical 
contaminants that behave differently from the elemental form, default correlations for estimating bioaccumulations based on octanol-water partition coefficients are available in the RAPS computer program. These correlations are to be used only when data for the specific contaminant are not available, as they represent only an order-of-magnitude estimate.

When the contaminant is tritium (water form), the fish tissue concentration is assumed to equal the water concentration. This assumption has been tested in the present study using data from the Mound Facility.

\section{2 .4 Crop Ingestion}

Either irrigation using contaminated water or direct deposition of airborne contaminants onto plants and soil can result in contamination of agricultural crops. Two food products associated with contaminated crop production are considered here: leafy vegetables and other vegetables (and fruit). The leafy vegetable category represents such plants as lettuce whose edible portions are exposed above ground and eaten directly with little processing. The other vegetable category represents all other crops, for which the chance that direct deposition will be incorporated directly into the edible portion of the plant is much less. The code used to estimate contaminant concentrations in the edible portions of the plant considers uptake from two pathways: direct deposition and absorption through roots from soil. The contribution to plant concentration from direct deposition onto leaves at the time of human consumption is calculated as follows:

$$
C l_{i p}=D u_{i} T v_{p} r\left[1-\exp \left(-\lambda e_{i} t e_{p}\right)\right]\left[\exp \left(-\lambda_{i} t h_{p}\right)\right] /\left(\lambda e_{i} Y_{p}\right)
$$

where $C l_{i p}=$ concentration of contaminant $i$ in the vegetable for vegetable type $p$ (leafy or root) from deposition onto leaves ( $\mathrm{pCi} / \mathrm{kg}$ or $\mathrm{mg} / \mathrm{kg}$ )

$p=$ index on plant or vegetable type $(1=$ leafy vegetable and 2 = root or other vegetable)

$D u_{i}=$ deposition rate of contaminant $i$ from air or water onto farmlands $\left(\mathrm{mg} / \mathrm{m}^{2} / \mathrm{d}\right.$ or $\mathrm{pCi} / \mathrm{m}^{2} / \mathrm{d}$ ) 


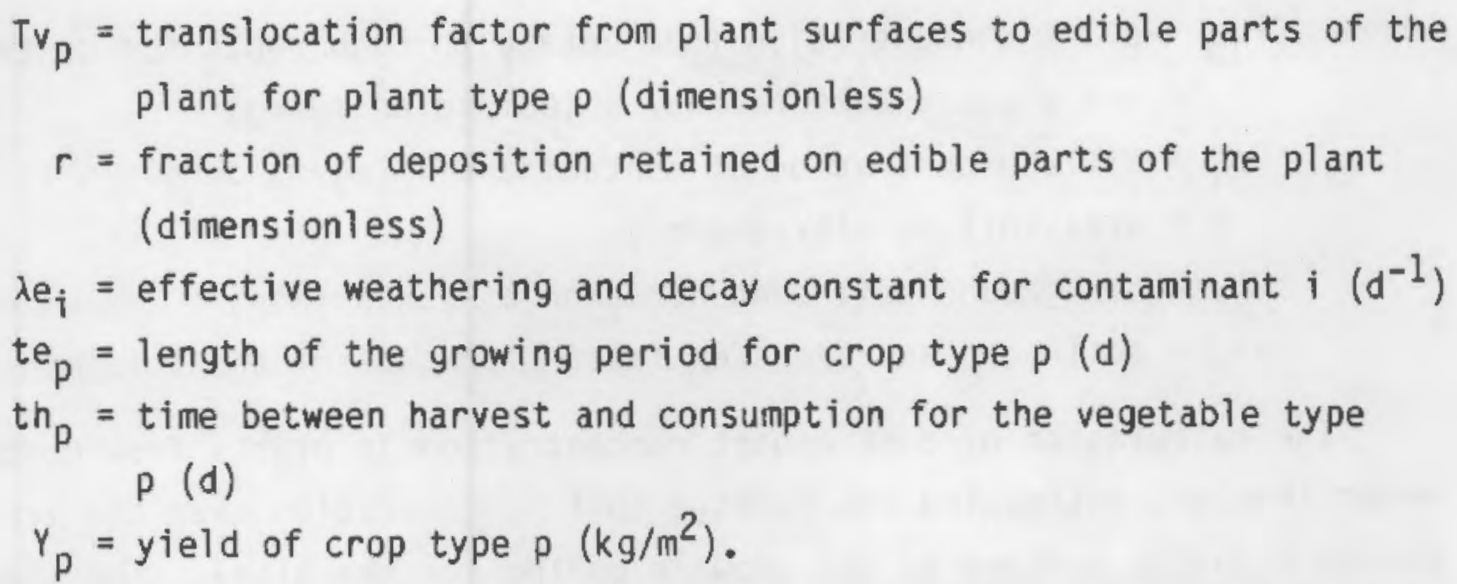

A default growing period of 60 days is assumed for both vegetable crops (NRC 1977).

For the air deposition pathway, the contaminant deposition rate $\left(\mathrm{Du}_{j}\right)$ is calculated from the air concentration and an average deposition velocity as follows:

$$
D u_{i}=86400 \mathrm{Ca}_{\mathbf{i}} \mathrm{Vd}_{\mathbf{i}}
$$

where $86400=$ unit conversion factor $(s / d)$

$\mathrm{Ca}_{j}=$ average air concentration of contaminant $i\left(\mathrm{mg} / \mathrm{m}^{3}\right.$ or $\left.\mathrm{pCi} / \mathrm{m}^{3}\right)$

$V_{d_{i}}=$ deposition velocity for contaminant $i(\mathrm{~m} / \mathrm{s})$.

For the water pathways, the contaminant deposition rate is calculated from the irrigation rate and water concentration as follows:

$$
\mathrm{Du}_{i}=\mathrm{Cw}_{\mathbf{i}} \mathrm{I} / 30
$$

where $I=$ irrigation water application rate $\left(1 / \mathrm{m}^{2} / \mathrm{mo}\right)$

30 = unit conversion factor $(\mathrm{d} / \mathrm{mo})$.

The contribution to contaminant concentration in plants from the root uptake pathway is calculated as follows for the air deposition pathway:

$$
C r_{i p}=\left(C s_{i} / P+C b_{i}\right) B v_{i}\left[\exp \left(-\lambda_{i} t h_{p}\right)\right] / \lambda_{i}
$$


where $C r_{i p}=$ plant concentration from uptake through roots for contaminant $i$ and plant uptake pathway $p$ ( $\mathrm{pCi} / \mathrm{kg}$ or $\mathrm{mg} / \mathrm{kg}$ )

$C s_{j}=$ soil concentration of contaminant $i\left(\mathrm{mg} / \mathrm{m}^{2}\right.$ or $\left.\mathrm{pCi} / \mathrm{m}^{2}\right)$

$P=$ area soil density $\left(\mathrm{kg} / \mathrm{m}^{2}\right)$

$\mathrm{Cb}_{j}=$ background soil concentration of contaminant $i$ (mg/kg or $\mathrm{pCi} / \mathrm{kg}$ )

$B v_{i}=$ soil-to-plant transfer factor for contaminant $i$ (dimensionless)

The calculation of contaminant concentration in plants from contaminated water involves estimating the average soil concentration over the irrigation period (usually defined as the growing period for the site). The plant concentration at the time of consumption by individuals is estimated as follows:

$$
C r_{i p}=B v_{i} C b_{i}+\frac{D u_{i}}{p \lambda_{i}}\left[1-\exp \left(-\lambda_{i} t e_{p}\right)\right] \exp \left(-\lambda_{i} t h_{p}\right)
$$

The soil-to-plant transfer factor $\left(B v_{j}\right)$ is available for all elements from NRC (1977). For chemical contaminants that are poorly described by elemental parameters, the transfer factor can be estimated using the correlation of Travis and Arms (1988) based on octanol-water partition coefficients. This correlation, which is included in RAPS, is an order-of-magnitude estimate and should only be used when contaminant-specific data are unavailable.

Equations (7.3) to (7.6) are used for most contaminants for computing the average contaminant concentration in plants. However, a more realistic model is required for the contaminant tritium because it is associated more closely with water. The concentration of tritium in plants is assumed to have the same specific activity as the contaminating medium (air or water). The fractional content of hydrogen in the plant is then used to estimate the tritium content of the food product. The concentration of tritium in vegetables from atmospheric deposition is calculated for air pathways as follows:

$$
\mathrm{C}_{i p}=9 \mathrm{Ca}_{i} \mathrm{Fh}_{p} / \mathrm{Ha}
$$


where $C_{i p}=$ average concentration of contaminant $i$ in the vegetable for vegetable type $p$ (leafy vegetables or other vegetables) at time of consumption $(\mathrm{mg} / \mathrm{kg}$ or $\mathrm{pCi} / \mathrm{kg}$ )

$9=$ inverse of hydrogen mass fraction in water $\left(\mathrm{kg} \mathrm{H}_{2} \mathrm{O} / \mathrm{kg} \mathrm{H}\right.$ )

$\mathrm{Fh}_{\mathrm{p}}=$ total fraction of hydrogen in $\mathrm{plants}$ of plant uptake pathway $\mathrm{p}$ ( $\mathrm{kg} \mathrm{H} / \mathrm{kg} \mathrm{plant}$ )

$\mathrm{Ha}=$ absolute humidity $\left(\mathrm{kg} \mathrm{H}_{2} \mathrm{O} / \mathrm{m}^{3}\right)$

A default absolute humidity of $0.008\left(\mathrm{~kg} / \mathrm{m}^{3}\right)$ is assumed. The default value for the plant hydrogen fraction for leafy vegetables and vegetables is 0.10 (Napier et al. 1980).

\subsubsection{Animal Products}

Either atmospheric deposition of contaminants onto feed crops or use of contaminated water to irrigate feed crops can result in the ingestion of contaminated crops by animals. In addition, contaminated water can be used as part of the animals' drinking-water supply. Human exposure to contaminants can then result from subsequent ingestion of contaminated animal products. The two animal products considered in the RAPS program are cow milk and beef. In evaluating the contaminant concentration in the milk and meat, the animals are assumed to eat crops containing contaminant levels defined by Equation (7.6), neglecting the decay correction between harvest and consumption [the exponential term with parameter $t h_{p}$ in Equations (7.2), (7.5), and (7.6)]. The animal-product pathway was not tested using Mound facility data because, for the available data (milk concentration), the location of production was poorly defined relative to air and soil concentration measurements. However, the concentration of contaminants in grass (representing a portion of the animalproduct pathway) was tested as described in Section 7.3.

In evaluating the feed concentration $\left(\mathrm{C}_{p}\right)$ from Equation (7.6), parameter values representative of animal pasture grass were used. These differ from the vegetable production parameters used for human consumption. For example, the growing period is set to 30 days to better represent animal grazing habits. Also, the crop yield is assumed to be less $\left(0.7 \mathrm{~kg} / \mathrm{m}^{2}\right)$ for animal feed production. 


\subsubsection{External Exposure to Radionuclides}

External radiation exposure is considered for individuals exposed to land surfaces contaminated by atmospheric deposition and for individuals involved in aquatic recreational activities associated with contaminated overland and surface waters. Aquatic recreational activities include boating, swimming, and shoreline fishing or hiking. The radiation dose is calculated from the water concentration or soil concentration (depending on which transport pathway is being studied) and the average time spent by an individual in each activity. Default values for exposure times associated with boating, swimming, and shoreline fishing are $12 \mathrm{hr} /$ year, $12 \mathrm{hr} /$ year, and $12 \mathrm{hr} /$ year, respectively.

The average contaminant concentration in shoreline sediment is estimated from a model developed by Soldat et al. (1974) relating water concentration to sediment concentration following a long period of deposition. The contaminant concentration in sediment is based on a transfer constant derived for several radionuclides using data obtained from an analysis of water and sediment samples taken from the Columbia River at Richland, Washington, and at Tillamook Bay, Oregon, $75 \mathrm{~km}$ south of the mouth of the Columbia River (Nelson 1965; Toombs and Cutler 1968).

Exposure to contaminated ground is considered only for the atmospheric deposition pathway because ground contamination from the water transport pathways will not expose large population groups. Although large areas of farmlands may become contaminated by irrigation with contaminated water, relatively few people, mostly farmworkers, will be subject to exposure. Airborne deposition is assumed to cover the entire region of the defined population group, and all individuals are potentially exposed.

\subsubsection{Dermal Contact/Inadvertent Ingestion}

Uptake of contaminants may result from dermal contact with soil contaminated from atmospheric deposition or from water contaminated from the groundwater, surface water, or overland transport pathways. Soil contact represents either ingestion from hand-to-mouth contact or absorption through the skin. The effective uptake of contaminants from dermal contact with soil is estimated based on inadvertent ingestion of soil. The actual intake through the skin is 
assumed to be small compared to intake through ingestion. In the model, to ensure that intake through the skin is small (relative to ingestion), the ingestion rate is estimated conservatively. Kimbrough et al. (1983) have presented conservative estimates of soil ingestion as a function of age. Using data from Kimbrough et al. (1983), an estimate of average soil ingestion over the lifetime of an individual of $410 \mathrm{mg} / \mathrm{d}$ is obtained.

Water contact may result in uptake during swimming or bathing. The dermal uptake during domestic bathing is assumed to contribute less to dose than does inadvertent ingestion of water; this may be more true for shower bathing than for tub bathing. For the present analysis, each person is assumed to bathe once per day and to ingest an average of $10 \mathrm{ml}$ of contaminated water per day as a result. The ingestion of water during bathing is normally insignificant compared to the ingestion of drinking water $(0.011 / d$ as compared to $21 / d)$; however, for locations where water is used for bathing but not for drinking, the bathing dose may be significant. Inadvertent ingestion of water may also occur during recreational swimming. The amount ingested is assumed to be $100 \mathrm{ml}$ for every hour of swimming time. Exposure from inadvertent ingestion of water and soil is considered for both chemical and radioactive contaminants.

\subsubsection{Dose Conversion Factors}

Factors must be defined for each contaminant to relate the rate of exposure to the dose. For radiological contaminants, dose is measured as effective dose equivalent for the average lifetime of an individual (i.e., 70 years). Inhalation and ingestion dose conversion factors are available from ICRP (1977, 1979-1982). The dose factors from these ICRP publications give the 50-year dose commitment from 1 year of intake.

Dose factors for chemical contaminants essentially represent unit conversion factors because the exposure and dose are the same. For inhalation and ingestion, the dose factor relates the average amount of contaminant taken in per day to the daily dose per unit body weight. 


\subsection{COMPARISON OF MONITORED AND SIMULATED PATHWAY CONCENTRATIONS FOR THE MOUND FACILITY}

The exposure pathway component of RAPS simulates the transfer of contaminants from selected locations in the environment through uptake by man. Testing of the RAPS exposure pathway simulations involves identification of data that can be used to relate environmental media concentrations to uptake-media concentrations. Data are available from the Mound facility for testing of the aquatic-food and the vegetable ingestion pathways for two contaminants, tritium and ${ }^{238} \mathrm{Pu}$. These data are available from the annual environmental monitoring reports for the Mound facility for the years 1973 through 1985. References for these annual reports are given in Table 7.1. Additional information on the Mound facility is presented in Chapter 4 of U.S. DOE (1979). The following discussions describe the available data and the results of the comparison of simulated and measured concentrations in fish and vegetation.

\subsubsection{Aquatic-Food Pathway Simulation}

Simulating the aquatic-food pathway involves estimation of the concentration of contaminants in fish or shellfish, based on the concentration of contaminants in the surrounding water. The concentration in the edible portions of a fish is proportional to the concentration in the water; the proportionality constant is the bioaccumulation factor in Equation (7.1). The data in the Mound facility annual reports include measured water concentrations and the corresponding fish concentrations for tritium and ${ }^{238} \mathrm{Pu}$ in the Great Miami River. Data on plutonium are available for the years 1973 through 1985, but tritium values are available for only the years 1973 through 1975. Tritium sampling of fish was discontinued because measurements indicated that tritium concentrations in fish were similar to the water concentration, and no harm to the fish or to individuals consuming the fish was likely.

The water-sampling program at the Mound facility has historically measured plutonium and tritium at nine locations along the Great Miami River, as indicated in Figure 7.3. During the period 1973 through 1978, measurements were 
TABLE 7.1. Mound Facility Annual Environmental Monitoring Report References

$\begin{array}{ll}\frac{\text { Year }}{1973} & \text { Reference } \\ 1974 & \text { Carfagno and Westendorf (1974) } \\ 1975 & \text { Farmer et al. (1976) } \\ 1976 & \text { Farmer et al. (1977) } \\ 1977 & \text { Farmer and Carfagno (1978) } \\ 1978 & \text { Farmer and Carfagno (1979) } \\ 1979 & \text { Farmer and Carfagno (1980) } \\ 1980 & \text { Farmer and Carfagno (1981) } \\ 1981 & \text { Farmer and Carfagno (1982) } \\ 1982 & \text { Carfagno and Farmer (1983) } \\ 1983 & \text { Carfagno and Farmer (1984) } \\ 1984 & \text { Carfagno and Farmer (1985) } \\ 1985 & \text { Carfagno and Farmer (1986) }\end{array}$

taken at locations 2, 3, 4, 5, and 8; during the period 1979 through 1985, measurements were taken at locations $1,4,6,7$, and 9. The water concentrations used for the simulation analysis were based on data from selected measurement locations, in an attempt to estimate the water concentration most likely to be associated with the fish being trapped near the Mound facility outfall (indicated by the dotted lines in Figure 7.3). For the years 1973 through 1978, measured water concentrations at locations 3, 4, and 5 were used, and for the years 1979 through 1985, data from locations 4, 6, and 7 were used.

The testing of the aquatic-food pathway in the Great Miami River involves estimating fish concentrations from measured water concentrations, and comparing the estimated values with measured values. The aquatic-food model for tritium assumes that the concentration in fish equals the water concentration. This assumption is in turn based on the assumption that tritium in the river water is at equilibrium with the water in the fish tissue. Figure 7.4 compares the measured tritium concentrations in water with those in fish tissue for the years 1973 through 1975. The results indicate that the concentration in fish 


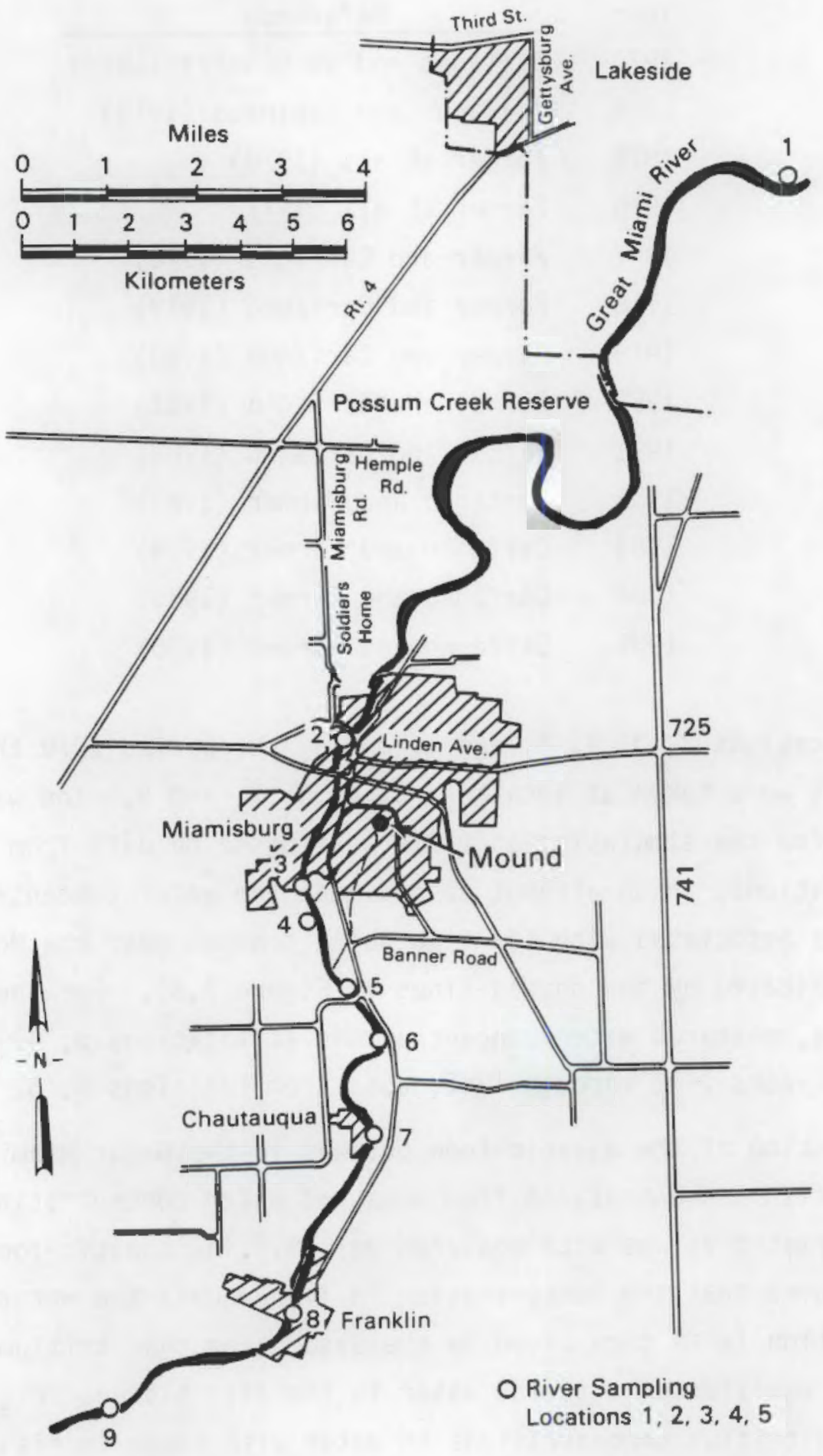

FIGURE 7.3. Offsite Water-Sampling Locations for the Mound Facility 


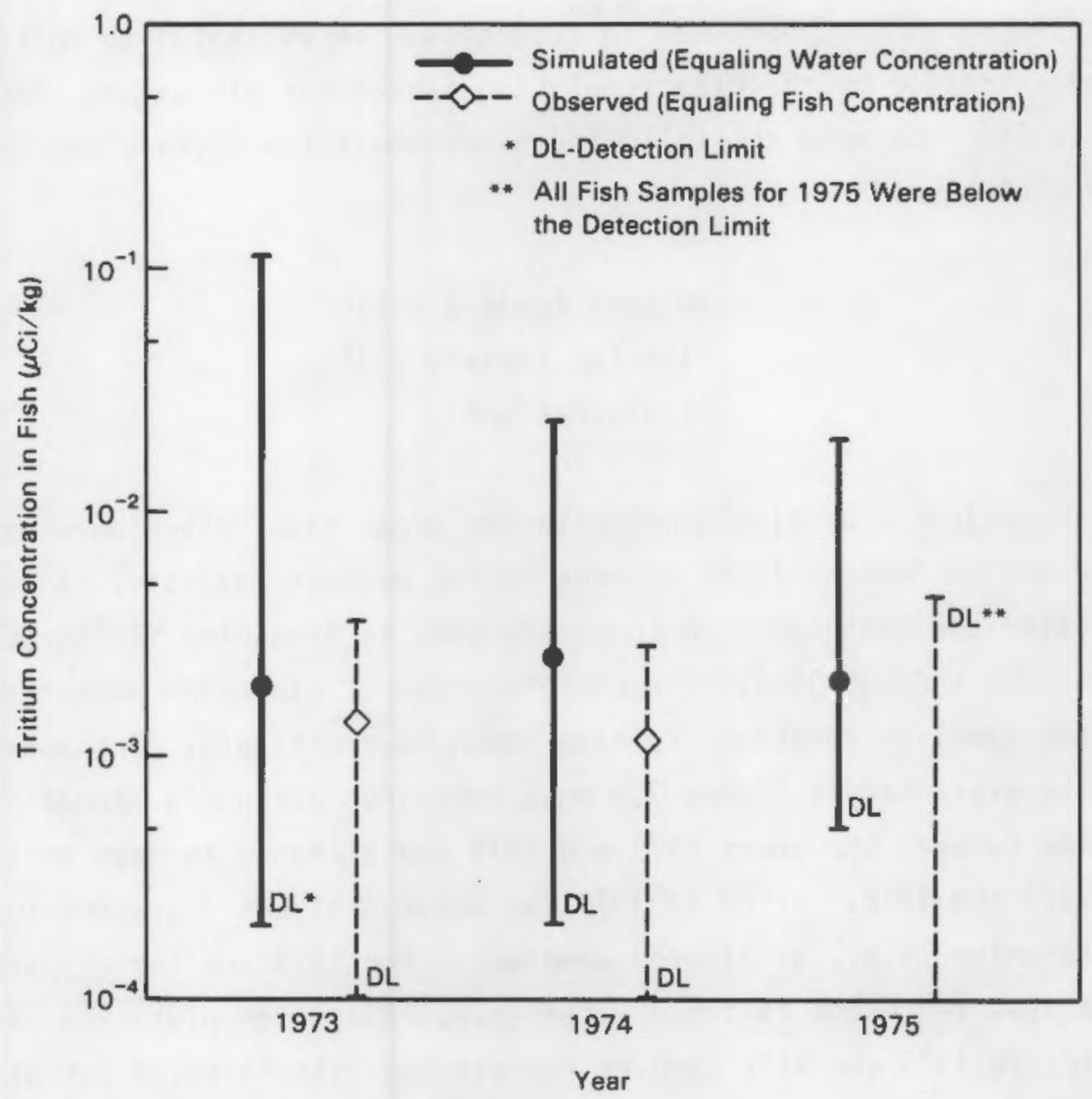

FIGURE 7.4. Comparison of Simulated and Observed Tritium Concentrations in Fish

is within a factor of two of the water concentration. This supports the model used in the RAPS methodology to estimate the tritium concentration in fish, that is, the assumption that the fish concentration is equal to the water concentration. The analysis of the fish samples involved oxidation of the sample (edible portions only), collection of the combustion products, and analysis of combustion products using liquid scintillation spectrometry. This method was selected to provide the total tritium concentration in the sample, including both the organically bound tritium and that in the cell water. Although the same method of analysis was used for all 3 years, the reason why the minimum detection limit was higher for 1975 than for 1973 and 1974 is unknown. 
The plutonium concentration in fish tissue is estimated by multiplying the water concentration by the bioaccumulation factor for plutonium. Poston and K1opfer (1986) recommend the following bioaccumulation factors for freshwater fish for plutonium:

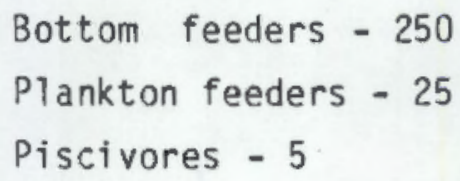

Because the majority of fish sampled in the Great Miami River were carp, (a) the value for bottom feeders $(250)$ is used in the present analysis. A comparison of calculated and measured fish concentrations is presented in Figure 7.5 for the years 1973 through 1985. The concentration of plutonium measured in silt at the same sampling locations is also shown in the figure. Interpretation of the results presented in Figure 7.5 must take into account a change in sampling method made between the years 1978 and 1979 and a change in data reporting made between 1977 and 1978. Prior to 1979 the water analyses represent total suspended plutonium (i.e., unfiltered samples). For 1979 and later years, the later analyses represent filtered water (i.e., dissolved plutonium only). Also, prior to 1979 the silt samples represented silt filtered out of the flowing water. For 1979 and later years, the silt samples were collected from bottom sediments.

The values reported for water and fish concentration measurements for 1977 and prior years are the actual measured values. After 1977 the values reported represent incremental activity, estimated by subtracting background levels for water or fish. The background levels are determined annually based on measurements taken at large distances from the Mound facility. The background levels of plutonium are typically a significant fraction of the measured values for both water and fish. Inclusion of the background levels with the values

(a) Telephone communication between D. G. Carfagno of Monsanto Research Corporation and D. L. Strenge of Pacific Northwest Laboratory on December 16, 1986. 


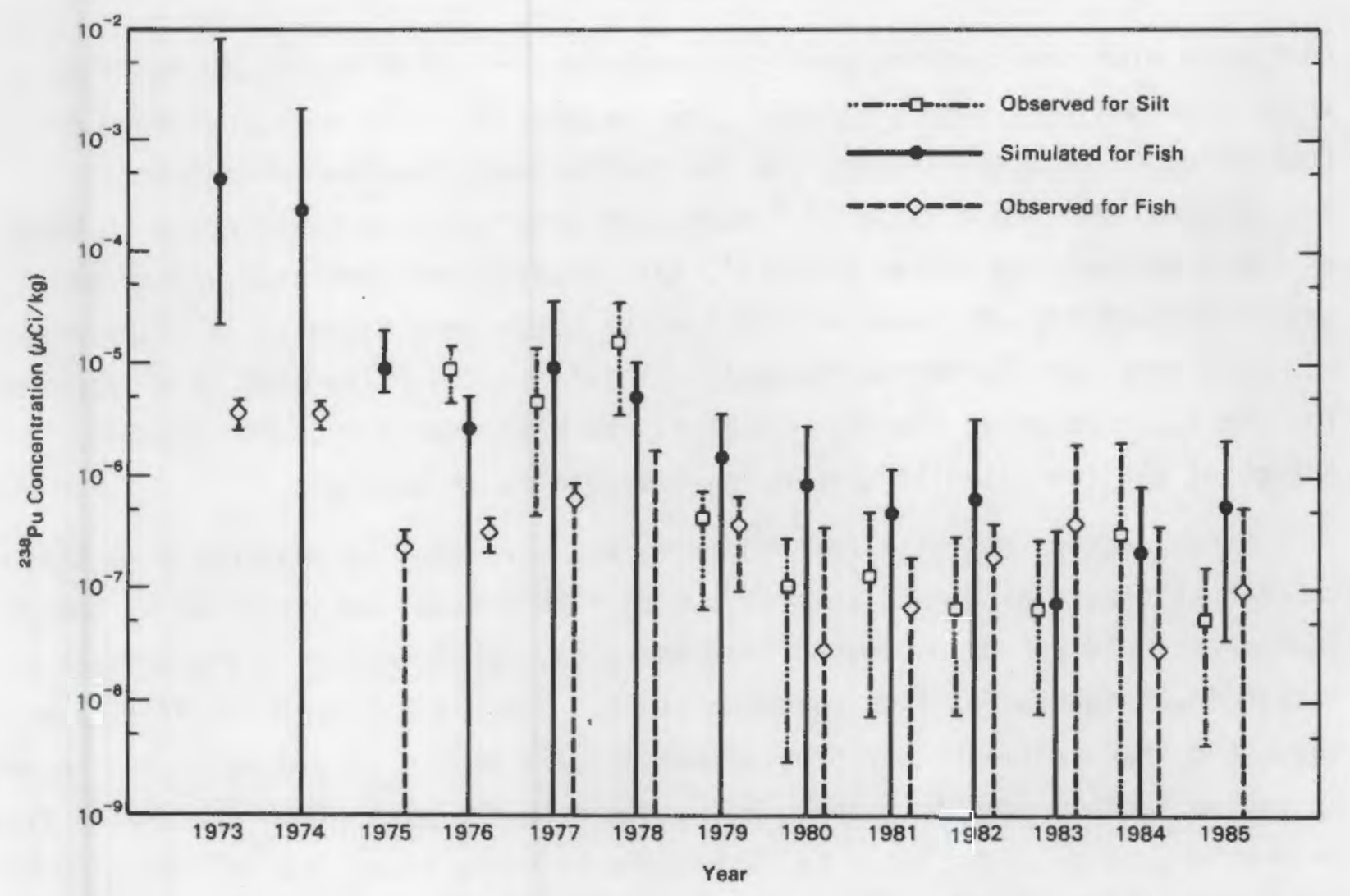

FIGURE 7.5. Comparison of Simulated and Observed ${ }^{238} \mathrm{Pu}$ Concentrations in Fish and Silt

presented in Figure 7.5 would shift the data values upward somewhat but would not greatly affect the relative magnitudes of the estimated versus measured fish tissue concentrations.

The estimated fish concentrations are in general one to two orders of magnitude greater than the measured values, with the larger differences occurring in the years before 1979. For recent years, the measured fish concentrations are generally about an order of magnitude lower than the estimated values. The change may be because suspended particulate material were included in the water concentration during the earlier years. Unfortunately, the effect of the suspended plutonium component cannot be determined because total suspended plutonium in the Great Miami River was not measured after 1978. The value used for the bioaccumulation factor in estimating the fish concentrations is critical to the comparison. Eyman and Trabalka (1980) note that the recommended value of 250 is hased on analysis of whole fish, including the content of the gut. This 
contrasts with the sampling analysis procedure in use at the Mound facility, which included only edible tissue. The recommended value must therefore be considered to be conservative, and the overestimate of fish concentration is not surprising. Had a value of 5 been used (representing piscivores) instead of 250 (representing bottom feeders), the measured and simulated values would have been much closer. Some of the samples taken were bluegill (a piscivore), but most were carp (a bottom feeder). Therefore, the value used is appropriate for the application of the RAPS model to the Mound facility. The biasing effect of the few bluegill samples on the results is unknown.

Other factors may also contribute to the variation in measured fish tissue concentrations. The amount contributed to fish tissue concentration by bottom sediments could not be estimated from the data, but it may be a significant factor in estimation of fish concentrations. Eyman and Trabalka (1977) have suggested that sediments may provide the primary source of plutonium for uptake by bottom-feeding aquatic biota. Also, how much the plutonium ingested by fish in previous years contributes to fish concentrations cannot be determined without a detailed study of the ages of the fish sampled. From studies of young channel catfish, Eyman and Trabalka (1977) have reported a long-term plutonium retention component with half-life of 534 years. This indicates that sampling of older fish may include activity taken in by fish in previous years. These factors complicate making definitive statements regarding the relationship between measured and calculated fish tissue concentrations. In general, the calculated fish tissue concentrations were about an order of magnitude greater than the concentration of dissolved plutonium in water.

\subsubsection{Vegetation Contamination Pathways}

The annual environmental monitoring reports for the Mound facility have presented tritium and plutonium concentrations measured in grass and vegetables since 1973. However, until 1979 the sampling locations were never identified. For the years 1979 through 1985, samples of grass and vegetables have been taken at three sites: Miamisburg, Centerville, and Bellbrook. The Centerville samples were taken close to the air monitoring location used in the present analysis to define the air concentrations of tritium and plutonium for 
estimating the grass and vegetable concentrations. Measured grass and vegetable concentrations at Miamisburg and Bellbrook are not used because representative air concentrations at these locations are poorly defined in the annual reports.

Results of tritium analyses of grass and tomato samples are presented in the Mound facility annual reports. The values reported represent incremental concentrations after subtraction of environmental background levels. For the present analysis, the background levels have been added to the reported values to give the total amount of tritium in the samples. The reported air concentrations have likewise been modified to represent the total tritium concentration to which the plants are exposed. The concentration of tritium in plants is estimated in RAPS from the air concentration using Equation (7.7). This equation requires an estimate of the average absolute humidity over the growing period. Because an estimate of average obsolute humidity is required, the growing period for vegetation must be identified. For grass the growing period (and so the sampling period) is assumed to the the 5 -month period from May through September, and for begetables (represented by tomatoes), the period is August and September. (a) Meterological data presented in U.S. DOE (1979) al lowed the average absolute humidity to be estimated as $11.1 \mathrm{~g} / \mathrm{m}^{3}$ for grass and $11.8 \mathrm{~g} / \mathrm{m}^{3}$ for tomatoes. The default value of 0.1 is used for the fraction of the plant mass that is hydrogen. With these assumptions the plan concentrations are estimated from the air concentration as follows:

$$
\begin{aligned}
& \text { grass concentration }=(\text { air concentration }) \times 81.1 \\
& \text { tomato concentration }=(\text { air concentration }) \times 76.3
\end{aligned}
$$

A comparison of simulated and observed plant concentrations is presented in Figures 7.6 and 7.7 for grass and tomatoes, respectively. The error bars in these figures represent the standard error of the estimated means at the $95 \%$ confidence level. The lack of a lower error limit indicates that the standard

(a) Telephone communication between D. G. Carfagno of Monsanto Research Corporation and D. L. Strenge of Pacific Northwest Laboratory, on December $16,1986$. 


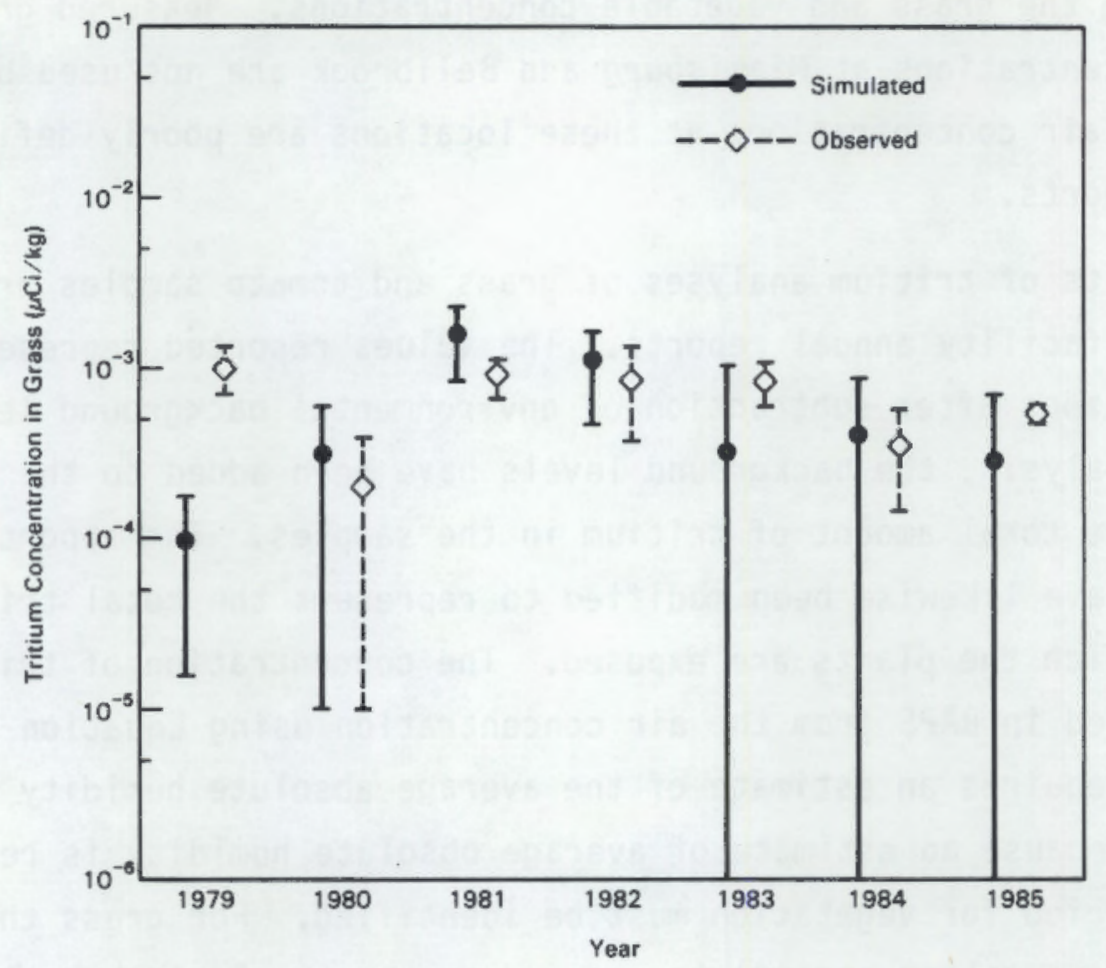

FIGURE 7.6. Comparison of Simulated and Observed Tritium Concentrations in Grass

error was larger than the estimated mean. Error bars for the calculated plant concentrations reflect the standard error reported for the air concentrations and do not include any estimate of uncertainty or variability in the parameters of Equation (7.7).

The comparisons indicate that the calculated plant concentrations are in general agreement with the measured values, and thus give support for the tritium plant model used in the RAPS methodology.

The RAPS model for estimation of plant concentration for particulates is given by Equations (7.2), (7.3), and (7.5). Contributions to plant concentration by direct deposition onto plant surfaces and by uptake by roots from contamination in soil are included. To exercise the RAPS vegetationcontamination model, measured air and soil concentration values are needed. Air concentration values are available for the years 1973 through 1985. However, soil measurement data are available for only 1977, as reported in the final environmental impact statement for the Mound facility (U.S. DOE 1979). 


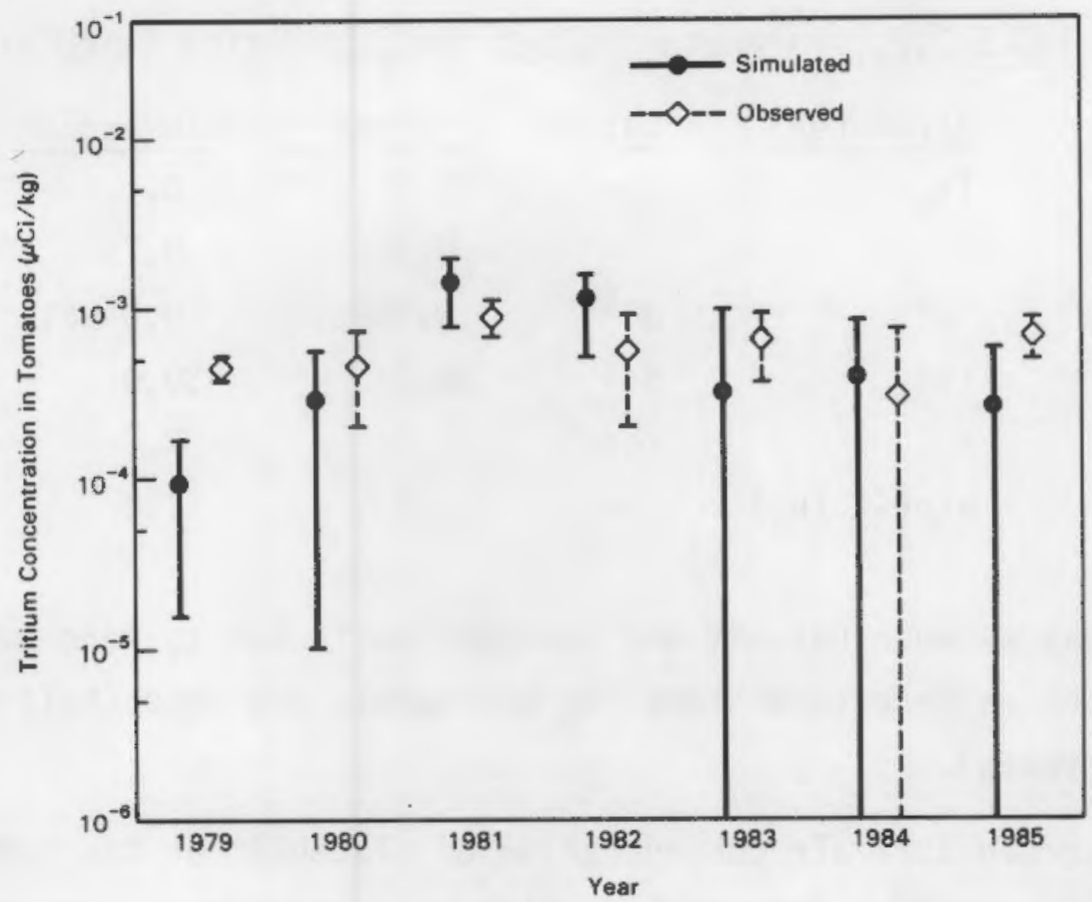

FIGURE 7.7. Comparison of Simulated and Observed Tritium Concentrations in Tomatoes

For the present analysis, it will be assumed that the air and soil concentrations near the air monitoring location used are representative of the location at which the plant samples were taken.

The soil concentration of ${ }^{238} \mathrm{Pu}$ at this location was reported to be about $5 \times 10^{-4} \mu \mathrm{Ci} / \mathrm{m}^{2}$ during 1977. When this soil concentration is used in Equation (7.5) with default values for soil density, and a soil-to-plant transfer factor of $2.5 \times 10^{-4}$, the estimated plant concentration from root uptake is $3 \times 10^{-5}$ $\mu \mathrm{Ci} / \mathrm{kg}$. The contribution from the air deposition pathway is obtained by combining Equations (7.2) and (7.3) and evaluating numerical terms. This results in the following estimates for grass and tomato concentrations:

$$
\begin{aligned}
& \text { grass concentration }=(\text { air concentration }) \times 965 \\
& \text { tomato concentration }=(\text { air concentration }) \times 41.2
\end{aligned}
$$

Paraneter values used in the evaluation of the above expressions are given in Table 7.2; all values are the default values used by RAPS. The exponential 
TABLE 7.2. Parameter Values for Vegetation Calculation

\begin{tabular}{|c|c|c|c|}
\hline Parameter & Units & Grass & Tomatoes \\
\hline$T v_{p}$ & - & 1.0 & 0.1 \\
\hline$r$ & - & 0.25 & 0.25 \\
\hline$\lambda \mathrm{e}$ & $d^{-1}$ & 0.049511 & 0.049511 \\
\hline$t_{p}$ & d & 30.0 & 30.0 \\
\hline & $\mathrm{kg} / \mathrm{m}^{2}$ & 0.7 & 2.0 \\
\hline $\exp \left(-\lambda t h_{p}\right)$ & - & 1.0 & 1.0 \\
\hline
\end{tabular}

term for decay between harvest and consumption is set to zero because there was essentially no decay between sampling and sample analysis (half-life of ${ }^{238} \mathrm{Pu}$ is about 88 years).

The reported 1977 air concentration of plutonium at the sampling location is $2.3 \times 10^{-11} \mu \mathrm{Ci} / \mathrm{m}^{3}$. The corresponding calculated grass and tomato concentrations attributable to air deposition are $2.2 \times 10^{-8}$ and $9.5 \times 10^{-10} \mu \mathrm{Ci} / \mathrm{kg}$, respectively. The contribution from the soil uptake component is much larger than the air deposition component, so the measured plant concentrations are unlikely to correlate with measured air concentrations. Rather, the measured plant contamination will be largely a result of residual plutonium from past releases. The measured grass and tomato concentrations reported for 1977 are $1.3 \times 10^{-6}$ and $8.4 \times 10^{-7} \mu \mathrm{Ci} / \mathrm{kg}$, respectively. These values may be compared to the calculated plant concentration of $3 \times 10^{-5} \mu \mathrm{Ci} / \mathrm{kg}$. The overestimation of plant concentration may be a result of the use of a conservative value for the soil-to-plant transfer factor. Another possibility is that the plant sampling location was poorly represented by the air sampling location, although the soil concentration at the air sampling location was only a factor of 5 above the estimated environmental background value. Overall, given the level of sophistication of the exposure assessment component, the differences between simulated and observed values are great. 


\subsection{SUMMARY OF EXPOSURE PATHWAY MODEL COMPARISONS}

Data from the Mound facility environmental monitoring program were used to evaluate the aquatic-food ingestion pathway for surface water transport, and the vegetable ingestion pathway for airborne transport. The comparisons of calculated fish and vegetable concentrations were performed for tritium and plutonium $\left({ }^{238} \mathrm{Pu}\right)$. The conclusions derived from the comparisons are

- The tritium concentration in fish is approximately equal to the tritium concentration in the water.

- The use of bioaccumulation factors to estimate fish tissue concentrations of plutonium results in an overestimate of about one order of magnitude. Reevaluation of recommended bioaccumulation factors may be necessary.

- The calculated tritium vegetation concentrations are in general agreement with the measured values for vegetables (tomatoes) and grass.

- The calculated plutonium vegetation concentration was approximately an order of magnitude above the measured value and was dominated by the soil-to-plant uptake route (because of relatively high prior depositions of ${ }^{238} \mathrm{Pu}$ ). The overestimation is in agreement with the use of conservative values for the soil-to-plant transfer factor.

\subsection{REFERENCES}

Bolten, J. G., P. F. Morrison and A. Soloman. 1983. Risk-Cost Assessment Methodology for Toxic Pollutants from Coal-Fired Power Plants. WD-1589 EPRI RP1826-5, Electric Power Research Institute, Palo Alto, California.

Carfagno, G., and B. M. Farmer. 1983. Environmental Monitoring at Mound: 1982 Report. MLM-3055, Environmental Section of the Administration Department at Monsanto Research Corporation, Miamisburg, Ohio.

Carfagno, D. G., and B. M. Farmer. 1984. Environmental Monitoring at Mound: 1983 Report. MLM-3143, Environmental Section of the Administration Department at Monsanto Research Corporation, Miamisburg, Ohio.

Carfagno, D. G., and B. M. Farmer. 1985. Environmental Monitoring at Mound: 1984 Report. MLM-3246, Environmental Section of the Administration Department at Monsanto Research Corporation, Miamisburg, Ohio. 
Carfagno, D. G., and B. M. Farmer. 1986. Environmental Monitoring at Mound: 1985 Report. MLM-3349, Environmental Section of the Administration Department at Monsanto Research Corporation, Miamisburg, Ohio.

Carfagno, O. G., and B. Robinson. 1975. Annual Environmental Monitoring Report: Calendar Year 1974. MLM-2232, Environmental Section of the Administration Department at Monsanto Research Corporation, Miamisburg, Ohio.

Carfagno, D. G., and W. H. Westendorf. 1974. Annual Environmental Monitoring Report: Calendar Year 1973. MLM-2142, Environmental Section of the Administration Department at Monsanto Research Corporation, Miamisburg, Ohio.

Eyman, L. D. and T. R. Trabalka. 1977. "Plutonium-237: Comparative Uptake in Chelated and Non-Chelated Form by Channel Catfish (Ictalurus Punctatus)." Health Phys. 32:475-478.

Eyman, L. D. and T. R. Trabalka. 1980. "Patterns of Transuranic Uptake by Aquatic Organisms: Consequences and Implications." In Transuranic Elements in the Environment. ed. W. C. Hanson. DOE/TIC-22800, Pacific Northwest Laboratory, Richland, Washington.

Farmer, B. M., and D. G. Carfagno. 1978. Annual Environmental Monitoring Report: Calendar Year 1977. MLM-2515, Environmental Section of the Administration Department at Monsanto Research Corporation, Miamisburg, Ohio.

Farmer, B. M., and D. G. Carfagno. 1979. Annual Environmental Monitoring Report: Calendar Year 1978. MLM-2608, Environinental Section of the Administration Department at Monsanto Research Corporation, Miamisburg, Ohio.

Farmer, B. M., and D. G. Carfagno. 1980. Annual Environmental Monitoring Report: Calendar Year 1979. MLM-2700, Environmental Section of the Administration Department at Monsanto Research Corporation, Miamisburg, Ohio.

Farmer, B. M., and D. G. Carfagno. 1981. Annual Environmental Monitoring Report: Calendar Year 1980. MLM- 2822, Environmental Section of the Administration Department at Monsanto Research Corporation, Miamisburg, Ohio.

Farmer, B. M., and D. G. Carfagno. 1982. Annual Environmental Monitoring Report: Calendar Year 1981. MLM-2930, Environmental Section of the Administration Department at Monsanto Research Corporation, Miamisburg, Ohio.

Farmer, B. M., Robinson and D. G. Carfagno. 1976. Annual Environmental Monitoring Report: Calendar Year 1975. MLM-2317, Environmental Section of the Administration Department at Monsanto Research Corporation, Miamisburg, Ohio. 
Farmer, B. M., B. Robinson and D. G. Carfagno. 1977. Annual Environmental Monitoring Report: Calendar Year 1976. MLM-2416, Environmental Section of the Administration Department at Monsanto Research Corporation, Miamisburg, Ohio.

International Commission on Radiological Protection (ICRP). 1977. Recommendations of the International Commission on Radiological Protection. ICRP PubTication 26, Pergamon Press, New York.

International Commission on Radiological Protection (ICRP). 1979-1982. Limits for Intakes of Radionuclides by Workers. ICRP Publication 30, Part 1 (and subsequent parts and supplements), Vol. 2, No. 3/4, through Vol. 8, No. 4, Pergamon Press, New York.

Kimbrough, R. D., H. Falk, P. Stehr and G. Fries. 1983. "Health Implications of $2,3,7,8,-$ Tetrachlorodibenzodioxin (TDCC) Contamination of Residential Soil." In Proceedings of Public Health Risks of the Dioxins. William Kaufmann, Los Angeles, California.

Napier, B. A., W. E. Kennedy, Jr. and J. K. Soldat. 1980. PABLM - A Computer Program to Calculate Accumulated Radiation Doses from Radionuclides in the Environment. PNL-3209, Pacific Northwest Laboratory, Richland, Washington.

Nelson, J. L. 1965. "Distribution of Sediments and Associated Radionuclides in the Columbia River below Hanford." In Hanford Radiological Sciences Research and Development Report for 1965, eds. D. W. Reece and J. K. Green. BNWL-36, Pacific Northwest Laboratory, Richl and, Washington.

Nuclear Regulatory Commission (NRC). 1977. Calculation of Annual Doses to Man from Routine Releases of Reactor Effluents for the Purpose of Evaluating Compliance with 10 CFR Part 50, Appendix I. Regulatory Guide 1.109, U.S. Nuclear Regulatory Commission, Washington, D.C.

Poston, T. M., and D. C. Klopfer. 1986. A Literature Review of the Concentration Ratios of Selected Radionuclides in Freshwater and Marine Fish. PNL-5484, Pacific Northwest Laboratory, Richland, Washington.

Soldat, J. K., N. M. Robinson and D. A. Baker. 1974. Models and Computer Codes for Evaluating Environmental Radiation Doses. BNWL-1754, Pacific Northwest Laboratory, Richland, Washington.

Toombs, G. L., and P. B. Cutler. 1968. Comprehensive Final Report for the Lower Columbia River Environmental Survey in Oregon June 5, 1961 - July 31 , 1967. Oregon State Board of Health, Division of Sanitation and Engineering, Salem, Oregon.

Travis, C. C., and A. D. Arms. 1988. "Bioconcentration of Organics in Beef, Milk, and Vegetation." Environ. Sci. Technol. 22(3):271-274. 
U.S. Department of Energy (DOE). 1979. Final Environmental Impact Statement: Mound Facility, Miamisburg, Ohio. D0E/EIS-0014, National Technical Information Service, Springfield, Virginia.

Whel an, S. M. Brown, D. L. Strenge, A. P. Schwab and P. J. Mitchell. 1988. Contaminant Assessment Modeling Under the Resource Conservation and Recovery Act. EA-5342, Electric Power Research Institute, Palo Alto, California.

Whelan, G., D. L. Strenge, J. G. Droppo, Jr. and B. L. Steelman. 1987. The Remedial Action Priority System (RAPS): Mathematical Formulations. PNL6200 , Prepared for the Office of Environment, Safety, and Health, U.S. Department of Energy, Washington, D.C. by Pacific Northwest Laboratory, Richland, Washington. 
PNL - 7102

UC $-602,630$

\section{DISTRIBUTION}

No. of

Copies

\section{OFFSITE}

2 DOE/Office of Scientific and Technical Information

\section{P. Brush \\ Acting Assistant Secretary for Environment, Safety and Health U.S. Department of Energy, EH-1 1000 Independence Ave., SW Washington, DC 20585}

\section{R. J. Aiken \\ Program Manager, Survey}

Prioritization

Office of Environmental Audit

U.S. Department of Energy, EH-24 1000 Independence Ave., SW Washington, DC 20585

\section{ONSITE}

4 DOE Richland 0perations Office
0 . Dunigan
R. E. Gerton
R. D. Izatt
D. Trader

No. of

Copies

24 Pacific Northwest Laboratory

J. W. Buck

P. G. Doctor

J. G. Droppo

J. W. Falco

M. D. Freshley

J. M. Hales

P. C. Hays

B. L. Hoopes

W. T. Penne11

L. E. Rogers

R. L. Skaggs

D. L. Strenge

M. B. Walter

G. Whel an (5)

Publishing Coordination

Technical Information (5) 
